\title{
Molecular mimicry by rat cytomegalovirus
}

\author{
Citation for published version (APA):
}

Beisser, P. S. (1999). Molecular mimicry by rat cytomegalovirus. [Doctoral Thesis, Maastricht University]. Universiteit Maastricht. https://doi.org/10.26481/dis.19991222pb

Document status and date:

Published: 01/01/1999

DOI:

10.26481/dis.19991222pb

Document Version:

Publisher's PDF, also known as Version of record

\section{Please check the document version of this publication:}

- A submitted manuscript is the version of the article upon submission and before peer-review. There can be important differences between the submitted version and the official published version of record.

People interested in the research are advised to contact the author for the final version of the publication, or visit the DOI to the publisher's website.

- The final author version and the galley proof are versions of the publication after peer review.

- The final published version features the final layout of the paper including the volume, issue and page numbers.

Link to publication

\footnotetext{
General rights rights.

- You may freely distribute the URL identifying the publication in the public portal. please follow below link for the End User Agreement:

www.umlib.nl/taverne-license

Take down policy

If you believe that this document breaches copyright please contact us at:

repository@maastrichtuniversity.nl

providing details and we will investigate your claim.
}

Copyright and moral rights for the publications made accessible in the public portal are retained by the authors and/or other copyright owners and it is a condition of accessing publications that users recognise and abide by the legal requirements associated with these

- Users may download and print one copy of any publication from the public portal for the purpose of private study or research.

- You may not further distribute the material or use it for any profit-making activity or commercial gain

If the publication is distributed under the terms of Article $25 \mathrm{fa}$ of the Dutch Copyright Act, indicated by the "Taverne" license above, 


\section{Molecular Mimicry by Rat Cytomegalovirus}

PATRICK S. BEISSER

Maastricht, 1999 
(C) Patrick Beisser, Maastricht 1999

ISBN: 90-9013421-2

Production: ANDI Press, Geleen, The Netherlands 


\section{Molecular Mimicry by Rat Cytomegalovirus}

\section{PROEFSCHRIFT}

ter verkrijging van de graad van doctor

aan de Universiteit Maastricht, op gezag van de Rector Magnificus Prof. dr. A. C. Nieuwenhuijzen Kruseman, volgens het besluit van het College van Decanen, in het openbaar te verdedigen op woensdag 22 december 1999 om 16.00 uur

door

PATRICK SINAR BEISSER

geboren op 1 oktober 1969 te Dordrecht. 


\title{
Promotor:
}

Prof. Dr. C. A. Bruggeman

\author{
Co-promotor: \\ Dr. C. Vink
}

Beoordelingscommissie:

Prof. Dr. H. Struyker Boudier (voorzitter)

Prof. Dr. M. J. Daemen

Dr. N. J. Davis-Poynter (Animal Health Trust, Newmarket)

Dr. S. Michelson (Institut Pasteur, Parijs)

Prof. Dr. F. C. Ramaekers

Prof. Dr. W. J. Spaan (Universiteit Leiden)

The investigations described in this thesis were carried out at the Department of Medical Microbiology, University of Maastricht, The Netherlands. 
Aan Gré van Marle - mijn moeder, aan Eline en Roosje 



\section{Contents}

\section{CHAPTER 1.}

Introduction - Page 9

\section{CHAPTER 2.}

The Maastricht Strain and England Strain of Rat Cytomegalovirus Represent Different Betaherpesvirus Species Rather than

$$
\text { Strains - Page } 21
$$

\section{CHAPTER 3.}

The R33 G Protein-Coupled Receptor Gene of Rat Cytomegalovirus Plays an Essential Role in the Pathogenesis of Viral Infection - Page 45

\section{CHAPTER 4.}

Deletion of the R78 G Protein-Coupled Receptor Gene from Rat Cytomegalovirus Results in an Attenuated, Syncytium-Inducing

$$
\text { Mutant Strain - Page } 77
$$

\section{CHAPTER 5.}

The r144 MHC Class I-Like Gene of Rat Cytomegalovirus is Dispensable for both Acute and Long-Term Infection in the Immunocompromised Host - Page 107

\section{CHAPTER 6.}

General Discussion - Page 133

Summary, Samenvatting, Dankwoord/Acknowledgements,

Curriculum Vitae, List of Publications - Page 151 
CHAPTER $1 \sim$

\section{Introduction}


CHAPTER 1 


\section{CYTOMEGALOVIRUS INFECTION AND DISEASE}

Human cytomegalovirus (HCMV) is one of the most common viruses present in individuals. The percentage of HCMV-seropositivity in Europe, Australia, and North America over the age of 35 is approximately $50 \%$ (23). The prevalence of HCMV infection increases with age (7), and is associated with the socioeconomic basis of the population group (23). Various routes of HCMV transmission were summarized by Ho (14): HCMV can be transmitted in utero, from mother to infant, via breast milk, saliva, tears, and urine, or through sexual intercourse, blood transfusion and organ transplantation. In immunocompetent individuals de novo $\mathrm{HCMV}$ infection is predominantly asymptomatic. However, in some cases, infection results in the development of mononucleosis syndrome ( 5 to $10 \%$ of all mononucleosis cases) which can be complicated by skin rashes, pneumonitis, hepatitis, and meningoencephalitis (16). Although predominantly benign in immunocompetent individuals, $\mathrm{HCMV}$ infection can pose a threat to humans with either an incomplete or compromised immune system. One group at risk consists of embryos and fetuses; pregnancies can be aborted prematurely due to HCMV infection of the fetus. HCMV infection of the fetus can also result in congenital disorders characteristically showing hepatosplenomegaly, developmental disorders of the central nervous system, and neurosensory deafness (15). Another group comprises either individuals that undergo artificial immunosuppression in order to prevent rejection of transplanted organs, or individuals suffering from acquired immune deficiency syndrome (AIDS). Under conditions of organ transplantation, $100 \%$ of both seropositive patients and patients receiving an organ from seropositive donors develop CMV infection either through de novo infection in HCMV seronegative patients (primary infection), de novo infection of HCMV seropositive patients (reinfection), or reactivation of HCMV infection in seropositive patients (the latter two are both termed reinfection) (17). Several factors suppress the resistance against primary and reinfection: the condition of the patient after organ transplantation, the use of cytotoxic immunosuppressive drugs and corticosteroids, and host-versus-graft/graftversus-host reactions (17). Of primary infected transplant patients, approximately 80 $\%$ develop HCMV disease, while approximately $40 \%$ of all reinfections are symptomatic (17). HCMV disease is also overt in AIDS patients. The major organs affected by HCMV disease in immunodeficient patients are the adrenal glands, the lungs, the gastrointestinal tract, the central nervous system and the eyes. The clinical manifestations vary from a combination of chronic rejection and transplantation-associated arteriosclerosis to mononucleosis, interstitial pneumonitis, hepatitis, retinitis, gastrointestinal disease, encephalitis, and meningoencephalitis, leading to organ failure and death (17). HCMV disease can be treated with antiviral drugs. The most commonly used agents to treat HCMV infection are ganciclovir and phosphonoformic acid (18). HCMV cannot be cleared by these agents. As soon as treatment is stopped, infection can re- 
TABLE 1. Taxonomy of a subset of herpesviruses

\begin{tabular}{|c|c|c|c|}
\hline Subfamily & ICTV designation & Common name & $\begin{array}{l}\text { Genome } \\
\text { size }(\mathrm{kb})\end{array}$ \\
\hline \multirow[t]{3}{*}{ Alphaherpesvirinae } & Human herpesvirus 1 & Herpes simplex virus 1 & 152 \\
\hline & Human herpesvirus 2 & Herpes simplex virus 2 & 152 \\
\hline & Human herpesvirus 3 & Varicella-zoster virus & 125 \\
\hline \multirow[t]{5}{*}{ Betaherpesvirinae } & Human herpesvirus 5 & Human cytomegalovirus & 230 \\
\hline & Murid herpesvirus 1 & Murine cytomegalovirus & 230 \\
\hline & & Rat cytomegalovirus & 230 \\
\hline & Human herpesvirus 6 & Roseolovirus & 159 \\
\hline & Human herpesvirus 7 & & 145 \\
\hline \multirow[t]{2}{*}{ Gammaherpesvirinae } & Human herpesvirus 4 & Epstein-Barr virus & 172 \\
\hline & Human herpesvirus 8 & KS-associated herpesvirus" & $>138$ \\
\hline
\end{tabular}

${ }^{2} \mathrm{KS}$, Kaposi s sarcoma.

emerge. In addition to these therapeuticals, several experimental vaccines have been developed to prevent HCMV disease. They consist of live laboratory HCMV strains such as AD169 and Towne 125. However, these vaccines fail to prevent primary infection with wild-type HCMV and have a marginal effect in alleviating HCMV disease (18). Thus, a continuing study of the biology of cytomegaloviruses is necessary to find new potential molecular targets and facilitate the development of new and more effective antiviral drugs and vaccines.

\section{THE BIOLOGY OF CYTOMEGALOVIRUSES.}

CMV taxonomy. Cytomegaloviruses (CMVs) are members of the family of herpesviridae. Membership was defined by the International Committee on Taxonomy of Viruses (35) based on the virion architecture. CMVs were categorized in the subfamily of species-specific betaherpesviruses, based on their host cell range and genomic organization. A representative set of members of the three subfamilies of herpesviruses is shown in Table 1. Like other herpesviruses, a mature CMV virion (Fig. 1) consists of a genomic double-stranded DNA core encapsulated by a 100-nm spanning icosahedral protein capsid. The capsid is surrounded by an amorphous protein mass termed 'tegument'. The outer layer of the virion, the viral envelope, is composed of 


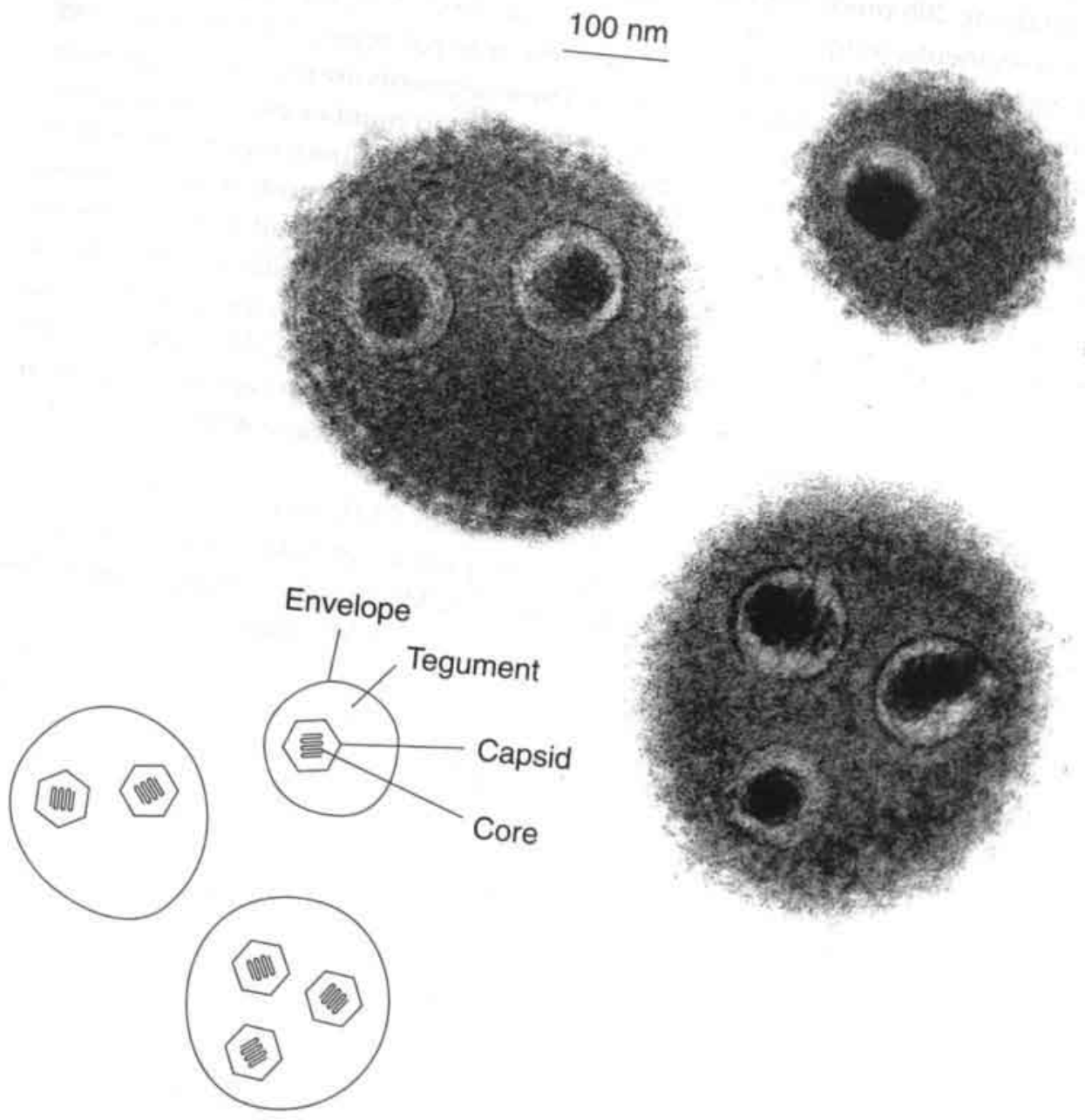

$G$. 
modified cellular membrane and glycoprotein spikes. Many CMV virions contain multiple capsids and genomic DNA strands per virus particle (Fig. 1). The size of an intact CMV virion can range from 120 to $300 \mathrm{~nm}$. The HCMV genome has a size of 230 $\mathrm{kb}(9)$, containing 208 predicted ORFs of greater than $300 \mathrm{bp}$ in length $(9,30)$. It consists of two segments, unique long (UL) and unique short (US), each flanked by large inverted repeat regions, terminal repeat long $(b)$, internal repeat long $\left(b^{\prime \prime}\right)$, internal repeat short ( $\left.c^{\prime \prime}\right)$ and terminal repeat short (c). These segments are joined by a junction, or a-sequence of small tandem repeats $\left(\mathrm{a}_{\mathrm{m}}{ }_{\mathrm{m}}\right)$ that vary in number per virus genome. These a-sequences are also found at the genome ends in a direct repeat orientation $\left(a_{n}\right)$. Thus, the HCMV genome organization can be denoted as follows: $a_{n} b U^{\prime \prime} a_{m} c^{\prime \prime U S c a}{ }_{n}(9,30)$ (Fig. 2). Viral DNA replication can result in the inversion of either or both of the UL and US regions, hence generating four different isoforms of the HCMV genome (30). The organization of other CMV species is less complex. The rat CMV (RCMV) (47), murine CMV (MCMV) (26) or guinea pig CMV (GpCMV) (28) genomes each consist of a single unique region flanked by direct repeat regions that vary in length among different species. The genomic organization of these CMV species is also shown in Fig. 2.

$\mathrm{CMV}$ gene regulation. Expression of the numerous CMV genes is conducted by a complex interplay between DNA and regulatory proteins of both virus and host origin. Relative to other herpesviruses, replication of HCMV in fully permissive cell types is slow, 48 to $72 \mathrm{~h}$, whereas replication of RCMV and MCMV requires 24 to $36 \mathrm{~h}$ ( 30 , 48). The expression pattern of HCMV in vitro can be classified in three temporal phases, the immediate early (IE), early (E) and late (L) phases of infection. During the IE phase (up to $12 \mathrm{~h}$ postinfection [p.i.]) particular HCMV (IE) genes are activated by regulatory proteins of the host cell (30). The resulting IE proteins activate genes of the E phase and silence most IE genes (30). Subsequently, HCMV E proteins (expressed approximately 12 to 24 hours p.i.) either activate L genes, or catalyse HCMV DNA replication (30). Most of the L gene products (expressed $24 \mathrm{~h}$ p.i. and further) are either structural HCMV proteins or play a role in the assembly, maturation and egress of new HCMV virions (30). In permissive cells, CMV infection undergoes all of these stages resulting in excretion of new virions and eventually cell lysis (30).

The cell tropism of CMV. A limited range of cell types can be infected by CMV in vitro. The most permissive cell types are fibroblasts, typically from either fetal or foreskin origin (30). CMVs also replicate efficiently in fetal trophoblasts (13), amnion (10), smooth muscle $(46,52)$ and stromal cells $(22,37)$. Epithelial cells $(2,40)$, astrocytes $(24$, $34)$, endothelial cells $(39,51,52)$, and macrophages (19) are to a lesser extent permissive to CMV infection. CMV abortively infects a range of cells of myeloid origin, varying from pre-CD34+ cells to monocytes and neutrophils (21, 12, 19, 25). In several subsets of myeloid cells HCMV was shown to persist in a latent state $(21,12)$ and could be reactivated upon cocultivation with fully permissive cell types (41). To fully 


\section{HCMV}

\section{B}

a

\section{RCMV/MCMV/GpCMV}

FIG. 2. The genomic organization of various cytomegalovirus species. (A) The human cytomegalovirus (HCMV) genome organization. Black boxes indicate inverted repeat regions. The prime marks denote inverse orientation. White boxes indicate direct repeats. ' $n$ ' And ' $m$ ' indicate the variability of length of the ' $a$ ' sequences (see text). (B) Genomic organization of rat cytomegalovirus (RCMV), murine cytomegalovirus (MCMV) and guinea pig cytomegalovirus (GpCMV). Note that the repeat regions in both $(A)$ and $(B)$ are not drawn to scale.

understand the complexity of latency and reactivation of HCMV and its relation to HCMV disease, in vivo models for infection and pathogenesis are required. However, due to its species specificity HCMV is difficult to study in an in vivo model. To certain limits, aspects of HCMV pathogenicity can be studied in the Hu/SCID mouse system (3). However, in order to study a wide range of characteristics of CMV infection, several CMV species have been utilized in animal infection models, such as GPCMV, MCMV and RCMV.

The RCMV model system. RCMV was isolated in 1982 from the salivary glands of wild rats and passed in both rat embryo fibroblasts in vitro and laboratory rats as a laboratory strain (RCMV Maastricht) (4). Following either intraperitoneal or subcutaneous inoculation of RCMV in immunocompetent rats, low amounts of RCMV could be recovered from kidney, heart, thymus, spleen, bone marrow, and blood between days 4 and 11 p.i. and high amounts in salivary glands peaking at day 28 p.i. (5). RCMV was also excreted in urine (low levels) and saliva (high levels) of infected rats (5). At 25 weeks p.i. RCMV could no longer be detected in rats by plaque assay or immunohistochemical analysis (5). RCMV causes no overt disease in infected immunocompetent rats. In contrast, RCMV was demonstrated a lethal agent in rats that were immunocompromised by receiving total body Röntgen irradiation prior to RCMV infection $(6,42)$. Upon administration of sublethal doses of RCMV to immunocompromised rats, virus could be detected at high levels in spleen, kidney, liver and lung. Determining virus titers in organs of infected, immunocompromised 
rats was shown to be a useful tool to study the effectiveness of antiviral agents in rat organ transplantation models in vivo $(6,42,43,44,45)$.

Molecular biology of RCMV. Additional to the examination of RCMV infection and pathogenesis in vivo, the RCMV genome was isolated, cloned and mapped by Meijer et al. (29). Subsequently, genes homologous to the HCMV genes encoding DNA polymerase, glycoprotein B, ICP18.5 and major DNA binding protein were identified and sequenced (1), and the RCMV genome termini as well as the origin of replication were characterized $(47,48)$. At present the complete RCMV genome sequence has been determined (49). Comparison of the RCMV genome sequence with sequences of MCMV (36) and HCMV (9) indicated that the genomes are collinear and that majority of the CMV genes are conserved (49). The genomic RCMV sequence as well as the in vivo RCMV infection model provide a powerful tool to study the role of RCMV genes in RCMV pathogenesis.

Herpesvirus genes homologous to genes of the host. Herpesviruses belong to the oldest group of animal viruses in evolution. Phylogenetic analysis of genes that were conserved among different species of herpesviruses indicated that the three herpesvirus subfamilies arose approximately 180 to $220 \mathrm{My}$ ago (27). The coexistence of herpesviruses together with their hosts during such a time-span, obviously resulted in the co-evolution and adaptation of herpesviruses to the host organism and its immune system. Part of this co-evolution appears to have involved viral hyjacking of genes of the host - incorporation of host genes into the viral genome to the benefit of either viral replication or resistance to immunological responses of the host. Such hyjacked, homologous genes were recently found in the genomes of beta- and gammaherpesviruses $(8,9,11,20,31,33,36,50)$, as well as poxviruses $(38,53)$. These virus families comprise the most complex of all known viral genomes, containing genes that encode either proteins with immunoglobulin domains, cytokines, cytokine receptors, chemokines, chemokine receptors, or apoptosis- and cell cycle-related genes. Some of these genes were discovered before their cellular counterparts, such as the HCMV chemokine receptor gene US28 (32), indicating that the list of hyjacked genes is not yet complete. The characterization of novel cellular genes may reveal more cell-homolog genes within viral genome sequences in the future.

\section{AIM OF THE THESIS.}

The HCMV MIE gene complex was shown to be the key regulatory gene complex during both active HCMV replication (30) as well as latency $(21,12)$. The determination of an analogous gene complex within the RCMV genome could accomplish a better understanding of latency and reactivation in the in vivo RCMV infection model. Therefore, the first subject of study for this thesis was the identification of a potential RCMV MIE gene locus, the results of which are presented in Chapter 2. In addition, 
other RCMV genes were subjected to examination. The functions of most of the currently known betaherpesvirus genes that appear to be hyjacked from the host organism are yet enigmatic. Most likely, they protect CMV-infected cells from immune surveillance by molecular mimicry. The aim of the studies that are presented in Chapter 3 , 4 and 5 was to identify and characterize putative mimicry genes within the RCMV genome. These chapters describe the identification of the loci of three RCMV genes that are homologous to genes of the host organism as well as their roles in RCMV pathogenesis in vivo: a putative chemokine receptor gene (Chapter 3), an orphan G protein-coupled receptor gene (Chapter 4) and a class I MHC homolog gene (Chapter 5 ). The characterization of these genes was facilitated by the development of a gene knock-out system to generate mutant RCMV strains in which either of these genes was deleted. The growth characteristics and pathogenicity of these knock-out viruses were systematically compared to those of wild-type RCMV both in vitro and in vivo, hence providing novel insights in the molecular mimicry by RCMV.

\section{REFERENCES}

1. Beuken, E., R. Slobbe, C.A. Bruggeman, and C. Vink. 1996. Cloning and sequence analysis of the genes encoding DNA polymerase, glycoprotein B, ICP 18.5 and major DNA-binding protein of rat cytomegalovirus. J. Gen. Virol. 77:1559-1562.

2. Bodaghi B., O. Goureau, D. Zipeto, L. Laurent, J--L. Virelizier, and S. Michelson. 1999. Role of IFN- $\gamma$-induced indoleamine 2,3 dioxygenase and inducible nitric oxide synthase in the replication of human cytomegalovirus in retinal pigment epithelial cells. J. Immunol. 62:957-964.

3. Brown J. M., H. Kaneshima, and E. S. Mocarski. 1995. Dramatic interstrain differences in the replication of human cytomegalovirus in SCID-hu mice. J. Infect. Dis. 171:1599-1603.

4. Bruggeman, C. A., H. Meijer, P. H. J. Dormans, W. H. M. Debie, G. E. L. M. Grauls, and C. P. A. van Boven. 1982. Isolation of a cytomegalovirus-like agent from wild rats. Arch. Virol. 73:231-241.

5. Bruggeman, C. A., H. Meijer, F. Bosman, and C. P. A. van Boven. 1985. Biology of rat cytomegalovirus infection. Intervirology 24:1-9.

6. Bruning, J. H., C. A. Bruggeman, C. P. van Boven, and P. J. van Breda Vriesman. 1986. Passive transfer of latent rat cytomegalovirus by cardiac and renal organ transplants in a rat model. Transplantation 41:695-698.

7. Carlström, G, and B. Jalling. 1970. Cytomegalovirus infections in different groups of paediatric patients. Acta Paedriatr. Scand. 59:303-309.

8. Cha, T.-A., T. Edward, G. W. Kemble, G. M. Duke, E. S. Mocarski, and R. R. Spaete. 1996. Human cytomegalovirus clinical isolates carry at least 19 genes not found in laboratory strains. J. Virol. 70:78-83.

9. Chee, M. S., A.T. Bankier, S. Beck, R. Bohni, C. M. Brown, R. Cerny, T. Horsnell, C. A. Hutchison III, T. Kouzarides, J. A. Martignetti, E. Preddie, S. C. Satchwell, P. Tomlinson, 
K. M. Weston and B. G. Barrell. 1990. Analysis of the protein-coding content of the sequence of human cytomegalovirus strain AD169. Curr. Top. Microbiol. Immunol. 154:125169.

10. Figueroa, M. E., L. Geder, and F. Rapp. 1978. Infection of human amnion cells with cytomegalovirus. J. Med. Virol. 2:369-375.

11. Gompels, U. A., J. Nicholas, G. Lawrence, M. Jones, B. J. Thomson, M. E. Martin, S. Efstathiou, M. Craxton, and H. A. Macaulay. 1995. The DNA sequence of human herpesvirus-6: structure, coding content, and genome evolution. Virology 209:29-51.

12. Hahn, G., R. Jores, and E. S. Mocarski. 1998. Cytomegalovirus remains latent in a common precursos of dendritic and myeloid cells. Proc. Natl. Acad. Sci. USA 95:3937-3942.

13. Hemmings D. G., R. Kilani, C. Nykiforuk, J. Preiksaitis, and L. J. Guilbert. 1998. Permissive cytomegalovirus infection of primary villous term and first trimester trophoblasts. J. Virol. 72:4970-4979.

14. Ho, M. 1991. Epidemiology of cytomegalovirus infection in man, p. 155-187. In M. Ho, Cytomegalovirus, biology and infection, Plenum Medical, Co., New York, N. Y.

15. Ho, M. 1991. Congenital and perinatal human cytomegalovirus infections, p. 205-227. In M. Ho, Cytomegalovirus, biology and infection, Plenum Medical, Co., New York, N. Y.

16. Ho, M. 1991. Acquired cytomegalovirus infection in immunocompetent patients, p. 229247. In M. Ho, Cytomegalovirus, biology and infection, Plenum Medical, Co., New York, N. Y.

17. Ho, M. 1991. Human cytomegalovirus infections in immunosuppressed patients, p. 249300. In M. Ho, Cytomegalovirus, biology and infection, Plenum Medical, Co., New York, N. Y.

18. Ho, M. 1991. Treatment and prevention of cytomegalovirus infections, p. 301-317. In M. Ho, Cytomegalovirus, biology and infection, Plenum Medical, Co., New York, N. Y.

19. Ibanez C. E., R. Schrier, P. Ghazal, C. Wiley, and J. A. Nelson. 1991. Human cytomegalovirus productively infects primary differentiated macrophages. J. Virol. 65:6581-6588.

20. Isegawa, Y., Z. Ping, K. Nakano, N. Sugimoto, and K. Yamanishi. 1998. Human herpesvirus 9 open reading frame U12 encodes a functional b-chemokine receptor. J. Virol. 72:61046112.

21. Kondo, K., J. Xu, and E. S. Mocarski. 1996. Human cytomegalovirus latent gene expression in granulocyte-macrophage progenitors in culture and in seropositive individuals. Proc. Natl. Acad. Sci. USA 93:11137-11142.s

22. Kowalik T. F., A. D. Yurochko, C. A. Rinehart, C. Y. Lee, and E. S. Huang. 1994. Productive infection of human endometrial stromal cells by human cytomegalovirus. Virology 202:247257.

23. Krech, U. 1973. Complement-fixing antibodies against cytomegalovirus in different parts of the world. Bull. WHO 49:103-106.

24. Lokensgard J. R., M. C. Cheeran, G. Gekker, S. Hu, C. C. Chao, and P. K. Peterson. 1999. Human cytomegalovirus replication and modulation of apoptosis in astrocytes. J. Hum. Virol. 2:91-101.

25. Maciejewski J. P., S. C. and St Jeor. 1999. Human cytomegalovirus infection of human hematopoietic progenitor cells. Leuk. Lymphoma 33:1-13. 
26. Marks, J. R., and D. H. Spector. 1988. Replication of the murine cytomegalovirus genome: structure and role of the termini in the generation and cleavage of concatenates. Virology 162:98-107.

27. McGeoch, D. J., S. Cook, A. Dolan, F. E. Jamieson, and E. A. R. Telford. 1995. Molecular phylogeny and evolutionary timescale for the family of mammalian herpesviruses. J. Mol. Biol. 247:443-458.

28. McVoy M. A., D. E. Nixon, and S. P. Adler. 1997. Circularization and cleavage of guinea pig cytomegalovirus genomes. J. Virol. 71:4209-4217.

29. Meijer, H., J.C. Dreesen, and C. P. van Boven. 1986. Molecular cloning and restriction endonuclease mapping of the rat cytomegalovirus genome. J. Gen. Virol. 67:1327-1342.

30. Mocarski, E. S. 1993. Cytomegalovirus biology and replication, p. 173-226. In B. Roitzman, R. J. Whitley, and C. Lopez, The human herpesviruses, Raven press, Ltd., New York, N. Y.

31. Neipel, F., J. C. Albrecht, and B. Fleckenstein. 1997. Cell-homologous genes in Kaposis's sarcoma-associated rhadinovirus human herpesvirus 8. J. Virol. 71:4187-4192.

32. Neote, K., D. DiGregorio, J. K. Mak, R. Horuk, and T. J. Schall. 1993. Molecular cloning, functional expression, and signalling characteristics of a C-C chemokine receptor. Cell 72:415425.

33. Nicholas, J. 1996. Determination and analysis of the complete nucleotide sequence of human herpesvirus 7. J. Virol. 70:5975-5989.

34. Poland S. D., P. Costello, G. A. Dekaban, and G. P. Rice. 1990. Cytomegalovirus in the brain: in vitro infection of human brain-derived cells. J. Infect. Dis. 162:1252-1262.

35. Pringle, C. R. 1998. The universal system of virus taxonomy of the international committee on virus taxonomy (ICTV), including new proposals ratified since publication of the Sixth ICTV report in 1995. Arch. Virol. 143:203-210.

36. Rawlinson, W. D., H. E. Farrell, and B. G. Barrell. 1996. Analysis of the complete DNA sequence of murine cytomegalovirus. J. Virol. 70:8833-8849.

37. Reza Nassiri M., J. Gilloteaux, R. S. Taichman, and J. C. Drach. 1998. Ultrastructural aspects of cytomegalovirus-infected fibroblastic stromal cells of human bone marrow. Tissue Cell 30:398-406.

38. Senkevich, T.G., J.J Bugert, J.R. Sisler, E.V. Koonin, G. Darai, and B. Moss. 1996. Genome sequence of a human tumorigenic poxvirus: prediction of specific host response-evasion genes. Science 273:813-816.

39. Slobbe-van Drunen M. E., A. T. Hendrickx, R. C. Vossen, E. J. Speel, M. C. van DamMieras, and C. A. Bruggeman. 1998. Nuclear import as a barrier to infection of human umbilical vein endothelial cells by human cytomegalovirus strain AD169. Virus Res. 56:149. 156.

40. Smith J. D. 1986. Human cytomegalovirus: demonstration of permissive epithelial cells and nonpermissive fibroblastic cells in a survey of human cell lines. J. Virol. 60:583-588.

41. Söderberg, C., S. Larsson, S. Bergstedt-Lindqvist, and E. Moller. 1993. Definition of a subset of human peripheral blood mononuclear cells that are permissive to human cytomegalovirus infection. J. Virol. 67:3166-3175.

42. Stals, F. S., F. Bosman, C. P. A. van Boven, and C. A. Bruggeman. 1990, An animal model for therapeutic intervention studies of CMV infection in the immunocompromised host. Arch. Virol. 114:91-107. 
43. Stals, F. S., E. de Clercq, and C. A. Bruggeman. 1991. Comparative activity of (S)-1-(3hydroxy-2-phosphonylmethoxypropyl)cytosine and 9-(1,3-dihydroxy-2-propoxymethyl)guanine against rat cytomegalovirus infection in vitro and in vivo. Antimicrob. Agents Chemother. 35:2262-2266.

44. Stals, F. S., A. Zeytinoglu, M. Havenith, E. de Clercq, and C. A. Bruggeman. 1993. Rat cytomegalovirus-induced pneumonitis after allogeneic bone marrow transplantation: effective treatment with (S)-1-(3-hydroxy-2-phosphonylmethoxypropyl)cytosine. Antimicrob. Agents Chemother. 37:218-223.

45. Stals, F. S., S. S. Wagenaar, and C. A. Bruggeman. 1994. Generalized cytomegalovirus (CMV) infection and CMV-induced pneumonitis in the rat: combined effect of 9-(1,3-dihydroxy-2propoxymethyl)guanine and specific antibody treatment. Antivral Res. 25:147-160.

46. Tumilowicz J. J., M. E. Gawlik, B. B. Powell, and J. J. Trentin. 1985. Replication of cytomegalovirus in human arterial smooth muscle cells. J. Virol. 56:839-845.

47. Vink C., E. Beuken, and C. A. Bruggeman. 1996. Structure of the rat cytomegalovirus genome termini. J. Virol. 70:5221-5229.

48. Vink, C., E. Beuken, and C. A. Bruggeman. 1997. Cloning and functional characterization of the origin of lytic-phase DNA replication of rat cytomegalovirus. J. Gen. Virol. 78:29632973.

49. Vink C., E. Beuken, and C. A. Bruggeman. Unpublished data.

50. Virgin VI, H. W., P. Latreille, P. Wamsley, K. Hallsworth, K. E. Weck, A. J. Dal Canto, and S. H. Speck. 1997. Complete sequence and genomic analysis of the murine gammaherpesvirus 68. J. Virol. 71:5894-5904.

51. Vossen, R. C. R. M., J. G. Derhaag, M. E. P. Slobbe-van Drunen, A. M. Duijvestijn, M. C. E. van Dam-Mieras, and C. A. Bruggeman. 1996. A dual role for endothelial cells in cytomegalovirus infection? A study of cytomegalovirus infection in a series of rat endothelial cell lines. Virus Res. 46:65-74.

52. Vossen R. C., M. C. Persoons, M. E. Slobbe-van Drunen, C. A. Bruggeman, and M. C. van Dam-Mieras. 1997. Intracellular thiol redox status affects rat cytomegalovirus infection of vascular cells. Virus Res. 48:173-183.

53. Xiang Y., and B. Moss. 1999. Identification of human and mouse homologs of the MC51L$53 \mathrm{~L}-54 \mathrm{~L}$ family of secreted glycoproteins encoded by the Molluscum contagiosum poxvirus. Virology 257:297-302. 
$\sim$ CHAPTER $2 \sim$

The Maastricht Strain and England Strain of Rat Cytomegalovirus Represent Different Betaherpesvirus Species Rather than Strains

PATRICK S. BEISSER, SUZANNE J. F. KAPTEIN, ERIK BEUKEN, CATHRIEN A. BRUGGEMAN AND CORNELIS VINK

Department of Medical Microbiology, Cardiovascular Research Institute Maastricht (CARIM), Maastricht University, PO Box 5800 , 6202 AZ Maastricht, The Netherlands

Virology, 1998, July 5, Vol. 246(2), p. 341-351. 
CHAPTER 2 


\section{ABSTRACT}

The major immediate early (MIE) locus of the Maastricht strain of rat cytomegalovirus (RCMV) was found to comprise five exons of which the first is noncoding. The first three exons are spliced to either exon 4, generating IE1, or exon 5, generating IE2. An additional splicing event unique to RCMV (Maastricht) was identified in exon 5, resulting in a 466-base pairs deletion. IE1 transcripts were detected exclusively during the IE phase of infection in vitro, whereas IE2 transcripts were detected during both the IE and late phase of infection. The similarities between amino acid sequences derived from the MIE gene of RCMV (Maastricht) and murine cytomegalovirus are low ( $22 \%$ and $37 \%$ for IE1 and IE2, respectively). Surprisingly, the similarities between the MIE proteins of RCMV (Maastricht) and the England strain of RCMV are also low ( $23 \%$ and $32 \%$ for IE1 and IE2, respectively). This suggests that these RCMV strains represent different betaherpesvirus species rather than strains. This is underscored by the difference between both viruses in genome size as well as growth characteristics. The existence of two different RCMV-like species might have important implications for the use of these viruses as models for human cytomegalovirus. 


\section{INTRODUCTION}

Cytomegaloviruses (CMVs) are species-specific betaherpesviruses which cause acute, persisting and latent infections both in man and animals. Infections of immunocompetent individuals with human CMV (HCMV) are usually not associated with overt clinical symptoms. However, infection of immunocompromised individuals can result in life-threatening disease.

As a model for HCMV infection and disease, we study the interaction between rat cytomegalovirus (RCMV) and its host. The RCMV-rat system is a highly suitable model system, since the pathogenesis of infection in HCMV-infected humans is similar to that in RCMV-infected rats (25). To date, two strains of RCMV have been studied: the Maastricht strain (4) and the England strain (20). Interestingly, both RCMV strains differ considerably in both restriction patterns and size of their genomes; the genome length was reported to be 224 kilobase pairs (kb) for the Maastricht strain (13) and 206 $\mathrm{kb}$ for the England strain (6). Currently, the nucleotide sequence of approximately $70 \%$ of the genome of RCMV (Maastricht) has been determined (1, 2, 29, 30, 31). This sequence information shows that the genome of RCMV (Maastricht) is collinear with the genomes of murine CMV (MCMV) as well as HCMV, of which the complete nucleotide sequences have been determined $(22,8)$. Additionally, the predicted amino acid sequences that are derived from most of the RCMV (Maastricht) open reading frames (ORFs) display a high level of similarity to the amino acid sequences derived from ORFs of other CMVs, and in particular MCMV $(2,31)$. The only sequence information that is currently available on the England strain of RCMV is that of the locus of major immediate early (MIE) gene transcription $(23,24)$. This locus was found to have an organization similar to that of both HCMV and MCMV $(23,24)$. The MIE locus of RCMV (England) consists of a promoter/enhancer region that directs transcription of a region consisting of five exons. These exons are differentially spliced to generate transcripts encoding two separate proteins, IE1 and IE2. The IE1 and IE2 transcripts share the first three exons, the first of which is noncoding. Splicing of these exons to either exon 4 or 5 generates the IE1 and IE2 transcripts, respectively (23).

In order to compare the nucleotide sequences from the Maastricht strain and England strain of RCMV, we set out to identify and characterize the MIE locus of the RCMV (Maastricht) genome. In this report, both the nucleotide sequence and transcriptional analysis of the MIE region are described. Additionally, the predicted amino acid sequences that are derived from the MIE locus are compared to those of other CMVs. Surprisingly, the sequence of the MIE locus of RCMV (Maastricht) was found to differ considerably from that of the England strain of RCMV, such that these viruses should be classified as different betaherpesvirus species rather than RCMV strains. 


\section{MATERIALS AND METHODS}

Virus and cell culture. Primary rat embryo fibroblasts (REF) were used in all infection experiments. Cells were grown in Eagle's minimum essential medium (EMEM, ICN Biomedicals) supplemented with nonessential amino acids, $2 \mathrm{mM} \mathrm{L}$-glutamine and $10 \%$ newborn calf serum (NCS). Infection of cells with RCMV (Maastricht) was done essentially as previously described (5).

Cloning and sequencing of the MIE region. Cloning of the $\mathrm{XbaI} F, \mathrm{U}, \mathrm{S}, \mathrm{K}, \mathrm{O}$ and $\mathrm{Y}$ fragments of the RCMV genome into vector PSP62-PL has previously been described (13). Each of these fragments was subcloned into vector pUC119 and both strands of the plasmid inserts were sequenced using the Cy5 AutoRead sequencing kit (Pharmacia Biotech) and an ALFexpress automated DNA sequencer (Pharmacia Biotech). PCR products were cloned into either vector pUC119 or pCR2.1 (Invitrogen) and sequenced similarly as described above. Sequence data were generated using overlapping plasmid constructs. Sequence analysis was done using the program PC/Gene (version 2.11, IntelliGenetics).

Poly(A)* RNA isolation, reverse transcriptase-PCR (RT-PCR) and rapid amplification of cDNA ends (RACE). Poly(A)* RNA from RCMV- as well as mock-infected cells was isolated at immediate early (IE), early (E) and late (L) times of infection of REF using a QuickPrep Micro mRNA Purification Kit (Pharmacia Biotech), similary as previously described (1). To obtain IE mRNA, REF were treated with $100 \mu \mathrm{g}$ of cycloheximide per $\mathrm{ml} 1 \mathrm{~h}$ before, during and $16 \mathrm{~h}$ after infection. During the 1-h infection period, the cells were exposed to RCMV at a multiplicity of infection (MOI) of 1. E mRNA was isolated after infection of REFs with RCMV $(\mathrm{MOI}=1)$ and treatment of the cells with $100 \mu \mathrm{g}$ of phosphonoacetic acid per $\mathrm{ml}$ from $3 \mathrm{~h}$ post infection (p.i.) until the cells were harvested at $13 \mathrm{~h}$ p.i. L mRNA was isolated after infection of REF with RCMV at an MOI of 1 and harvesting of cells at $48 \mathrm{~h}$ p.i. To obtain mRNA from mock-infected (M) cells, a similar procedure to that described for L mRNA was used, except that RCMV infection was omitted. Approximately $3 \mu \mathrm{g}$ of the purified RNA was treated with DNase I (Pharmacia Biotech), after which cDNA was synthesized using oligonucleotide primer 3'-RACE1 (Fig. 3A) and a Superscript Plasmid System for cDNA Synthesis and Plasmid Cloning (Gibco BRL). As controls, reactions were also performed in the absence of reverse transcriptase. In order to elucidate the intron-exon structure of the MIE region, each cDNA mixture was amplified by the polymerase chain reaction (PCR) using various primer sets. All primers used are listed in Fig. $3 \mathrm{~A}$. To determine the $5^{\prime}$ ends of the MIE transcripts, the $5^{\prime}$ RACE System for Rapid Amplification of cDNA Ends (Version 2.0) was used (Gibco BRL). Primer 3c was used as gene-specific primer in order to synthesize first-strand cDNA. After tailing of the CDNA with dCTP and Terminal deoxynucleotidyl transferase, PCR was performed using the " 5 ' RACE Abridged Anchor Primer" (AAP; Gibco BRL) and primer 2b. In a second, nested PCR, the " 5 ' RACE Abridged Universal Amplification Primer" (AUAP; Gibco BRL) and primer $1 \mathrm{~b}$ were used. The $3^{\prime}$ ends of the MIE transcripts were determined by PCR amplification of CDNA using primers $4 a$ and 3'RACE2 for IE1-specific transcripts and primers 6a and 3'-RACE2 for IE2-specific transcripts. PCR mixtures ( $50 \mu \mathrm{l}$ ) contained $10 \mathrm{mM}$ Tris- $\mathrm{HCl}$ ( $\mathrm{pH} 9.0$ ), $50 \mathrm{mM} \mathrm{KCl}, 1.5 \mathrm{mM} \mathrm{MgCl}, 0.01 \%$ Triton X-100, $0.2 \mathrm{mM}$ of each dNTP, $0.5 \mu \mathrm{M}$ of each primer, $0.1 \mathrm{U} / \mu \mathrm{I}$ Taq DNA polymerase (Pharmacia Biotech) and $2.5 \mu \mathrm{l}$ of a 7 -fold dilution of a cDNA mixture. Amplification ( $5 \mathrm{~min}$ at 
$95^{\circ} \mathrm{C}, 35$ cycles of $1 \mathrm{~min}$ at $95^{\circ} \mathrm{C}, 1 \mathrm{~min}$ at $55^{\circ} \mathrm{C}$ and $1 \mathrm{~min}$ at $72{ }^{\circ} \mathrm{C}$, followed by $10 \mathrm{~min}$ at $72^{\circ} \mathrm{C}$ ) was done in a GeneAmp PCR System 9600 thermal cycler (Perkin Elmer).

Cloning of RT-PCR products. PCR products were purified using MicroSpin Sephacryl S400 columns (Pharmacia Biotech). The PCR fragment that was generated using primers $2 \mathrm{a}$ and $2 \mathrm{~b}$ was digested with $\mathrm{BclI}$ and $\mathrm{Ncol}$, of which the recognition sites are located near the termini of the fragment (Fig. 3A). After the generation of blunt ends by treatment with dNTPs and DNA polymerase I Klenow fragment (Klenow; Pharmacia Biotech), the fragment was cloned into the Hincll site of pUC119. The PCR fragment that was produced using primers $3 \mathrm{a}$ and $3 \mathrm{~b}$ was cloned in a similar fashion as described above, except that the fragment was digested with other restriction endonucleases, i.e. NcoI and BstBI. When primers $5 \mathrm{a}$ and $5 \mathrm{~b}$ were used in PCR, two different fragments were generated with lengths of $479 \mathrm{bp}$ and $945 \mathrm{bp}$, respectively. The 479-bp fragment was treated with dNTPs and T4 DNA polymerase (Pharmacia Biotech) in order to create blunt ends. Subsequently, the fragment was cloned into the HincII site of pUC119. The 945-bp fragment was also cloned into the Hincll site of pUC119, after digestion of the fragment with NotI and Asp 718, and subsequent treatment with Klenow. The PCR fragment that was produced with primers $3 \mathrm{a}$ and $5 \mathrm{~b}$ was cloned directly into plasmid pCR2.1 (Invitrogen) by using a Eukaryotic TA Cloning Kit (Invitrogen). The fragment that was generated by 5 ' RACE using primers AUAP and $1 \mathrm{~b}$ was digested with Sall (the recognition site of which is located within primer AUAP) and Bcll, followed by treatment with Klenow and cloning into the Hincll site of pUC119. The products that were generated by PCR amplification using either primers 4a and 3'-RACE2 or primers 6a and 3'-RACE2 were first treated with Klenow and then cloned into the Hincll site of pUC119. Escherichia coli JM83 was used for propagation of all plasmid constructs.

Northern blot analysis. Poly(A)* RNA from RCMV-as well as mock-infected cells was isolated at immediate early (IE), early (E) and late (L) times of infection of REF as described above. Denaturing agarose gelelectrophoresis of RNA and transfer to Hybond-N membranes (Amersham) has also been described (1). The integrity of the separated RNA was confirmed by ethidium bromide-staining of agarose gels and methylene blue-staining of filters. To discriminate between IE1 and IE2 transcripts, two probes were generated that exclusively contain either exon 4 or exon 5 sequences. As exon 4-specific probe, a 571-bp Xbal-EcoRI fragment was used and as exon 5-specific probe, a 1.5-kb Xbal-NotI fragment was used; the positions of these fragments within the MIE region are indicated in Fig. 3A. Labeling of DNA fragments with [ $\left.{ }^{2} \mathrm{P}\right] \mathrm{dATP}$ (ICN) was done using a Random Primed DNA labeling Kit (Boehringer Mannheim). Hybridization and autoradiography were performed as described earlier (3).

GenBank accession number. Nucleotide sequence data reported in this paper have been deposited with the GenBank nucleotide sequence database under accession no. AF046125

\section{RESULTS}

Cloning and sequencing of the MIE locus of RCMV (Maastricht). In order to localize a putative MIE locus within the genome of the Maastricht strain of RCMV, we hypothesized that this locus would be present at a position within the genome analogous to that of the MIE loci of HCMV (8), MCMV (22) and RCMV (23). This hypothesis 
followed the observation that the genome of RCMV (Maastricht) is collinear with the HCMV and MCMV genomes $(2,30,31)$. Consequently, we anticipated the RCMV (Maastricht) MIE locus to be present within the XbaI F-Y region of the genome (Fig. 1, 13). Thus, each of the $\mathrm{XbaI}$ fragments that is contained within this region was cloned into vector $\mathrm{PUC} 119$ and sequenced. Comparison of the generated nucleotide sequences with the MIE sequences of other CMVs indicated that the MIE locus of RMCV (Maastricht) had indeed been cloned. The MIE region was found to overlap three successive XbaI fragments: U, S and K (Fig. 1). On the basis of alignments of nucleotide sequences as well as derived amino acid sequences, a gene structure for the RMCV (Maastricht) MIE locus was predicted that is similar to that of the MIE loci of other CMVs (Fig. 1). Analogous to these loci, the RCMV (Maastricht) MIE locus might comprise at least five exons encoding two separate proteins, IE1 and IE2, by alternative splicing of exons 1-3 to either exon 4 or exon 5, respectively. Interestingly, the nucleotide sequence of the MIE region of the Maastricht strain of RCMV differs considerably from that of the MIE region of the England strain of RCMV ( $50 \%$ identity over a 1296-bp region containing the protein-coding content of exon 4, as determined by the global alignment algorithm described by Myers and Miller [17]). By comparison, the identity between this sequence of RCMV (Maastricht) and the corresponding sequences of HCMV and MCMV is $48 \%$ and $47 \%$, respectively.

It has previously been reported that, in contrast to the MIE promoter/enhancer regions of HCMV, MCMV and simian CMV (SCMV), the corresponding region of the England strain of RCMV almost completely lacks repetitive elements and only contains a limited number of consensus binding sites for cellular transcription factors (24). However, the Maastricht strain contains a large number of AP-1 and ATF/CREB consensus binding sites within the putative promoter/enhancer region of the MIE locus (MIEP, Fig. 2A). In addition, this region comprises four copies (A1 to A4) of a 121-bp direct repeat and three copies (B1 to B3) of a 73-bp direct repeat (Fig. 2B). The sequences of repeats $\mathrm{A} 1$ and $\mathrm{B} 1$ are highly similar to those of $\mathrm{A} 2$ and $\mathrm{B} 2$, respectively ( $94 \%$ and $99 \%$ identity). The sequences of A3, and A4 share only $83 \%$ and $50 \%$ identity, respectively, with the A1 sequence. Repeat B3 shares $55 \%$ identity with B1. None of the repeats were found to share significant sequence similarity with MIEPs of other CMVs. Likewise, the remaining sequence of the RCMV (Maastricht) MIEP lacks similarity with sequences of other MIEPs.

Most of the putative AP-1 and ATF/CREB binding sites are located within the repeat sequences of the RCMV (Maastricht) MIEP (Fig. 2A). A characteristic that is shared between the RCMV (Maastricht) MIEP and MCMV MIEP is the large number of potential AP-1 binding sites. Features that are not shared with any of the other MIEPs are the large number of NF- $\kappa$ B and NF-1 sites within the sequences of MCMV and SCMV, respectively. As noted by Sandford and Burns (1996), the RCMV (England) MIEP is unique in its low content of putative transcription factor binding sites as compared to 


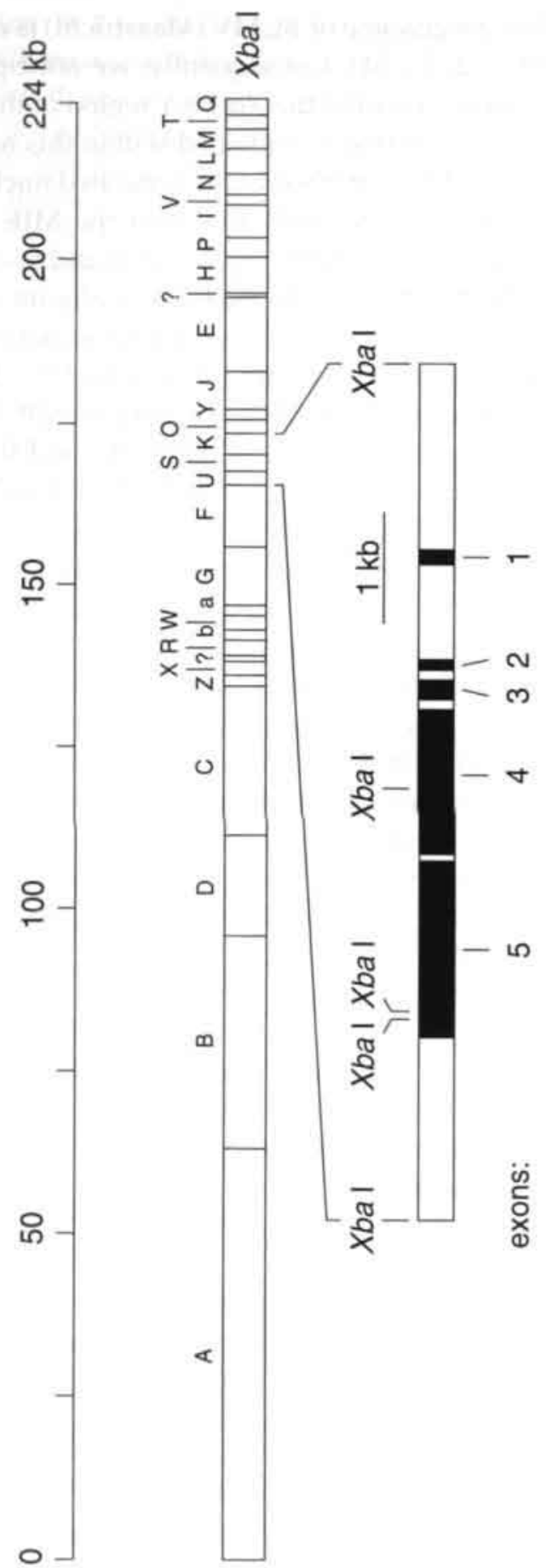

빌 날 ปั 븐 $\sum_{3}$ ㄴ 을 於 ญ . 홀 है Е 혼 कल 흔 는 픈 $\geq \frac{5}{2}$ i $\approx$ ปั

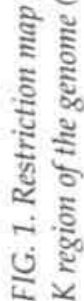


the MIEPs of other CMVs. However, this sequence was shown to function as an efficient transcriptional activator (24). Whether the corresponding sequence from RCMV (Maastricht) is also able to activate transcription, will have to be addressed in future studies.

Structural organization of the MIE locus. To investigate the exon-intron structure of the MIE region, we subjected transcripts that were produced at IE times of RCMV infection to reverse transcriptase-PCR (RT-PCR). The positions and sequences of the primers that were used in this analysis are listed in Fig. 3A. The primers were chosen such that the resulting RT-PCR products would contain the splice junctions between adjacent exons as predicted in Fig. 1. Except for the 5' RACE protocol, cDNA to be used in PCR was synthesized using primer 3'-RACE1 (Fig. 3A). The 5' ends of transcripts from the MIE region were determined by 5 ' RACE as described in Materials and Methods. First, cDNA was synthesized from IE poly(A)* RNA using ìgene-specificî primer $3 \mathrm{c}$ (Fig. 3A). Then, a poly $\mathrm{C}$ tail was added to the 3 ' end of the $\mathrm{CDNA}$, enabling annealing of primer AAP, which contains a stretch of $\mathrm{G}$ and I residues at its $3^{\prime}$ end. In a subsequent $\mathrm{PCR}$ with primers $\mathrm{AAP}$ and $2 \mathrm{~b}$ (which is able to anneal to a sequence within predicted exon 3), a major DNA fragment was produced with a length of approximately 500 bp (Fig. 3B, lane 2). This fragment was subjected to a second PCR with primers AUAP (which is identical in sequence to the $5^{\prime}$ end of primer AAP) and $1 \mathrm{~b}$ (which is able to anneal to a sequence within predicted exon 2). This amplification resulted in a product of approximately $300 \mathrm{bp}$ (Fig. 3B, lane 3). Similar results were obtained when using primer $3 b$ instead of primer $3 c$, and $\mathrm{L}$ instead of IE poly(A)* RNA in cDNA synthesis (data not shown). The length difference of approximately $200 \mathrm{bp}$ between the first and second PCR product is in accordance with splicing of predicted exon 2 to exon 3 (see below). The second, 300-bp 5' RACE product was cloned and sequenced. Similar to the MIE transcripts of other CMVs, the 5 ' ends of the RCMV (Maastricht) MIE transcripts were found to contain a noncoding leader sequence. This sequence, which was designated exon 1 , has a length of $152 \mathrm{bp}$, and is spliced to exon 2 , which contains an open reading frame (ORF). The first AUG of this ORF is located 4 nucleotides downstream of the $5^{\prime}$ boundary of exon 2 (position 2915). In the RCMV (Maastricht) genome, exon 1 and exon 2 are separated by a 954-bp intron, which was termed intron I (Fig. 5A).

To confirm the splicing of predicted exon 2 to exon 3, PCR amplification of cDNA was carried out with primers $2 \mathrm{a}$ and $2 \mathrm{~b}$. As shown in Fig. $3 \mathrm{C}$ (lane 2), amplification resulted in a product with a length of $250 \mathrm{bp}$. The generation of this RT-PCR product was dependent on the use of reverse transcriptase during cDNA synthesis, indicating that RNA and not contaminating DNA was amplified (data not shown). The length of the 250 -bp fragment is in accordance with the presence of the predicted intron between exons 2 and 3 . The nucleotide sequence of this fragment was determined and revealed an in-frame fusion between the ORFs of exon 2 and 3. This indicates that 
A
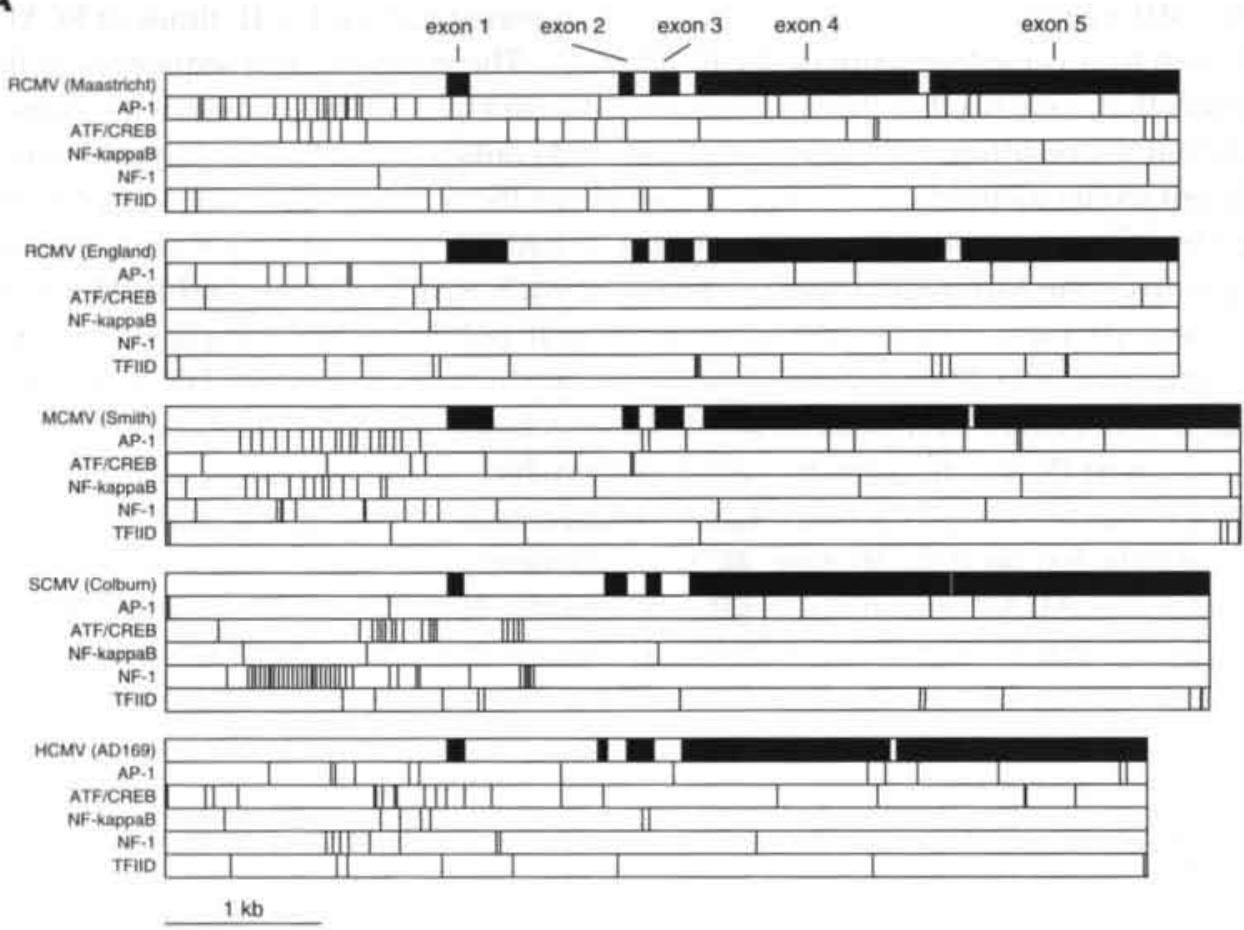

FIG. 2. Comparison of CMV MIE sequences for known consensus binding sites of cellular transcription factors. (A) The positions of the putative binding sites were determined by comparing five MIE loci to a database of cellar transcription factors (TRANSFAC [32]) with SIGSCAN 4.05 (19). Black boxes indicate exons. ( $B$ - Next page) Direct repeats within the RCMV (Maastricht) MIE promoter/enhancer region. The sequences of the direct repeats are shown below the diagram. These repeats can be found under GenBank accession number AF046125, at the following positions: nucleotides 688 to 808 (A1), nucleotides 882 to 1002 (A2), nucleotides 1076 to 1196 (A3), nucleotides 442 to 560 (A4), nucleotides 809 to 881 (B1), nucleotides 1003 to 1075 (B2) and nucleotides 592 to 664 (B3). Nucleotides identical to those in the top sequences ( $A 1$ or B1) are indicated by periods. Gaps are represented by a blank space. The numbers at the right-hand side indicate the percentages of identity with the sequences at the top. 
B

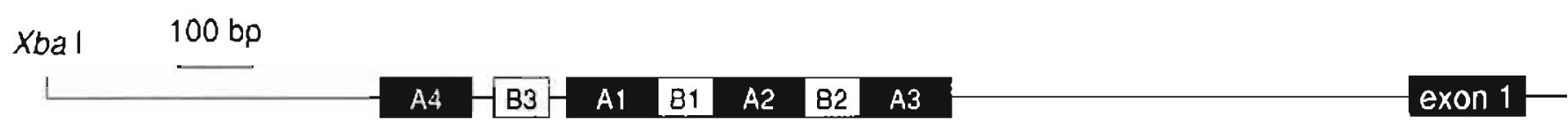

AI AAGTATCAGCCAAAGTTATTCACCCACACATGGGACATGTGTTCTGAAAACCGCTGACGAGCGGGGTCAGCCCGGGTCCACGTCCCGATACGTGAGGGTGATTCAGGGCCAATGTCACAA 100\%

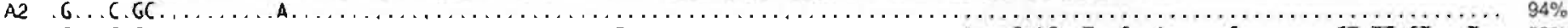

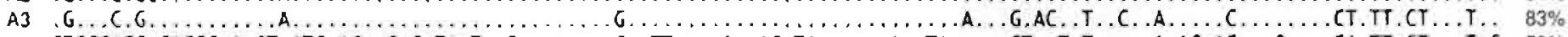

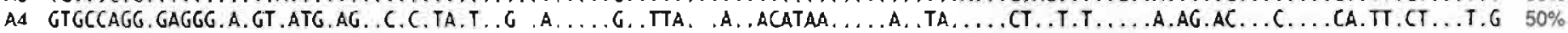

B1 TCAGTTGGGTGAACGGGTCTGAATCACCGACGCGGGATGCGCTGATICAGACGTCAGTTGATGTGCCACGAT 100\%

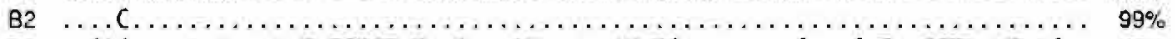

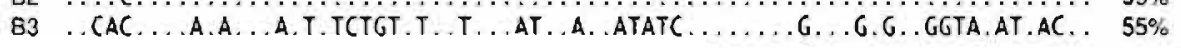




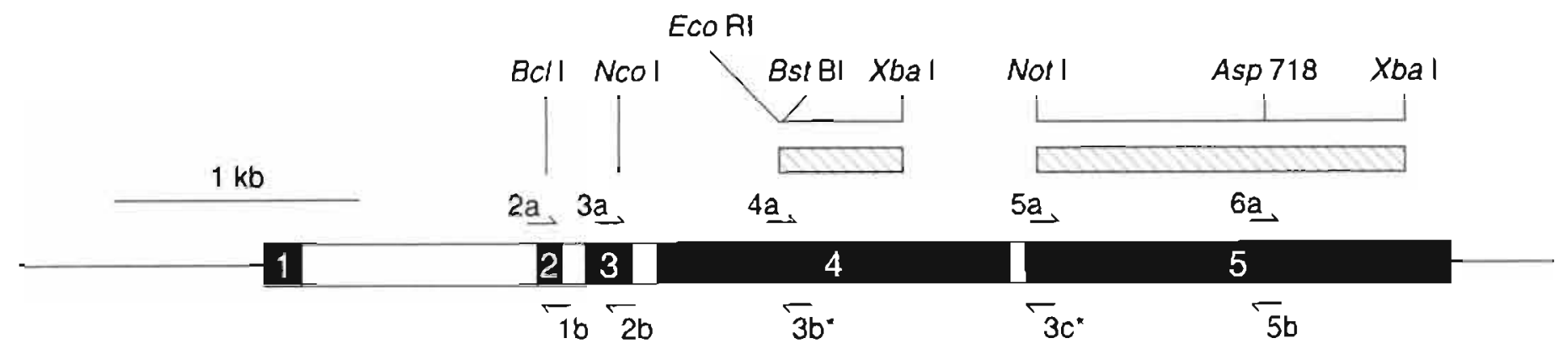

AAP 5'-GGCCACGCGICGACTAGTACGGGIIGGGIIGGGIIG - 3'

AUAP 5 - GGCCACGCGTCGACTAGTAC - 3 '

1b 5' - CGGAGGAAGAGACTCGCGATC - 3' (complement, 2975-2995)

$2 a 55^{\prime}$ - ATGGAACTCAGCAACCCCAGG - $3^{\prime}$ (2921-2941)

2b $5^{\prime}$ - CCATCTTGCCGGAGAGAGTGTC - 3' (complement, 3246-3268)

3a $55^{\prime}$ - CCTATGATCGAAGCCATGGACAC - 3' (3228-3250)

3b" 5' - GTTGTAGGACCTTAGCGATGATGTTC - 3' (complement, 3912-3937)

$3 c^{*} 5^{\prime}$ - ACCTGACATAGATGCGGCCG - 3' (complement, 4942-4961)

4a 5' - CGGATGATAACTITTCAAATTCGAAC - 3' (3890-3915)

$5 a \quad 5^{\prime}$ - CACAGCGGCCGCATCTATG - 3' (4937-4955)

5b $5^{\prime}$ - TGGATGGTACCCTCTCTGCACAG - 3' (complement, 5859-5881)

$6 a \quad 5^{\prime}$ - AACTGTGCAGAGACGGTACCATCC - 3' (5857-5880)

3' RACE1' 5' - GTACGATTCGGACACCCTGCAGTITIIITITITITITI - 3'

3' RACE2 5'- GTACGATTCGGACACCCTGCAG - 3' 
B

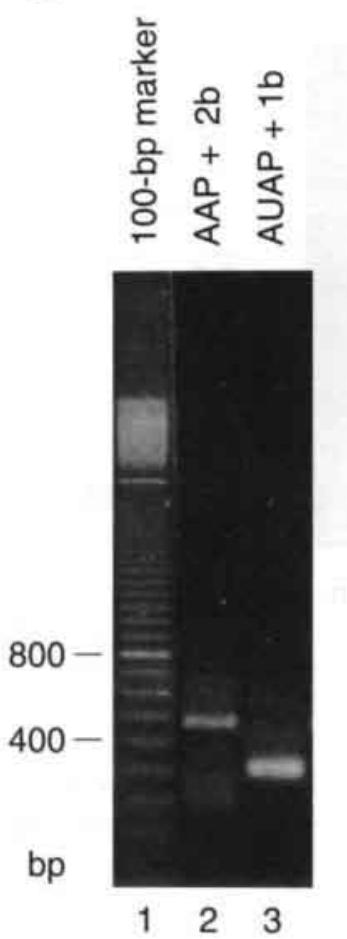

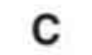

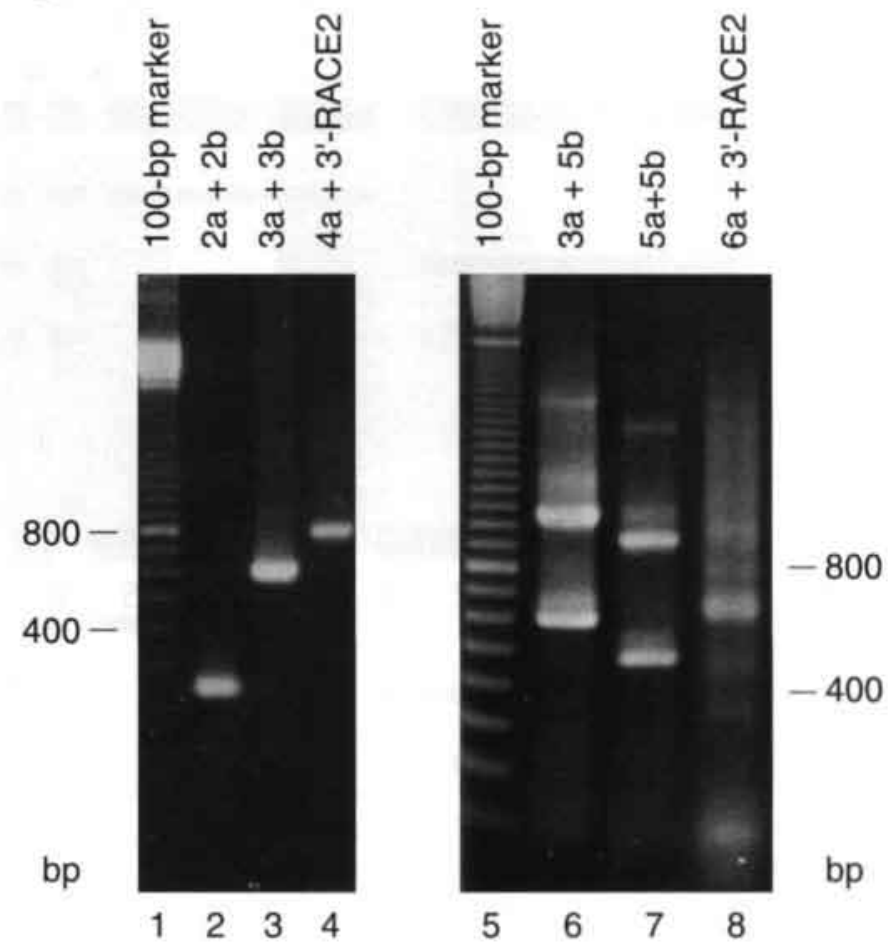

FIG. 3. Determination of the RCMV (Maastricht) MIE transcript ends and splice junctions. (A - Previous page) Positions of DNA probes and positions and sequences of oligonucleotides that were used in Northern blot hybridization, RACE and RT-PCR. Black boxes indicate exons. Introns are indicated by open boxes. Probe positions are indicated by hatched boxes above exon 4 and 5. Primers AAP ( $5^{\prime}$ RACE Abridged Anchor Primer) and AUAP (5' RACE Abridged Universal Amplification Primer) were supplied by the 5' RACE System for Rapid Amplification of CDNA Ends (Gibco BRL). (B) 5' RACE products of MIE transcripts. Lane 1 contains a molecular mass reference (100-bp marker). The primer pair combinations that were used are indicated above lanes 2 and 3. (C) RT-PCR of MIE transcripts. Lanes 1 and 5 contain a molecular mass reference (100-bp marker). The primer pair combinations that were used in each RT-PCR are indicated above lanes 2-4, and 6-8. 


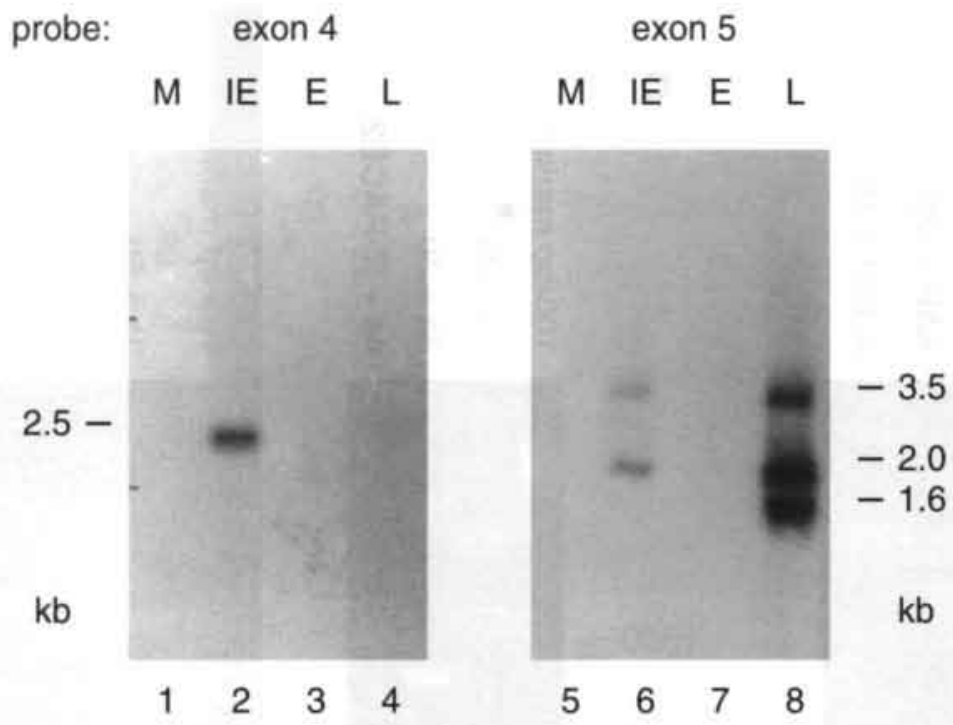

FIG. 4 - Above. Differentially spliced transcripts of the RCMV (Maastricht) MIE locus emerge during the IE and $L$ phases of infection. The figure shows autoradiographs of Northern blots that were hybridized with either an exon 4-specific probe (lanes 1-4) or an exon 5-specific probe (lanes 5-8). In lanes 1 and 5, $m R N A$ from mock-infected $(M)$ cells was separated. Lanes 2 and 6 represent the IE phase, lanes 3 and 7 the E phase and lanes 4 and 8 the L phase of infection. IE, E and L phase mRNA were obtained as described in the Materials and Methods section. The estimated lengths of the transcripts are indicated on the outer sides of the panels in $k b$.

FIG. 5 - Next page. The intron-exon structure of the RCMV (Maastricht) MIE locus. (A) Differentially spliced transcripts from both the HCMV MIE locus (21) and the RCMV (Maastricht) MIE locus. Open boxes indicate untranslated exon regions. Black boxes indicate ORFs. Exons and introns have been assigned Arabic and Roman numerals, respectively. Phases of infection during which the MIE transcripts can be detected are indicated at the 3' ends of each transcript. MIEP, major immediate early promotor/ enhancer/modulator region. (B) Sequences of splice donor and acceptor sites. The sequences shown are at the following positions of GenBank accession number AF046125: nucleotides 1954 to 1968 (exon 1intron 1), nucleotides 2901 to 2915 (intron I-exon 2), nucleotides 3012 to 3026 (exon 2-intron II), nucleotides 3102 to 3116 (intron II-exon 3), nucleotides 3303 to 3317 (exon 3-intron III), nucleotides 3393 to 3407 (intron III-exon 4), nucleotides 4895 to 4909 (intron IV-exon 5), nucleotides 4956 to 4970 (exon 5intron V), and nucleotides 5415 to 5429 (intron V-exon 5). 
A

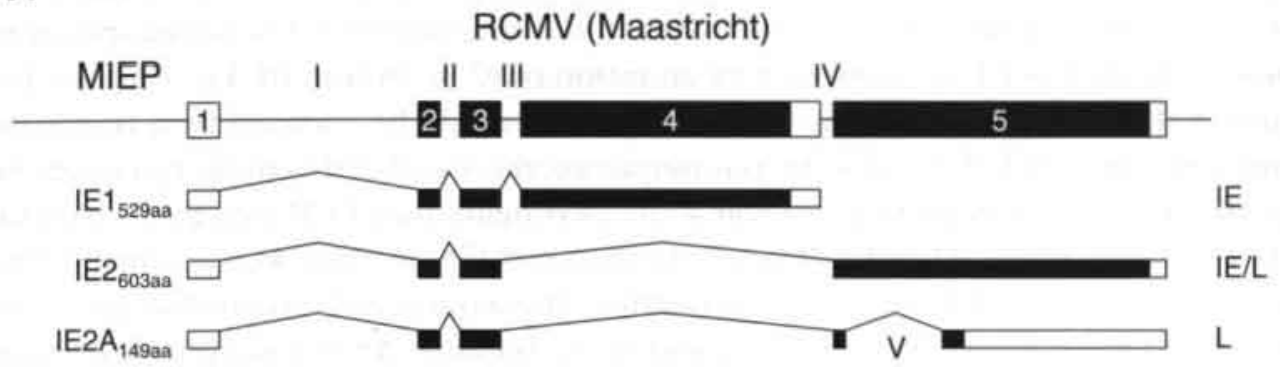

HCMV (AD169)
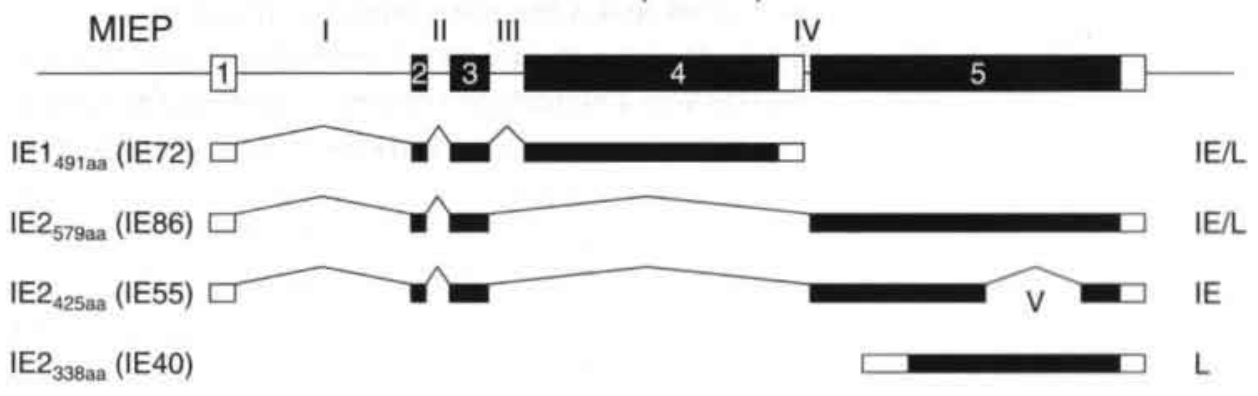

B

exon - intron

1-I: TAAG - GTAAGAATTT

2-II : AAAA - GTAAGTATGT

3-III : GCAG - GTAAGACTGT

$5-\mathrm{V}$ : TCAG - GTATCTCCCC intron - exon

1-2: TATCTGACAG - ACAA

II-3: ATCTTTACAG - AATT

III- 4 : TGGTTTACAG - TGAA

IV-5: TGATTCACAG - GGGA

V-5 : CTTCCTTCAG - ATCC 
exon 2 is indeed properly spliced to exon 3 . The 97 -bp intron between exons 2 and 3 was termed intron II (Fig. 5A).

The predicted splicing of exon 3 to exon 4 was examined by RT-PCR using primer pair $3 \mathrm{a}$ and $3 \mathrm{~b}$. Amplification resulted in a product with a length of approximately 600 bp (Fig. 3C, lane 3). The nucleotide sequence of this product showed an in-frame fusion between the ORFs of exon 3 and exon 4, indicating that exon 3 is indeed spliced to exon 4 . Exon 3 and 4 are separated by an intron of 97 bp (intron III, Fig. 5A). As discussed above, an RCMV (Maastricht) IE1 protein might be encoded by a transcript consisting of exon 1,2,3 and 4. As a consequence, the $3^{\prime}$ end of this transcript might be located near the 3' boundary of exon 4 . To investigate this, PCR was performed on cDNA using primers $4 \mathrm{a}$ and 3'-RACE2. As shown in Fig. 3C (lane 4), a product with a length of approximately $800 \mathrm{bp}$ was generated. The sequence of this product indicated that it did not represent the proper 3 ' end of the putative IE1 transcript, since it was generated after annealing of oligonucleotide 3'-RACE1 (which was used in cDNA synthesis) to an internal A-rich stretch (and not to a 3'-terminal poly A sequence) at position 4644 to 4658 within the $3^{\prime}$ region of exon 4 . Other attempts to efficiently amplify fragments other than the 800 -bp product were not successful, probably due to annealing of primer 3'-RACE1 to the internal exon 4 sequence, thereby competing for binding to 3'-terminal poly A tails of exon 4 transcripts. Nevertheless, since a consensus polyadenylation site ( $5^{\prime}$-AATAAA- $3^{\prime}$ ) is located at position 4811 to 4816,113 -bp downstream of the TAG termination codon of exon 4, we hypothesize that this exon has a length of approximately $1.5 \mathrm{~kb}$. In conclusion, RCMV (Maastricht) might produce exon 4- or IE1-specific transcripts consisting of exon 1,2,3 and 4 with a combined length of at least $1.9 \mathrm{~kb}$.

Splicing of exon 3 to exon 5, which could generate a putative IE2-specific transcript, was investigated by RT-PCR using primers $3 \mathrm{a}$ and $5 \mathrm{~b}$. Interestingly, two major DNA fragments with respective lengths of approximately $600 \mathrm{bp}$ and $1,1 \mathrm{~kb}$ were produced with this primer pair (Fig. 3C, lane 6). The length of the larger species is as expected from splicing of exon 3 to exon 5 . The nature of the 600 -bp species, however, was not clear. Since it was previously reported that the MIE region of HCMV produces alternative transcripts that have a part of exon 5 deleted (27), we hypothesized that the 600-bp PCR fragment might represent an alternative splicing event deleting part of exon 5 from RCMV (Maastricht) MIE transcripts. To investigate this, the 600-bp fragment was cloned and sequenced. The fragment was found to contain a splice junction of exon 3 and exon 5, resulting in an in-frame fusion of both ORFs. In addition, the fragment lacked a $466-\mathrm{bp}$ sequence (from position 4960 to 5425 ) that is present near the 5 ' end of exon 5. This deletion results in a frame-shift to an ORF with a length of only 98 bp (Fig. 5A). To confirm alternative splicing of exon 5, RT-PCR was also done with two exon 5 -specific primers, $5 \mathrm{a}$ and $5 \mathrm{~b}$. Similarly as described for primer pair $3 \mathrm{a}$ and $5 \mathrm{~b}$, two major DNA fragments were amplified (Fig. 3C, lane 7). The larger frag- 
ment (approximately $950 \mathrm{bp}$ ) represents "full-length" exon 5, whereas the smaller fragment (approximately $500 \mathrm{bp}$ ) represents the alternative splicing product, as confirmed by DNA sequencing. No evidence was found for splicing of exon 4 to exon 5 using various primer combinations in RT-PCR (data not shown). This indicates that, similar to the situation for other CMVs, transcription of the MIE region of RCMV (Maastricht) generates either exon 4- or exon 5-specific mRNAs, which share exon 1 to 3.

In order to determine the 3 ' end(s) of the exon 5 transcripts, RT-PCR was carried out with primers $6 \mathrm{a}$ and 3'-RACE2. A major product of approximately $650 \mathrm{bp}$ (Fig. 3C, lane 8 ) was generated, which was subsequently cloned and sequenced. Based on the presence of a poly A stretch downstream of exon 5, we inferred that this product indeed represented the authentic 3 ' end of an exon 5-specific transcript. The poly A tail followed either nucleotide 6500 or 6501 (which is an A), located at a distance of 26 or $27 \mathrm{bp}$, respectively, from a consensus polyadenylation site (5'-AATAAA-3', position 6469 to 6474 ). We conclude that RCMV (Maastricht) expresses at least two exon 5- or IE2-specific transcripts, which are composed of exons 1,2 and 3, alternatively spliced to either "full-length" exon 5 (resulting in a transcript termed IE2) or a deleted version of exon 5 (resulting in transcript IE2A). The IE2 and IE2A transcripts were estimated to have a length of $2046 \mathrm{bp}$ and $1580 \mathrm{bp}$, respectively. All characterized introns from the MIE locus of RCMV (Maastricht) were found to share the consensus sequence GT at their 5' ends and AG at their 3' ends (Fig. 5B [16]).

Transcription from the MIE locus. To further investigate transcription from the MIE region of RCMV (Maastricht), poly (A)+ RNA from RCMV-infected cells was purified at immediate early (IE), early (E) and late (L) times of infection of rat embryo fibroblasts (REF). After separation on an agarose gel, the RNA was transferred to a nylon filter and hybridized with two different probes. These probes were used to allow discrimination between putative IE1- and IE2-specific transcripts and were derived from exon 4 and exon 5, respectively. As shown in Fig. 4, a single exon 4-specific transcript with a length of approximately $2.5 \mathrm{~kb}$ was observed exclusively at IE times of infection (lane 2). It is likely that this transcript corresponds to the exon 4-specific transcript that was identified by RT-PCR, which was estimated to have a length of at least $1.9 \mathrm{~kb}$ (see above). Using the exon 5 -specific probe, two different major transcripts with respective lengths of approximately $3.5 \mathrm{~kb}$ and $2.0 \mathrm{~kb}$ were detected both at IE and L times of infection (lanes 6 and 8, respectively). An additional exon 5-specific transcript of $1.6 \mathrm{~kb}$ was observed at $\mathrm{L}$ times only (lane 8 ). The lengths of the $2.0-\mathrm{kb}$ and 1.6-kb transcripts correspond with the estimated lengths of the IE2 and IE2A transcripts, respectively (see above). It is therefore likely that the $1.9-\mathrm{kb}, 2.0-\mathrm{kb}$ and $1.6-\mathrm{kb}$ transcripts represent transcripts IE1, IE2 and IE2A, respectively. As a consequence, IE2A would only be abundantly expressed at $\mathrm{L}$ times of infection. However, we were able to detect the putative IE2A transcript during the IE phase by RT-PCR (see above). This is probably due to the higher sensitivity of RT-PCR compared to Northern blot 
analysis. The structure of the $3.5-\mathrm{kb}$ RNA is not clear. Since this transcript does not hybridize with an exon 4-specific probe, it is probably composed of exon 5 sequences as well as sequences downstream of this exon. The structure of this 3.5-kb transcript was not subjected to further studies. Aschematic representation of the different mRNAs transcribed from the RCMV (Maastricht) MIE locus, as inferred from the RT-PCR and Northern data, is depicted in Fig. 5A. The IE1 transcript has the capacity to encode a protein with a molecular mass of $61 \mathrm{kD}$. The protein is hydrophilic, containing $16 \%$ acidic and $18 \%$ basic amino acids. The calculated isoelectric point of the IE1 protein is $\mathrm{pH}$ 6.8. Two putative nuclear localization signals (IE1 NLS-1: RKRK, residues 466 to 469 and IE1 NLS-2: KKKQAKKGKKRCKKGKKKCKKE, residues 508 to 529) were found by screening the predicted amino acid sequence according to a method described by Nakai and Kanehisa (18). The IE2 transcript has the potential to encode a protein with a molecular mass of $68 \mathrm{kD}$ and a predicted isoelectric point of $\mathrm{pH} 8.7$. Like IE1, the IE2 protein is hydrophilic, containing $13 \%$ acidic and $17 \%$ basic amino acids. Two potential nuclear localization signals are localized within the predicted IE2 polypeptide (IE2 NLS-1: KRRGETRSPSPPSSRRRY, residues 284 to 301, and IE2 NLS-2: HRRKPR, residues 379 to 384 ). The IE2A protein has the capacity to encode a protein with a molecular mass of $16 \mathrm{kD}$. Similarly as IE1 and IE2, the IE2A protein is hydrophilic, containing $18 \%$ acidic and $11 \%$ basic amino acids. The calculated isoelectric point of IE2A is $\mathrm{pH} 4.4$. In contrast to the other IE proteins, IE2A does not possess any nuclear localization signals.

Comparison of the predicted amino acid sequences of the RCMV (Maastricht) IE proteins with those of other CMVs. The amino acid sequences that were derived from the ORFs of the IE1 and IE2 transcripts were compared to the corresponding sequences of other CMVs. The overall similarity (17) between the predicted amino acid sequence of RCMV (Maastricht) IE1 and that of MCMV (Smith) IE1 and HCMV

TABLE 1. Similarities ${ }^{\natural}$ of IE1 and IE2 amino acid sequences among various CMV strains

RCMV-E MCMV-S SCMV-C HCMV-A RCMV-E MCMV-S SCMV-C HCMV-A

\begin{tabular}{|c|c|c|c|c|c|c|c|c|}
\hline RCMV-M & 23 & 22 & 18 & 16 & 32 & 37 & 25 & 27 \\
\hline RCMV-E & & 26 & 17 & 21 & & 34 & 25 & 25 \\
\hline MCMV-S & & & 17 & 21 & & & 25 & 26 \\
\hline SCMV-C & & & & 27 & & & & 45 \\
\hline
\end{tabular}

- Percentages of similarity were calculated according to the global alignment algorithm described by Myers and Miller (17). M, Maastricht (this study); E, England (24); S, Smith (22); C, Colburn (7); A, AD169 (90). 
(AD169) IE72 is $22 \%$ and $16 \%$, respectively. As could be expected from the low level of homology between the MIE regions of the Maastricht and England strain of RCMV on the DNA level, the predicted sequences of the IE1 proteins of these viruses showed an identity of only $23 \%$. When the sequences of putative IE2-like proteins were compared, higher identities were seen, indicating that exon 5-like sequences are more conserved than exon 4-like sequences. The identities between the putative IE2 protein of RCMV (Maastricht) and the corresponding proteins of MCMV and HCMV are $37 \%$ and $27 \%$, respectively. Surprisingly, the identity between the putative IE2 proteins of the Maastricht and England RCMV strains (32\%) is lower than between IE2 of RCMV (Maastricht) and ie3 (the IE2 counterpart) of MCMV. The similarities of IE1 and IE2 amino acid sequences among various CMV strains are presented in Table 1. To further investigate the relationships between the putative IE proteins of different CMVs as well as different CMV strains, a phylogenetic tree was generated using a part of exon 4 of which the nucleotide sequence of three MCMV strains and three HCMV strains is known (Fig. 6). On the one hand, this phylogenetic tree demonstrates the close relationship among MCMV strains as well as among HCMV strains. On the other hand, this tree clearly underlines the considerable divergence in sequence between RCMV (Maastricht) and RCMV (England).

In conclusion, both nucleotide sequence and predicted amino acid alignments strongly suggest that RCMV (Maastricht) and RCMV (England) are similarly related to one another as each of these viruses is related to MCMV. This suggests that these socalled strains of RCMV actually represent different CMV-like species. As a consequence, rats might harbor two different CMV-like viruses, which as yet has not been demonstrated for any other CMV host.

\section{DISCUSSION}

The MIE locus of RCMV (Maastricht) shows a similar structural organization as the corresponding regions of HCMV, MCMV and RCMV (England). Each of these regions consists of differentially spliced genes in which a noncoding leader sequence (exon 1) is followed by a large intron (intron I) and four coding exons (exons 2-5) that are separated by small introns (introns II-IV) (Fig. 5A). Two major IE transcripts of RCMV (Maastricht) were identified that are similar to IE transcripts of other CMVs. These transcripts, which were designated IE1 and IE2, share identical 5 ' ends, consisting of exons 1 to 3, but differ at their 3' ends, having either exon 4 (in IE1) or exon 5 (in IE2) spliced to the 3' end of exon 3. In both the IE1 and IE2 transcripts, which have the capacity to encode proteins of $61 \mathrm{kDa}$ and $68 \mathrm{kDa}$, respectively, the exon 3 splice donor site is identical (Fig. 5B). Similar to their counterparts from $\operatorname{HCMV}(27,21)$ and MCMV $(11,14)$, both IE1 and IE2 of RCMV (Maastricht) are transcribed during the immediate early phase of infection. During the late phase of RCMV (Maastricht) infection, IE2 but 


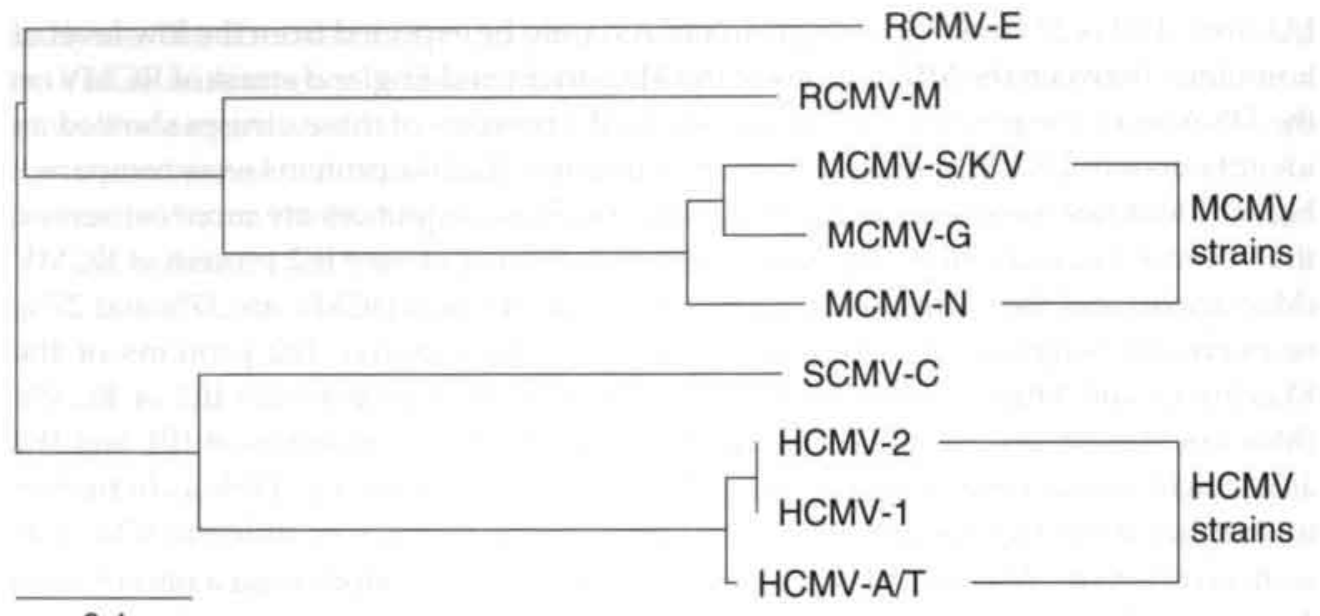

0.1

FIG. 6. The Maastricht strain and England strain of RCMV are two different species rather than strains. The phylogenetic tree is based on a multiple alignment of amino acid sequences that were derived from a region within exon 4 . The alignment was made with amino acid sequences that are encoded by the following nucleic acid sequences: RCMV-M (Maastricht strain), nucleotides 3544 to 3678 of GenBank accession number (GB\#) AF046125; RCMV-E (England strain [23]), nucleotides 1863 to 1991 of GB\# L13150; MCMV-G (G1A strain [12]), GB\# L41001; MCMV-K (K181 strain [12]), GB\# L41029; MCMV-N (N1 strain [12]), GB\# L41036; MCMV-S (Smith strain [22]), the complement of nucleotides 180972 to 181107 of GB\# U68299; MCMV-V (Vancouver strain [12]), GB\# L41001; SCMV-C (simian cytomegalovirus, Colburn strain [7]), nucleotides 6652 to 6677 of GB\# U38308; HCMV-1 (individual isolate C327MIE [9]), nucleotides 144 to 270 of GB\# M95639; HCMV-2 (individual isolate C327MIE [9]), nucleotides 144 to 270 of GB\# M95638; HCMV-A (AD169 strain [8]), the complement of nucleotides 171960 to 172084 of GB\# X17403; HCMV-T (Towne strain [26]), nucleotides 154 to 279 of GB\# M11630. CLUSTAL W pairwise alignment (28) was set to BLOSUM 30 protein weight matrix, gap open penalty $=10$, and gap extension penalty $=0.1$. Multiple alignment was set to BLOSUM series, gap open penalty $=10$, gap extension penalty $=0.05$, delay divergent sequences $=0.4$.

not IE1 is transcribed, while in the late phase of HCMV infection both $\operatorname{IE} 1_{491 a a}$ and IE2 ${ }_{579 a \mathrm{a}}$ transcripts are produced (21). In addition to IE1 and IE2 transcripts, we identified a third major transcript from the RCMV (Maastricht) MIE locus, which was termed IE2A. This transcript is an IE2-like, alternatively spliced RNA in which a 466-bp sequence from exon 5 has been deleted (Fig. 5A). A similar alternative splicing event has previously been reported for the HCMV IE $2_{425 a \mathrm{a}}$ transcript, in which a 465 -bp sequence (Fig. 5A) has been deleted from exon 5 (27). Interestingly, splicing of IE $2_{425 a}$ of HCMV results in an in-frame deletion, whereas alternative splicing of IE2A of RCMV (Maastricht) results in an out-of-frame deletion. As a consequence, the 5'-terminal 18 
codons of exon 5 are coupled to 33 novel codons in the IE2A transcript, which has the potential to encode a 16-kDa protein (Fig. 5A). By Northern blot hybridization, an exon 5 -specific transcript with a length of $1.6 \mathrm{~kb}$ was identified. Since this length corresponds with the predicted length of IE2A, we inferred that the 1.6-kb mRNA represents the IE2A transcript. Interestingly, this mRNA species was almost exclusively produced at late times of infection. A late phase-specific transcript from the MIE locus has previously also been identified for HCMV. This mRNA is transcribed from a promoter near the 5 ' end of exon 5 and encodes an abundant 338-amino acid protein (IE2 2338 ) (reviewed by Mocarski [15]). The IE2 ${ }_{33 s a a}$ protein was found to repress expression of HCMV IE or alpha genes at late times postinfection. The function of any of the polypeptides that are predicted to be derived from the MIE locus of RCMV (Maastricht) will have to come out of future studies. Nevertheless, on the basis of both structural and positional similarity between the MIE locus of RCMV (Maastricht) and that of other CMVs, it is likely that the RCMV (Maastricht) IE genes play a role in transcriptional activation of many promoters in a cell-specific as well as promoter-specific manner (reviewed by Mocarski [15]).

To date, two strains of RCMV are under study, the Maastricht strain (4) and the England strain (20). Unlike strains of HCMV and MCMV, these RCMV strains were found to differ considerably in both length and restriction fragment pattern of their genomes $(13,6)$. In addition, these strains showed different growth characteristics in vitro as well as in vivo. First, the England strain was found to replicate in rat and mouse embryo fibroblast cells in vitro to similar levels (20), whereas the Maastricht strain was found to replicate exclusively in cells from rat origin (4). Second, after infection of lacrimal gland acinar epithelial cells in vitro, the England strain but not the Maastricht strain replicated efficiently (10). Third and most notably, virus could not be detected in saliva from rats infected with the England strain (10), whereas large amounts of virus was found in saliva of rats infected with the Maastricht strain (5). We here show that these differences between RCMV (Maastricht) and RCMV (England) can be attributed to a considerable divergence in genome sequence between these viruses. Minor differences are found when comparing MIE sequences from either different MCMV strains or different HCMV strains (Fig. 6). By contrast, the predicted amino acid sequences derived from the MIE loci of the Maastricht strain and England strain of RCMV are similarly related to one another as each of these sequences is related to the corresponding sequences of MCMV (Fig. 6). Taken together, these data indicate that RCMV (Maastricht) and RCMV (England) represent different betaherpesvirus species rather than RCMV strains. Since the only sequence available of the genome of RCMV (England) is that of the MIE locus, it is not yet possible to perform additional sequence comparisons. Currently, approximately $70 \%$ of the genome of RCMV (Maastricht) has been sequenced (31). Most of the RCMV (Maastricht) ORFs that have been identified have counterparts within the genomes of both HCMV and MCMV. 
These ORFs share similarity in sequence as well as relative position within the genome. Examples of RCMV (Maastricht) genes that were previously characterized are R33 (1) and R54 to R57 (2). Each of these genes was found to have a counterpart at a similar position in the genomes of HCMV and MCMV. Also, the sequence directing the initiation of lytic-phase DNA replication (oriLyt) of RCMV (Maastricht) was found to be located at a conserved position within the genome (30). It will be interesting to investigate whether a similar level of conservation exists between the genome of RCMV (England) and that of other CMVs. Additional sequence data from the genome of RCMV (England) is essential in order to classify this virus within the subfamily of betaherpesviruses.

\section{ACKNOWLEDGMENTS}

We thank Rien Blok, Henk Bruning and Joanne van Dam for critically reading the manuscript.

\section{REFERENCES}

1. Beisser, P. S.,C. Vink, J. G. Van Dam, G. Grauls, S. J. V. Vanherle, and C. A. Bruggeman, (1998). The R33 G protein-coupled receptor gene of rat cytomegalovirus plays an essential role in the pathogenesis of viral infection. J. Virol. 72:2352-2363.

2. Beuken, E., R. Slobbe, C.A. Bruggeman, and C. Vink, (1996). Cloning and sequence analysis of the genes encoding DNA polymerase, glycoprotein B, ICP 18.5 and major DNA-binding protein of rat cytomegalovirus. J. Gen. Virol. 77:1559-1562.

3. Brown, T., and K. Mackey, (1997). Analysis of RNA by Northern and slot blot hybridization. In "Current protocols in molecular biology" (F.M. Ausubel, R. 1. Brent, R.E. Kingston, D.D. Moore, J.G. Seidman, J.A. Smith and K. Struhl, Eds.), pp. 4.9.1-4.9.16. John Wiley \& Sons, Inc., New York.

4. Bruggeman, C. A., H. Meijer, F. Bosman, and C. P. A. van Boven, (1985). Biology of rat cytomegalovirus infection. Intervirology 24:1-9.

5. Bruggeman, C. A., H. Meijer, P. H. J. Dormans, W. H. M. Debie, G. E. L. M. Grauls, and C. P. A. van Boven, (1982). Isolation of a cytomegalovirus-like agent from wild rats. Arch. Virol. 73:231-241.

6. Burns, W. H., G. M. Barbour, and G. R. Sandford, (1988). Molecular cloning and mapping of rat cytomegalovirus DNA. Virology 166:140-148.

7. Chang, Y., K. Jeang, T. Lietman, and G. S. Hayward, (1995). Structural organization of the spliced immediate-early gene complex that encodes the major acidic nuclear (IE1) and transactivator (IE2) proteins of african green monkey cytomegalovirus. J. Biomed. Sci. 2:105130.

8. Chee, M. S., A.T. Bankier, S. Beck, R. Bohni, C. M. Brown, R. Cerny, T. Horsnell, C. A. Hutchison III, T. Kouzarides, J. A. Martignetti, E. Preddie, S. C. Satchwell, P. Tomlinson, K. M. Weston, and B. G. Barrell, (1990). Analysis of the protein-coding content of the se- 
quence of human cytomegalovirus strain AD169. Curr. Top. Microbiol. Immunol. 154:125169.

9. Chou, S. (1992). Effect of interstrain variation on diagnostic DNA amplification of the cytomegalovirus major immediate-early region. J. Clin. Microbiol. 30:2307-231.

10. Huang, Z., R. W. Lambert, A. Wickham, and D. A. Sullivan, (1996). Analysis of cytomegalovirus infection and replication in acinar epithelial cells of the rat lacrimal gland. Invest. Ophthalmol. Vis. Sci. 37:1174-1186.

11. Keil, G. M., A. Ebeling-Keil, and U. H. Koszinowski, (1987). Sequence and structural organization of murine cytomegalovirus immediate-early gene 1. J. Virol. 61:1901-1908.

12. Lyons, P. A., J. E. Allan, C. Carrello, G. R. Shellam, and A. A. Scalzo, (1996). Effect of natural sequence variation at the H-2Ld-restricted CD8 ${ }^{+} \mathrm{T}$ cell epitope of the murine cytomegalovirus ie1-encoded pp89 on T cell recognition. J. Gen. Virol. 77:2615-2623.

13. Meijer, H., J.C. Dreesen, and C. P. van Boven, (1986). Molecular cloning and restriction endonuclease mapping of the rat cytomegalovirus genome. J. Gen. Virol. 67:1327-1342.

14. Messerle, M., B. Buhler, G. M. Keil, and U. H. Koszinowski, (1992). Structural organization, expression, and functional characterization of the murine cytomegalovirus immediate-early gene 3. J. Virol. 66:27-36.

15. Mocarski Jr., E. S. (1993). Cytomegalovirus biology and replication. In iThe human herpesvirusesî (B. Roizman, R. J. Whitley and C. Lopez, Eds.), pp 173-226. Raven Press, New York.

16. Mount, S. M. (1983) Sequences that signal where to splice. Nature 304:309-310.

17. Myers, E. W., and W. Miller, (1988). Optimal alignments in linear space. Comput. Appl. Biosci. 4:11-17.

18. Nakai, K., and M. Kanehisa, (1992). A knowledge base for predicting protein localization sites in eukaryotic cells. Genomics 14:897-911.

19. Prestridge, D. S. (1991). SIGNAL SCAN: a computer program that scans DNA sequences for eukaryotic transcriptional elements. Comput. Appl. Biosci. 7:203-206.

20. Priscott, P. K., and D. A. J. Tyrrell, (1982). The isolation and partial characterization of a cytomegalovirus from the brown rat, Rattus norvegicus. Arch. Virol. 73:145-160.

21. Rawlinson, W. D., and B. G. Barrell, (1993) Spliced transcripts of human cytomegalovirus. J. Virol. 67:5502-5513.

22. Rawlinson, W. D., H. E. Farrell, and B. G. Barrell, (1996). Analysis of the complete DNA sequence of murine cytomegalovirus. J. Virol. 70:8833-8849.

23. Sandford, G. R., and W. H. Burns, (1996). Rat cytomegalovirus has a unique immediate early gene enhancer. Virology 222:310-317.

24. Sandford, G. R., K. Ho, and W. H. Burns, (1993). Characterization of the major locus of immediate early genes of rat cytomegalovirus. J. Virol. 67:4093-4103.

25. Stals, F. S., F., Bosman, C. P. van Boven, and C. A. Bruggeman, (1990). An animal model for therapeutic intervention studies of CMV infection in the immunocompromised host. Arch. Virol. 114:91-107.

26. Stenberg, R. M., A. S. Depto, J. Fortney, and J. A. Nelson, (1989). Regulated expression of early and late RNAs and proteins from the human cytomegalovirus immediate-early gene region. J. Virol. 63:2699-2708. 
27. Stenberg, R. M., D. R. Thomsen, and M. F. Stinski, (1984) Structural analysis of the major immediate early gene of human cytomegalovirus J. Virol. 49:190-199.

28. Thompson, J. D., D. G. Higgins, and T. J. Gibson, (1994). CLUSTAL W: improving the sensitivity of progressive multiple sequence alignment through sequence weighting, position-specific gap penalties and weight matrix choice. Nucleic Acids Res. 22:4673-4680.

29. Vink, C., E. Beuken, and C. A. Bruggeman, (1996). Structure of the rat cytomegalovirus genome termini. J. Virol. 70:5221-5229.

30. Vink, C., E. Beuken, C. A. Bruggeman, (1997). Cloning and functional characterization of the origin of lytic-phase DNA replication of rat cytomegalovirus. J. Gen. Virol. 78:29632973.

31. Vink, C., E. Beuken, C. A. Bruggeman, (1998). Unpublished data.

32. Wingender, E. (1988). Compilation of transcription regulating proteins. Nucleic Acid Res. 16:1879-1902. 
$\sim$ CHAPTER $3 \sim$

\section{The R33 G Protein-Coupled Recep- tor Gene of Rat Cytomegalovirus} Plays an Essential Role in the Pathogenesis of Viral Infection

PATRICK S. BEISSER, CORNELIS VINK, JOANNE G. VAN DAM, GERT GRAULS, SABINA J. V. VANHERLE, AND CATHRIEN A. BRUGGEMAN

Department of Medical Microbiology, Cardiovascular Research Institute Maastricht (CARIM), Maastricht University, P.O. Box 5800, 6202 AZ, Maastricht, The Netherlands.

Journal of Virology, 1998, March, Vol. 72, No. 3, p. 2352-2363. 
CHAPTER 3 


\section{ABSTRACT}

We have identified a rat cytomegalovirus (RCMV) gene that encodes a G protein-coupled receptor (GCR) homolog. This gene (R33) belongs to a family that includes the human cytomegalovirus UL33 gene. R33 was found to be transcribed during the late phase of RCMV infection in rat embryo fibroblasts. Unlike the mRNAs from all other members of the UL33 family that have been studied to date, the R33 mRNA is not spliced. To study the function of the R33 gene, we constructed an RCMV strain in which the R33 open reading frame is disrupted. The mutant strain (RCMV $\triangle R 33$ ) did not show differences in replication with wild-type RCMV upon infection of several rat cell types in vitro. However, marked differences were seen between the mutant and wild-type strain in the pathogenesis of infection in immunocompromised rats. First, the mutant strain was found to induce a significantly lower mortality than wild-type virus. Second, in contrast to wild type RCMV, the mutant strain did not efficiently replicate in the salivary gland epithelial cells of immunocompromised rats. Although viral DNA was detected in salivary glands of RCMV $\triangle \mathrm{R} 33$-infected rats up to 14 days post infection, it could not be detected at later time-points. This indicates that although the R33-deleted strain is probably transported to the salivary glands in a similar fashion as wild-type virus, the mutant virus is not able to either enter or replicate in salivary gland epithelial cells. We conclude that the RCMV R33 gene plays a vital role in the pathogenesis of infection. 


\section{INTRODUCTION}

G protein-coupled receptors (GCRs) are proteins that have a crucial function in signal transduction through cell membranes. Upon interaction with extracellular ligands, GCRs transduce a signal into the cell by activating a cascade of cellular processes, which is initiated by the activation of GTP-binding proteins (G proteins). Interestingly, GCRs are not only encoded by eukaryotic or prokaryotic genes, but also by genes of viruses. To date, eighteen putative GCR genes have been discovered within viral genomes: sixteen of these genes are located within the genomes of $\beta$ - and $\gamma$-herpesviruses $(17,20,28,41,42,45,48)$, and two within poxviruses $(15,36)$. The functions of any of these GCRs in the pathogenesis of viral disease are yet unclear.

Within the genome of human cytomegalovirus (HCMV), four genes were identified that encode GCR homologs: UL33, UL78, US27 and US28 $(19,28)$. The amino acid sequences derived from the latter two genes were found to have the highest sequence similarity to cellular chemokine receptors $(23,26)$. In addition, the US28 translation product has been shown to be capable of binding $b$ chemokines in vitro, hence triggering mobilization of intracellular $\mathrm{Ca}^{2+}(33)$. Due to the species-specificity of $\mathrm{HCMV}$ it is difficult to study the function of the US27 and US28 genes in vivo. Moreover, these genes do not seem to have any counterparts within the genomes of other herpesviruses. In contrast, UL33 and UL78-like genes are conserved among all $\beta$-herpesviruses. The function of these genes can therefore be studied in vivo. Genes similar to UL33 and UL78 have been found within the genomes of murine cytomegalovirus (MCMV; M33 and M78 respectively [45]), human herpesvirus type 6 (HHV-6; U12 and U51 respectively, [28]) and human herpesvirus type 7 (HHV-7; ORF U12 and U51 respectively, [42]). Although the positions of UL78-like genes within the $\beta$-herpesvirus genomes are conserved, their sequences are highly divergent $(28,42,45)$. In contrast, both genome location and sequence of UL33-like genes are conserved among all $\beta$ herpesviruses studied to date $(28,42,45)$. The HCMV UL33 gene was found to be expressed both in membranes of cultured fibroblasts and in viral envelopes (35). Both the HCMV UL33 and MCMV M33 genes were found to be dispensable for viral replication in vitro in human and murine fibroblasts, respectively $(35,24)$. Recombinant MCMV strains that lack a functional M33 gene were also examined in vivo (24). In contrast to wild-type MCMV, recombinant MCMV could not be recovered from salivary glands of infected mice. In addition, recombinant MCMV was found not to replicate after direct administration of the virus into the salivary glands (24). Although these data clearly provided evidence for an important role of UL33-like GCRs in salivary gland tropism, it remained unclear whether these receptors play a role in dissemination of virus to various target organs. It is also unknown whether the UL33-like genes have a function in the pathogenesis of infection and mortality among hosts. 
In order to gain more insight in the function of UL33-like genes, we set out to identify a UL33 homolog within the rat cytomegalovirus (RCMV) genome. Here we present the sequence and transcriptional analysis of this gene, which we termed R33. To investigate the role of R33 in the pathogenesis of RCMV infection, an RCMV strain was generated that does not contain a functional R33 gene. Although disruption of the R33 open reading frame (ORF) did not affect RCMV replication in different permissive cell types in vitro, it dramatically reduced the mortality among a group of RCMV-infected rats. We found that although the mutant virus was transported to the salivary glands of infected rats, the virus was not able to either enter or replicate in these glands. Taken together, these findings indicate that R33 is not only important for replication of RCMV in salivary glands, but also for the pathogenesis of RCMV infection in immunocompromised rats.

\section{MATERIALS AND METHODS}

Cells and virus. Primary rat embryo fibroblasts (REF), rat heart endothelium cell line 116 (RHEC) and monocyte/macrophage cell line R2 (MФ) were cultured as described previously 11, 22, 54). RCMV (Maastricht strain) was propagated in REF (11). Virus titers were determined by plaque assay according to standard procedures (11). RCMV DNA was isolated from culture medium as described by Vink et al. (53).

Identification, cloning and sequence analysis of the RCMV R33 gene. Approximately 5 mg of RCMV virion DNA was digested with EcoRI. After separation through a $0.6 \%$ low-melting-point agarose gel, the EcoRI A fragment, which has a length of approximately $50 \mathrm{~kb}$ (37), was excised and purified. The EcoRI A fragment (Fig. 1) was subsequently digested with BgIII and the resulting fragments were cloned into the BamHI site of vector pUC119 and (partially) sequenced. The sequences were checked for the presence of HCMV UL33-homologous regions by alignment to the EMBL nucleic acid sequence database (Heidelberg, Germany) using FASTA (43). Thus, a 3.4-kb RCMV BgII fragment was identified that showed significant similarity with the HCMV UL.33 gene. Both strands of the 3.4-kb BgIII fragment were sequenced using a T7sequencing Kit (Pharmacia Biotech, Roosendaal, The Netherlands). All sequence information was generated using overlapping plasmid constructs. Sequence analysis was performed with the Geneskipper software package (EMBL, Heidelberg, Germany).

Recombination plasmid construction. A 2.8-kb BamHI/BgIII RCMV fragment containing the $\mathrm{R} 33$ open reading frame (ORF) was cloned into the BamHI site of pUC119, resulting in construct p026 (Fig. 2). A recombination plasmid (p031) was constructed by replacing the $0.5 \mathrm{~kb}$ MluNI fragment within the R33 ORF of p026 with a 1.5-kb DNA fragment that contains the neomycin resistance gene (neo). The $1.5-\mathrm{kb}$ fragment was derived from plasmid $\mathrm{Rc} / \mathrm{CMV}$ (Invitrogen, Leek, The Netherlands) by digestion with BamHI and EcoRI, followed by incubation with dNTPs and DNA polymerase I Klenow fragment (Pharmacia Biotech) in order to create blunt ends. The neo ORF is flanked by an SV40 early promoter and an SV40 polyadenylation signal.

Generation of an RCMV R33 null mutant. Approximately $10^{7}$ cells (REF) were trypsinized and subsequently centrifuged for 5 minutes at $500 \times \mathrm{g}$. The cells were resuspended in $0.25 \mathrm{ml}$ of 
culture medium after which $10 \times \mathrm{g}$ of $\mathrm{XbaI} / \mathrm{KpnI}$-digested plasmid p031 was added. The suspension was transferred to a 0.4-cm electroporation cuvette (Biorad, Veenendaal, The Netherlands), and pulsed at $0.25 \mathrm{kV}, 500 \mu \mathrm{F}$ in a Biorad Gene Pulser electroporator. Cells were subsequently seeded in 10-cm culture dishes. Six hours after transfection, the cells were infected with RCMV at a multiplicity of infection (MOI) of 1 . Culture medium was supplemented with 50 $\mu \mathrm{g} / \mathrm{ml} \mathrm{G} 418$ at 16 hours post infection (p.i.). When transfected and infected REF cultures showed extensive cytopathic effect (CPE), the tissue culture medium was transferred to a fresh subconfluent REF monolayer. One hour after transfer, the culture medium was refreshed and supplemented with G418. The procedure of virus propagation under G418 selection and transfer of culture medium to fresh REF monolayers was repeated twice. Subsequently, recombinant virus (RCMVAR33) was purified by two rounds of plaque purification.

Southern blot hybridization. Both wild-type RCMV and RCMV $\triangle$ R33 DNA were isolated, digested with Bam $\mathrm{HI}$, electrophoresed through a $1 \%$ agarose gel and blotted onto a Hybond $\mathrm{N}^{*}$ nylon membrane (Amersham, 's-Hertogenbosch, The Netherlands) as described previously (8). Both a 2.4-kb BamHI fragment, containing the intact R33 ORF (R33 probe, Fig 2), and a 1.5-kb $\mathrm{Bam} \mathrm{HI} /$ EcoRI fragment containing the neo gene (neo probe, Fig. 2) were used as probes. Hybridization and detection experiments were performed with digoxigenin DNA labeling and chemoluminescence detection kits (Boehringer Mannhein, Almere, The Netherlands).

Isolation of poly(A)* RNA and Northern blot analysis. RCMV poly(A)* RNA was isolated at immediate early (IE), early (E) and late (L) times of infection of REF. To obtain IE mRNA, REF were treated with $100 \mu \mathrm{g} / \mathrm{ml}$ cycloheximide 1 hour before, during and 16 hours p.i. During the 1-hour infection period, cells were exposed to RCMV at an MOI of 1. E mRNA was isolated after infection of REFs with RCMV $(\mathrm{MOI}=1)$ and treatment of the cells with $100 \mu \mathrm{g} / \mathrm{ml}$ phosphonoacetic acid from 3 hours p.i. until harvesting of the cells at 13 hours p.i. L mRNA was isolated after infection of REF with either RCMV or RCMV RR33, (MOI =0.01) and harvesting of cells at 72 hours p.i. To obtain mRNA from mock-infected (M) cells, a similar procedure was followed as described for the purification of L mRNA, except that RCMV infection was omitted. mRNA was purified using a QuickPrep Micro mRNA Purification Kit (Pharmacia Biotech, Roosendaal, The Netherlands). One- $\mu$ g aliquots of mRNA were electrophoresed through agarose under denaturing conditions, as described by Brown et al. (9). Then, the RNA was transferred to Hybond $\mathrm{N}$ membranes (Amersham, 's-Hertogenbosch, The Netherlands) as described previously (9). The 402-bp XbaI/ BamHI fragment, 960-bp SacI fragment and 550-bp KpnI fragment from p026 (Fig. 7) were used to generate probes. These fragments contain R32, R33 and R34-specific sequences, respectively (Fig. 2). Labeling with [a- $\left.{ }^{32} \mathrm{P}\right] \mathrm{dATP}$ (ICN, Zoetermeer, The Netherlands) was carried out using a Random Primed DNA Labeling Kit (Boehringer Mannheim, Almere, The Netherlands). Hybridization and autoradiography were carried out as described earlier (9).

Reverse transcriptase-PCR (RT-PCR). L mRNA was treated with DNase I (Pharmacia Biotech) and subsequently reverse transcribed, using a Superscript Plasmid System for cDNA Synthesis and Plasmid Cloning (Gibco BRL, Breda, The Netherlands). The following primers (obtained from Eurogentec, Seraing, Belgium) were used for amplification of the CDNA: 5'GATCGGATCCATGAGGGTGATTGAAGAGATTCGG-3' (the sequence in italics is located at position 532 to 555 of Fig. 2) and 5'-CGTAAAGCTTAGTCCCTCGCCACCGACAGG-3' (the complement of the sequence in italics is located at position 815 to 833 of Fig. 2). PCR reaction 
mixtures contained $10 \mathrm{mM}$ Tris- $\mathrm{HCl}$ ( $\mathrm{pH} 9.0$ ), $50 \mathrm{mM} \mathrm{KCl}, 1.5 \mathrm{mM} \mathrm{MgCl}, 0.01$ \% Triton X-100, $0.2 \mathrm{mM}$ of each $\mathrm{dNTP}, 0.5 \mu \mathrm{M}$ of each oligonucleotide primer, $0.1 \mathrm{U} / \mu \mathrm{l}$ Taq DNA polymerase (Pharmacia Biotech), and either (i) $\mathrm{H} 2 \mathrm{O}$ (negative control), (ii) first strand cDNA synthesis reaction mixture from which reverse transcriptase was omitted (negative control), (iii) $1 \mu \mathrm{l}$ of $10 \mathrm{x}$ diluted first strand DNA synthesis reaction mixture or (iv) 1 ng of genomic RCMV DNA (positive control). The reaction tubes were placed in a GeneAmp PCR System 9600 thermal cycler (Perkin Elmer, Nieuwerkerk aan de IJssel, The Netherlands), that was programmed to incubate samples for $5 \mathrm{~min}$ at $95^{\circ} \mathrm{C}$, followed by $35 \mathrm{cycles}$ of $60 \mathrm{sec}$ at $95^{\circ} \mathrm{C}, 60 \mathrm{sec}$ at $58^{\circ} \mathrm{C}$ and $60 \mathrm{sec}$ at $72^{\circ} \mathrm{C}$. Finally, the tubes were incubated for $10 \mathrm{~min}$ at $72^{\circ} \mathrm{C}$. PCR products were analyzed by agarose gel electrophoresis, followed by staining with ethidium bromide.

Replication of RCMV $\triangle R 33$ in vitro. REF, RHEC and MF were grown in 96-well plates and infected with either RCMV or RCMV $\triangle \mathrm{R} 33$ at an MOI of either 0.1 or 1.0. Culture medium samples ( $n=3$ per virus) were taken at 1, 3, 5 and 7 days p.i., and subjected to plaque titration. The cells were fixed and stained with monoclonal antibodies (MAb) against RCMV E proteins (MAb RCMV 8, [12]) as described previously (54). The degree of infection was determined by counting the number of antigen-positive cells relative to the total number of cells in six different wells (four microscopic fields per well at a magnification of $400 \times$ ).

Survival of RCMV-infected and RCMV $\triangle R 33$-infected rats. Male specific-pathogen-free (SPF) Lewis/N RT1 rats (Central Animal Facility, Maastricht University, the Netherlands) were kept under standard conditions (46). Six-week-old rats (body weights ranging from 140 to 180 g) were divided into 4 groups of each 5 rats. Rats were immunosuppressed by 5 Gray of total body Röntgen irradiation given one day prior to infection, as described by Stals et al. (46). Intraperitoneal infection was carried out with either $1 \times 10^{6}$ plaque forming units (PFU) of RCMV, 1 $\times 10^{6} \mathrm{PFU}$ of RCMV $\triangle \mathrm{R} 33,5 \times 10^{6} \mathrm{PFU}$ of RCMV or $5 \times 10^{6} \mathrm{PFU}$ of RCMV $\triangle R 33$. Virus stocks were derived from tissue culture medium of virus-infected REF. The number of surviving rats was recorded daily until day 28 p.i., at which the surviving rats were sacrificed. Several internal organs of these rats were subjected to plaque assay as described below.

Pathogenesis of infection with RCMV $\triangle$ R33. Two groups of 15 male SPF Lewis/N RT1 rats (10 weeks old, with a body weight of 250 to $300 \mathrm{~g}$, immunosuppressed 1 day before infection) were infected with $5 \times 10^{6} \mathrm{PFU}$ of either RCMV or RCMV $\triangle \mathrm{R} 33$. At days $3,5,7,10$ and 14 p.i., 3 rats from each group were sacrificed and internal organs were collected. These organs were subjected to both plaque assay and immunohistochemistry (10). Four- $\mu \mathrm{m}$ tissue sections of (submaxillary) salivary gland, spleen, kidney, liver, lung, heart, and pancreas were stained with MAb RCMV 8 (which detects Early phase-expressed RCMV polypeptides in the nuclei of RCMVinfected cells [12]). Four- $\mu \mathrm{m}$ frozen sections of salivary gland, liver and pancreas tissue from rats sacrificed at 7 and 14 days p.i., were stained with either MAb 341 (which detects CD8 ${ }^{+}$cells [50]), MAb R73 (which detects TCR $\alpha \beta^{+}$cells [30]), MAb W3/25 (which detects CD4 $4^{*}$ cells; Serotec, Oxford, United Kingdom), MAb ED1 (which detects inflammatory macrophages [25]), MAb ED2 (which detects resident tissue macrophages [25]), MAb 323 (which detects natural killer cells [18]), or MAb OX6 (which detects class II MHC proteins; Sanbio B.V., Volendam, The Netherlands).

PCR. Total cellular DNA was extracted from spleen, kidney, liver, lung, heart and pancreas using a DNA extraction kit (Gull laboratories, Salt lake City, Utah). DNA concentrations were determined by spectrophotometry. DNA samples were serially diluted from $10^{0}$ to $10^{-8} \mu \mathrm{g}$. Each 
of the diluted DNA samples was incubated for $10 \mathrm{~min}$ at $95^{\circ} \mathrm{C}$, immediately cooled on ice and included in a two-round PCR. In the first PCR, primers (obtained from Eurogentec) were used that hybridized with the RCMV DNA polymerase gene (6). The sequences of the primers are 5'AAGGGTC CGATTTCGCCAGCCTCTACC-3' (in which the sequence in italics represents nucleotides 11,726 to 11,744 of GenBank file U50550) and 5'-AAGGGATCCTGTC GGTGTCCCCGTACAC-3' (in which the sequence in italics represents the sequence complementary to nucleotides 12,221 to 11,239 of GenBank file U50550). The use of these primers results in a product of $536 \mathrm{bp}$. The nested PCR results in a product with a length of $431 \mathrm{bp}$, using primers 5'-AAGGGATCCCCTCTGTTACTCCACCCTGC-3' (in which the sequence in italics represents nucleotides 11,767 to 11,786 of GenBank file U50550) and 5'-TTCGGATCCACG CCGACCTCGGAGACCAG-3' (in which the sequence in italics represents the sequence complementary to nucleotides 12,158 to 12,177 of GenBank file U50550). Reaction mixtures ( $50 \mu \mathrm{l}$ ) contained diluted target DNA, $80 \mu \mathrm{M}$ of each dNTP, $0.37 \mu \mathrm{M}$ of each oligonucleotide primer, 1 unit Taq DNA Polymerase (Pharmacia Biotech) and Taq DNA Polymerase Reaction Buffer (Pharmacia Biotech). The reaction tubes were placed in a GeneAmp PCR System 9600 thermal cycler (Perkin Elmer), that was programmed to incubate samples for $150 \mathrm{sec}$ at $95^{\circ} \mathrm{C}, 30 \mathrm{sec}$ at $58^{\circ} \mathrm{C}$ and $60 \mathrm{sec}$ at $72^{\circ} \mathrm{C}$, followed by $35 \mathrm{cycles}$ of $30 \mathrm{sec}$ at $95^{\circ} \mathrm{C}, 30 \mathrm{sec}$ at $58^{\circ} \mathrm{C}$ and $60 \mathrm{sec}$ at $72^{\circ}$ C. Finally, the tubes were incubated for 10 minutes at $72^{\circ} \mathrm{C}$. Five $\mu \mathrm{l}$ of each reaction mixture from the initial PCR was transferred to $45 \mu \mathrm{l}$ of a nested-PCR mixture. Nested PCR was run immediately after completion of the initial PCR. PCR products were analyzed by agarose gel electrophoresis, followed by staining with ethidium bromide.

GenBank accession number. The nucleotide and amino acid sequences discussed in this paper have been deposited in the GenBank database under accession number U91788.

\section{RESULTS}

Identification, cloning and sequence analysis of the RCMV R33 gene. In order to identify a putative RCMV homolog of the HCMV UL33 gene, we hypothesized that this homolog would be located at a position within the RCMV genome analogous to the position of UL33 within the HCMV genome. This hypothesis was based on the observation that the genomes of HCMV and RCMV are largely colinear ([6], C. Vink, E. Beuken and C. A. Bruggeman, unpublished results). Previously, we identified the RCMV homolog of the HCMV UL54 gene (6). In the HCMV genome, the UL33 gene is separated approximately $35 \mathrm{~kb}$ from UL54. If the RCMV homologs of the UL 33 and UL54 genes are separated by a similar distance, the UL33-homologous gene would be situated near the center of the EcoRI A fragment of the RCMV genome (Fig. 1) (6,37). To localize the putative UL33-like RCMV gene, we purified the RCMV EcoRI A fragment and subjected it to digestion with restriction endonuclease BgIII. The resulting fragments were cloned and their sequences determined. The presence of UL33-like sequences was investigated by alignment of the various sequences to the EMBL nucleic acid sequence database. Thus, a 3.4-kb BgIII fragment was identified that showed considerable similarity to the HCMV UL33 gene. The $3.4-\mathrm{kb}$ fragment was found to con- 
RCMV genome, $224 \mathrm{~kb}$

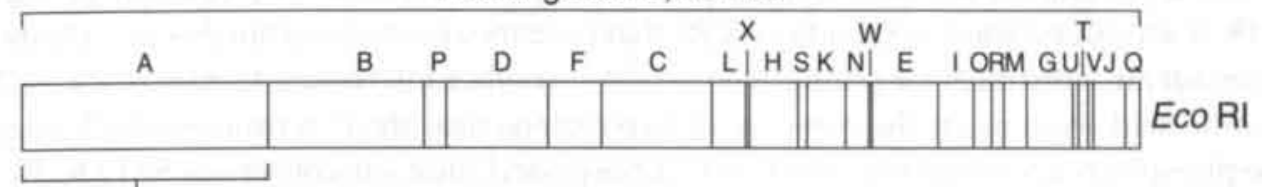

Bg/ll digestion of the Eco RI A fragment

Bg/ II subfragments

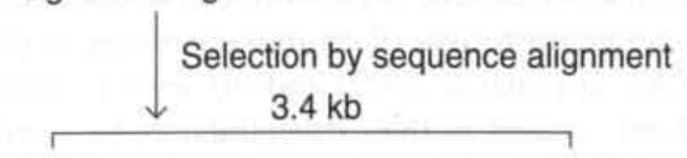

$B g / I I$

$B g / I$

\section{R33}

FIG. 1. Restriction map of the RCMV genome (37) and the relative position of the R33 gene that encodes a putative G protein-coupled receptor ( $p R 33$ ). The $3.4-k b$ Bglll fragment that contains the R33 ORF is indicated below the genome map.

tain an open reading frame (ORF) that putatively encodes a 387 -amino acid polypeptide with a predicted molecular mass of $43.2 \mathrm{kDa}$. The amino acid sequence of this polypeptide was found to be highly similar to that of the proteins that were predicted to be encoded by the MCMV M33 gene (45) and the HCMV UL33 gene (20) $(65 \%$ and $40 \%$ identity, respectively, according to a global alignment protocol by Myers et al., [39]). This indicated that the RCMV homolog of these genes had indeed been cloned. In analogy to the nomenclature of the corresponding HCMV and MCMV genes, the RCMV UL33-like gene was termed R33.

To investigate whether the predicted amino acid sequence of the R33-derived protein ( $\mathrm{pR} 33$ ) possesses features that are characteristic for $\mathrm{G}$ protein-coupled receptors (GCRs), the pR33 amino acid sequence was analyzed using the computer program TMpred (ISREC Bioinformatics Group, Epalinges, Switzerland). This program can predict potential transmembrane regions in amino acid sequences by comparing the hydrophobicity profiles of these sequences with those of existing transmembrane domains. As expected, computation revealed an extracellular $\mathrm{N}$-terminus and seven potential transmembrane regions, each of which might be folded as an a-helix. In addition, several amino acid residues were identified that are conserved among most GCRs (reviewed by Probst et al. [44]): two cysteine residues at position 106 and 187 (Fig. 2) which may form a disulФde bridge, and a conserved arginine-tyrosine motif (RY, position 31-32) which might be involved in G protein coupling. Within the fourth cyto- 
plasmic domain of the R33-derived protein a cysteine residue is located at position 319. It was found for several other GCRs that cysteine residues within this cytoplasmic domain are substrates for palmitoylation (44). Another interesting feature of the $\mathrm{pR} 33$ amino acid sequence is the presence of two regions near the $\mathrm{C}$-terminus which might be phosphorylated by protein kinase $C$ (phosphorylation site consensus S/TXK/R, at positions 321-323 and 326-328). An unusual stretch of 11 prolines is found near the $C$ terminus of pR33. The biological relevance of this large proline stretch is unknown.

In addition to features that are conserved among GCRs in general, the R33-derived amino acid sequence shows several features characteristic of chemokine receptors ( 1 , 24): (i) an N-linked glycosylation site (NYT, at position 20-22) and (ii) several negatively charged amino acid residues that are located in the extracellular $\mathrm{N}$-terminal region, (iii) two cysteine residues (Cys23 and Cys277), likely to form a disuphide bridge, thereby joining the $\mathrm{N}$-terminal region with the fourth extracellular loop, (iv) several positively charged amino acid residues within the third intracellular loop, (v) invariant amino acids within the transmembrane regions (these amino acid residues are indicated in black circles in Fig. 2), and (vi) several serine and threonine residues in the intracellular C-terminal region (Fig. 2). UL33-like GCRs also have conserved amino acid residues in or near the transmembrane regions, which are not present in typical chemokine receptors (these residues are indicated in open circles in Fig. 2).

To futher investigate the relationship between pR33 and chemokine receptors, we compared the amino acid sequences of the $\beta$-herpesvirus-encoded pUL33-like GCRs with sequences from a representative set of mammalian chemokine receptors as well as nine non-chemokine-binding GCRs. The entire sequence of each predicted protein was used in a CLUSTAL W multiple alignment (49). As expected, the pR33 polypeptide was found to have the highest similarity with other pUL33-like GCRs. The amino acid residues that are conserved among this group of virus-encoded GCRs are circled in Fig. 2. Many residues present in pUL33-like GCRs can also be found in chemokine receptors (enclosed in black circles in Fig. 2). Most of the conserved residues are local-

FIG. 2 - Next page. The nucleotide sequence of the R33 gene and the predicted amino acid sequence of the $p R 33$ peptide. The open boxes indicate seven putative transmembrane domains ( $\operatorname{tm} 1 \mathrm{to} t \mathrm{tm} 7)$ and a putative $\mathrm{N}$-linked glycosylation site (NXT/S). Charged amino acid residues in the $\mathrm{N}$-terminal (extracellular) region and the 3 rd intracellular region (between tm 5 and tm6) are enclosed in open squares. The charges of these residues are printed at the top right of each square. Black boxes indicate consensus sequences $(S / T X K / R)$ of which the $S / T$ residue might be phosphorylated by protein kinase $C$. The amino acid residues that are conserved between all pUL33-like proteins (Fig. 3), are encircled. The residues that are conserved between chemokine receptors (Fig. 3) are enclosed in black circles. The underlined nucleotide sequences indicate sequences identical or complementary to the sequences of oligonucleotides that were used in RT-PCR (Fig. 5B). 
్ㅠ 융 \& \&

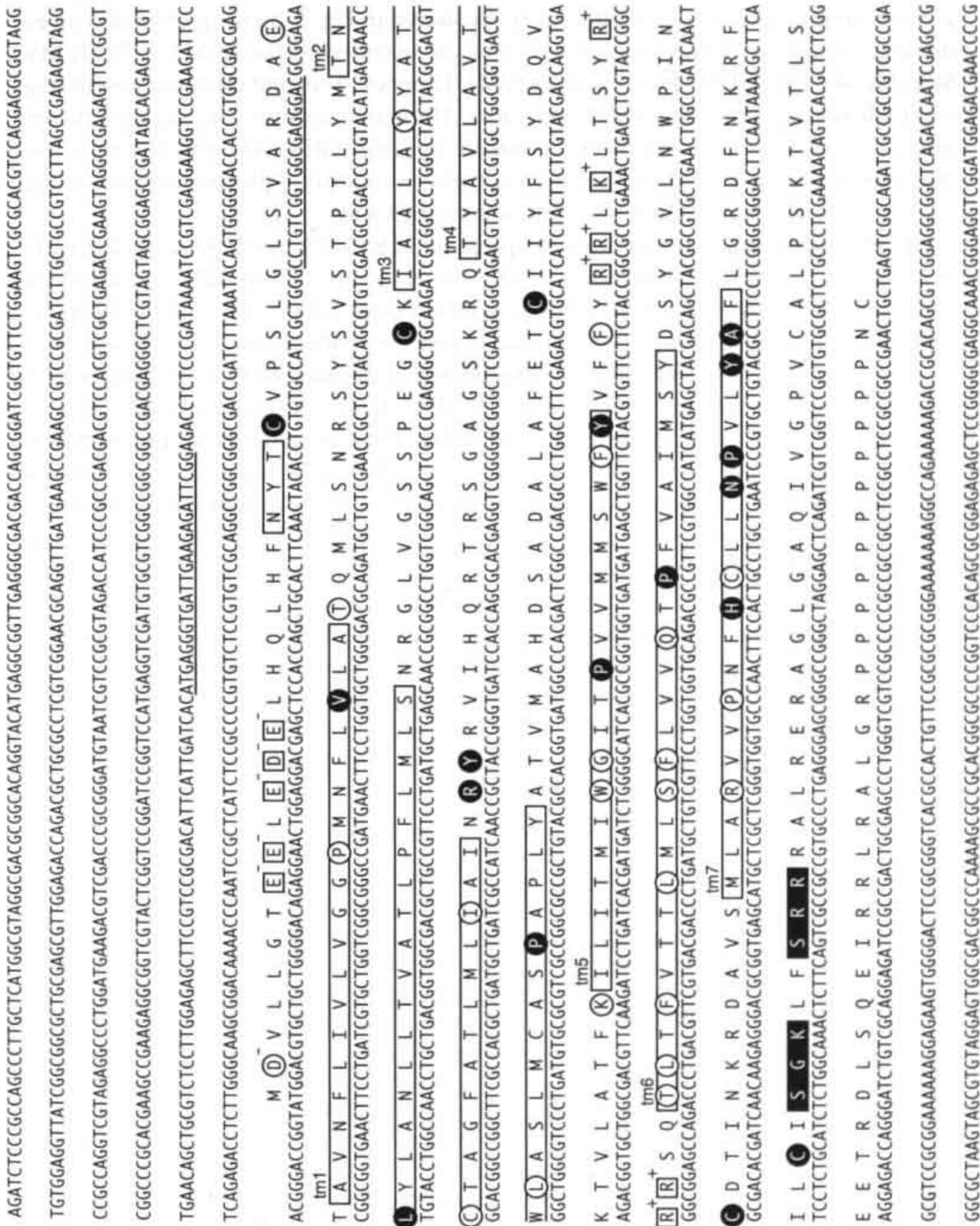


ized within the predicted 7 th transmembrane region ( $t \mathrm{~m} 7)$ of pR33. By using the regions of the aligned GCR sequences that correspond to this transmembrane region, a phylogenetic tree was calculated (Fig. 3). As shown in Fig. 3, a group of GCRs can be distinguished that includes the proteins that are encoded by the RCMV R33, MCMV M33, HCMV UL33, HHV-6 U12 and HHV-7 U12 genes. A second group represents the complete set of human chemokine receptors. These two groups can clearly be distinguished from the remaining (non-chemokine-binding) GCRs. The phylogenetic tree indicates that the UL33-like GCRs share a higher similarity with chemokine-binding receptors than with other, non-chemokine-binding GCRs.

R33 transcription. To examine the expression of R33 at immediate early (IE), early (E) and late (L) times of infection in REF, we set out to identify R33 transcripts by Northern blot analysis. As shown in Fig. 4, R33-specific transcripts could only be detected in the L phase of infection. Similar expression patterns have previously been reported for the UL33 and M33 gene, which were both found to be transcribed exclusively during the L phase of HCMV and MCMV infection, respectively $(55,24)$. Two major R33 transcripts can be distinguished in Fig. 4, having lengths of approximately 4.0 and $6.0 \mathrm{~kb}$, respectively. Since the length of the $\mathrm{R} 33$ open reading frame (ORF) is only 1,161 bp and a consensus polyadenylation signal is lacking at the $3^{\prime}$ end of the gene, it is likely that the R33 transcripts not only contain R33 sequences, but also sequences from one or more neighboring genes. Northern blot hybridization data (shown below) support the hypothesis of cotranscription.

Transcripts from both UL33 and M33 are spliced near the 5 ' ends, within regions that encode the $\mathrm{N}$-terminal parts of pUL33 and pM33, respectively (24). It was proposed that transcripts of UL33-like genes from the $\beta$-herpesviruses HHV- 6 and HHV7 are spliced in a similar fashion (24). This proposal was based on an alignment of $\mathrm{N}$ terminal amino acid sequences of UL33-like GCRs: a higher degree of similarity was

FIG. 3 - Next page, pR33 is a member of the chemokine receptor-like GCR family. To compare the sequences of UL33-like GCRs, chemokine receptors and non-chemokine-binding GCRs, a phylogenetic tree was calculated. The tree is based on a multiple alignment of amino acid sequences that are colinear to the putative seventh transmembrane region (amino acid position 288 to 307) of pR33 (Fig. 2). CLUSTAL W pairwise alignment (49) was set to BLOSUM30 protein weight matrix, gap open penalty $=10$, and gap extension penalty $=0.1$. Multiple alignment was set to BLOSUM series, gap opening penalty $=10$, gap extension penalty $=0.05$, delay divergent sequences $=0.4$. The virus-encoded GCRs are indicated analogous to $p R 33$, i.e. the ORF designation is preceded by a ' $p$ '. CC-CK $=C-C$ chemokine receptor. IL- 8 $=$ interleukin 8 receptor. $A 1 A A=a A 1$ adrenergic receptor (13). $\mathrm{H}$. halobium $B A C R=$ Halobacterium halobium bacteriorhodopsin (31). CD97 = cluster designation 97 (29). OPSD = rhodopsin (40). $A C M 1=$ M1 muscarinic acetylcholine receptor (3). D. discoideum CAR1 = Dictyostelium discoideum cAMP receptor 1 (32). S. cerevisiae STE2 = Saccharomyces cerevisiae pheromone a factor receptor (14). CASR = extracellular calcium-sensing receptor (2). FSHR = follicle stimulating hormone receptor (38). 


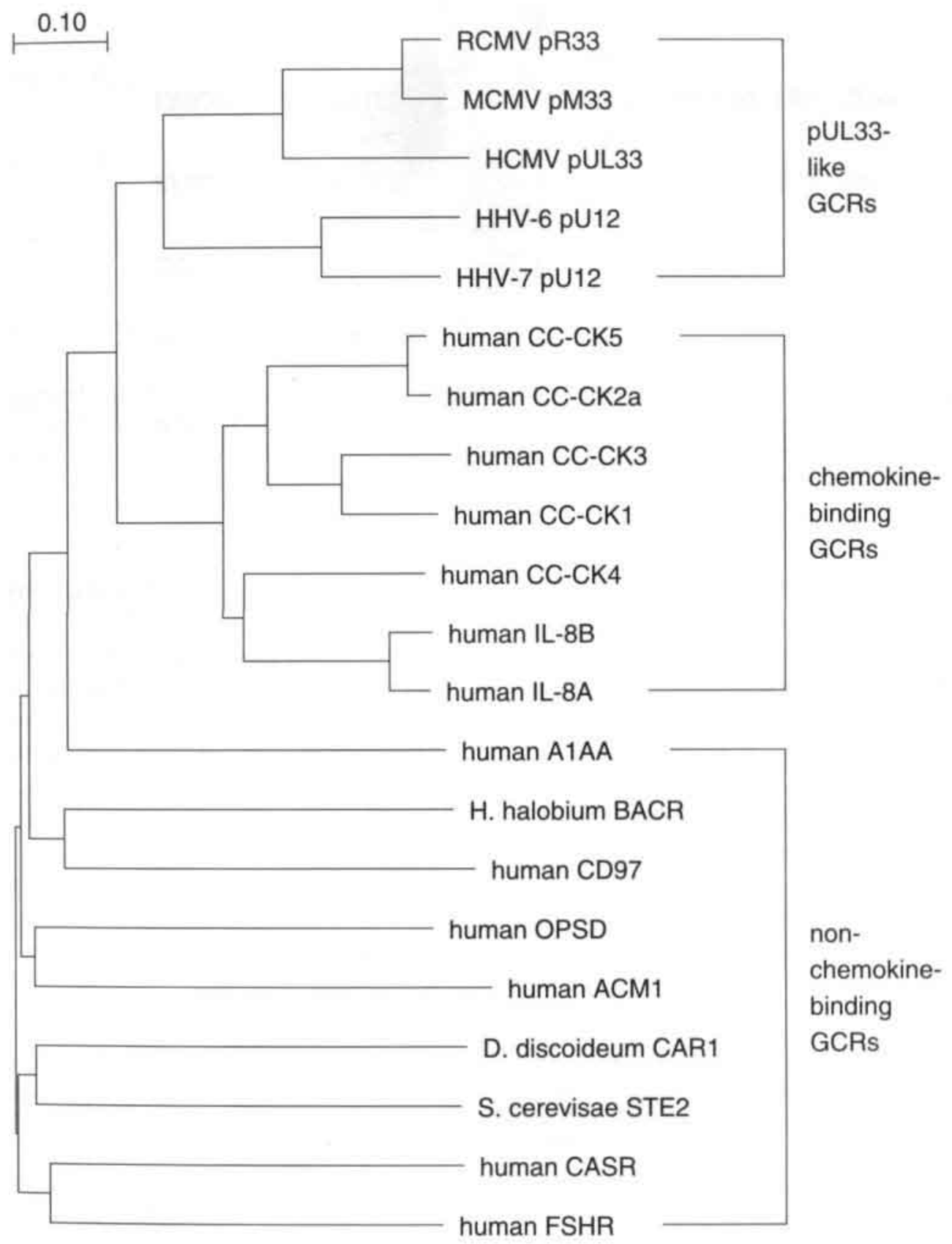




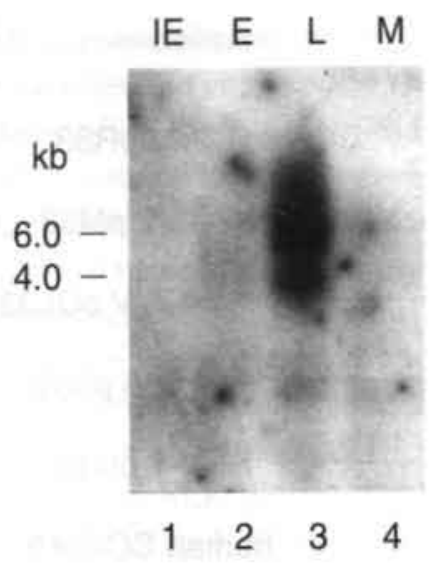

FIG. 4. The RCMV R33 gene is transcribed at late times of infection in rat embryo fibroblasts. The figure shows an autoradiograph of a Northern blot that was hybridized with an R33-specific probe. Lanes 1, 2 and 3 represent the IE, E and $L$ phase of infection, respectively. In lane 4, $m R N A$ from mock-infected (M) cells was separated. The estimated lengths of the transcripts are indicated on the left.

seen between these $\mathrm{N}$-terminal sequences if the presence of an intron was suggested in the corresponding genes of HHV-6 and HHV-7 (24). Interestingly, RCMV R33 transcripts are probably not spliced, since the $\mathrm{N}$-terminal amino acid sequence that is predicted from the unspliced R33 sequence is highly similar to the amino acid sequences that are derived from the spliced UL33 and M33 transcripts (Fig. 5A). To investigate the presence of a potential intron near the predicted start codon of the R33 gene, the R33 mRNA was analyzed using RT-PCR (Fig. 5B). As anticipated, the PCR products that were generated using either R33 cDNA that was derived from L-phase mRNA or genomic RCMV DNA had a similar length (approximately 320 bp; Fig. 5B, lanes 4 and 5). A control reaction, in which the L-phase mRNA was not treated with RT prior to PCR, did not generate any PCR products (Fig. 5B, lane 3 ), indicating that the amplified products were derived from mRNA rather than contaminating genomic DNA. These

FIG 5 - Next page. R33 transcripts are not spliced near the $5^{\prime}$ end. (A) Alignment of $\mathrm{N}$-termini of UL33-like GCRs, and the position of introns within the 5' region of the corresponding genes. Amino acid residues that are conserved between $p R 33$ and at least one of the other pUL33-like proteins are indicated as white letters in black boxes. (B). To identify a potential intron near the $5^{\prime}$ end of the R33 gene, an RT$P C R$ was performed on poly $(A)+R N A$ of $R C M V$-infected cells (lane $4,+R T)$. As negative controls, either target DNA (lane 2, - CDNA), or reverse transcriptase (lane $3,-R T$ ) was omitted. Genomic RCMV DNA was included as a positive control for the PCR reaction (lane 5, genomic DNA). Lane 1 contains a molecular weight reference (100-bp marker). A photograph of an ethidium bromide-stained agarose gel is shown. 
A

(unspliced)

RCMV R33

MDVLLGTEELEDELHQLHFIYTCVPSLGLSVARDAET ...

MCMV M33

161 bp intron

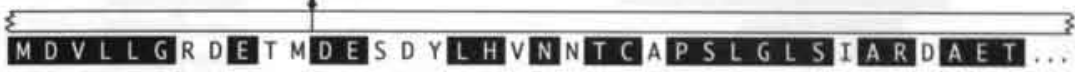

HCMV UL33

118 bp intron

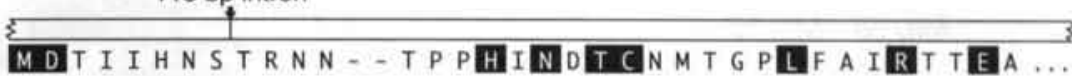

$89 \mathrm{bp}$ intron

HHV-6 U12

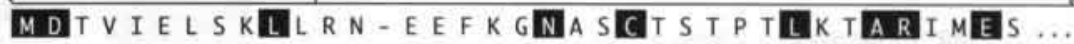

HHV-7 U12

102 bp intron

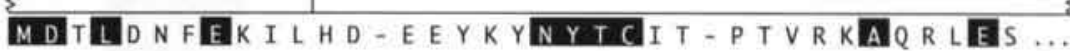

B

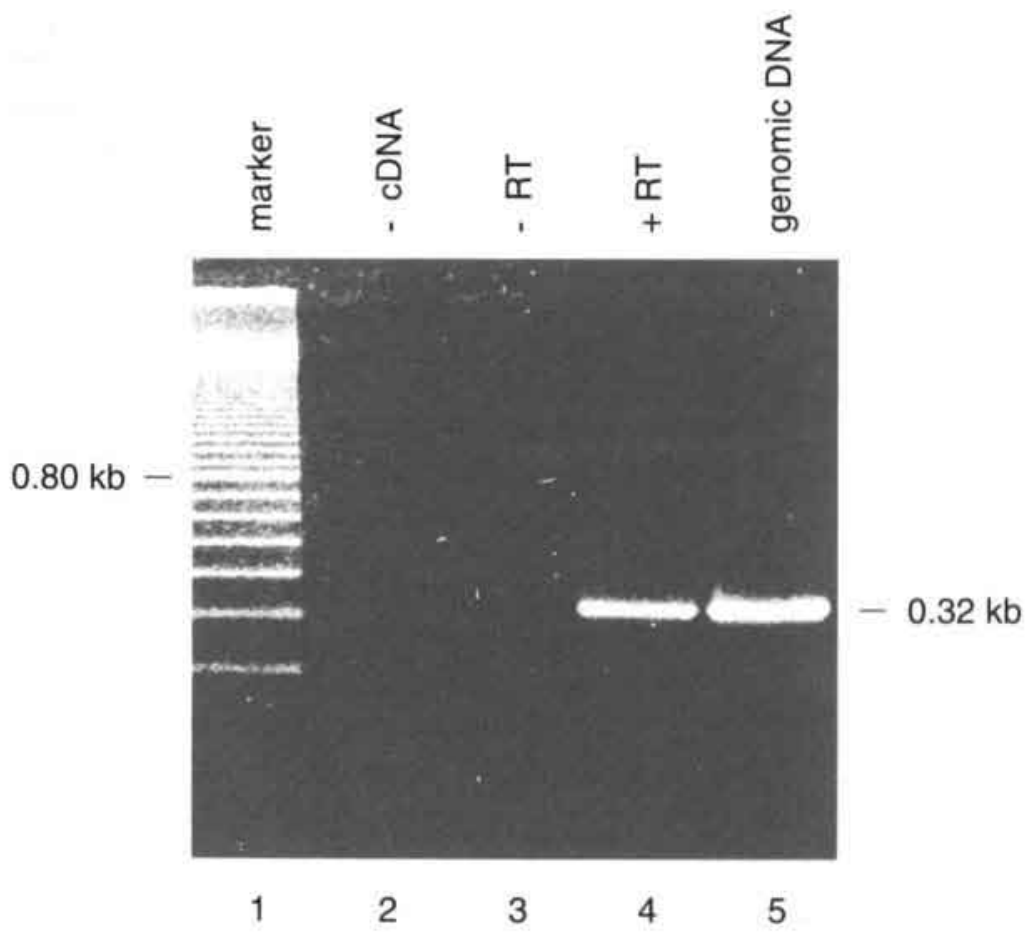


A

\section{$1 \mathrm{~kb}$}

RCMV genome

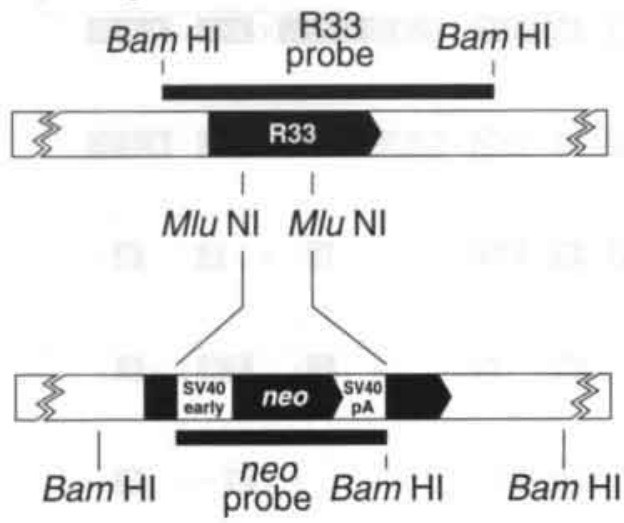

RCMV $\triangle R 33$ genome
B

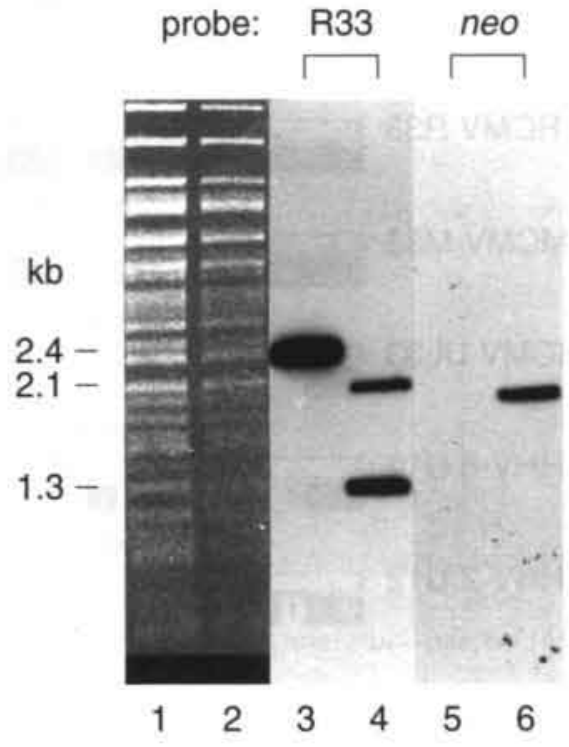

FIG. 6. Generation of an RCMV R33 null mutant. (A) To determine the role of R33 in RCMV infection, a mutant RCMV strain was generated by replacing part of the R33 ORF by a neomycin resistance gene (neo). ORFs are indicated by black arrows. Black rectangles above and below each genome indicate the position of the DNA probes that were used for Southern blot hybridization. 'SV40 early' = Simian Virus 40 early promotor. 'SV40 $P A^{\prime}=$ polyadenylation signal. Note that the indicated MluNI sites are lost in the RCMVAR33 genome. (B) Southern blot hybridization of RCMV and RCMVAR33 virion DNA. Photograph of an ethidium bromide-stained gel containing BamHI-digested genomic DNA from RCMV (lane 1) and RCMV $\triangle R 33$ (lane2), respectively. After transfer to a nylon filter, the DNA from lanes 1 and 2 was hybridized to either the $R 33$ probe (lanes 3 and 4, respectively) or the neo probe (lanes 5 and 6 , respectively).

results indicate that splicing does not occur within a region spanning from $199 \mathrm{bp}$ upstream of the R33 start codon to 103 bp downstream of the start codon (nucleotides 532 to 833 in Fig. 2).

Generation of an RCMV R33 null mutant. To investigate the role of R33 in the pathogenesis of RCMV disease, a mutant RCMV strain (RCMV in which the R33 gene was disrupted by replacing the $0.5-\mathrm{kb} M l u \mathrm{NI}$ fragment from the R33 ORF with a 1.5-kb neomycin expression cassette (Fig. 6A). The deletion/insertion mutation was first introduced into a plasmid containing the R33 gene. The R33 gene within the RCMV genome was subsequently replaced by the mutated R33 gene via homologous recombination, after transfection of fibroblasts with the recombination 
plasmid followed by infection with RCMV. Selection for recombinant virus was established by supplementing the growth medium with G418. After plaque purification, the purity of the recombinant virus was checked by both Southern blot analysis as well as PCR. Virion DNA from both RCMV and RCMV $\triangle$ R33 was purified and digested with $\mathrm{BamHI}$. After agarose gelelectrophoresis and transfer of the DNA to a filter, hybridization was done with either an R33-specific probe or a neo-specific probe. Cleavage of RCMV DNA with BamHI should generate a single 2.4-kb fragment containing R33 sequences, whereas cleavage of RCMV $\triangle$ R33 DNA should result in two fragments (of $1.3 \mathrm{~kb}$ and $2.1 \mathrm{~kb}$ ) containing R33 sequences (Fig. 6A). In addition, the $2.1-\mathrm{kb}$ BamHI fragment of RCMV $\Delta \mathrm{R} 33$ should also contain neo sequences. As shown in Fig. 6B, BamHI digestion of RCMV $\triangle \mathrm{R} 33$ DNA indeed resulted in two R33-hybridizing fragments with a length of $1.3 \mathrm{~kb}$ and $2.1 \mathrm{~kb}$, respectively (lane 4 ). As predicted, the 2.1-kb RCMV $\triangle \mathrm{R} 33$ BamHI fragment also hybridized to the neo probe (lane 6). Since a 2.4-kb R33-hybridizing Bam $\mathrm{HI}$ fragment was not detected in lane 4, we conclude that the recombinant virus is pure. The integrity of the RCMV $\triangle R 33$ genome was also confirmed both by comparing seven different restriction endonuclease patterns of wild type and mutant RCMV genomes, and PCR using various primer combinations (data not shown).

RCMV $\Delta$ R33 transcripts. To investigate the effect of disruption of the R33 gene on transcription of both the R33 gene and genes neighboring the disrupted gene in the RCMV $\Delta R 33$ genome, a Northern blot hybridization experiment was performed. The genes upstream and downstream of the R33 gene were found to have considerable sequence similarity to the MCMV M32 and M34 genes, respectively (data not shown). These RCMV genes are therefore referred to as R32 and R34, respectively. Probes were generated from R32-, R33-, R34- and neo-specific DNA fragments (Fig. 7B) and were hybridized with poly(A) ${ }^{+}$RNA extracted from either RCMV- or RCMVAR33-infected fibroblasts (Fig. 7A). RCMV generates one major transcript from the R32 gene with a length of approximately $2.5 \mathrm{~kb}$ (lane 1). Minor R32 transcripts can be seen with lengths of approximately 4.0 and $6.0 \mathrm{~kb}$. Disruption of the R33 gene did not result in dramatic changes in R32 transcription (compare lane 1 and 2). Transcription of R34 of RCMV resulted in three major transcripts with respective lengths of approximately 2.8, 4.0 and $6.0 \mathrm{~kb}$ (Fig. 7A, lane 7). Since the 4.0 - and 6.0-kb R34 transcripts comigrate with the R33 transcripts (compare lane 4 and 7), these RNAs are likely to represent cotranscripts of both the R33 and the R34 genes. Although there is no detectable difference between RCMV and RCMV $\triangle R 33$ in expression of the 2.8-kb R34 transcript, modest differences can be seen between the larger transcripts (lane 7 and 8 ). Most notably, the $4.0-\mathrm{kb}$ transcript seems to be replaced by a $4.2-\mathrm{kb}$ species. A similar observation can be made for the R33 4.0-kb transcript (lane 4 and 5), which further supports the notion that this species represents a R33-R34 cotranscript. In the genome of RCMV $\Delta$ R33, part of the $\mathrm{R} 33$ gene is replaced by the neo gene. The RCMV $\Delta \mathrm{R} 33$ transcripts that hybridized to 
R33 as well as R34 sequences, also hybridized to the neo probe (lane 11). In addition, RCMV $\Delta$ R33 expressed a unique $1.2-\mathrm{kb}$ neo transcript (lane 11). Another transcript unique to RCMV $\triangle R 33$ is a $2.8-\mathrm{kb}$ species that contained R33 as well as neo sequences (lane 5 and lane 11). The lengths and predicted positions of each of the transcripts that are generated in the R32 to R34 region of the genomes of RCMV and RCMV 2 R3 are summarized in Fig. 7B. Although there are clear differences between RCMV and RCMV $\triangle R 33$ in the transcription of R33 or ' $\triangle R 33$ ', the major transcripts of the R32 and R34 genes are unaffected. Therefore, we conclude that the genes which are neighboring the disrupted R33 ORF are functional.

The R33 gene is not essential for virus replication in various cell types in vitro. To study whether RCMV $\triangle \mathrm{R} 33$ and RCMV have different replication characteristics in vitro, three different cell types which are thought to play a role in CMV infection in vivo were infected with both viruses, and the ratio of infected cells over uninfected cells was determined at various time-points. In addition, the amount of infectious virus that was produced by each cell type was investigated. Cell types that were included in these experiments were rat primary fibroblasts (REF), endothelial cells (RHEC) and macrophages (MФ). As shown in Fig. 8, the ratios of infected over uninfected cells did not differ significantly between RCMV-and RCMV $\triangle$ R33-infected cells, regardless of the cell type. Also, no significant differences were seen between the recombinant virus and RCMV in the virus titers produced by each cell type. These data indicate that R33 is not essential for viral replication in REF, RHEC and MФ in vitro.

$R 33$ has an critical function in the pathogenesis of RCMV infection in vivo. The role of R33 in the pathogenesis of RCMV disease was investigated by infection of groups of immunosuppressed rats with either RCMV or RCMV $\triangle$ R33. In an initial experiment, 6-week-old immunosuppressed Lewis/N RT1 rats were inoculated with either $1 \times 10^{6}$

FIG 7 - Next page. The expression of genes neighboring the R33 gene is not affected by disruption of R33. (A) To determine whether transcription of the R32 and R34 genes was affected by disruption of R33, transcription of the R33 region of the genomes of both RCMV and RCMV $\triangle R 33$ was analyzed by Northern blot hybridization, using probes specific for R32, R33, R34 and neo. The figure shows autoradiographs in which lanes 1, 4, 7 and 10 represent poly $(A)^{*} R N A$ from $R C M V$-infected $R E F$, lanes 2, 5, 8 and 11 represent poly $(A) \cdot R N A$ from $R C M V \Delta R 33$-infected REF and lanes 3, 6, 9 and 12 represent poly $(A)^{+}$ RNA from mock-infected REF. The estimated lengths of the transcripts are indicated on the left in $k b$. (B) Estimated lengths and positions of transcripts from the RCMV R32, R33 and R34 genes, as derived from (A). The lengths of the indicated R32 and R34 ORFs are estimated and based on the lenghts of MCMV $M 32$ and M34 (45); the complete DNA sequence of this region of the RCMV genome is not yet available. (C) Estimated lengths and positions of transcripts from the RCMV $\triangle R 33 R 32, ' \Delta R 33$ ', R34 and neo genes, as derived from (A). Both the $2.8-k b^{*}$ and $4.2-k b$ RNA transcripts hybridize to the R33, R34 and neo probes. It is not known whether the 5' ends of these transcripts map to the 5' end of the R33 gene or the 5 ' end of the neo gene. 
A

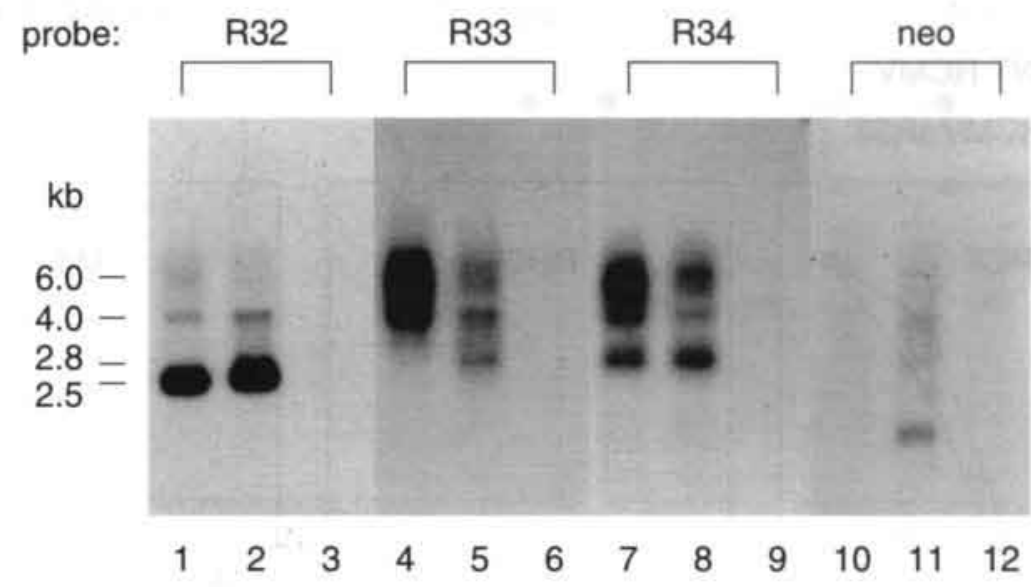

B
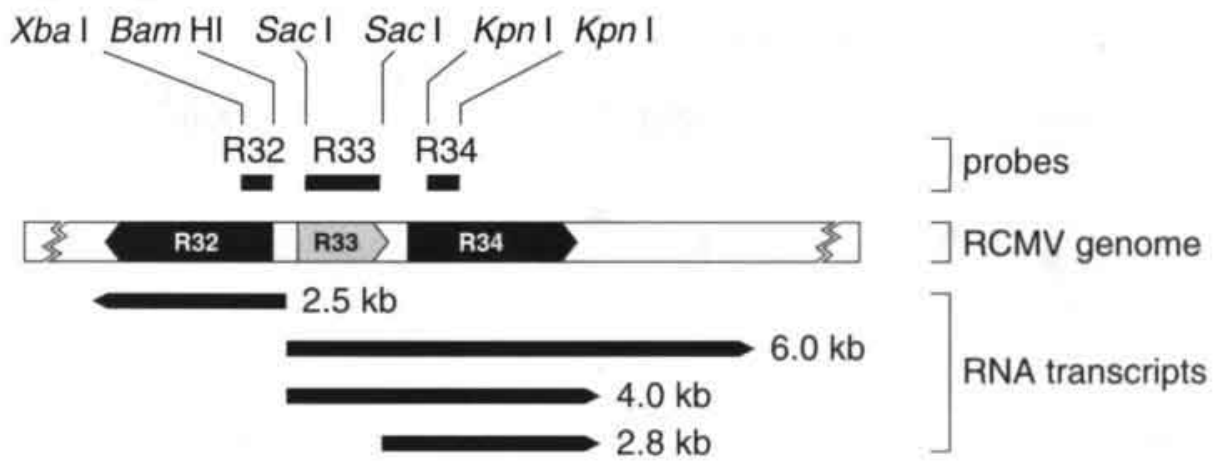

C

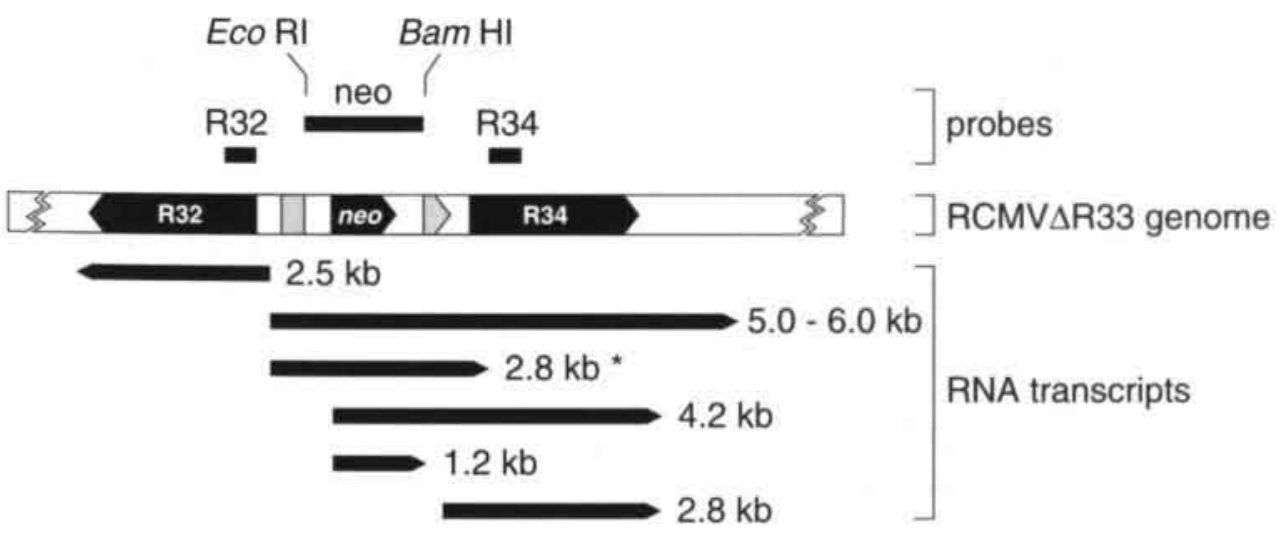


O WT RCMV

- RCMV $\triangle \mathrm{R} 33$
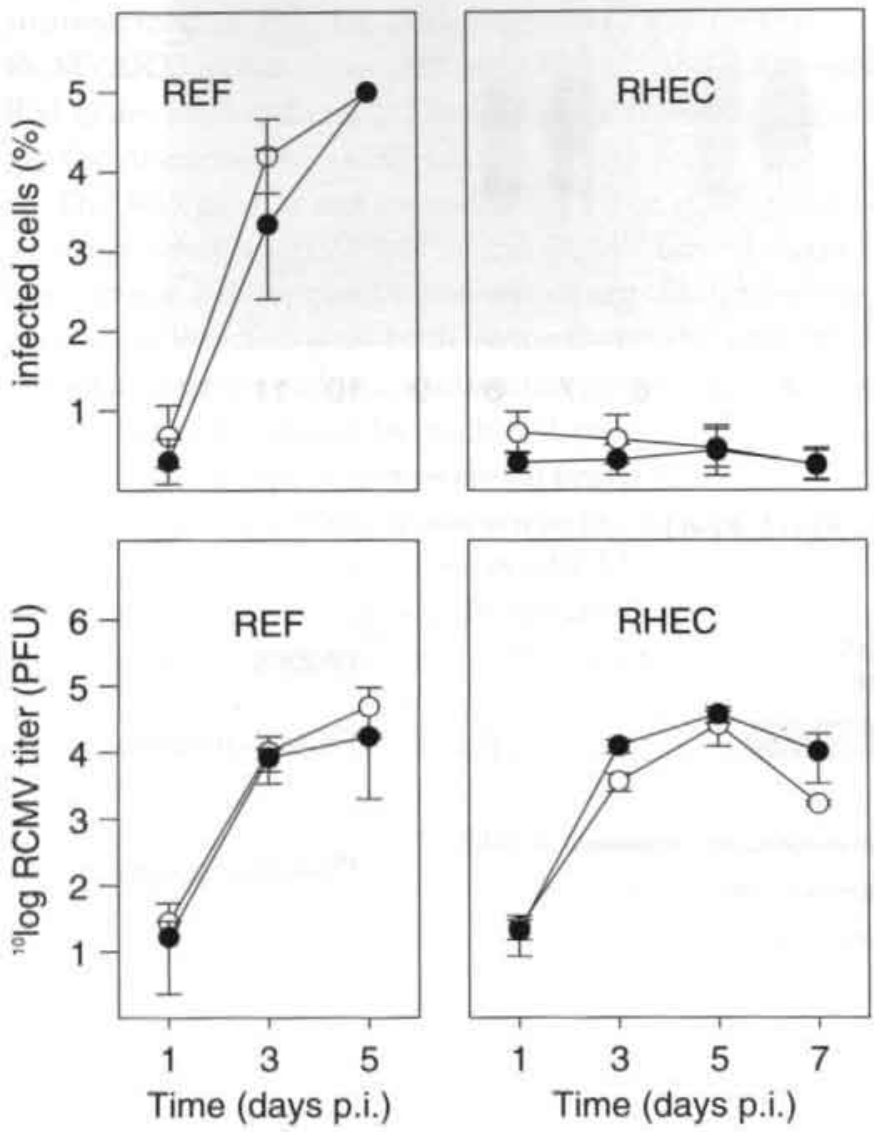

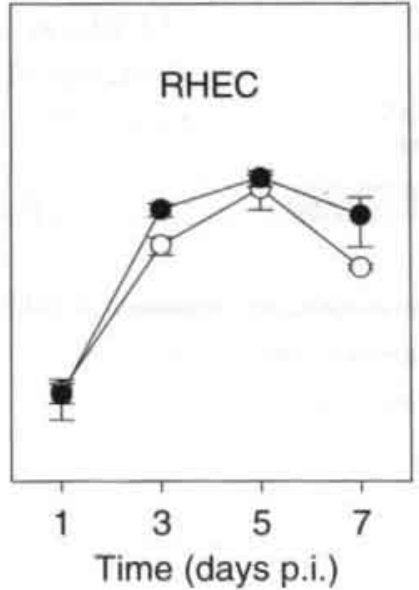

$M \Phi$
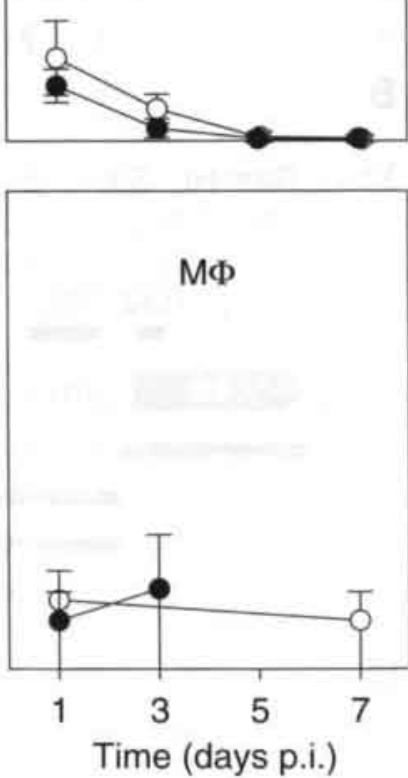

FIG. 8. The R33 gene is not essential for virus replication in vitro. REF, MHEC and MФ cells were infected with either RCMV or RCMVAR33 and the replicative potential of these viruses was assessed by immunofluorescence and plaque assay. The upper graphs show the infected-cell/total-cell ratios at various time-points p.i. The lower graphs show virus titers that were determined in culture medium up to 7 days p.i. Standard deviations are indicated by vertical bars. REF were monitored up to 5 days p.i., when $100 \%$ of the cells showed cytopathic effect. At days 5 and 7 p.i. virus could not be detected in medium samples that were taken from cultures of infected $M \Phi$ cells. Data from these time-points are therefore not included in the graph. 

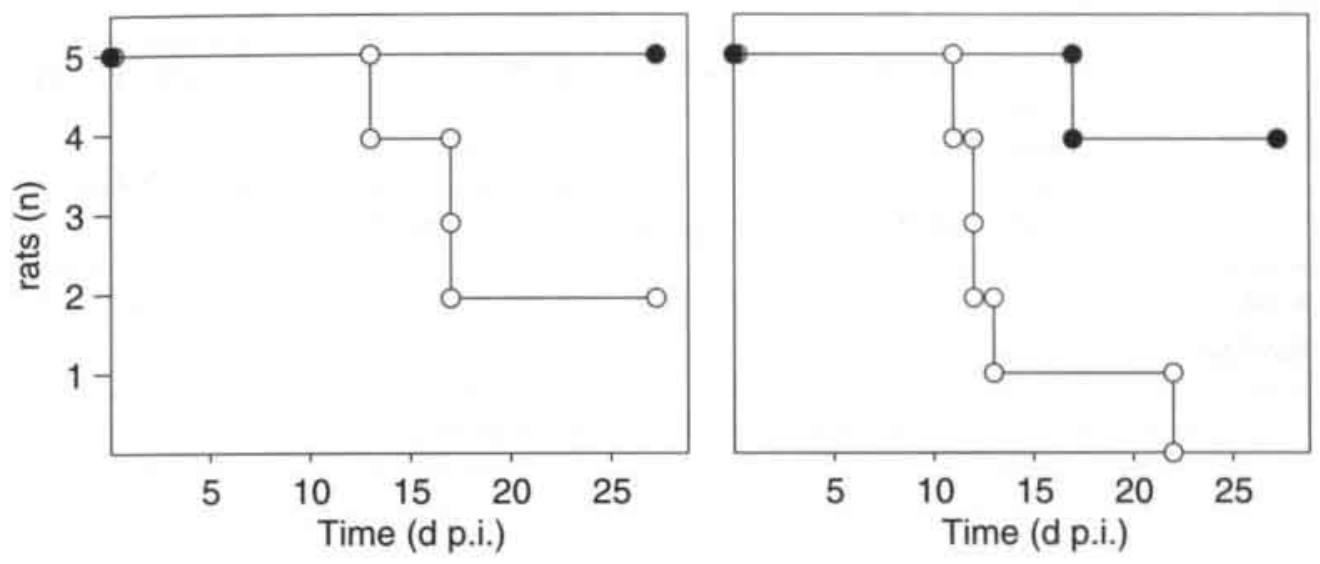

FIG. 9. Survival of two groups of immunocompromised rats after intraperitoneal inoculation with either wild-type RCMV or RCMVAR33. Two groups of rats (5 each) were infected with either $1 \times 10^{6} \mathrm{PFU}$ or 5 $\times 10^{\circ} \mathrm{PFU}$ of virus. Survival was recorded up to 28 days p.i.

or $5 \times 10^{6} \mathrm{PFU}$ of RCMV or RCMV $\triangle \mathrm{R} 33$. The number of surviving rats in each group was monitored until 28 days p.i. Surprisingly, a dramatically higher survival was observed in the group of RCMV $\triangle R 33$-infected rats than in the group of RCMV-infected rats (Fig. 9). This suggests that R33 plays and important role in the pathogenesis of RCMV disease. At day 28 p.i., the surviving rats were sacrificed and several organs were subjected to plaque assay. Although in most organs no significant differences in virus titers were observed between RCMV-and RCMV $\triangle \mathrm{R} 33$-infected rats, virus could not be detected in salivary glands from RCMV $\triangle R 33$-infected rats, whereas virus could easily be detected in salivary glands from RCMV-infected rats (data not shown). To study this observation in more detail, a follow-up experiment was performed in which two groups of 1510 -week-old rats were infected with $5 \times 10^{6} \mathrm{PFU}$ of either RCMV or RCMV $\Delta R 33$. At days $3,5,7,10$ and 14 p.i., 3 rats from each group were sacrificed and the presence of virus in internal organs was analyzed by both immunohistochemistry and plaque assay. During a period of 14 days p.i., virus titers did not differ significantly between organs from RCMV- or RCMV $\triangle$ R33-infected rats. Virus titers ranged from $<1$ to $3.3 \times 10^{2} \mathrm{PFU} / \mathrm{ml}$ in organs from RCMV-infected rats, and from $<1$ to 1.0 $\times 10^{3} \mathrm{PFU} / \mathrm{ml}$ in organs from RCMV $\triangle \mathrm{R} 33$-infected rats. In contrast, although high titers of virus $\left(>10^{4} \mathrm{PFU} / \mathrm{ml}\right)$ were found within salivary glands of RCMV-infected rats at day 10 p.i. and at later time-points, virus could not be recovered from salivary glands 
TABLE 1. Virus titers ${ }^{a}$ and immunohistochemical detection of RCMV and RCMV $\triangle R 33$ in salivary glands

\begin{tabular}{|c|c|c|c|c|c|c|c|}
\hline \multirow{3}{*}{ Virus } & \multicolumn{6}{|c|}{10 week-old rats, $5 \times 10^{6} \mathrm{PFU}$ of RCMV } & \multirow{3}{*}{$\begin{array}{l}6 \text { week-old rats, } 1 \times \\
10^{6} \mathrm{PFU} \text { of RCMV } \\
\end{array}$} \\
\hline & \multicolumn{2}{|c|}{3,5 , and 7 days p.i. } & \multicolumn{2}{|c|}{10 days p.i. } & \multicolumn{2}{|c|}{14 days p.i. } & \\
\hline & Titer $^{a}$ & $\operatorname{IPOX}^{b}$ & Titer ${ }^{a}$ & $\operatorname{IPOX}^{b}$ & Titer $^{a}$ & $\operatorname{IPOX}^{b}$ & \\
\hline RCMV & $<1$ & $0 / 3$ & $3.6 \pm 0.3$ & $2 / 3$ & $>4$ & $3 / 3$ & $>4$ \\
\hline RCMV $\triangle R 33$ & $<1$ & $0 / 3$ & $<1$ & $0 / 3$ & $<1$ & $0 / 3$ & $<1$ \\
\hline
\end{tabular}

${ }^{4} \log _{10}$ virus titers are shown as mean \pm standard deviation (PFU per milliliter).

"Immune peroxidase assay (IPOX) data are represented as number of rats of which the salivary glands were found RCMV positive/ total number of rats tested.

of RCMV $\triangle$ R33-infected rats (Table 1). In addition, RCMV antigens were not detected in salivary gland sections of RCMV $\Delta$ R33-infected rats (Table 1 and Fig. 10B), whereas these antigens could easily be detected in the salivary gland epithelial cells of RCMVinfected rats (Table 1 and Fig. 10A). These data indicate that R33 is important for entry and/or replication of RCMV in salivary glands of the rat.

To investigate whether or not RCMV $\triangle \mathrm{R} 33$ is transported to the salivary glands, we set out to study dissemination of the virus in infected rats by PCR, which has a higher sensitivity than both plaque assay and immunohistochemistry. To this purpose, several internal organs of infected rats were subjected to PCR in order to detect viral DNA. DNA was purified from salivary gland, spleen, kidney, liver, lung, heart and pancreas derived from rats that were sacrificed at day $7,10,14$ and 28 p.i. After purification, the DNA was serially diluted. By subjecting the DNA dilutions to PCR, a rough estimate could be made of the quantity of viral DNA in each organ. The sensitivity of a PCR assay was approximately $300 \mathrm{RCMV}$ genome copies per mg tissue DNA (approximately 1 RCMV genome copy per 800 cells, data not shown). The virus DNA levels did not differ between most organs from either RCMV or RCMV $\triangle \mathrm{R} 33$-infected animals (Fig 11). In contrast, marked differences were observed between viral DNA levels in the salivary glands of RCMV-and RCMV $\triangle R 33$-infected rats, at day 10,14 and 28 p.i. (Fig. 11). While RCMV DNA could easily be detected at all indicated time-points, RCMV $\triangle$ R33 DNA could only be detected in salivary glands up to 14 days p.i. and not at later time-points. These data suggest that although RCMV $\Delta \mathrm{R} 33$ is presumably transported to the salivary glands, the virus does not enter and/or replicate in salivary gland epithelial cells. 

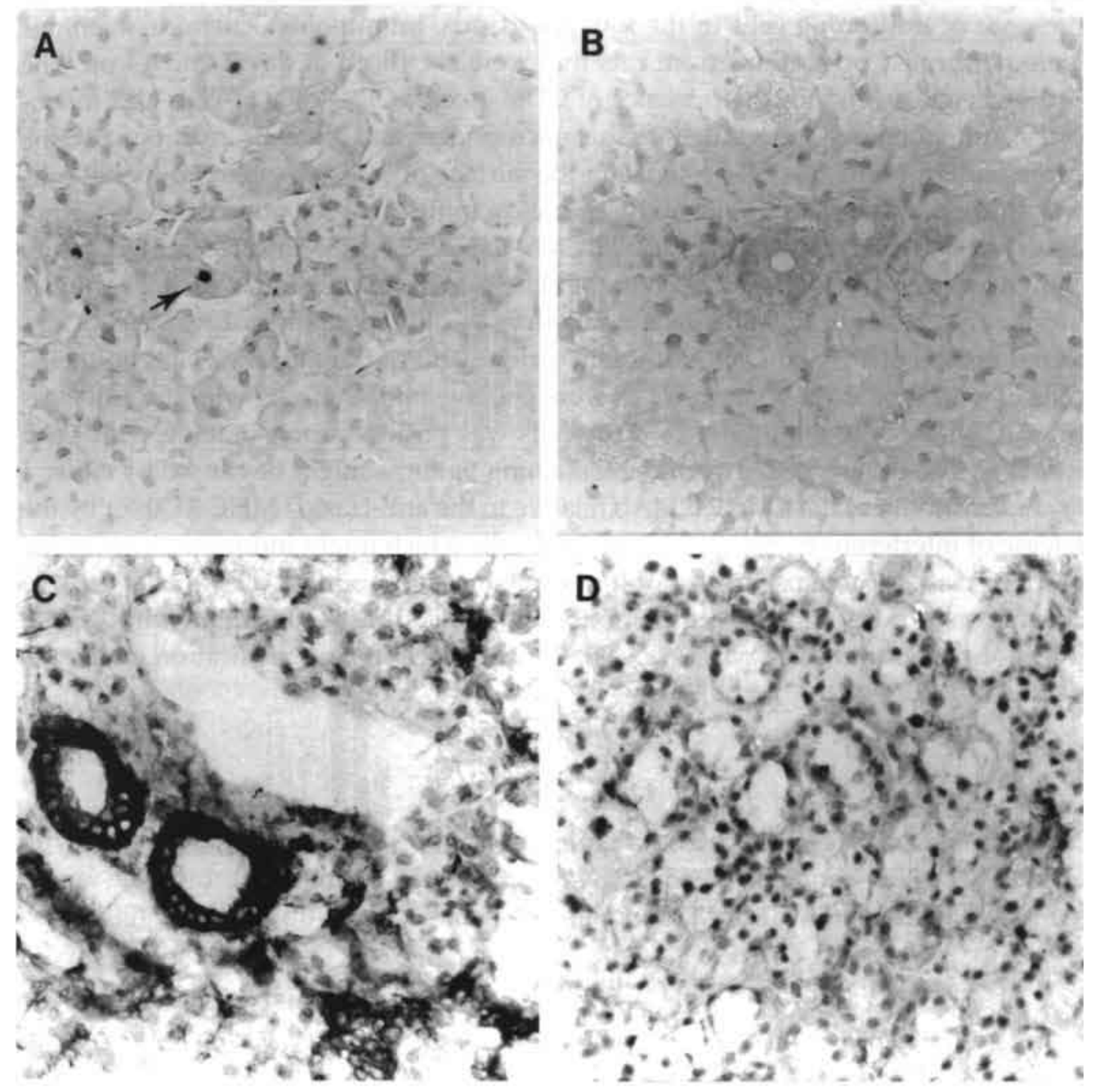

FIG. 10. Expression of RCMV (early) proteins and rat class II MHC proteins in salivarys of RCMV-and $R C M V \Delta R 33$-infected rats. The figure shows micrographs of 4-mm sections of rat salivary glands infected with either RCMV ( $A$ and $C$ ) or RCMV $\triangle R 33$ ( $B$ and $D$ ). Tissue sections were stained with either MAb against viral (early) antigens (MAb RCMV8; $A$ and B) or MAb against class II MHC proteins (OX-6; C and D). The tissue sections were photographed at a magnification of $400 \times$. 
Van Dam et al. (21) recently showed that infection of rats with RCMV resulted in an increase of both influx of inflammatory cells into the salivary glands and class II MHC expression by salivary gland cells. To study the effect of RCMV $\Delta R 33$ infection on the presence of infiltrating cells in the salivary glands, immunohistochemical stainings were performed on sections from rats that were sacrificed at day 7 and 14 p.i. The sections were scored for the presence of CD8 ${ }^{+} \mathrm{T}$-cells, CD4 cells (T-cells and monocytes), inflammatory and resident tissue macrophages and NK cells. Additionally, the expression of MHC class II proteins on the surface of salivary gland epithelial cells was studied. Although significant differences in infiltrating cell populations were not observed between salivary glands of RCMV- or RCMV $\triangle$ R33-infected rats (data not shown), a clear difference was seen in the class II MHC expression, which was higher in salivary glands of RCMV-infected rats than in salivary glands of RCMV $\triangle \mathrm{R} 33$-infected rats (Fig. 10C and 10D). Although virtually all of the salivary gland epithelial cells of wild-type RCMV-infected rats were positive upon staining with the anti-class II MHC MAb, only a minority of these cells was positive upon staining with MAb RCMV 8. The difference between these staining patterns might be caused by either a lower sensitivity of the RMCV 8 MAb relative to the anti-class II MHC MAb or by the release of interferons by the RCMV-infected cells which might induce the expression of MHC class II proteins in most of the neighboring, non-infected epithelial cells. In conclusion, our results support the notion that, in contrast to infection with RCMV, infection of rats withRCMV $\triangle R 33$ does rac resuth in active virus replication in the salivary glands.

\section{DISCUSSION}

The RCMV R33 gene is part of a family of $\beta$-herpesvirus genes that are likely to encode G protein-coupled receptors (GCRs). The other members of this gene family are HCMV UL33 and MCMV M33 and the U12 genes of HHV-6 and HHV-7 (20, 28, 42,

FIG. 11 - Next page. Detection of RCMV DNA in several organs of RCMV-and RCMVAR33-infected rats by PCR. To detect viral DNA in organs from either RCMV-or RCMV $\triangle R 33$-infected rats, PCR was performed on serial dilutions of DNA that was purified from these organs. At each indicated time-point, the results are shown from $3 R C M V$-infected (open bars) and 3 RCMVAR33-infected rats (black bars). The height of each bar indicates the maximum dilution of a given DNA isolate with which a positive PCR result could still be obtained. * Below detection level. The amount of virus genome copies in these samples is lower than 300 . We were able to detect a minimum of approximately 300 genome copies in $1 \mu \mathrm{g}$ of tissue DNA (data not shown). + The 5 samples indicated by * at day 28 p.i. were infected with RCMVAR33. The samples taken at day 28 p.i. were obtained from the experiment shown in Fig. 9, in which the rats were infected with $1 \times 10^{\circ} \mathrm{PFU}$ of virus. All other samples were taken from rats that were infected with 5 $\times 10^{\circ}$ PFU of virus. 
${ }^{1} \log$ maximum dilution
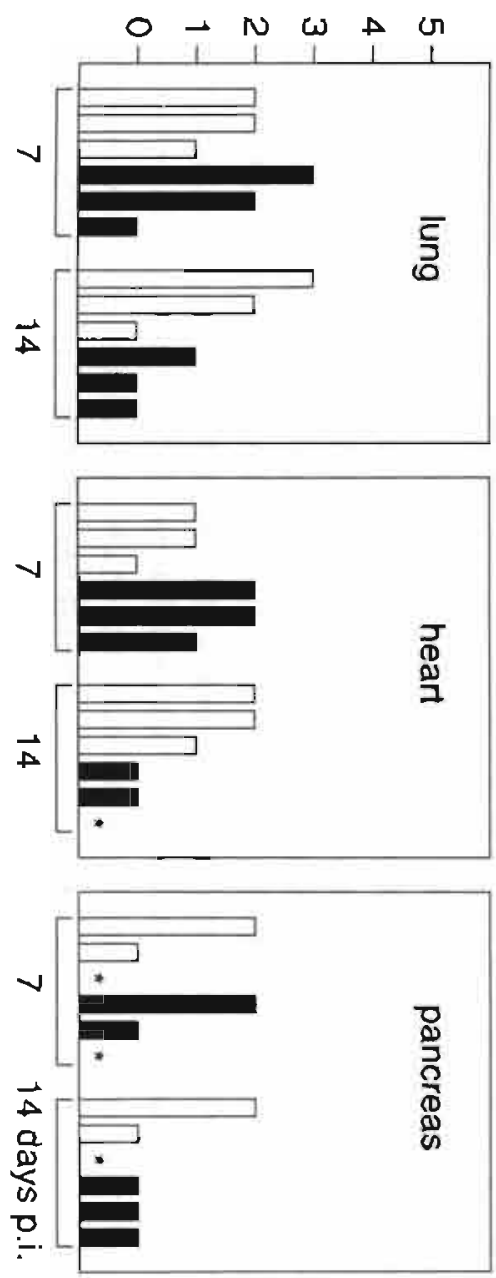

${ }^{10} \mathrm{log}$ maximum dilution
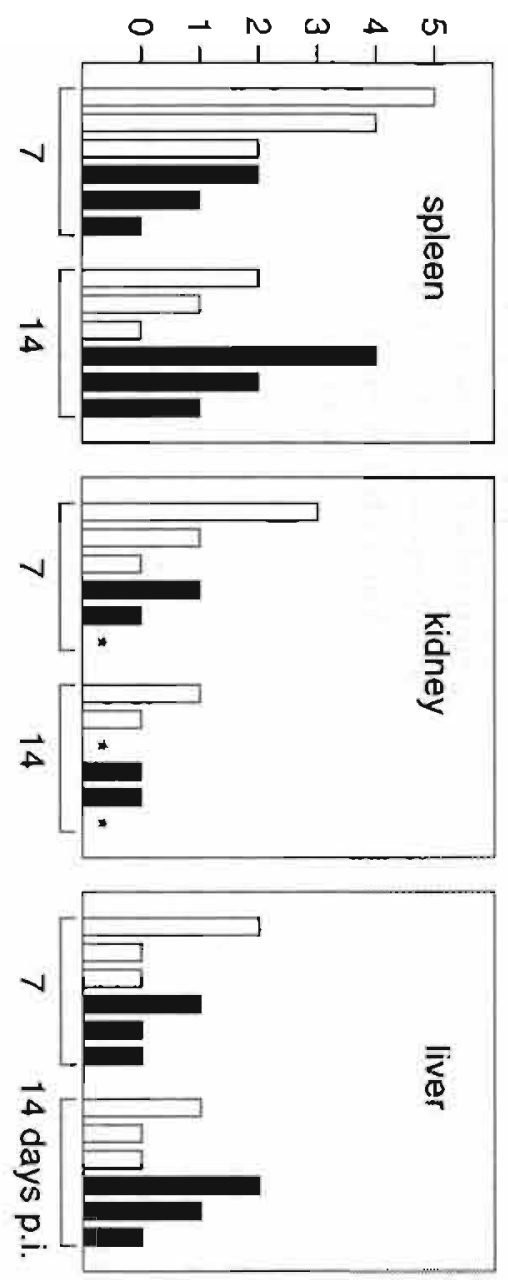

${ }^{10} \mathrm{log}$ maximum dilution

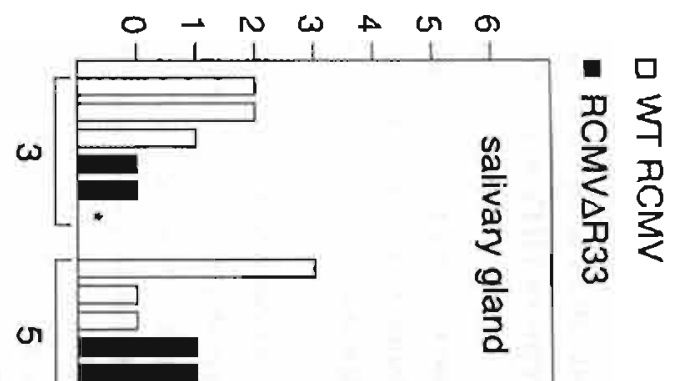


45). Both sequence and genome location is conserved between the UL33-like genes. As expected, the amino acid sequence that was predicted to be encoded by the RCMV R33 ORF shares more similarity with the amino acid sequences derived from HCMV UL33 and MCMV M33 (40\% and $65 \%$ identity, respectively) than with those derived from the U12 genes ( $24 \%$ and $26 \%$ identity with the proteins of HHV- 6 and HHV-7, respectively). Phylogenetic analysis based on multiple alignment of predicted amino acid sequences showed that the pUL33-like GCRs are more related to chemokine receptors than to non-chemokine-binding GCRs. In accordance with this, the R33-derived amino acid sequence shows several features characteristic of chemokine receptors $(1,24)$.

Sixteen $\beta$ - and $\gamma$-herpesvirus-encoded GCRs have been recognized to date $(17,20$, $28,41,42,45,48)$. In addition, the BILF1 gene from Epstein-Barr virus (5) may also encode a GCR, since its predicted amino acid sequences shares $25 \%$ identity with the equine herpesvirus 2 ORF 6-encoded GCR $(23,48)$. Three of the herpesvirus-encoded GCRs have been studied in detail and were found to be capable of binding chemokines and stimulate cellular downstream effectors. The herpesvirus saimiri (HVS) ECRF3 gene product, was found to be activated by a chemokines (1), resulting in mobilization of intracellular $\mathrm{Ca}^{2+}$. The HCMV US28 gene product could be activated by b chemokines (27), whereas the Kaposi's sarcoma-related herpesvirus (KSHV) ORF 74 gene product could be activated by both a and b chemokines (4). For members of the UL33 family ligands have not yet been identified. Whether or not UL33-like GCRs can be activated by binding to either chemokines or ligands from another class is not yet known. Similar to what was found for the KSHV ORF 74 gene product, it is possible that UL33-like GCRs can be constitutively active, irrespective of ligand binding.

Similarly as was reported for the UL33 and M33 genes $(24,55)$, R33 was expressed at the late phase of infection as a cotranscript with at least one of the genes downstream of R33 (R34). However, in contrast to the UL33 and M33 transcripts, the RCMV R33 mRNA is not spliced near the 5 ' terminus. On the basis of amino acid sequence alignment it was inferred that the U12 genes of both HHV-6 and HHV-7 contain a $5^{\prime}$ intron similar to that of the UL33 and M33 genes (24). These data indicate that among the members of the UL33-like family that have been identified to date, the R33 gene is the only gene that does not contain an intron near the start codon.

Both RCMV and MCMV replicate efficiently in salivary glands of infected rats (11) and mice (24), respectively. These viruses can easily be detected in the salivary glands using conventional techniques like immunohistochemistry or plaque assay. In contrast, recombinant MCMV strains lacking a functional M33 gene could not be detected in mouse salivary glands by plaque assay, which indicated that M33 is important for either dissemination or replication in the salivary glands (24). Similarly, the R33 gene of RCMV was found to be important for either entry or replication in salivary glands. Although RCMV $\triangle$ R33 could not be detected in salivary glands of infected rats by ei- 
ther plaque assay or immunohistochemistry, viral DNA could be detected up to 14 days p.i. by PCR. At later time-points, RCMV $\triangle R 33$ DNA could no longer be detected in the salivary glands. These data show that although recombinant virus (DNA) is able to reach the salivary glands, the virus is unable to persist in the epithelial cells of this tissue. It is possible that the ability to detect recombinant RCMV DNA in salivary glands early after infection is not the actual result of infection of salivary gland cells, but instead the result of the presence of recombinant RCMV (DNA)-containing circulating cells (e.g. detached endothelial cells or monocytes/macrophages) that passage through blood vessels of the salivary glands. The finding that R33 is essential for virus replication in salivary glands is also supported by the inability to detect class II MHC expression in the salivary gland epithelium of RCMV $\triangle$ R33-infected rats. Class II MHC expression is evoked by RCMV infection, of rat heart endothelium (51) in liver and kidney cells (52) and salivary gland epithelium (Fig. 10).

Salivary gland tropism has also been shown to be affected by mutations in other $\mathrm{CMV}$ genes. The MCMV Vancouver strain could not be detected in the salivary glands of infected mice by plaque assay (7). Since this virus strain was found to have both a 9.4-kb deletion and a $0.9-\mathrm{kb}$ insertion relative to the parental MCMV Smith strain (7), salivary gland tropism might be affected through the combined deletion and/or disruption of several genes. Another set of genes of the MCMV K181 strain (ORF m137 to $\mathrm{m} 143,[16])$ is shown to be essential for replication in salivary glands. Combined disruptions of at least two of these genes were found to (partially) affect salivary gland tropism (16). Manning et al, (34) showed the importance of yet another gene in salivary gland tropism of MCMV, the salivary gland growth gene 1 (sgg1). Deletion of this gene reduced the replicative potential of MCMV, although recombinant virus could still be detected in the salivary glands by plaque assay. The biological significance of the complete loss of salivary gland tropism through disruption of R33 and M33 from RCMV and MCMV, respectively, will have to be assessed in future studies.

A remarkable finding from our study is the increased survival that was seen among groups of RCMV $\triangle$ R33-infected rats as compared to groups of RCMV-infected rats. Since this increased survival is probably not solely the result of lack of RCMV $\triangle R 33$ replication in the salivary glands, it is likely that disruption of the R33 gene also affects RCMV replication in other organs or tissues, such as lymphal nodes or bone marrow. It is possible that the observed differences in behavior between RCMV and RCMV $\triangle R 33$ in vivo might be the result of expression of Neo by the recombinant virus. However, since the expression of Neo did not have an influence on virus growth in rat fibroblasts in vitro, it was inferred that the putative expression of Neo by the recombinant virus in vivo does not dramatically influence the behavior of the virus.

In a first comparison of organs from RCMV- and RCMV $\triangle$ R33-infected rats other that the salivary glands, no obvious differences were seen both in virus load and expression of RCMV (E) proteins. In a future study, the pathogenesis of RCMV- and 
RCMV $\Delta$ R33-infection will have to be studied in greater detail, e.g. by looking at the expression of viral IE, E and L proteins and by a detailed analysis of the host's immune response to viral challenge.

\section{ACKNOWLEDGEMENTS}

We thank Erik Beuken for generating BgIII subclones of the EcoRI A fragment, Jeroen Kloover and Harry van der Heijden for immunological staining of tissue sections, and Rien Blok for critical reading of the manuscript.

\section{REFERENCES}

1. Ahuja S. K., and P. M. Murphy. 1993. Molecular piracy of mammalian interleukin-8 receptor type B by herpesvirus saimiri. J. Biol. Chem. 268:20691-20694.

2. Aida K., S. Koishi, M. Tawata, and T. Onaya. 1995. Molecular cloning of a putative $\mathrm{Ca}^{2+}-$ sensing receptor cDNA from human kidney. Biochem. Biophys. Res. Commun. 214:524529.

3. Allard W.J., I. S. Sigal, and R. A. Dixon. 1987. Sequence of the gene encoding the human M1 muscarinic acetylcholine receptor. Nucleic Acids Res. 15:10604.

4. Arvanitakis, L., E. Geras-Raaka, A. Varma, M. C. Gershengorn, and E. Cesarman. 1997. Human herpesvirus KSHV encodes a constitutively active G-protein-coupled receptor linked to cell proliferation. Nature 385:347-350.

5. Baer, R. J., A. T. Bankier, M. D. Biggin, P. L. Deininger, P. J. Farrell, T. J. Gibson, G. F. Hatful, G. S. Hudson, S. C. Satchwell, C. Sequin, P. S. Tuffnell, and B. G. Barrell. 1984. DNA sequence and expression of the B95-8 Epstein-Barr virus genome. Nature 310:207-211.

6. Beuken, E., R. Slobbe, C.A. Bruggeman, and C. Vink. 1996. Cloning and sequence analysis of the genes encoding DNA polymerase, glycoprotein B, ICP 18.5 and major DNA-binding protein of rat cytomegalovirus. J. Gen. Virol. 77:1559-1562.

7. Boname, J. M., and J. K. Chantler. 1992. Characterization of a strain of murine cytomegalovirus which fails to grow in the salivary glands of mice. J. Gen. Virol. 73:2021-2029.

8. Brown, T. 1993. Analysis of DNA sequences by blotting and hybridization, p. 4.2.1-4.2.15. In F.M. Ausubel, R. Brent, R.E. Kingston, D.D. Moore, J.G. Seidman, J.A. Smith, \& K. Struhl (ed.), Current protocols in molecular biology, John Wiley \& Sons, Inc., New York, N.Y.

9. Brown, T., and K. Mackey. 1997. Analysis of RNA by Northern and slot blot hybridization, p. 4.9.1-4.9.16. In F.M. Ausubel, R. Brent, R.E. Kingston, D.D. Moore, J.G. Seidman, J.A. Smith, \& K. Struhl (ed.), Current protocols in molecular biology, John Wiley \& Sons, Inc., New York, N.Y.

10. Bruggeman, C. A., H. Meijer, P. H. J. Dormans, W. H. M. Debie, G. E. L. M. Grauls, and C. P. A. van Boven. 1982. Isolation of a cytomegalovirus-like agent from wild rats. Arch. Virol. 73:231-241.

11. Bruggeman, C. A., H. Meijer, F. Bosman, and C. P. A. van Boven. 1985. Biology of rat cytomegalovirus infection. Intervirology 24:1-9. 
12. Bruning, J., W. H. M. Debie, P. H. J. Dormans, H. Meijer and C. A. Bruggeman. 1987. The development and characterization of monoclonal antibodies against rat cytomegalovirus induced agents. Arch. Virol. 94:55-70.

13. Bruno J. F., J. Whittaker, J. F. Song, and M. Berelowitz. 1991. Molecular cloning and sequencing of a cDNA encoding a human $\alpha 1 \mathrm{~A}$ adrenergic receptor. Biochem. Biophys. Res. Commun. 179:1485-1490.

14. Burkholder A.C., and L. H. Hartwell. 1985. The yeast $\alpha$-factor receptor: structural properties deduced from the sequence of the STE2 gene. Nucleic Acids Res. 13:8463-8475.

15. Cao, J. X., P. D. Gershon, and D. N. Black. 1995. Sequence analysis of HindIII Q2 fragment of capripoxvirus reveals a putative gene encoding a G-protein-coupled chemokine receptor homologue. Virology 209:207-212.

16. Cavanaugh, V. J., R. M. Stenberg, T. L. Staley, H. W. Virgin IV, M. R. MacDonald, S. Paetzold, H. E. Farrell, W. D. Rawlinson, and A. E. Campbell. 1996. Murine Cytomegalovirus with a deletion of genes spanning HindIII-J and -I displays altered cell and tissue tropism. J. Virol. 70:1365-1374.

17. Cesarman, E., R. G. Nador, F. Bai, R. A. Bohenzky, J. J. Russo, P. S. Moore, Y. Chang, and D. M. Knowles. 1996. Kaposi's sarcoma-associated herpesvirus contains G protein-coupled receptor and cyclin D homologs which are expressed in Kaposi's sarcoma and malignant lymphoma. J. Virol. 70:8218-8223.

18. Chambers, W. H., N. L. Vujanovic, A. B. DeLeo, M. W. Olsowy, R. B. Herberman, and J. C. Hiserodt. 1989. Monoclonal antibody to a triggering structure expressed on rat natural killer cells and adherent lymphokine-activated killer cells. J. Exp. Med. 169:1373-1789.

19. Chee, M. S., A.T. Bankier, S. Beck, R. Bohni, C. M. Brown, R. Cerny, T. Horsnell, C. A. Hutchison III, T. Kouzarides, J. A. Martignetti, E. Preddie, S. C. Satchwell, P. Tomlinson, K. M. Weston and B. G. Barrell. 1990. Analysis of the protein-coding content of the sequence of human cytomegalovirus strain AD169. Curr. Top. Microbiol. Immunol. 154:125169.

20. Chee, M. S., Satchwell, S. C., Preddie, E., Weston, K. M. and Barrell, B. G. 1990. Human cytomegalovirus encodes three $\mathrm{G}$ protein-coupled receptor homologues. Nature 344: 774777.

21. Dam, J. G. van, J. G. M. C. Damoiseaux, H. A. M. D. van der Heijden, G. Grauls, P. J. C. van Breda Vriesman, and C. A. Bruggeman. Infection with rat cytomegalovirus in the immunocompromised host is associated with the appearance of a T-cell population with reduced CD8 and T cell receptor expression. Clin. Exp. Immunol. 110:349-357.

22. Damoiseaux, J. G. M. C., E. A. Döpp, W. Calame, D. Chao, G. G. MacPherson, and C. D. Dijkstra. 1994. Rat macrophage lysosomal membrane antigen recognized by monoclonal antibody ED1. Immunology. 83:140-147.

23. Davis-Poynter, N. J., and H. E. Farrell. 1996. Masters of deception: A review of herpesvirus immune evation strategies. Immunol. Cell Biol. 74:513-522.

24. Davis-Poynter, N. J., D. M. Lynch, H. Vally, G. R. Shellam, W. D. Rawlinson, B. G. Barrell, and H. E. Farrell. 1997. Identification and characterization of a $\mathrm{G}$ protein-coupled receptor homolog encoded by murine cytomegalovirus. J. Virol. 71:1521-1529. 
25. Dijkstra, C. D., A. E. Döpp, P. Joling, and G. Kraal. 1985. The heterogeneity of mononuclear phagocytes in lymphoid organs: distinct macrophage subpopulations in the rat recognized by monoclonal antibodies ED1, ED2 and ED3. Immunol. 54:589-599.

26. Gao, J. L., D. B. Kuhns, H. L. Tiffany, D. McDermott, X. Li, U. A. Francke, and P. M. Murphy. 1993. Structure and functional expression of the human macrophage inflammatory protein $1 \alpha /$ RANTES receptor. J. Exp. Med. 177:1421-1427.

27. Gao. J. L. and P. M. Murphy. 1994. Human cytomegalovirus open reading frame US28 encodes a functional $\beta$ chemokine receptor. J. Biol. Chem. 269:28539-28542.

28. Gompels, U. A., J. Nicholas, G. Lawrence, M. Jones, B. J. Thomson, M. E. Martin, S. Efstathiou, M. Craxton, and H. A. Macaulay. 1995. The DNA sequence of human herpesvirus-6: structure, coding content and genome evolution. Virology 209:29-51.

29. Hamann J., W. Eichler, D. Hamann, H. M. Kerstens, P. J. Poddighe, J. M. Hoovers, E. Hartmann, M. Strauss, and R. A. van Lier. 1995. Expression, cloning and chromosomal mapping of the leukocyte activation antigen CD97, a new seven-span transmembrane molecule of the secretion receptor superfamily with an unusual extracellular domain. J. Immunol. 155:1942-1950.

30. Hünig, T., H. J. Wallny, J. K. Hartley, A. Lawetzky, and G. Tiefenthaler. 1989. A monoclonal antibody to a constant determinant of the rat $\mathrm{T}$ cell antigen receptor that induces $\mathrm{T}$ cell activation. J. Exp. Med. 169:73-86.

31. Khorana H. G., G. E. Gerber, W. C. Herlihy, C. P. Gray, R. J. Anderegg, K. Nihei, and K. Biemann. 1979. Amino acid sequence of bacteriorhodopsin. Proc. Natl. Acad. Sci. U.S.A. 76:5046-5050 .

32. Klein P.S., T. J. Sun, C. L. Saxe III, A. R. Kimmel, R. L. Johnson, and P. N. Devreotes. 1988. A chemoattractant receptor controls development in Dictyostelium discoideum. Science 241:1467-1472.

33. Kuhn, D. E., C. J. Beall, and P. E. Kolattukudy. 1995. The cytomegalovirus US28 protein binds multiple CC chemokines with high affinity. Biochem. Biophys. Res. Commun. 211:325330.

34. Manning, W. C., C. A. Stoddart, L. A. Lagenaur, G. B. Abenes, and E. S. Mocarski. 1992. Cytomegalovirus determinant of replication in salivary gland. J. Virol. 66:3794-3802.

35. Margulies, B. J., H. Browne, and W. Gibson. 1996. Identification of the human cytomegalovirus G protein-coupled receptor homologue encoded by UL 33 in infected cells and enveloped virus particles. Virology 225:111-125.

36. Massung, R. F., V. Jayarama, and R. W. Moyer. 1993. DNA sequence analysis of conserved and unique regions of swinepox virus: identification of genetic elements supporting phenotypic observations including a novel G protein-coupled receptor homologue. Virology 197:511-528.

37. Meijer, H., J.C. Dreesen, and C. P. van Boven. 1986. Molecular cloning and restriction endonuclease mapping of the rat cytomegalovirus genome. J. Gen. Virol. 67:1327-1342.

38. Minegishi T., K. Nakamura, Y. Takakura, Y. Ibuki, M. Igarashi. 1991. Cloning and sequencing of human FSH receptor cDNA. Biochem. Biophys. Res. Commun. 175:1125-1130.

39. Myers, E. W., and W. Miller. 1988. Optimal alignments in linear space. Comput. Appl. Biosci. 4:11-17. 
40. Nathans J., and D.S. Hogness. 1984. Isolation and nucleotide sequence of the gene encoding human rhodopsin. Proc. Natl. Acad. Sci. U.S.A. 81:4851-4855.

41. Nicholas, J., K. R. Cameron, and R. W. Honess. 1992. Herpesvirus saimiri encodes homologues of G protein-coupled receptors and cyclins. Nature 355:362-365.

42. Nicholas, J. 1996. Determination and analysis of the complete nucleotide sequence of human herpesvirus 7. J. Virol. 70:5975-5989.

43. Pearson, W. R. 1990. Rapid and sensitive sequence comparison with FASTP and FASTA. Methods Enzymol. 183:63-98.

44. Probst, W.C., L. A. Snyder, D. I. Schuster, J. Brosius, and S. C. Sealfon. 1992. Sequence alignment of the G-protein coupled receptor superfamily. DNA and Cell Biol. 11:1-20.

45. Rawlinson, W. D., H. E. Farrell, and B. G. Barrell. 1996. Analysis of the complete DNA sequence of murine cytomegalovirus. J. Virol. 70:8833-8849.

46. Stals, F. S., F. Bosman, C. P. van Boven, and C. A. Bruggeman. 1990. An animal model for therapeutic intervention studies of CMV infection in the immunocompromised host. Arch. Virol. 114:91-107.

47. Stoddart, C. A., R. D. Cardin, J. M. Boname, W. C. Manning, G. B. Abenes, and E. S. Mocarski. 1994. Peripheral blood mononuclear phagocytes mediate dissemination of murine cytomegalovirus. J. Virol. 68:6243-6253.

48. Telford, E. A., M. S. Watson, H. C. Aird, J. Perry, and A. J. Davison. 1995. The DNA sequence of equine herpesvirus 2. J. Mol. Biol. 249:520-528.

49. Thompson, J. D., D. G. Higgins, and T. J. Gibson. 1994. CLUSTAL W: improving the sensitivity of progressive multiple sequence alignment through sequence weighting, positionspecific gap penalties and weight matrix choice. Nucleic Acids Res. 22:4673-4680.

50. Torres-Nagel, N., E. Kraus, M. Brown, G. Tiefenthaler, R. Mitnacht, A. F. Williams, and T. Hünig. 1992. Differential thymus dependence of rat CD8 isoform expression. Eur. J. Immunol. 22:2841-2848.

51. Ustinov, J. A., R. J. Loginov, C. A. Bruggeman, P. H. van der Meide, P. J. Häyry, and I. T. Lautenschlager. 1993. Cytomegalovirus induces class II expression in rat heart endothelial cells. J. Heart. Lung. Transplant. 12:644-651.

52. Ustinov, J. A., R. J. Loginov, C. A. Bruggeman, J. Suni, P. J. Häyry, and I. T. Lautenschlager. 1994. CMV-induced class II antigen expression in various rat organs. Transpl. Int. 7:302-308.

53. Vink, C., E. Beuken, and C. A. Bruggeman. 1996. Structure of the rat cytomegalovirus genome termini. J. Virol. 70:5221-5229.

54. Vossen, R. C. R. M., J. G. Derhaag, M. E. P. Slobbe-van Drunen, A. M. Duijuestijn, M. C. E. van Dam-Mieras, and C. A. Bruggeman. 1996. A dual role for endothelial cells in cytomegalovirus infection? A study of cytomegalovirus infection in a series of rat endothelial cell lines. Virus Res. 46:65-74.

55. Welch, A. R., L. M. McGregor, and W. Gibson. 1991. Cytomegalovirus homologs of cellular G protein-coupled receptor genes are transcribed. J. Virol. 65:3915-3918. 
CHAPTER 3 
$\sim$ Chapter 4

\section{Deletion of the R78 G Protein- Coupled Receptor Gene from Rat Cytomegalovirus Results in an At- tenuated, Syncytium-Inducing Mu- tant Strain}

PATRICK S. BEISSER, GERT GRAULS, CATHRIEN A. BRUGGEMAN, AND CORNELIS VINK

Department of Medical Microbiology, Cardiovascular Research Institute Maastricht (CARIM), Maastricht University, P.O. Box 5800, 6202 AZ, Maastricht, The Netherlands

Journal of Virology, 1999, September, Vol. 73, No. 9, p. 7218-7230. 
CHAPTER 4 


\section{ABSTRACT}

The rat cytomegalovirus (RCMV) R78 gene belongs to an uncharacterized class of viral G protein-coupled receptor (GCR) genes. The predicted amino acid sequence of the $\mathbf{R} 78$ open reading frame (ORF) shares $25 \%$ and $20 \%$ similarity with the gene products of murine cytomegalovirus M78 and human cytomegalovirus UL78, respectively. The R78 gene is transcribed throughout the early and late phase of infection in rat embryo fibroblasts (REF) in vitro. Transcription of R78 was found to result in three different mRNAs: (i) a 1.8-kb mRNA containing the R78 sequence, (ii) a 3.7-kb mRNA containing both $R 77$ and R78 sequences, and (iii) a 5.7-kb mRNA containing at least ORF R77 and R78 sequences. To investigate the function of the R78 gene, we generated two different recombinant virus strains: an RCMV R78 null mutant (RCMV $\triangle$ R78a) and an RCMV mutant encoding a GCR from which the putative intracellular C-terminus has been deleted (RCMV $\Delta \mathrm{R} 78 \mathrm{c}$ ). These recombinant viruses replicated with a 10- to 100-fold lower efficiency than wt virus in vitro. Interestingly, unlike wt virus-infected REF, REF infected with the recombinants develop a syncytium-like appearance. A striking difference between wt and recombinant viruses was also seen in vivo: a considerably higher survival was seen among recombinant virus-infected rats than among RCMV-infected rats. We conclude that the RCMV R78 gene encodes a novel GCR-like polypeptide that plays an important role in both RCMV replication in vitro, and the pathogenesis of viral infection in vivo. 


\section{INTRODUCTION}

G protein-coupled receptors (GCRs) play a key role in transduction of extracellular signals to the intracellular environment. They can be activated by a variety of stimuli, like neurotransmitters, hormones, and photons (reviewed by Probst et al. [53]). Upon ligand binding, GCRs activate G-proteins, which in turn activate effector enzymes and ion channels in a cascade-like fashion. Thousands of GCR variants are encoded by genes of both prokaryotes and eukaryotes. Additionally, some are encoded by virus genes. To date, 20 putative viral GCR genes have been discovered: 2 of these genes are located within the genomes of poxviruses $(21,44), 11$ in betaherpesvirus genomes $(9$, $22,33,49,54)$, and 7 in gammaherpesvirus genomes $(4,26,48,57,63)$. The majority of these genes was found to share similarity to genes encoding cellular chemokine receptors. Although the functions of most of the putative viral GCRs are yet unclear, several of these are capable of binding chemokines, hence invoking a classical signal transduction response $(1,4,31,38,42,47)$. The herpesvirus saimiri (HVS) ECRF3-encoded chemokine receptor is capable of transducing signals upon activation by $\alpha$ chemokines (1). The human cytomegalovirus (HCMV) US28-encoded chemokine receptor was shown both to be a promiscuous calcium-mobilizing receptor for several $\beta$ chemokines (31). Additionally, the US28 protein was suggested to be responsible for $\beta$ chemokine sequestration in HCMV-infected fibroblasts (15). The GCR encoded by Kaposi's sarcoma-associated herpesvirus (KSHV) open reading frame (ORF) 74 not only binds both $\alpha$ and $\beta$ chemokines, but is also constitutively active, inducing second messenger signalling in vitro (4). The KSHV chemokine receptor was also shown to stimulate cellular proliferation (4), transformation and angiogenesis (7). A distinctive set of chemokine-like receptors is exclusively encoded by betaherpesviruses: HCMV UL33 (23), rat cytomegalovirus (RCMV) R33, murine cytomegalovirus (MCMV) M33 (54), and human herpesvirus 6 and 7 (HHV-6 and HHV-7) U12 $(33,49)$. Recently, we found that the RCMV R33 gene is essential for the pathogenesis of viral infection in vivo, and that, unlike wild-type (wt) virus an RCMV R33 null mutant could neither enter nor replicate in salivary gland epithelial cells of infected rats (9). A similar observation was made for MCMV M33: upon infection of mice with an MCMV M33 deletion mutant strain, virus could not be recovered from mouse salivary glands (26). Interestingly, betaherpesviruses encode another distinctive set of yet uncharacterized viral GCRs: HCMV UL78 (22), MCMV M78 (54), and HHV-6 and HHV-7 U51 (33, 49). Although the positions of these UL78-like genes within the betaherpesvirus genomes are conserved, their sequences are rather divergent. Despite the presence of distinct GCR characteristics, such as seven transmembrane domains, two conserved cysteine residues and a G protein-coupling domain (53), these UL78-like gene products share little similarity with any of the thousands of GCRs known to date. Yet, characterization of this unique family of GCRs might be crucial to the development of new antiviral therapeu- 
tics. In this report we present the sequence and transcriptional analysis of the RCMV member of this family of GCR genes, which we termed R78. In addition, RCMV strains were generated in which the R78 open reading frame (ORF) is either partially or completely deleted from the genome (RCMV $\triangle R 78 a$ and RCMV $\triangle R 78 c$, respectively). We show that disruption of the R78 gene affects RCMV replication in permissive cell types in vitro, and that the RCMV R78 deletion mutant strains induce syncytium formation in rat embryo fibroblasts (REF) in vitro, in contrast to wt RCMV. In addition, a dramatically lower mortality was observedwithin groups of either RCMV $\triangle R 78 \mathrm{a}-$, or RCMVAR78c-infected rats, than within a group of wt RCMV-infected rats. We conclude that the RCMV R78 gene plays a vital role in both RCMV replication in vitro, and the pathogenesis of viral infection in vivo.

\section{MATERIALS AND METHODS}

Cells and virus. Primary rat embryo fibroblasts (REF), rat fibroblast cell line Rat2 TK- (ATCC CRL 1764), rat heart endothelium cell line 116 (RHEC), monocyte/macrophage cell line R2 (R2MФ), and rat aorta medial smooth muscle cells (RSMC) were cultured as described previously $(18,24,60,50)$. RCMV (Maastricht strain) was propagated in REF (18). Virus titers were determined by a plaque assay using standard procedures (19). RCMV DNA was isolated from culture medium as described by Vink et al. (61).

Identification, cloning and sequence analysis of the RCMV R78 gene. Cloning of the 30$\mathrm{kb}$ XbaI B fragment of the RCMV genome into vector PSP62-PL has previously been described (45). The XbaI B fragment was digested with various restriction endonucleases and the resulting fragments were cloned into vector pUC119. Both strands of each clone were sequenced using the Cy5 Autoread sequencing kit (Pharmacia Biotech, Roosendaal, The Netherlands) and an ALFexpress automated DNA sequencer (Pharmacia Biotech). Sequence analysis was done using the program PC/Gene (version 2.11; IntelliGenetics). The sequences were checked for the presence of HCMV UL78-homologous regions by alignment with the GenBank nucleic acid database using the BLASTN search algorithm (39). Thus, a $3.7-\mathrm{kb}$ BamHI fragment was identified, which contains an ORF with considerable similarity to the HCMV UL78 ORF.

RCMV $\triangle R 78$ a recombination plasmid construction. Plasmid p115, which contains a large part of the R78 ORF on a 2.4-kb Sall fragment (Fig. 1), was digested with Sall and subsequently treated with deoxynucleotide triphosphates (dNTPs) and DNA polymerase I Klenow fragment (Pharmacia Biotech). Subsequently, the DNA was digested with Bglll, and the resulting 1.4-kb fragment was cloned into Bam $\mathrm{HI} / \mathrm{Smal}$-treated vector $\mathrm{pUC119}$, generating plasmid pA. Plasmid p114, which contains the remaining part of the R78 ORF on a 1.7-kb Sall fragment (Fig. 1), was digested with Sall. The 1.7-kb Sall-insert from p114 was ligated into the Sall site of pA, generating pB. A 1.5-kb BamHI/EcoRI fragment from Rc/CMV (Invitrogen, Leek, The Netherlands), containing the neomycin resistance gene (neo) was treated with Klenow and ligated into a XbaI-digested and Klenow-treated vector pB. This final construct (p147; Fig. 4) was linearized by digestion with Asp718 and HindIII and used for transfection, in order to generate mutant RCMV $\triangle R 78 \mathrm{a}$. 
RCMV $\triangle R 78 \mathrm{c}$ recombination plasmid construction. Plasmid $\mathrm{p} 116$, which contains the complete R78 ORF on a $3.7-\mathrm{kb}$ BamHI fragment (Fig. 1) was digested with Asp718 and Ncol. The resulting 2.9-kb fragment was treated with Klenow and subsequently circularized with T4 DNA ligase, resulting in plasmid $\mathrm{pC}$. One Sall site was removed from $\mathrm{pC}$ by digesting the plasmid with $\mathrm{XbaI}$ and HindIII, subsequently followed by treatment with Klenow. The resulting fragment was circularized, generating plasmid, pD. Plasmid pD was digested with Sall, treated with Klenow, and ligated to the blunt-ended DNA fragment containing the Rc/CMV neo gene (see above). The resulting plasmid p120 (Fig. 4), was linearized with Asp718 and XbaI prior to transfection, in order to generate mutant RCMV $\triangle R 78 \mathrm{c}$.

Generation of RCMV R78 deletion mutants. Approximately $10^{7}$ Rat 2 cells were trypsinized and subsequently centrifuged for $5 \mathrm{~min}$ at $500 \times \mathrm{g}$. The cells were resuspended in $0.25 \mathrm{ml}$ of culture medium, after which $10 \mu \mathrm{g}$ of linearized plasmid of either p120 or p147 was added. The suspension was transferred to a 0.4-cm electroporation cuvette (Bio-Rad, Veenendaal, The Netherlands), and pulsed at $0.25 \mathrm{kV}$ and $500 \mu \mathrm{F}$ in a Bio-Rad Gene Pulser electroporator. The cells were subsequently seeded in 10-cm culture dishes. At $6 \mathrm{~h}$ after transfection, the cells were infected with RCMV at a multiplicity of infection (MOI) of 1 . The culture medium was supplemented with $50 \mu \mathrm{g}$ of $\mathrm{G} 418$ per $\mathrm{ml}$ at $16 \mathrm{~h}$ postinfection (p.i.). Recombinant viruses were plaquepurified and cultured on REF monolayers as described earlier (9).

Southern blot hybridization. DNA was isolated from wt RCMV, RCMV $\triangle R 78$ a and RCMV $\Delta R 78$ c, and digested with either BamHI, BamHI-BglII, BamHI-EcoRV, BamHI-Ncol, Sall, or Sall-EcoRV. Subsequently, the digested DNA was electrophoresed through a $1 \%$ agarose gel and blotted onto a Hybond $\mathrm{N}$ * nylon membrane (Amersham, 's-Hertogenbosch, The Netherlands) as described previously (16). Both a $3.7-\mathrm{kb}$ insert from p116 containing the intact R78 ORF, as well as sequences from R77 and R79 (R78 probe [Fig. 5A]), and a 1.5-kb BamHI-EcoRI fragment containing the neo gene (neo probe) from Rc/CMV were used as probes. Hybridization and detection experiments were performed with digoxigenin DNA-labeling and chemoluminescence detection kits (Boehringer Mannheim, Almere, The Netherlands).

Isolation of poly(A)* RNA and Northern blot analysis. RCMV poly(A)* RNA was isolated from REF at 2, 8 and 48 h postinfection (p.i.), and at immediate early (IE), early (E), and late (L) times of infection with RCMV $(\mathrm{MOI}=1)$. To obtain IE mRNA, REF were treated with $100 \mu \mathrm{g}$ of cycloheximide per $\mathrm{ml}, 1 \mathrm{~h}$ before, during and $16 \mathrm{~h}$ after infection. During the 1 - $\mathrm{h}$ infection period, the cells were exposed to RCMV. E mRNA was isolated after infection of REF with RCMV and treatment of cells with $100 \mu \mathrm{g}$ of phosphonoacetic acid per $\mathrm{ml}$ from $3 \mathrm{~h}$ p.i. until the cells were harvested at $13 \mathrm{~h}$ p.i. L mRNA was isolated after infection of REF with either RCMV, RCMV $\triangle R 78$ a, or RCMV $\Delta R 78 \mathrm{c}$, and harvesting of cells at $72 \mathrm{~h}$ p.i. To obtain mRNA from mock(M) infected cells, a similar procedure to that described for the purification of L mRNA was used, except that RCMV infection was omitted. Poly(A)-RNA was purified with a QuickPrep Micro mRNA purification kit (Pharmacia Biotech). Aliquots $(1 \mu \mathrm{g})$ of poly $(\mathrm{A})+\mathrm{RNA}$ were electrophoresed through agarose under denaturing conditions, as described by Brown and Mackey (17). Then, the RNA was transferred to positively charged nylon membranes (Boehringer Mannheim) as described previously (17). The 754-bp BamHI-Sall fragment from p115, and the 950-bp BgIII- Sall fragment, the 206-bp BgIII-NarI fragment and the 1088-bp BgIII-SalI fragment from p116 (see Fig. 6A) were used to generate probes. These fragments contain R77, R78, R79 and R79/R80-specific sequences, respectively. Hybridization and detection experiments were 
performed with digoxigenin DNA-labeling and chemoluminescence detection kits (Boehringer Mannheim).

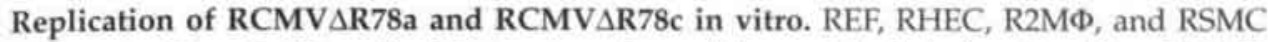
were grown either in 96-well plates or on glass slides and infected with either RCMV, RCMV $\triangle$ R78a or RCMV $\triangle \mathrm{R} 78 \mathrm{c}$ at an MOI of either 0.1 or 1. Culture medium samples (three per virus) were taken at 1,3,5 and 7 days p.i. and subjected to plaque titer determination. The cells were fixed and stained with monoclonal antibodies (MAb) against RCMV E proteins (MAb RCMV 8 [20]) as described previously (60). The degree of infection was determined by counting the number of antigen-positive cells relative to the total number of cells in three different wells (four microscopic fields per well at a magnification of $\times 400$ ).

Dissemination of wt RCMV and RCMV $\Delta$ R78c in vivo. Male specific-pathogen-free Lewis/ N RT1 rats (Central Animal Facility, Maastricht University, Maastricht, The Netherlands), used for all in vivo experiments in this study, were kept under standard conditions (55). Rats were immunocompromised by $5 \mathrm{~Gy}$ of total-body Röntgen irradiation 1 day before infection, as described by Stals et al. (55), and all virus stocks that were used for inoculation in vivo were derived from tissue culture medium of virus-infected REF. Two groups of rats (10 weeks old, with a body weight of 250 to $300 \mathrm{~g}$ ) were infected with $5 \times 10^{6}$ plaque forming units (PFU) of either RCMV or RCMVAR78c. On days 4 and 21 p.i., five rats from each group were sacrificed, and their internal organs were collected. These organs were subjected to both plaque assay and immunohistochemistry (19). Tissue sections $(4 \mu \mathrm{m})$ of the submaxillary salivary gland, spleen, kidney, liver, lung, heart, pancreas, thymus, aorta, and cervical lymphal nodes were stained with MAb RCMV 8.

Survival of immunocompromised rats infected with either RCMV, RCMV $\triangle$ R78a or RCMV $\Delta$ R78c. Four-week-old rats (body weights ranging from 100 to $120 \mathrm{~g}$ ) were divided into three groups of five rats. Intraperitoneal infection was carried out with $1 \times 10^{6} \mathrm{PFU}$ of either RCMV, RCMV $\triangle R 78 \mathrm{a}$ or RCMV $\triangle \mathrm{R} 78 \mathrm{c}$. The number of surviving rats was recorded daily until day 28 p.i.

GenBank accession number. The nucleotide sequence of the $3.7-\mathrm{kb} \mathrm{BamHI}$ fragment containing the R78 gene (Fig. 1) and the predicted amino acid sequence derived from R78 have been deposited in the GenBank database under accession no. AF077758.

\section{RESULTS}

Identification, cloning, and sequence analysis of the RCMV R78 gene. Previously, it was shown that the majority of RCMV genes is collinear with genes of both HCMV and MCMV $(9,10,11,61,62)$. We hypothesized that the position of a putative RCMV UL78 homolog would be analogous to that of both HCMV UL78 (22) and MCMV M78 (54). Accordingly, we focused on the 33-kb RCMV XbaI B fragment (Fig. 1) (45). This fragment was digested with various restriction endonucleases, subcloned and sequenced. The GenBank database was subsequently screened for homology with the generated sequence. Thus, a 3.7- $\mathrm{kb}$ Bam $\mathrm{HI}$ fragment was identified (in plasmid p116) showing considerable similarity to a region within the genomes of HCMV as well as MCMV, containing the UL78 and M78 gene, respectively. A 1422-bp ORF was identi- 


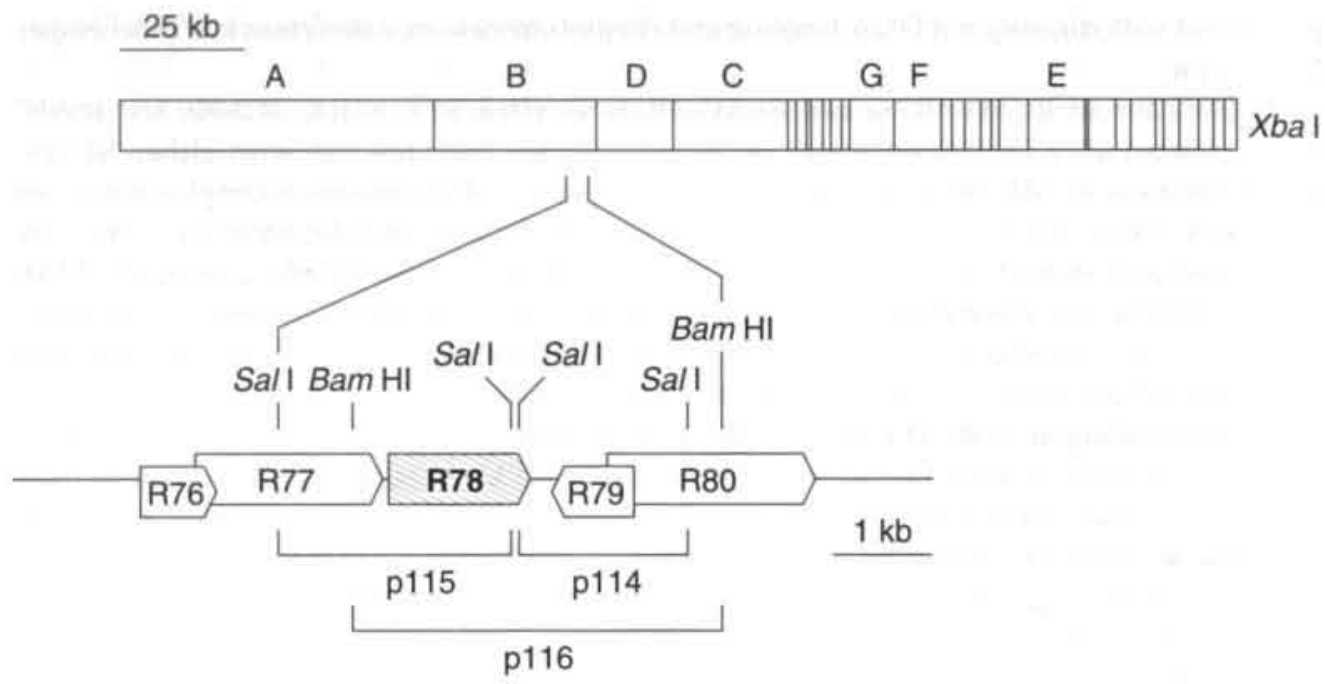

FIG. 1. Restriction map of the RCMV genome and the relative position of the R78 gene, which encodes a putative $\mathrm{G}$ protein-coupled receptor. A section of this map has been enlarged below the main map. Arrow boxes indicate the size and polarity of conserved RCMV ORFs.

fied within the BamHI fragment (Fig. 1), which has the potential to encode a 474-amino acid polypeptide with a predicted molecular mass of $50 \mathrm{kDa}$. This polypeptide shows $25 \%$ and $20 \%$ similarity with the amino acid sequences of M78 (54) and UL78 (22), respectively (Table 1). This low level of similarity is not uncommon to UL78-like sequences, since the amino acid sequences derived from UL78 and M78 share only $21 \%$ similarity (Table 1). Analogous to the nomenclature of the corresponding HCMV and MCMV genes, the 1422-bp RCMV ORF was termed R78.

To investigate whether the amino acid sequence of the R78-derived polypeptide (pR78) possesses features that are characteristic of GCRs, the pR78 sequence was analyzed with computer program TMpred (ISREC Bioinformatics Group, Epalinges, Switzerland [58]). This program utilizes a database of existing transmembrane domains to predict potential transmembrane domains of an uncharacterized sequence. Computation revealed an extracellular $\mathrm{N}$-terminus and eight transmembrane domains, each of which might be folded as an $\alpha$-helix. Seven of these domains are collinear with the predicted transmembrane domains of the gene products of MCMV M78 and HCMV UL78 (Fig. 2). In addition, several amino acid residues that are conserved among most GCRs were identified (reviewed by Probst et al. [53]): two conserved cysteine residues at positions 94 and 190, which may form a disulfide bridge, and a conserved aspartic acid-arginine-tyrosine motif (DRL, positions 118 to 120) which might be involved in 
TABLE 1. Similarities of predicted amino acid sequences among R78-like gene products

Gene product

Similarity $(\%)^{n}$

\begin{tabular}{llll}
\hline RCMV R78 HCMV M78 & HCMV UL78
\end{tabular}

\section{M78}

HCMV UL78

HHV-6 U51

HHV7 U51

\section{0}

20.1

13.9

14.8
20.8

14.9

15.9
15.4

15.9

36.0

"Similarities were calculated with a pairwise global alignment program (2) that uses an alignment algorithm described by Myers an Miller (46).

G-protein coupling (Fig. 2). These residues are also present within analogous regions of the UL78 and M78 gene products and the HHV-6 and -7 U51 gene products (Fig. 2). Another interesting feature is the presence of a putative tyrosine kinase phosphorylation site (phosphorylation consensus [R/K]X ${ }_{2 / 3}\left[\mathrm{D} / \mathrm{E} \mathrm{X}_{2 / 3} \mathrm{Y}\right.$, at positions 392 to 400) (Fig. 2). These putative tyrosine phosphorylation sites are found in the predicted amino acid sequences of RCMV R78, MCMV M78 and HCMV UL78, but not within analogous regions of the predicted U51 amino acid sequences of either HHV- 6 or HHV-7 (Fig. 2).

In order to classify the GCRs encoded by the R78-like genes, the predicted amino acid sequences of R78, M78, UL78 and HHV-6 and HHV-7 U51 were screened against a non-redundant protein sequence dataset (a combination of all non-redundant GenBank complete protein coding gene translations, sequences from the Protein Data Bank, SwissProt and Protein Information Resource databases [39]). This analysis demonstrated a clear relationship between pR78-like peptides and other GCRs; the predicted amino acid sequence of the UL78 gene was similar to GCRs such as a thrombin receptor (32) and opoid receptor (66), while the M78 gene product shares similarity with a lysophosphatidic acid receptor (3) and a somatostatin-like receptor (64). Surprisingly, the C-terminal part of the R78 gene product was found to be similar to collagen-like sequences (in particular sequences such as human collagen (51) and spider silk protein (65). Although previously examined virus-encoded GCRs were shown to be related to chemokine receptors $(1,4,9,21,26,30,38,42,44,47,57,63)$, none of the pR78-like GCRs showed a collective similarity with GCRs of any particular class. Most notably, the $\mathrm{N}$-terminal part of the R78-like gene products lack the signals for $\mathrm{N}$-linked glycosylation, which are present in the $\mathrm{N}$-terminal sequences of all other known virus-encoded GCRs, making this a unique set of receptors among virus-encoded GCRs. 


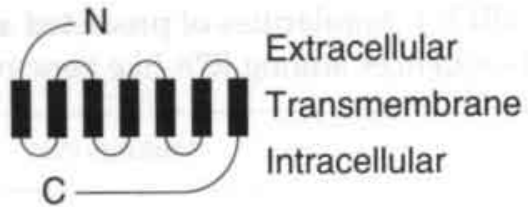
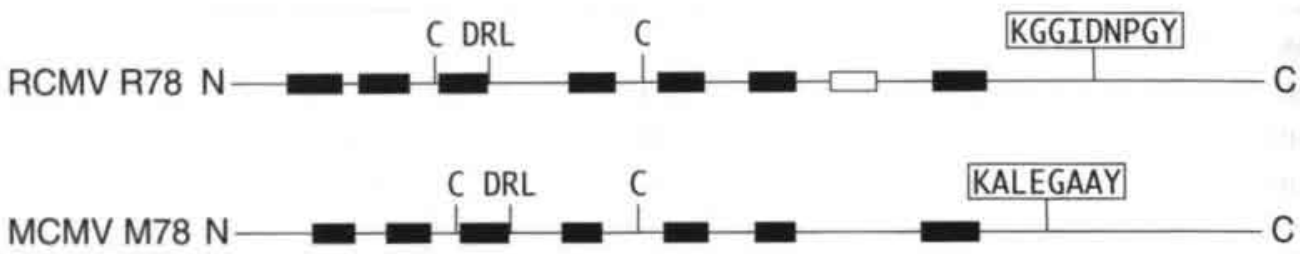

HCMV UL78

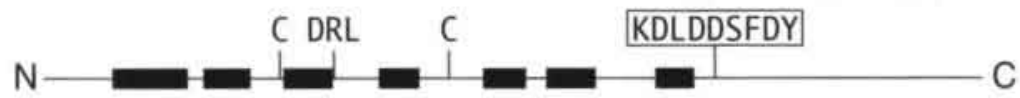

HHV-6 U51

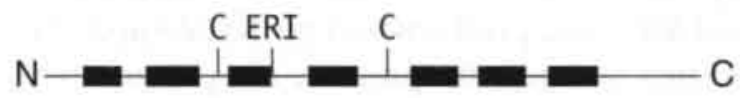

HHV-7 U51

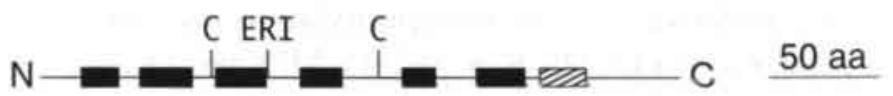

FIG. 2. Schematic representation of the gene products of RCMV R78, MCMV M78, HCMV UL78, HHV-6 and HHV-7 U51. The top figure shows the two-dimensional orientation of GCRs (not to scale with the other GCR figures). The horizontal lines represent the one-dimensional structure of the R78-like gene products. The designations of the genes that encode these receptors are shown on the left-hand side of each line. Black boxes represent putative transmembrane $\alpha$-helices. The white box indicates an additional unique hydrophobic $\alpha$-helix domain predicted by the computer program TMpred (58). The hatched box indicates a hydrophobic stretch of amino acid residues collinear with predicted transmembrane domains of the other GCRs, although not predicted by TMpred. Conserved cysteine residues are indicated by 'C's. The '(D/E)R(I/L)' motifs indicate the position of the conserved putative G-protein coupling domains. The sequences enclosed in white boxes indicate the position of a putative tyrosine kinase phosphorylation sites that are conserved among cytomegalovirus genes relative to $R 78$.

R78 transcription. Although the ORFs of R78-like betaherpesvirus genes are poorly conserved, they are all preceded by a remarkable double TATA signal motif. Moreover, the start codons of R78, M78 and UL78 conform to the Kozak consensus (41). The positions and sequences of these motifs are summarized in Table 2. We set out to identify transcripts derived from the RCMV R78 gene by Northern blot analysis. As shown in Fig. 3, R78-specific hybridization signals were detected in PAA-treated cells 
TABLE 2. Transcription initiation and translation signals of R78-like genes are conserved

\begin{tabular}{|c|c|c|c|c|c|c|}
\hline \multirow{2}{*}{ Gene } & \multicolumn{2}{|c|}{ TATA box 1} & \multicolumn{2}{|c|}{ TATA box 2} & \multicolumn{2}{|c|}{ Kozak } \\
\hline & Sequence & Position & Sequence & Position & Sequence & Pusition \\
\hline RCMV R78 & TATITG & -108 to- -103 & TATAAG & -62 to -57 & GCCACGATGG & - \\
\hline MCMV M78 & TATTIT & -148 to -143 & TATAAG & -104 10 -99 & GTCGCCATGC & - \\
\hline HCMV UL78 & TATITT & -149 to -144 & TAATTT & -91 to -86 & TCCATCATGT & 37 to $46^{\circ}$ \\
\hline HHV-6 U51 & TATITI & -140 to -135 & TATATA & -103 เo -97 & & \\
\hline HHV7 U51 & TATTIT & -146 to -141 & TATAAA & -69 to -64 & & \\
\hline
\end{tabular}

-The sequences shown in this table are described in references 22, 33, 49, and 54. All positions are relative to the first nucleotide of the corresponding $\mathrm{ORF}$.

Contains an in-frame ATG sequence and is present downstream of the previously predicted start codoe of UL.78.

\section{$\begin{array}{llllllll}M & \text { IE } & \text { E } & \text { L } & 0 & 2 & 8 & 48\end{array}$}

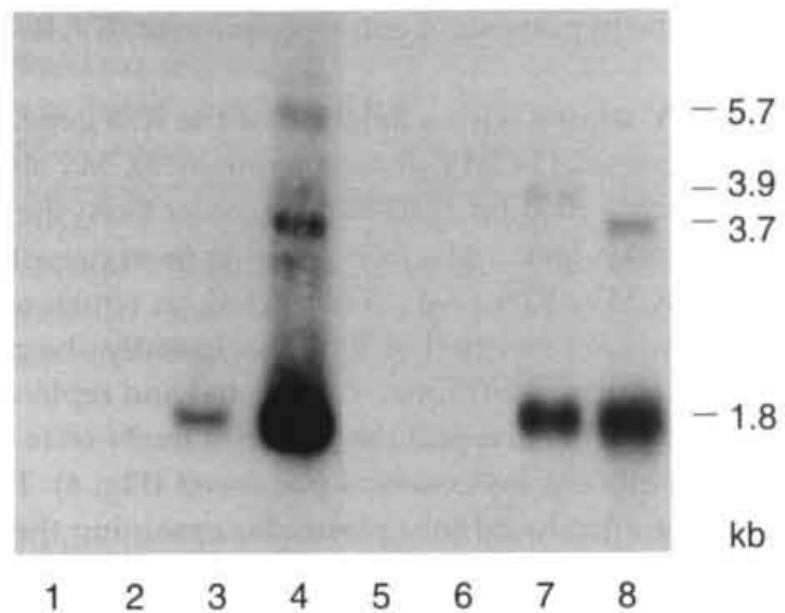

FIG. 3. The RCMV R78 gene is transcribed at both early and late times of infection in REF. The figure shows an autoradiograph of a Northern blot that was hybridized with an R78-specific probe. In lanes 1 and 5, mRNA from mock-infected cells was separated. Lanes 2, 3, and 4 represent the IE, E, and L phases of infection, respectively. Lanes 6,7 , and 8 represent transcripts from REF at 2, 8, and 48 hours p.i., respectively. The estimated lenghts of the different transcripts are indicated at the right-hand side in $k b$. 
(E phase, lane 3) and in untreated cells (L phase, lane 4), but not in cycloheximidetreated cells (IE phase, lane 2 ) or mock-infected cells (M, lane 1 ). In untreated, RCMVinfected REF, R78-specific signals were detected at 8 and 48 h p.i. (lanes 7 and 8 , respectively), but not at earlier time points (lane 5 and 6, respectively). These results classify R78 as an E gene that is also transcribed during the L phase of infection in vitro.

An R78-specific transcript with a length of approximately $1.8 \mathrm{~kb}$ was detected during both the E and L phase (Fig. 3, lanes 3, 4, 7 and 8). Since the R78 ORF was found to comprise $1422 \mathrm{bp}$, and a putative polyadenylation signal (AATAAA) is located $94 \mathrm{bp}$ downstream of the R78 ORF, we postulate that the 1.8-kb transcript corresponds to an mRNA that exclusively contains the R78 ORF. Two other R78-specific trancripts (3.7$\mathrm{kb}$ and 5.7-kb, respectively) were detected during the L phase (Fig. 3, lane 4) and at 48 h p.i. (Fig. 3, lane 8). At 8 h p.i., a 3.9-kb transcript was found (Fig. 3, lane 7), whereas the $3.7-\mathrm{kb}$ transcript was not detected. It is possible that early after infection the combined transcription of R77 and R78 is initiated at a location $0.2 \mathrm{~kb}$ upstream of the transcription start site of the $3.7-\mathrm{kb}$ transcript. Alternatively, since we did not use strandspecific probes, the $3.9-\mathrm{kb}$ transcript can be derived from the opposite strand of the R77/R78 locus. However, this was not investigated further. The $3.9-\mathrm{kb}$ and $3.7-\mathrm{kb}$ transcripts may contain the R78 ORF as well as one or more neighboring ORFs. This hypothesis is supported by the notion that the gene upstream of R78 (R77, see below) lacks a polyadenylation site at its 3 ' end. Additional Northern blot hybridization data (shown below) support the hypothesis of cotranscription of R77, R78 and other RCMV genes.

Generation of RCMV strains with a deletion of the R78 gene. To investigate the role of R78 in the pathogenesis of RCMV disease, a mutant RCMV strain (RCMV RR78a) was constructed, in which a 1030-bp BglII-Sall fragment from the R78 gene was deleted and replaced with a 1.5 -kb neomycin expression (neo) cassette (Fig. 4). Another RCMV mutant strain (RCMVAR78c) was constructed, in which an 80-bp Sal I fragment was replaced by the neo cassette (Fig. 4). Consequently, the part of R78 that encodes the putative intracellular C-terminus was deleted and replaced by an irrelevant sequence of similar length, while the part that encodes the $\mathrm{N}$-terminus (including the seven predicted transmembrane helices) was preserved (Fig. 4). The deletion/insertion mutations were first introduced into plasmids containing the R78 gene (Fig. 4). The R78 gene within the RCMV genome was subsequently replaced by either of the mutated R78 genes via homologous recombination, after transfection of fibroblasts with the recombination plasmids and infection with RCMV. Selection for recombinant strains was established by supplementing the growth medium with G418. Subsequent to plaque purification of the virus, the purity and integrity of the recombinant strains were checked by Southern blot analysis. Virion DNA from RCMV, RCMVAR78a and RCMV $\Delta$ R78c was purified and digested with BamHI-NcoI (Fig. 5). We also digested 


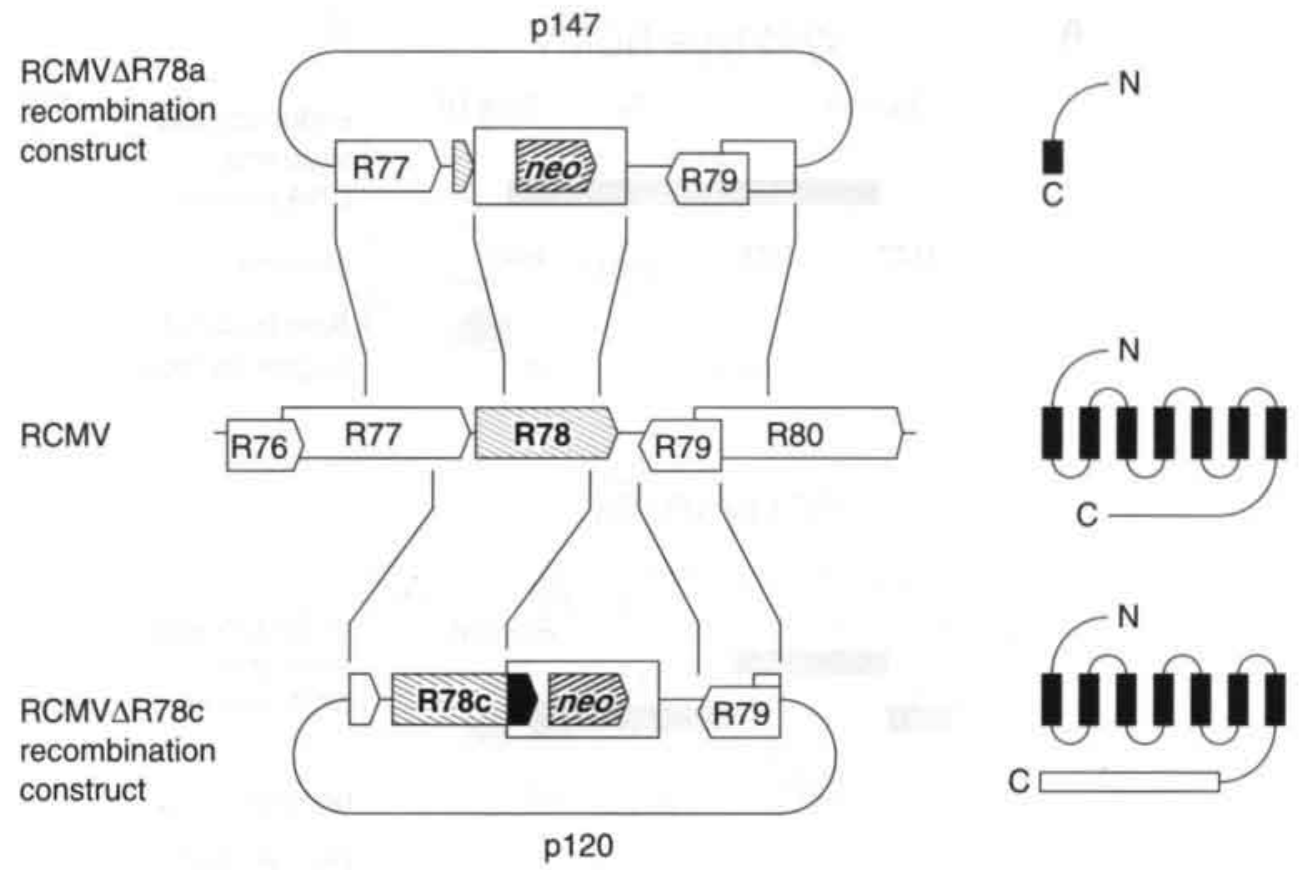

FIG. 4. Construction of RCMV in which the R78 gene is disrupted. The RCMV genome, of which a segment representing the $R 78$ region is shown in the center of the figure, was modified by homologous recombination with different recombination plasmids ( $p 147$ at the top, and p120 at the bottom), resulting in either RCMV $\triangle R 78$ a or RCMV $\triangle R 78$ c, respectively. Approximately $85 \%$ of the R78 ORF has been deleted in the RCMV $\triangle R 78$ a genome (resulting in a gene encoding only the $\mathrm{N}$-terminal part including half of the first predicted transmembrane domain, shown at the top right of the figure). In mutant $R C M V \Delta R 78 c$, the part of the $R 78$ that encodes the putative intracellular $C$-terminus has been replaced by a sequence encoding a strech of 97 amino acids of irrelevant sequence (right bottom, indicated as a black arrow box). ORFs are shown as arrow boxes. Wild-type and mutated R78 ORFs are indicated with descending hatches. The neo genes that were inserted in the recombination plasmids are indicated with ascending hatches.

purified virion DNA with either BamHI, BamHI-BgIII, BamHI-EcoRV, NcoI, Sall or SallEcoRV (data not shown). After agarose gel electrophoresis and transfer of the DNA to a filter, hybridization was done with either an R78-specific probe or a neo-specific probe. As shown in Fig. 5, the observed hybridization signals correspond exactly to the predicted restriction fragments. In addition, contaminating wt virus fragments were not detected in the RCMV $\triangle R 78 \mathrm{a}$ and RCMV $\triangle R 78 \mathrm{c}$ lanes (Fig. 5). These findings indicated that both recombinant strains are pure and contain the appropriate mutations. 
A

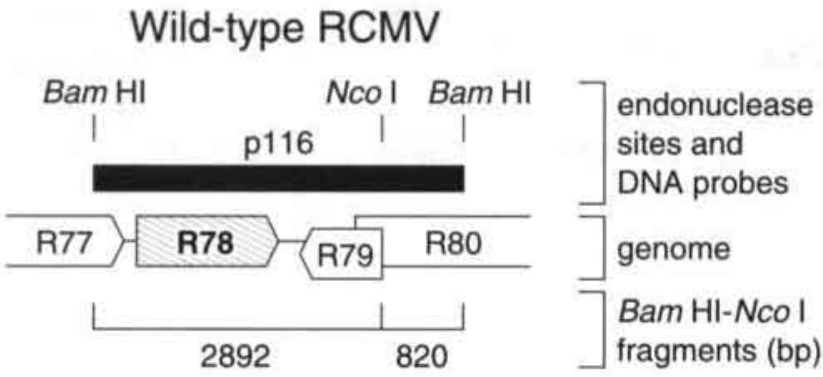

$\mathrm{RCMV} \triangle \mathrm{R} 78 \mathrm{a}$

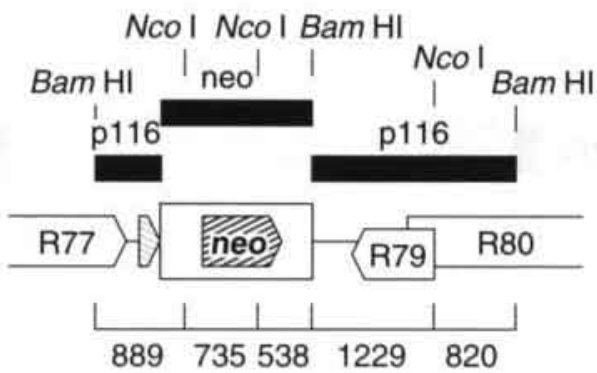

endonuclease

sites and

DNA probes

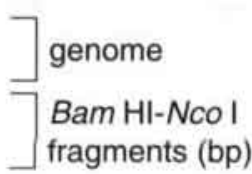

\section{RCMV $\triangle \mathrm{R} 78 \mathrm{c}$}

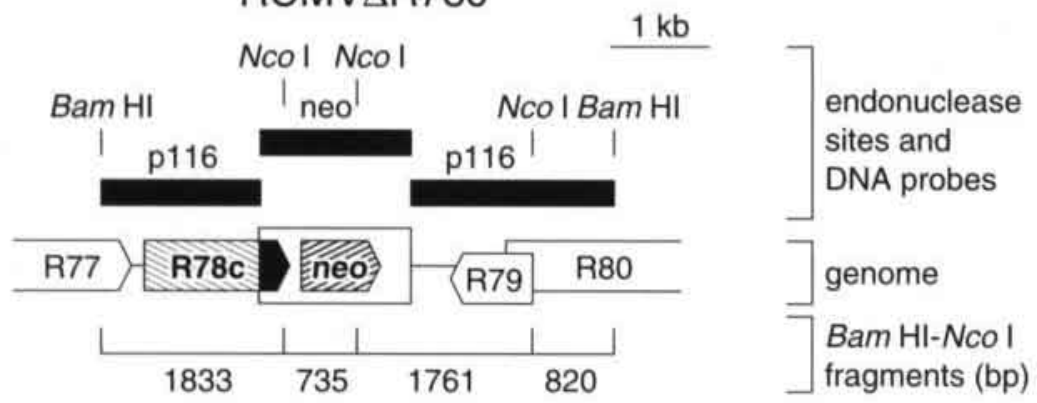

FIG. 5. Southern blot analysis of recombinant viruses RCMV $\triangle R 78 \mathrm{a}$ and $R C M V \triangle R 78 c$. (A) DNA from $R C M V, R C M V \triangle R 78 a$, and RCMV $\triangle R 78 \mathrm{c}$ was digested with BamHI and Ncol, electrophoresed, blotted and hybridized with either a probe derived from the 116 insert or a neo probe (both probes indicated with black boxes). ORFs are shown as arrow boxes. Wt and mutated R78 ORFs are indicated by descending hatches. The neo genes that were inserted in the recombination plasmids are indicated by ascending hatches. ( $B$ - Next page) An autoluminograph of a Southern blot containing wt (w) DNA, RCMV $A R 78 a(a)$ $D N A$, and RCMV $\triangle R 78 c$ (c) DNA. The estimated lengths of BamHI-NcoI-digested wt (w) DNA fragments are indicated at sides. 


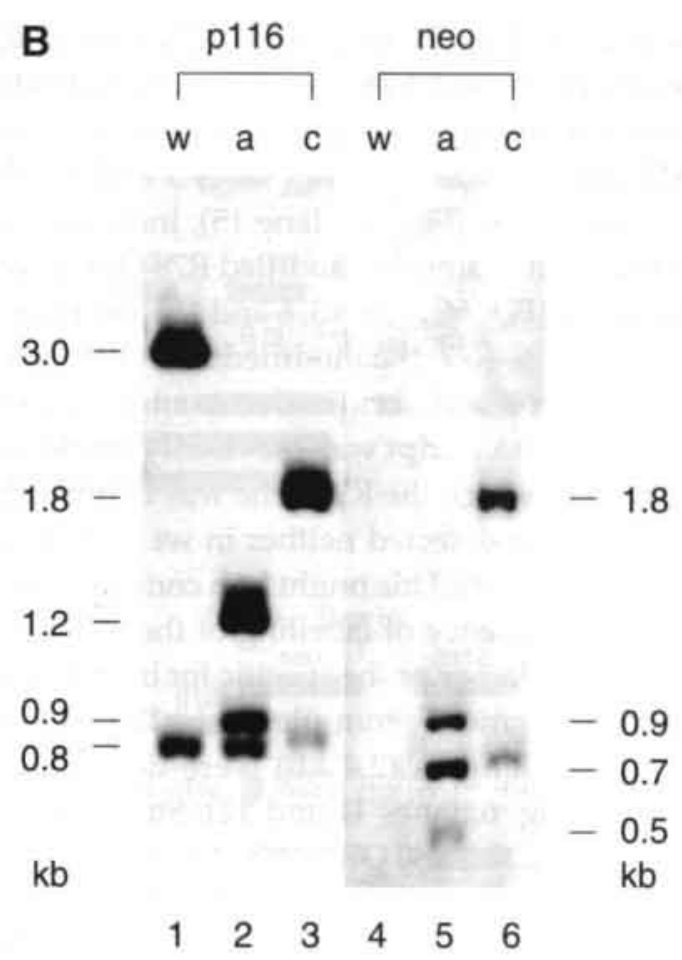

RCMV $\Delta$ R78c transcripts. The deletion of the R78 ORF might invoke unforeseen events such as disruption of unknown promoter/enhancer regions of the neighboring genes R77, R79 or R80. To investigate the effect of modification of the R78 genes on transcription of these neighboring genes, a Northern blot hybridization experiment was performed with poly(A)* RNA from REF infected with one of the two recombinant viruses (RCMV $\triangle R 78 \mathrm{c}$ ) and wt RCMV-infected REF. The genes upstream and downstream of the R78 gene were found to have considerable sequence similarity to the MCMV M77, M79 and M80 genes (54), respectively (data not shown). These RCMV genes are therefore referred to as R77, R79 and R80, respectively. Probes were generated from R77-, R78-, R79-, R79/R80-, and neo-specific DNA fragments (Fig. 6A and B) and hybridized with poly $(\mathrm{A})^{+}$RNA extracted from either mock-, RCMV- or RCMV $\Delta$ R78c-infected fibroblasts at 48 h p.i. (Fig. 6C).

In agreement with a previous Northern blot hybridization experiment (Fig. 3), the R78-specific probe hybridized to three distinct RCMV transcripts of $1.8 \mathrm{~kb}, 3.7 \mathrm{~kb}$ and, albeit weakly, $5.7 \mathrm{~kb}$, respectively (Fig. 6C, lane 5). It was hypothesized that the larger two of these R78-specific transcripts also contained the R77 ORF. This was verified by hybridization with an R77-specific probe, which led to the detection of similar $3.7-\mathrm{kb}$ 
and 5.7-kb transcripts (Fig. 6C, lane 2). In poly(A)+ RNA from RCMV $\Delta$ R78c-infected REF both the R77-specific probe and R78-specific probe hybridized to similar transcripts. Interestingly, these transcripts are approximately $1 \mathrm{~kb}$ longer than their counterparts from wt RCMV-infected REF (Fig. 6C, lanes 3 and 6). These transcripts also hybridized to a neo-specific probe (Fig. 6C, lane 15), indicating that the $2.8-\mathrm{kb}$ transcript (Fig. 6C, lanes 6 and 15) contains the modified R78 ORF as well as neo sequences, and both the 4.7-kb transcript (Fig. 6C, lanes 3,6 and 15) and the 6.7-kb transcript (Fig. $6 \mathrm{C}$, lanes 3,6 and 15) encompass R77, the modified R78 ORF as well as neo sequences (Fig. 6B). Additionally, the neo probe hybridized to a unique 1.2-kb transcript (Fig. 6C, lane 15). A similar neo-specific transcript was previously found to be expressed by an RCMV strain (RCMV $\triangle R 33$ ) of which the R33 gene was disrupted by the neo gene (9).

R79-specific transcripts were detected neither in wt RCMV- nor in RCMV $\Delta$ R78cinfected REF (Fig. 6C, lanes 8 and 9). This might be a consequence of either a low level of R79 transcription or low efficiency of labelling of the R79-specific probe that was used for hybridization. Thus, a larger probe specific for both R79 and R80 was derived from the 1088-bp BgIII-Sall fragment prom plasmid p116 (Fig. 6A and B). With this probe, transcripts of similar lengths $(2.4 \mathrm{~kb})$ were detected in either RCMV- or RCMV $\triangle$ R78c-infected REF (Fig. 6, lanes 11 and 12). Since the lengths of these transcripts correspond to the size of the R80 ORF (2457 bp [13]), we hypothesize that they contain R80 mRNA rather than R79 mRNA (Fig. 6A and B). Although we can not formally exclude the possibility that disruption of the R78 ORF affects transcription of the R79 gene, we hypothesize that transcription of R79 does not differ between RCMV and RCMVAR78c. This hypothesis is based on the following two observations. First, the putative promoter of R79 is likely to be situated upstream of the R79 ORF, within the R80 ORF distant from the disrupted R78 site in RCMV $\triangle R 78 \mathrm{c}$. In addition, a potential polyadenylation site downstream of the R79 ORF, and neighboring the R78 ORF (complementory to nucleotides 1858 to 1863 of GenBank accession number AF077758), is preserved in RCMV $\triangle R 78 \mathrm{c}$ as well as RCMV $\Delta \mathrm{R} 78 \mathrm{a}$.

The R78 gene is important for efficient virus replication in various cell types in vitro. The replication characteristics of RCMV, RCMV $\triangle R 78 \mathrm{a}$ and RCMV $\triangle R 78 \mathrm{c}$ were assessed in four different cell types, including REF which are thought to play a role in CMV infection in vivo and cells rat heart endothelial cells (RHEC), rat smooth muscle

FIG. 6 - Next page. Transcription of R78 and its neighboring genes. The wo RCMV (A) and RCMV $A R 78 \mathrm{C}$ (B) genomes are represented by a line, ORFs are indicated by white, hatched, and black arrow boxes, probes by black boxes, and transcripts by black arrow boxes below the genomes. The lengths are shown at the sides of the transcripts in $k b$. (C) Autoluminographs from Northern blots that contain poly $(A)^{*} R N A$ from virus-infected REF. The transcript lengths that correspond to the detected hybridization signals are indicated in $k b . M$, mock-infected; $W$, wt RCMV-infected; $\triangle, R C M V \Delta R 78 c$-infected. 
A
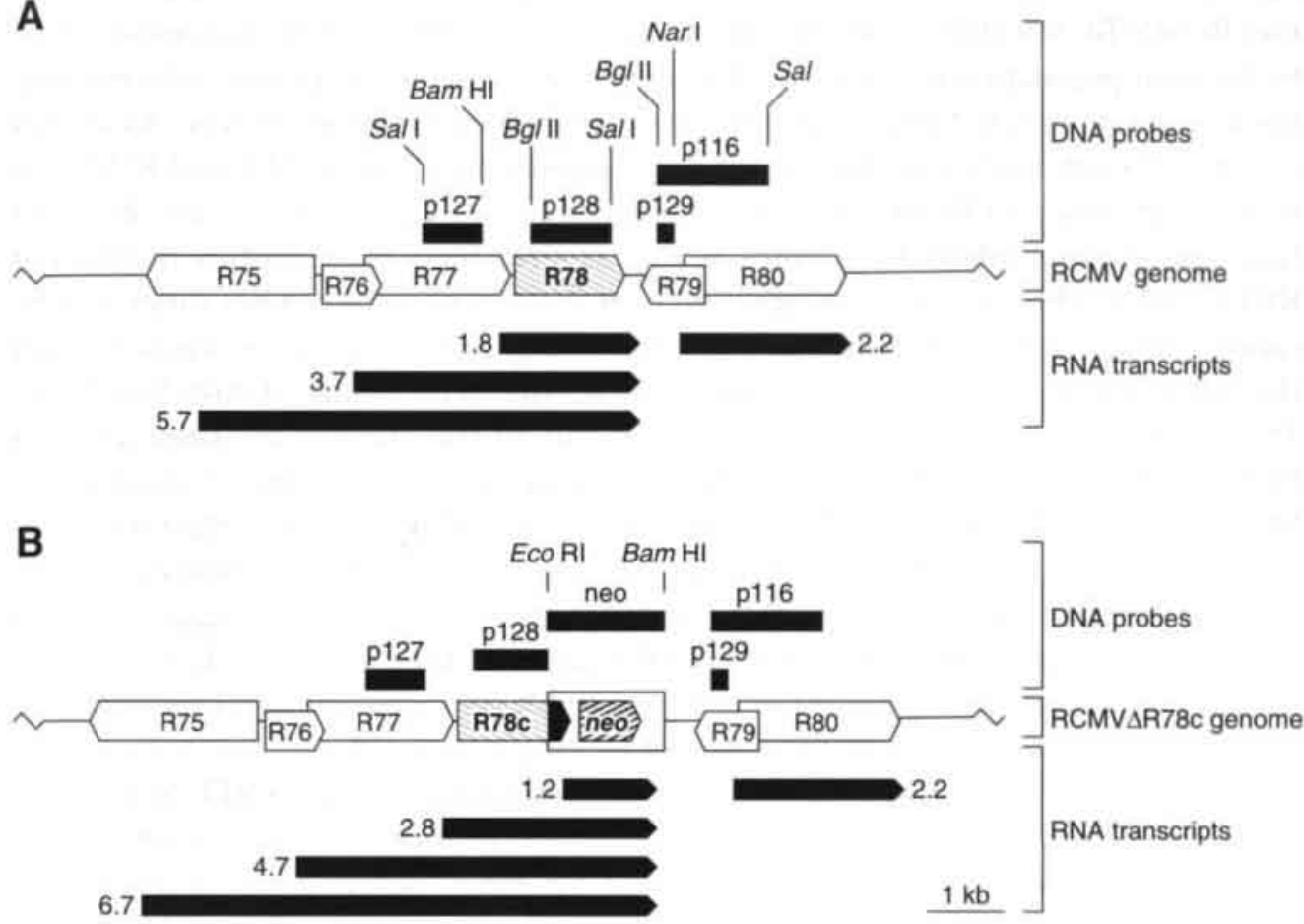

C

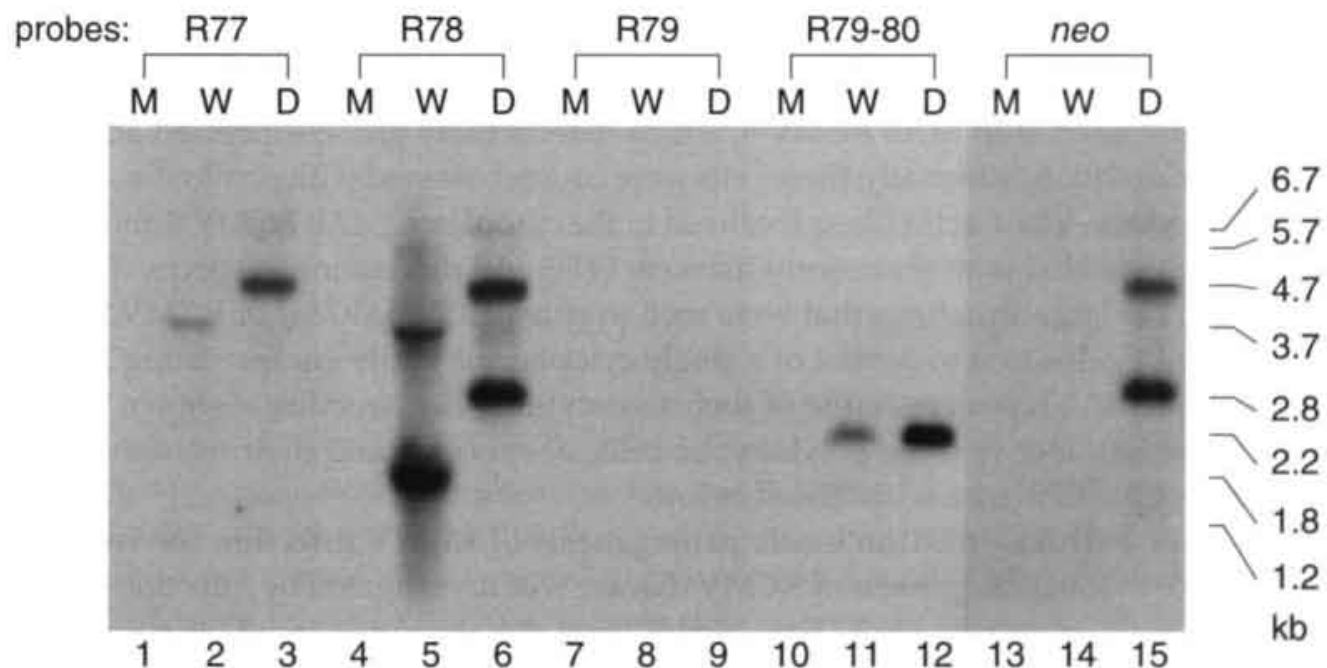


cells (RSMC) and rat monocytes/macrophages (R2MФ). Cells were infected with either RCMV, RCMV $\triangle R 78 \mathrm{a}$ or RCMV $\triangle \mathrm{R} 78 \mathrm{c}$, and the proportion of infected cells relative to the total population of cells was determined at various time points. Additionally, the amount of excreted infectious virus was determined for each cell type. As shown in Fig. 7, the infected-cell ratio did not differ significantly among REF and RSMC infected with either wt RCMV or each of the recombinant viruses during the observed time course. Also, infected-cell ratios as well as virus titers in the culture medium of RHEC and R2MФ infected with either wt or recombinant virus did not differ significantly (data not shown). However, clear differences were observed in virus titers in the culture medium of virus-infected REF and RSMC. In particular, at days 5 and $7 \mathrm{p}$.i. 10 - to 100 -fold lower virus titers were found in the culture medium of both RCMV $\triangle R 78 \mathrm{a}-$ and RCMV $\triangle R 78 \mathrm{c}$-infected REF, than in the of culture medium of wt RCMV-infected REF (Fig. 7). Additionally, at day 5 p.i., 10-fold lower virus titers were found in the culture medium of recombinant virus-infected RSMC than in the medium of wt virus-infected RSMC (Fig. 7). Taken together, these data suggest that (i) R78-deleted viruses enter cells and spread throughout the monolayers of cells at similar rates as wt virus, and that (ii) in REF and RSMC, the production of recombinant virus is less efficient than the production of wt virus.

RCMV $\triangle R 78 a$ and RCMV $\triangle R 78 c$ induce syncytium formation in REF. In addition to the differences in virus replication between wt and mutant viruses, the morphology of REF infected with either RCMV $\Delta R 78 \mathrm{a}$ or RCMV $\Delta \mathrm{R} 78 \mathrm{c}$ clearly contrasted with that of wt virus-infected REF. Within the monolayers of mutant RCMV-infected REF (Fig. $8 \mathrm{C}$ and D), but not in those of infected RSMC, RHEC or R2MФ, we observed syncytium-like cellular cultures that were larger than normally seen in wt RCMV-infected REF monolayers (Fig, 8B). These structures appear 3 to 4 days after infection. To investigate the nature of these structures more closely, they were subjected to immune fluorescence staining and confocal laserscan microscopy. To this purpose, virus-infected REF were stained with MAb RCMV 8, which detects Early phase-expressed antigens in the nuclei (20). Additionally, these cells were counter-stained with phalloidin, which binds to cytoskeletal f-actin fibers localized in the cytoplasm. MAb RCMV 8 and phalloidin were labeled with fluorescent markers FITC and rhodamine, respectively. Surprisingly, the large structures that were seen in either RCMV $\triangle R 78 \mathrm{a}-$ or RCMV $\Delta R 78 \mathrm{c}$ infected REF appeared to consist of a single cytoplasmic entity encapsulating 2 to 20 distinct nuclei. A typical example of such a syncytium-like structure is shown in Fig. $8 \mathrm{E}$. The significance of these polykaryotic cells, or syncytia, and their relation to the function of the R78 gene is discussed below.

$\mathrm{R} 78$ has a critical function in the pathogenesis of RCMV infection in vivo. The role of R78 in the pathogenesis of RCMV disease was investigated by infection of rats with either wt or mutant virus. To compare virus dissemination in wt virus-infected and mutant virus-infected rats, two groups of immunocompromised rats were infected 
O RCMV

- RCMV $\Delta R 78 a$

- RCMV $\triangle \mathrm{R} 78 \mathrm{c}$
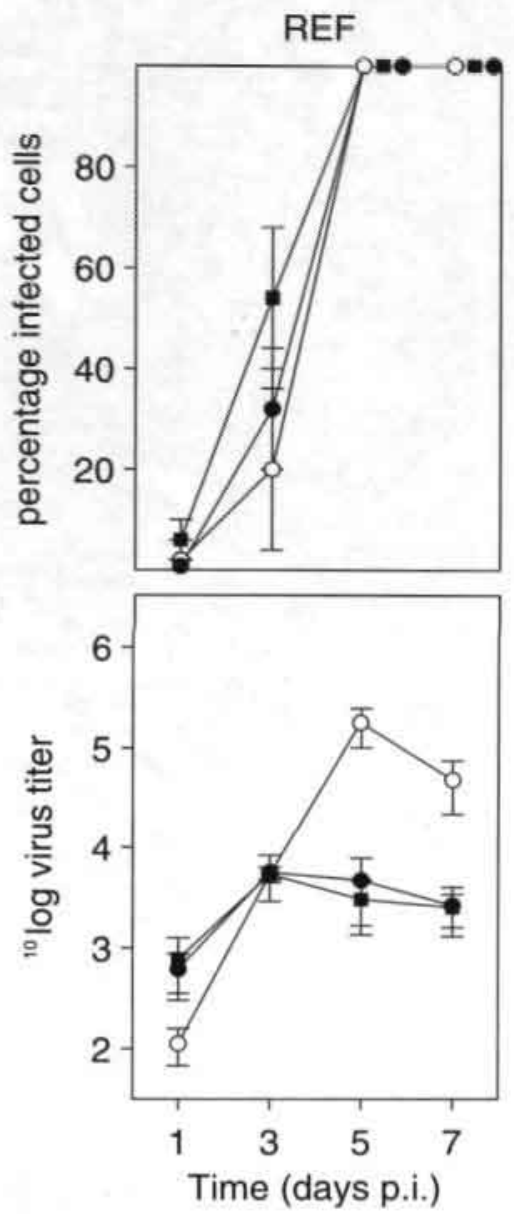

RSMC
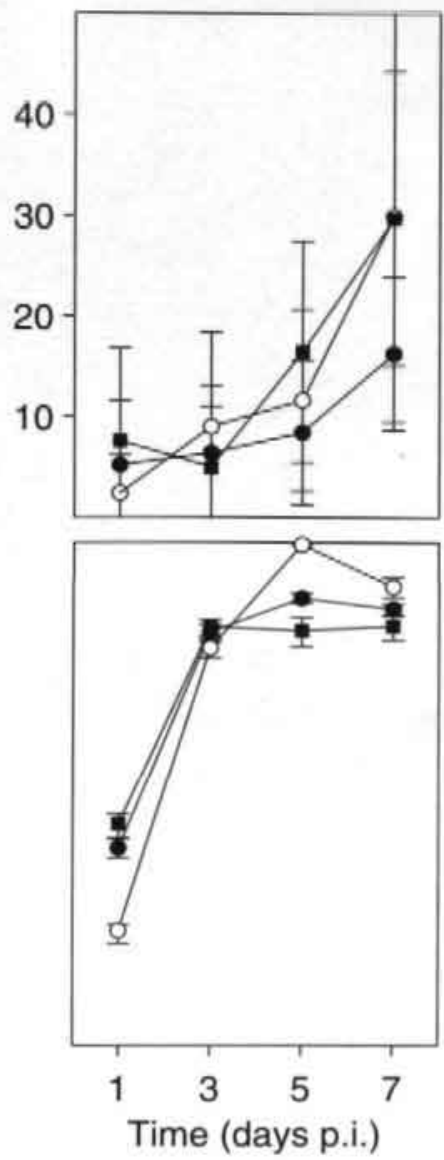

FIG. 7. RCMV is attenuated upon deletion of the R78 gene. Rat embry fibroblasts (REFs) were infected at an MOI of 0.01 with either wt RCMV (0), RCMV $\triangle R 78 a(\bullet)$, or RCMV $\triangle R 78 C(\bullet)$. Rat smooth muscle cells (RSMC) were infected with wt and mutant virus at an MOI of 1 (relative to REF infection). The upper graphs show the infected cell/total cell ratios at various time points p.i. The lower graphs show virus titers that were determined in culture medium up to 7 days p.i. Standard deviations are indicated by vertical bars. 
A

$$
\text { (4) }
$$

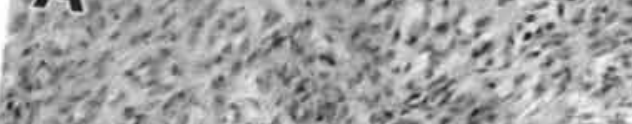

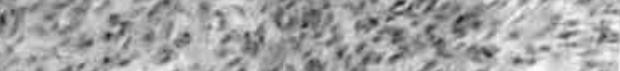

\section{B}

73.

(1) 9.

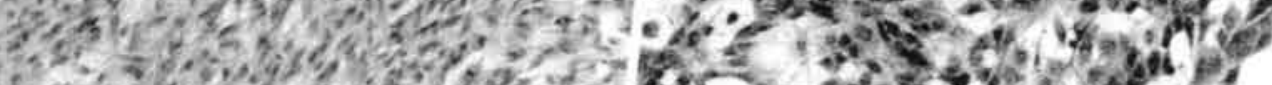

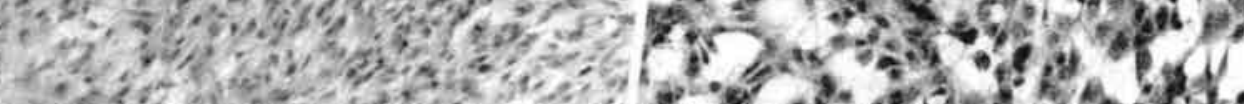
4
$7 y$

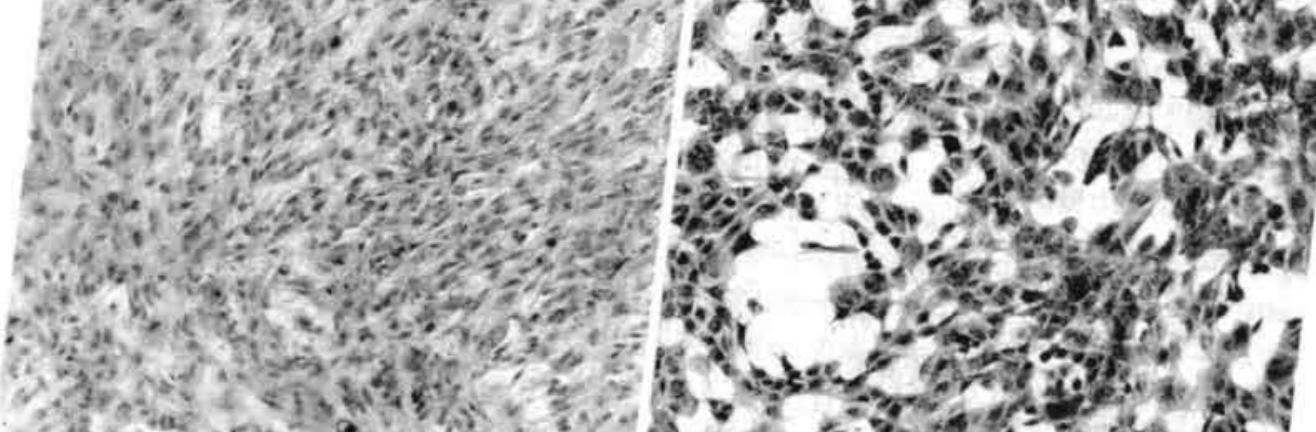

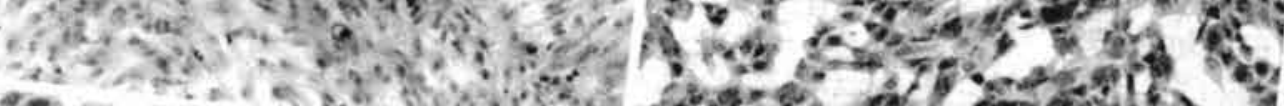
Q 0 mabromen.

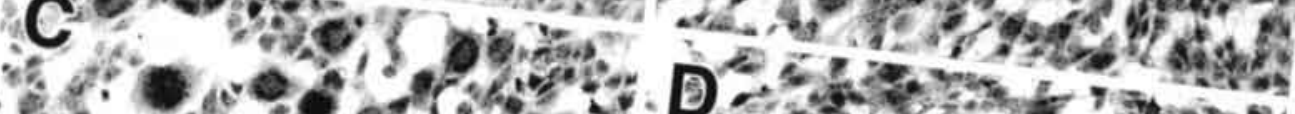

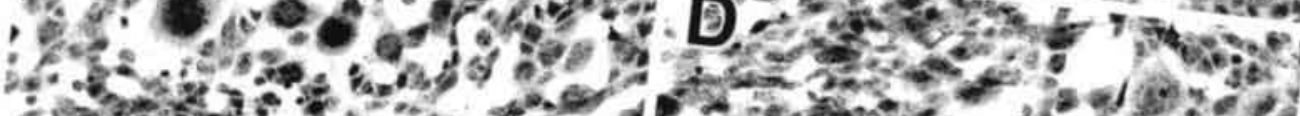

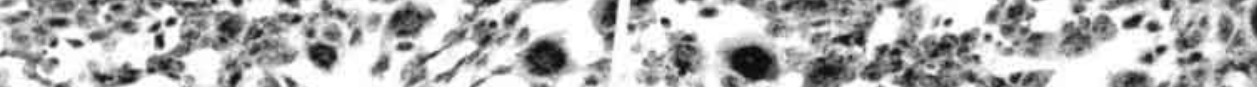

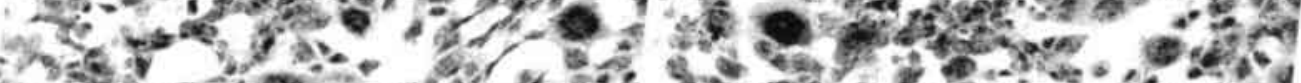

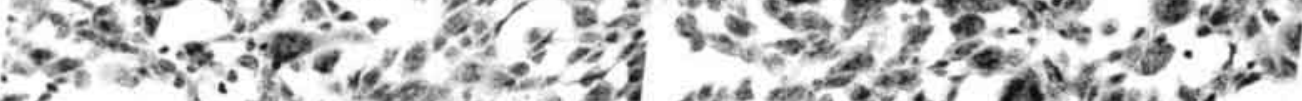

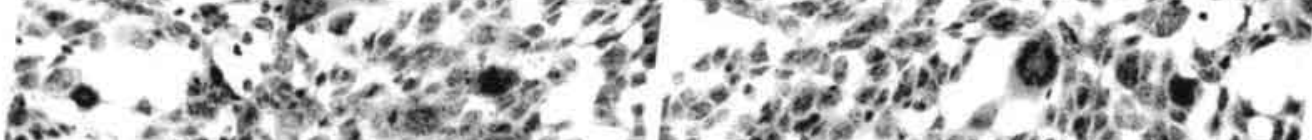
giv at.

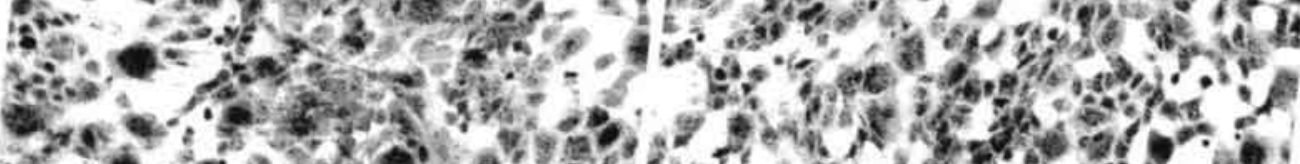

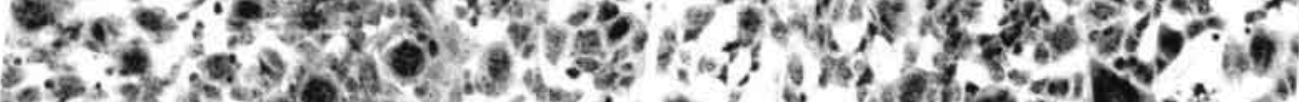

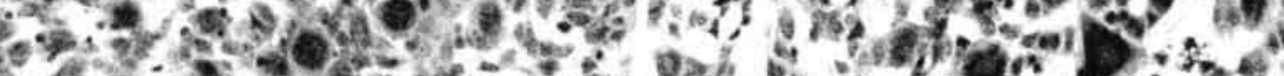
3.6. L. -

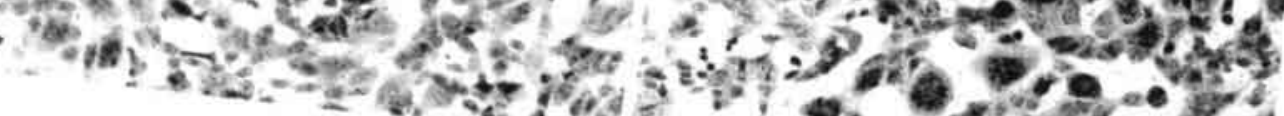




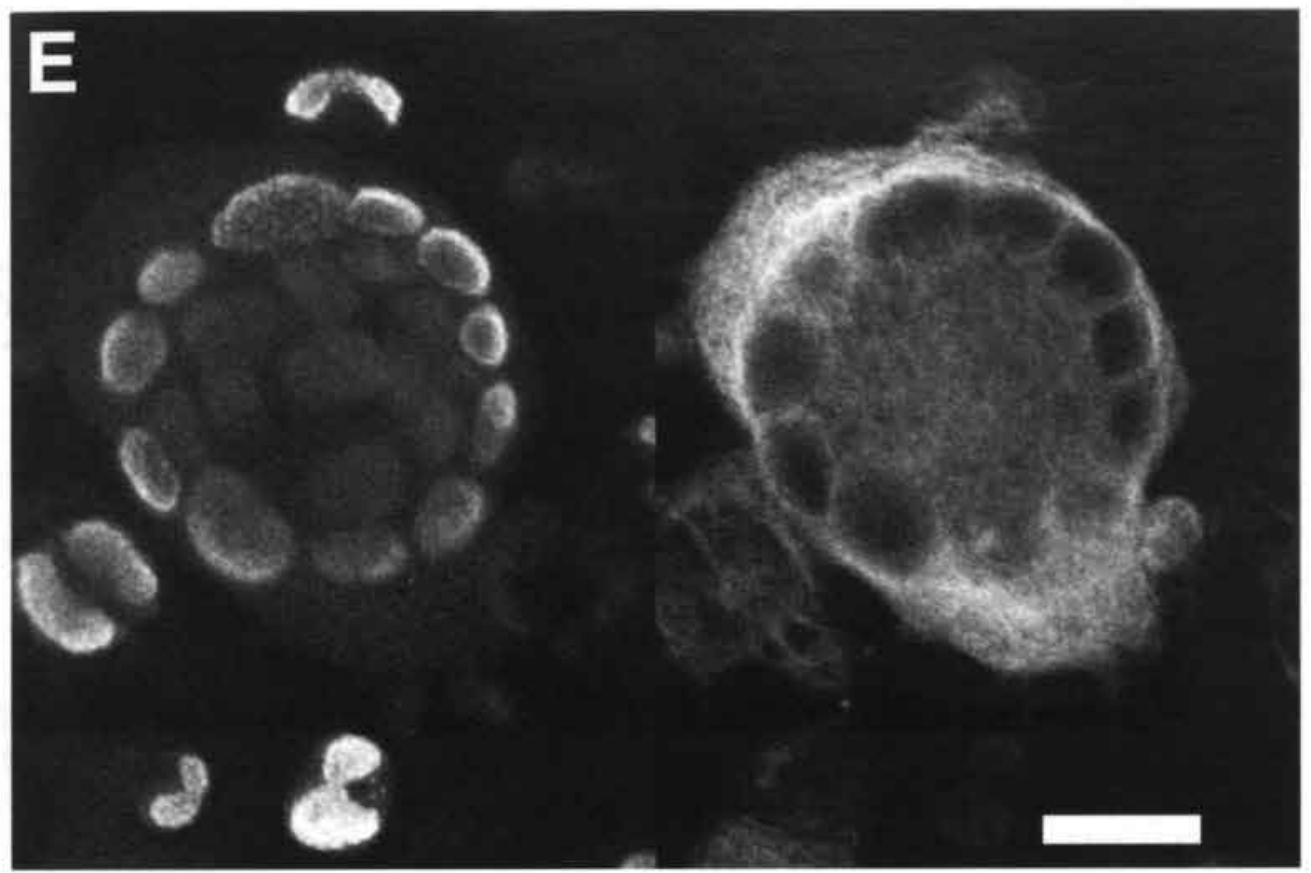

FIG. 8 - Previous page and above. RCMV R78 deletion mutants induce syncytium formation in vitro. The figure shows immunofluorescence micrographs $(\times 400)$ of uninfected REF $(A)$ and REF infected with either wo $R C M V(B), R C M V \triangle R 78 a(C)$ or $R C M V \Delta R 78 c(D)$. (E) A confocal laserscan micrograph taken from a syncytium structure in a monolayer of RCMV $\triangle R 78 \mathrm{c}$-infected REE. The scale bar indicates $20 \mu \mathrm{m}$. The left-hand frame shows the nucleic distribution of RCMV Early antigens detected by MAb RCMV 8/ anti mouse-FITC. The right-hand frame was taken of the same microscopic view and shows intracellular $f$-actin fibers that were stained with phalloidin-rhodamin (Eugene, Leiden, The Netherlands).

with $5 \times 10^{6} \mathrm{PFU}$ of either RCMV or RCMV $\Delta$ R78c. At days 4 and 21 p.i., the presence of virus in internal organs (aorta, heart, kidney, liver, lung, lymphal nodes, pancreas, salivary glands, spleen and thymus) of the infected rats was determined. At day 4 p.i., virus could be detected in $18 \%$ of the aforementioned organs in wt RCMV-infected rats, and in $9 \%$ of the organs of RCMV $\triangle R 78 \mathrm{c}$-infected rats, as determined by either plaque assay or immunohistochemistry. At this time point, the highest virus titers were found in the spleen of wt virus- or mutant virus-infected rats. In contrast to the marked differences in replication efficiency between wt and deletion mutant virus in vitro, the differences in the amount of virus recovered from either spleen (Table 3) or other organs (not shown) of infected rats were less dramatic. Neither wt, nor mutant virus could be detected in the liver, pancreas, and the salivary glands at day 4 p.i.. At 
TABLE 3. Virus titers and immunohistochemical detection of RCMV and RCMV $\triangle R 78 \mathrm{c}$ in salivary glands and spleen tissue

\begin{tabular}{|c|c|c|c|c|c|c|c|c|}
\hline \multirow{3}{*}{ Virus } & \multicolumn{4}{|c|}{ Salivary gland } & \multicolumn{4}{|c|}{ Spleen } \\
\hline & \multicolumn{2}{|c|}{ Day 4 pi. } & \multicolumn{2}{|c|}{ Day 28 p.i. } & \multicolumn{2}{|c|}{ Day 4 p.i. } & \multicolumn{2}{|c|}{ Day 28 p.i. } \\
\hline & Titer & IPOX $^{b}$ & Titer" & IPOX $^{b}$ & Titer $^{2}$ & IPOX & Titer" & IPOX \\
\hline RCMV & $<1$ & 0 & $8.6 \pm 0.3$ & 5 & $2.7 \pm 0.3$ & 2 & $<1$ & 0 \\
\hline$R C M V \triangle R 78$ & $<1$ & 0 & $8.2 \pm 0.2$ & 5 & $1.3 \pm 0.7$ & 0 & $<1$ & 0 \\
\hline
\end{tabular}

"Virus titers are shown as "log mean standard deviation ( $\mathrm{PFU}$ per ml).

"Immune peroxidase assay (IPOX) data are presented as the number of rats of which the organ tissue was found RCMV positive of five rats tested.

day 21 p.i., virus could be recovered from salivary glands of both wt RCMV- and RCMV $\Delta$ R78c-infected rats, but not from any of the other organs that were analyzed. Surprisingly, virus titers in salivary glands did not differ significantly between RCMVand RCMV $\Delta$ R78c-infected rats (Table 3 ).

In a separate in vivo experiment, the virulence of wt and mutant viruses was determined by infecting rats with potentially lethal doses of virus. To this purpose, three groups of four-week-old immunosuppressed rats were infected with $10^{6} \mathrm{PFU}$ of either RCMV, RCMV $\triangle$ R78a or RCMV $\triangle$ R78c. Surprisingly, a dramatically lower mortality was observed in the groups of RCMV $\triangle R 78 \mathrm{a}$ - and RCMV $\triangle \mathrm{R} 78 \mathrm{c}$-infected rats than in the group of RCMV-infected rats (Fig. 9). This result indicates that R78 plays an important role in the pathogenesis of RCMV infection.

\section{DISCUSSION}

Herpesviruses are known for the large size and complexity of their genomes. These encompass a vast number of genes, many of which are homologous to genes of the host organism. Beta- and gammaherpesvirus genomes contain genes homologous to GCR genes of the host. Nineteen $\beta$ - and $\gamma$ herpesvirus-encoded GCR genes have been recognized to date $(4,9,21,22,23,25,33,44,49,48,54,57,63)$. These genes can be arranged into four groups based on sequence homology, genome location and function of the respective gene product. One group (the US28 family) consists of two GCR genes: US27 and US28 (23). Both are exclusively present within an unconserved region of the HCMV genome (22). These GCRs are highly similar to mammalian chemokine receptors $(15,30)$. Although little is known about the function of the GCR encoded by US27, the HCMV US28-encoded GCR is a well studied example of a virus-encoded 


\section{O RCMV}

- RCMV $\triangle \mathrm{R} 78 \mathrm{a}$

- RCMV $\triangle \mathrm{R} 78 \mathrm{c}$

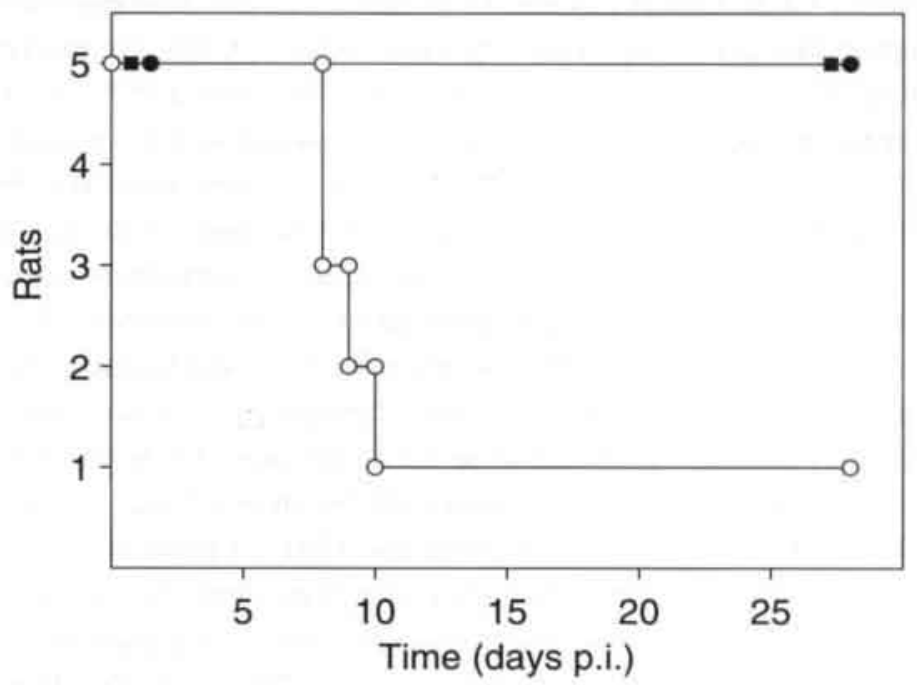

FIG 9. The R78 gene plays a vital role in RCMV pathogenesis in vivo. The graph indicates survival of three groups of immunocompromised rats after intraperitoneal inoculation with $10^{\circ} \mathrm{PFU}$ of either wt $R C M V(0), R C M V \Delta R 78 a(\bullet)$, or $R C M V \Delta R 78 c(\bullet)$. Survival was recorded up to day 28 p.i.

GCR with an immunomodulatory function. This receptor was shown to bind $\beta$ chemokines MIP1 $\alpha$, MIP1 $\beta$, RANTES, MCP-1 and MCP-3 $(14,31,47)$. Additionally, Bodaghi et al. reported that the US28 gene product modifies the chemokine environment of HCMV-infected cells through sequestering of $\beta$ chemokines by continuous internalization (15). A second group (the UL33 family) contains five GCR genes: HCMV UL33 (23), RCMV R33 (9), MCMV M33 (26), and HHV-6 and HHV-7 U12 (33, 49). Both sequence and position of these genes within their respective genomes are conserved. Similar to the US28 family, GCRs of the UL33 family were shown to be related to chemokine receptors. Previously, we reported that the predicted amino acid sequences of UL33-like receptors share more similarity with mammalian chemokine receptors than with non-chemokine receptors (9). Moreover, Isegawa et al. (38) demonstrated that one member of the UL33-family of GCRs, HHV-6 U12, is a functional $\beta$ chemokine receptor capable of binding MIP1 $\alpha$, MIP1 $\beta$, RANTES and MCP-1 (38). Although not much is known about the function of this chemokine receptor-like family, Margulies et al. were able to detect the UL33 protein in both the membranes of HCMV-infected 
cells and the envelopes of HCMV virions (43b). Additionally, both RCMV R33 and MCMV M33 genes were shown to be essential for RCMV and MCMV replication in salivary glands of infected rats and mice, respectively $(9,26)$. A third group (the gammaherpesvirus GCR family) consists of seven gammaherpesvirus-encoded chemokine receptor-like genes: Epstein-Barr virus BILF1 $(5,25)$, Herpesvirus Saimiri ECRF3 (48), Kaposi's Sarcoma-associated Herpesvirus ORF 74 (4), Murine gammaherpesvirus 68 ORF 74 (63) and Equine Herpesvirus E1, E6 and E8 (57). In contrast to GCR genes of the US28 and UL33 family, sequences of the rherpesvirus GCR family are less well conserved. However, like GCR genes of the US28 and UL33 family, they share significant similarity with mammalian chemokine receptors $(4,26$, $48,57,63$ ). The role of any of these GCRs in replication or persistence of $\gamma$ herpesviruses is unknown. To date, two members of this family have been studied in detail. The HVS ECRF3-encoded GCR was shown to be capable of binding $\alpha$ chemokines IL-8, GRO/ MGSA and NAP-2 (1). Another gammaherpesvirus-encoded GCR, the KSHV ORF 74 gene product, was demonstrated to bind both $\alpha$ (IL-8, MGSA, NAP-2 and PF-4) and $\beta$ chemokines (I-309 and RANTES). In addition, the ORF 74 protein was found to be constitutively active (4), having both oncogenic and angiogenic potential (7). A fourth, novel group of GCR genes (the UL78 family) comprises five betaherpesvirus ORFs that were recently recognized as putative GCR genes: HCMV UL78, RCMV R78, MCMV M78, and HHV-6 and HHV-7 U51 (33, 49, 54, this report). Similar to the positions of GCR genes of the UL33 family, the positions of the UL78-like genes are conserved within $\beta$ herpesvirus genomes. However, in contrast to the sequences of the UL33-like genes, the sequences of the UL78 family are poorly conserved. The predicted amino acid sequences derived from the UL78-like genes do neither significantly resemble chemokine receptors nor any other of the thousands of GCRs currently known. The assumption that UL78-like genes are GCRs is based on three characteristics: (i) the presence of 7 hydrophobic regions within the predicted amino acid sequences derived from all UL78-like genes (53), (ii) the presence of two cysteine residues within these amino acid sequences, which might be required for correct folding of the GCR polypeptide (53), and (iii) a stretch of amino acids within these amino acid sequences which bears similarity to a domain know to be required for $G$ protein-coupling (53). Consequently, the UL78 family is a novel class of orphan GCRs encoded by betaherpesviruses.

To investigate the role of the R78 gene in virus replication, RCMV strains were constructed in which the R78 gene is disrupted. These R78 deletion mutant strains were found to replicate 10 - to 100 -fold less efficiently than wt RCMV in fibroblasts and smooth muscle cells in vitro. By contrast, RCMV and MCMV strains that carry a deletion of the R33 and M33 gene, respectively, were previously found to replicate in vitro with a similar efficiency as the corresponding wt viruses $(9,26)$. A difference between these mutants and the R78 deletion mutants was also seen in vivo: both R33 and M33 deletion mutants were found to be impaired in replication in salivary glands of in- 
fected animals, whereas R78 deletion mutants were demonstrated to replicate as efficiently as wt RCMV in salivary glands. It is therefore likely that, although both R33 and R78 putatively encode GCRs, these genes exert unrelated functions.

A lower efficiency of virus replication in vitro was not only observed after deletion of the complete R78 ORF from the RCMV genome, but also after deletion of the region that encodes the putative R78 GCR C-terminus. This putative intracellular part of the protein is therefore likely to be essential for the function of the R78 protein. The Cterminus, like the DRL motif in the second intracellular domain of the R78 protein, might be essential for $\mathrm{G}$ protein-coupling and signal transduction, similar to what was found for other GCRs (53).

The RCMV R78 gene plays an important part in the pathogenesis of virus infection in vivo. This was inferred from the lower mortality that was seen among immunocompromised rats infected with either RCMV $\triangle R 78 \mathrm{a}$ or RCMV $\Delta \mathrm{R} 78 \mathrm{c}$ than among animals infected with wt virus. Although we did not find significant differences in virus replication between recombinant and wt viruses in vivo, it is possible that the decrease in virulence that is seen after disruption of the R78 gene of RCMV, is correlated with the observation that both RCMV $\triangle R 78 \mathrm{a}$ and RCMV $\triangle R 78 \mathrm{c}$ replicate less efficiently in fibroblasts and smooth muscle cells in vitro than wt virus. Similar to the R78 gene, the R33 GCR-like gene was reported to have a vital function in the pathogenesis of RCMV infection (9). It is likely that the HCMV counterparts of these genes (UL78 and UL33, respectively) have similar, important functions in the pathogenesis of HCMV infections in humans. The gene products of both UL78 and UL33 can therefore be considered as potential targets for future development of novel antiviral strategies.

The two recombinant RCMV strains described in this report induce syncytium formation in infected fibroblasts in vitro. Previously, syncytium formation has been observed in many different cell types infected with a variety of herpesvirus species: HCMV-infected human amnion cells (28), varicella-zoster virus-infected human melanoma cells (34), Epstein-Barr virus-superinfected Raji cells (8), HHV-6-infected human primary fetal astrocytes (35), HHV-7-infected T-lymphocytes (56), and RCMVinfected Rat2 cells (11). In these cases, syncytium formation appears to be associated with the cell type or MOI, since the same virus strains fail to produce these syncytium $(s y n)$ phenotypes upon infection of other permissive cell lines $(8,28,34,35)$, or after infection at lower titers $(8,56)$. Well-defined syn loci were found within genomes of a limited number of herpesvirus species, in particular within the genomes of herpes simplex type 1 (HSV-1) strains: UL20 (6), UL24 (40), UL27-gB (29), and UL53-gK (37). Some HCMV genes were likewise associated with syncytium formation. Syncytia are produced in human glioblastoma cells that constitutively express HCMV UL55-gB (59). Additionally, the chemokine receptor encoded by HCMV US28 was shown to enhance cell-cell fusion in cells constitutively expressing retroviral envelope glyco- 
proteins (52). The recombinant RCMV strains RCMV $\triangle R 78 \mathrm{a}$ and RCMV $\triangle R 78 \mathrm{c}$ are the first sym mutant CMVs reported. We postulate that functional R78-encoded GCRs transduce signals to the cellular interior, thereby creating an intracellular environment essential for the formation of protein complexes to establish intercellular junctions. In HCMV- and HSV-1-infected cells these cell-to-cell junctions are basically composed of viral glycoproteins $(27,36,43)$. Since many syn mutations are localized in herpesvirus glycoprotein genes $(29,37)$, syncytia could be generated as a result of destabilized cellto-cell contacts. The putative GCR encoded by R78 may mediate stabilization of glycoprotein complexes, directly by association with these glycoprotein complexes, or indirectly, through signal transduction to establish cell-to-cell contacts. These possible mechanism for the function of the R78 gene product will have to be addressed in future studies.

\section{ACKNOWLEDGEMENTS}

We thank Erik Beuken for cloning and sequencing of RCMV DNA. We also thank Joanne van Dam, Suzanne Kaptein and Marjorie Nelissen for processing rat organs, Jos Broers for generating the confocal laserscan micrographs and Rien Blok for critically reading the manuscript.

\section{REFERENCES}

1. Ahuja S. K., and P. M. Murphy. 1993. Molecular piracy of mammalian interleukin-8 receptor type B by herpesvirus saimiri. J. Biol. Chem. 268:20691-20694.

2. ALIGN Query using sequence data. [Online.] ALIGN program. Genestream, Institut de Génétique Humaine, Montpellier, France. http://www2.igh.cnrs.fr/bin/align-guess.cgi. [11 January, last date accessed.]

3. An S., T. Bleu, O. G. Hallmark, and E. J. Goetzl. 1998. Characterization of a novel subtype of human G protein-coupled receptor for lysophosphatidic acid. J. Biol. Chem. 273:79067910.

4. Arvanitakis, L., E. Geras-Raaka, A. Varma, M. C. Gershengorn, and E. Cesarman. 1997. Human herpesvirus KSHV encodes a constitutively active G-protein-coupled receptor linked to cell proliferation. Nature 385:347-350.

5. Baer, R. J., A. T. Bankier, M. D. Biggin, P. L. Deininger, P. J. Farrell, T. J. Gibson, G. E. Hatful, G. S. Hudson, S. C. Satchwell, C. Sequin, P. S. Tuffnell, and B. G. Barrell. 1984. DNA sequence and expression of the B95-8 Epstein-Barr virus genome. Nature 310:207-211.

6. Baines, J. D., P. L. Ward, G. Campadelli-Fiume, and B. Roizman. 1991. The UL20 gene of herpes simplex virus 1 encodes a function necessary for viral egress. J. Virol. 65:6414-6424.

7. Bais, C., B. Santomasso, O. Coso, L. Arvanitakis, E. Geras Raaka, J. S. Gutkind, A. S. Asch, E. Cesarman, M. C. Gerhengorn, and E. A. Mesri. 1998. G-protein-coupled receptor of Kaposi's sarcoma-associated herpesvirus is a viral oncogene and angiogenesis activator. Nature 391:86-89,

8. Bayliss, G. J., and H. Wolf. 1981. An Epstein-Barr virus early protein induces cell fusion. Proc. Natl. Acad. Sci. USA 78:7162-7165. 
9. Beisser, P. S., C. Vink, J. G. van Dam, G. Grauls, S. J. Vanherle, and C. A. Bruggeman. 1998. The R33 G protein-coupled receptor gene of rat cytomegalovirus plays an essential role in the pathogenesis of viral infection. J. Virol. 72:2352-2363.

10. Beisser, P. S., S. J. F. Kaptein, E. Beuken, C. A. Bruggeman, and C. Vink. 1998. The Maastricht strain and England strain of rat cytomegalovirus represent different betaherpesvirus species rather than strains. Virology 245:341-351.

11. Beisser, P. S., C. A. Bruggeman, and C. Vink. Unpublished data.

12. Beuken, E., R. Slobbe, C.A. Bruggeman, and C. Vink. 1996. Cloning and sequence analysis of the genes encoding DNA polymerase, glycoprotein B, ICP 18.5 and major DNA-binding protein of rat cytomegalovirus. J. Gen. Virol. 77:1559-1562.

13. Beuken, E., C. A. Bruggeman, and C. Vink. Unpublished data.

14. Billstrom, M. A., G. L. Johnson, N, J, Avdi, and G. S. Scott Worthen. 1998. Intracellular signalling by the chemokine receptor US28 during human cytomegalovirus infection. J. Virol. 72:5535-5544.

15. Bodaghi, B., T. R. Jones, D. Zipeto, C. Vita, L. Sun, L. Laurent, F. Arenzana-Seisdedos, J. Virelizier, and S. Michelson. 1998. Chemokine sequenstration by viral chemoreceptors as a novel viral escape strategy: withdrawal of chemokines from the environment of cytomegalovirus-infected cells. J. Exp. Med. 188:855-866.

16. Brown, T. 1993. Analysis of DNA sequences by blotting and hybridization, p. 4.2.1-4.2.15. In F.M. Ausubel, R. Brent, R.E. Kingston, D.D. Moore, J.G. Seidman, J.A. Smith, \& K. Struhl (ed.), Current protocols in molecular biology, John Wiley \& Sons, Inc., New York, N.Y.

17. Brown, T., and K. Mackey. 1997. Analysis of RNA by Northern and slot blot hybridization, p. 4.9.1-4.9.16. In F.M. Ausubel, R. Brent, R.E. Kingston, D.D. Moore, J.G. Seidman, J.A. Smith, \& K. Struhl (ed.), Current protocols in molecular biology, John Wiley \& Sons, Inc., New York, N.Y.

18. Bruggeman, C. A., H. Meijer, P. H. J. Dormans, W. H. M. Debie, G. E. L. M. Grauls, and C. P. A. van Boven. 1982. Isolation of a cytomegalovirus-like agent from wild rats. Arch. Virol. 73:231-241.

19. Bruggeman, C. A., H. Meijer, F. Bosman, and C. P. A. van Boven. 1985. Biology of rat cytomegalovirus infection. Intervirology 24:1-9.

20. Bruning, J., W. H. M. Debie, P. H. J. Dormans, H. Meijer and C. A. Bruggeman. 1987. The development and characterization of monoclonal antibodies against rat cytomegalovirus induced agents. Arch. Virol. 94:55-70.

21. Cao, J. X., P. D. Gershon, and D. N. Black. 1995. Sequence analysis of HindIII Q2 fragment of capripoxvirus reveals a putative gene encoding a G-protein-coupled chemokine receptor homologue. Virology 209:207-212.

22. Chee, M. S., A.T. Bankier, S. Beck, R. Bohni, C. M. Brown, R. Cerny, T. Horsnell, C. A. Hutchison III, T. Kouzarides, J. A. Martignetti, E. Preddie, S. C. Satchwell, P. Tomlinson, K. M. Weston and B. G. Barrell. 1990. Analysis of the protein-coding content of the sequence of human cytomegalovirus strain AD169. Curr. Top. Microbiol. Immunol. 154:125169.

23. Chee, M. S., Satchwell, S. C., Preddie, E., Weston, K. M. and Barrell, B. G. 1990. Human cytomegalovirus encodes three $\mathrm{G}$ protein-coupled receptor homologues. Nature 344:774777. 
24. Damoiseaux, J. G. M. C., E. A. Döpp, W. Calame, D. Chao, G. G. MacPherson, and C. D. Dijkstra. 1994. Rat macrophage lysosomal membrane antigen recognized by monoclonal antibody ED1. Immunology. 83:140-147.

25. Davis-Poynter, N. J., and H. E. Farrell. 1996. Masters of deception: A review of herpesvirus immune evation strategies. Immunol. Cell Biol. 74:513-522.

26. Davis-Poynter, N. J., D. M. Lynch, H. Vally, G. R. Shellam, W. D. Rawlinson, B. G. Barrell, and H. E. Farrell. 1997. Identification and characterization of a $\mathrm{G}$ protein-coupled receptor homolog encoded by murine cytomegalovirus. J. Virol. 71:1521-1529.

27. Dingwell, KS, C. R. Brunetti, R. L. Hendricks, Q Tang, M Tang, A. J. Rainbow, and D. C. Johnson. 1994. Herpes simplex virus glycoproteins E and I facilitate cell-to-cell spread in vivo and across junctions of cultured cells. J. Virol. 68:834-845.

28. Figueroa, M. E., L. Geder, and F. Rapp. 1978. Infection of human amnion cells with cytomegalovirus. J. Med. Virol. 2:369-375.

29. Gage, P. J., M. Levine, and J. C. Glorioso. 1993. Syncytium-inducing mutations localize to two discrete regions within the cytoplasmic domain of herpes simplex virus type 1 glycoprotein B. J. Virol. 67:2191-2201.

30. Gao. J. L. and P. M. Murphy. 1994. Human cytomegalovirus open reading frame US28 encodes a functional $\beta$ chemokine receptor. J. Biol. Chem. 269:28539-28542.

31. Gao, J. L., D. B. Kuhns, H. L. Tiffany, D. McDermott, X. Li, U. Franke, and P. M. Murphy. 1993. Structure and functional expression of the human macrophage imflammatory protein $1 \alpha /$ RANTES receptor. J. Exp. Med. 177:1421-1427.

32. Gerszten, R.E., J. Chen, M. Ishii, K. Ishii, T. Nanevicz, C. W. Turck, T. H. Vu, and S. R. Coughlin. 1994. Thrombin receptor's specificity for agonist peptide is determined by its extracellular surface. Nature 368:648-651.

33. Gompels, U. A., J. Nicholas, G. Lawrence, M. Jones, B. J. Thomson, M. E. Martin, S. Efstathiou, M. Craxton, and H. A. Macaulay. 1995. The DNA sequence of human herpesvirus-6: structure, coding content and genome evolution. Virology 209:29-51.

34. Harson, R., and C. Grose. 1995. Egress of varicella-zoster virus from the melanoma cell: a tropism for the melanocyte. J. Virol. 69:4994-5010.

35. He, J., M. McCarthy, Y. Zhou, B. Chandran, and C. Wood. 1996. Infection of primary human fetal astrocytes by human herpesvirus 6. J. Virol. 70:1296-1300.

36. Huber, M. T., and T. Compton. 1998. The human cytomegalovirus UL74 gene encodes the third component of the glycoprotein $\mathrm{H}$-glycoprotein L-containing envelope complex. J. Virol. 72:8191-8197.

37. Hutchinson, L., K. Goldsmith, D. Snoddy, H. Ghosh, F. L. Graham, and D. C. Johnson. 1992. Identification and characterization of a novel herpes simplex virus glycoprotein, gK, involved in cell fusion. J. Virol. 66:5603-5609.

38. Isegawa, Y., Z. Ping, K. Nakano, N. Sugimoto, and K. Yamanishi. 1998. Human herpesvirus 9 open reading frame U12 encodes a functional $\beta$-chemokine receptor. J. Virol. 72:61046112.

39. ISREC WU-BLAST server. [Online.] BLAST program, version 2.0. ISREC Bioinformatics group, Swiss Institute of Bioinformatics, Genève, Switzerland. http:/ / www.ch.embnet.org/ software/WUBLAST_form.html. [11 January 1999, last date accessed.] 
40. Jacobson, J. G., S. L. Martin, and D. M. Coen. 1989. A conserved open reading frame that overlaps the herpes simplex virus thymidine kinase gene is important for viral growth in cell culture. J. Virol. 63:1839-1843.

41. Kozak, M. 1987. An analysis of 5 -noncoding sequences from 699 vertebrate messenger RNAs. Nucleic Acids Res. 15:8125-48.

42. Kuhn, D. E., C. J. Beall, and P. E. Kolattukudy. 1995. The cytomegalovirus US28 protein binds multiple CC chemokines with high affinity. Biochem. Biophys. Res. Commun. 211:325330 .

43. Laquerre, S., R. Argnani, D. B. Anderson, S. Zucchini, R. Manservigi, and J. C. Glorioso. 1998. Heparan sulfate proteoglycan binding by herpes simplex virus type 1 glycoproteins B and $\mathrm{C}$, which differ in their contributions to virus attachment, penetration, and cell-to-cell spread. J. Virol. 72:6119-6130.

43b. Margulies, B. J., H. Browne, and W. Gibson. 1996. Identification of the human cytomegalovirus G protein-coupled receptor homologue encoded by UL33 in infected cells and enveloped virus particles. Virology 225:111-125.

44. Massung, R. F., V. Jayarama, and R. W. Moyer. 1993. DNA sequence analysis of conserved and unique regions of swinepox virus: identification of genetic elements supporting phenotypic observations including a novel $\mathrm{G}$ protein-coupled receptor homologue. Virology 197:511-528.

45. Meijer, H., J.C. Dreesen, and C. P. van Boven. 1986. Molecular cloning and restriction endonuclease mapping of the rat cytomegalovirus genome. J. Gen. Virol. 67:1327-1342.

46. Myers, E. W., and W. Miller. 1988. Optimal alignments in linear space. Comput. Appl. Biosci. 4:11-17.

47. Neote, K., D. DiGregorio, J. Y. Mak, R. Horuk, and T. J. Schall. 1993. Molecular cloning, functional expression, and signaling characteristics of a C-C chemokine receptor. Cell 72:415425 .

48. Nicholas, J., K. R. Cameron, and R. W. Honess. 1992. Herpesvirus saimiri encodes homologues of $\mathrm{G}$ protein-coupled receptors and cyclins. Nature 355:362-365.

49. Nicholas, J. 1996. Determination and analysis of the complete nucleotide sequence of human herpesvirus 7. J. Virol. 70:5975-5989.

50. Orlandi, A., H. Paul Ehrlich, P Ropraz, L.G. Spagnioli, and G. Gabbiani. 1994. Rat aortic smooth muscle cells isolated from different layers amd different times after endothelial denudation show distinct biological features in vitro. Arterioscler. Thromb. 14:982-989.

51. Parente, M.G., L. C. Chung, J. Ryynanen, D. T. Woodley, K. W. Wynn, E. A. Bauer, M. G. Mattei, M.-L. Chu, and J. Uitto. 1991. Human type VII collagen: cDNA cloning and chromosomal mapping of the gene. Proc. Natl. Acad. Sci. USA. 88:6931-6935.

52. Pleskoff, O., C. Tréboute, and M. Alizon. 1998. The cytomegalovirus-encoded chemokine receptor US28 can enhance cell-cell fusion mediated by different viral proteins. J. Virol. 72:6389-6397.

53. Probst, W.C., L. A. Snyder, D. I. Schuster, J. Brosius, and S. C. Sealfon. 1992. Sequence alignment of the G-protein coupled receptor superfamily. DNA and Cell Biol. 11:1-20.

54. Rawlinson, W. D., H. E. Farrell, and B. G. Barrell. 1996. Analysis of the complete DNA sequence of murine cytomegalovirus. J. Virol. 70:8833-8849. 
55. Stals, F. S., F. Bosman, C. P. van Boven, and C. A. Bruggeman. 1990. An animal model for therapeutic intervention studies of CMV infection in the immunocompromised host. Arch. Virol. 114:91-107.

56. Secchiero, P., Z. N. Berneman, R. C. Gallo, and P. Lusso. 1994. Biological and molecular characteristics of human herpesvirus 7 : in vitro growth optimalization and development of a syncytia inhibition test. Virology 202:506-512.

57. Telford, E. A., M. S. Watson, H. C. Aird, J. Perry, and A. J. Davison. 1995. The DNA sequence of equine herpesvirus 2. J. Mol. Biol. 249:520-528.

58. TMpred - Prediction of Transmembrane Regions and Orientation. [Online.] TMpred program. ISREC Bioinformatics group, Swiss Institute of Bioinformatics, Genève, Switzerland. http:/ / www.ch.embnet.org/software/TMPRED_form.html. [11 January 1999, last date accessed.]

59. Tugizov, S., Y. Wang, I Qadri, D. Navarro, E. Maidji, and L. Pereira. 1995. Mutated forms of human cytomegalovirus glycoprotein B are impaired in inducing syncytium formation. Virology 209:580-591.

60. Vossen, R. C. R. M., J. G. Derhaag, M. E. P. Slobbe-van Drunen, A. M. Duijvestijn, M. C. E. van Dam-Mieras, and C. A. Bruggeman. 1996. A dual role for endothelial cells in cytomegalovirus infection? A study of cytomegalovirus infection in a series of rat endothelial cell lines. Virus Res. 46:65-74.

61. Vink, C., E. Beuken, and C. A. Bruggeman. 1996. Structure of the rat cytomegalovirus genome termini. J. Virol. 70:5221-5229.

62. Vink, C., E. Beuken, and C. A. Bruggeman. Unpublished results.

63. Virgin, H. W. IV, Latreille, P., Wamsley, P., Hallsworth, K., Weck, K. E., Dal Canto, A. J., and S. H. Speck. 1997. Complete sequence and genomic analysis of murine gammaherpesvirus 68. J. Virol. 71:5894-5904.

64. Wilson, R., R. Ainscough, K. Anderson, C. Baynes, M. Berks, J. Bonfield, J. Burton, M. Connell, T. Copsey, J. Cooper, A. Coulson, M. Craxton, S. Dear, Z. Du, R. Durbin., A. Favello, L. Fulton, A. Gardner, P. Green, T. Hawkins, L. Hillier, M. Jier, L. Johnston, M. Jones, J. Kershaw, J. Kirsten, N. Laister, P. Latreille, J. Lightning, C. Lloyd, A. McMurray, B. Mortimore, M. O'Callaghan, J. Parsons, C. Percy, L. Rifken, A. Roopra, D. Saunders, R. Shownkeen, N. Smaldon, A. Smith, E. Sonnhammer, R. Staden, J. Sulston, J. ThierryMieg, K. Thomas, M. Vaudin, K. Vaughan, R. Waterston, A. Watson, L. Weinstock, J. Wilkinson-Sproat, and P. Wohldman. 1994.2.2 Mb of contiguous nucleotide sequence from chromosome III of C.elegans. Nature 368:32-38.

65. Xu, M., and R. V. Lewis. 1990. Structure of a protein superfiber: spider dragline silk. Proc. Natl. Acad. Sci. USA. 87:7120-7124.

66. Yasuda, K., K. Raynor, H. Kong, C. D. Breder, J. Takeda, T. Reisine, and G. I. Bell. 1993. Cloning and functional comparison of $\kappa$ and $\delta$ opioid receptors from mouse brain. Proc. Natl. Acad. Sci. USA. 90:6736-6740. 
$\sim$ Chapter $5 \sim$

\section{The r144 MHC Class I-Like \\ Gene of Rat Cytomegalovirus is \\ Dispensable for both Acute \\ and Long-Term Infection in the Immunocompromised Host}

PATRICK S. BEISSER, JEROEN S. KLOOVER, GERT GRAULS, MARINUS J. BLOK, CATHRIEN A. BRUGGEMAN, AND CORNELIS VINK

Department of Medical Microbiology, Cardiovascular Research Institute Maastricht (CARIM), Maastricht University, PO Box 5800, 6202 AZ Maastricht, The Netherlands

This chapter will be published in a modified form in the January 2000 edition of the Journal of Virology 
CHAPTER 5 


\section{ABSTRACT}

The rat cytomegalovirus (RCMV) r144 gene encodes a polypeptide homologous to mammalian major histocompatibility complex (MHC) class I heavy chains. The amino acid sequence derived from the RCMV r144 open reading frame shows $30 \%$ and $19 \%$ similarity with amino acid sequences encoded by murine cytomegalovirus m144 and human cytomegalovirus UL18, respectively. To study the role of r144 in virus replication in vitro as well as in vivo, an RCMV r144 null mutant strain (RCMV r144) was generated. This strain replicated with similar efficiency as wild-type (wt) RCMV in various cell lines in vitro. In addition, wt RCMV and RCMV r144 were not found to differ in their replication characteristics in vivo. First, the survival rate was similar among groups of immunosuppressed rats infected with either RCMV r144 or wt RCMV. Second, the dissemination of virus did not differ in either RCMV r144- or wt RCMV-infected, immunosuppressed rats, both in the acute phase of infection and approximately one year after infection. These data indicate that the RCMV r144 gene is neither essential for virus replication in the acute phase of infection nor for long-term infection in immunocompromised rats. Interestingly, in a local infection model in which virus was inoculated in the footpad of immunosuppressed rats, a significantly higher number of infiltrating macrophage cells as well as CD8 ${ }^{+} \mathrm{T}$ cells was observed in wt RCMV-infected paws than in RCMV r144-infected paws. This suggests that r144 might function in the interaction with these leukocytes in vivo. 


\section{INTRODUCTION}

The genomes of cytomegaloviruses (CMVs) comprise approximately 180 open reading frames (ORFs) $(17,34)$, several of which are homologous to genes of the host organism. Most of these ORFs are suspected to interfere with the immune system of the host, and encode putative chemokines (29), chemokine receptors $(5,18)$, and T-cell receptors (2). In addition, genes homologous to mammalian major histocompatibility complex (MHC) class I genes have been identified within the genomes of two CMV species: human CMV (HCMV) (1) and murine CMV (MCMV) (34).

Mammalian MHC class I proteins are members of the immunoglobulin superfamily. They are polymorphic, consisting of a membrane-bound, cell surface-expressed heavy chain, and an extracellular globulin-like light chain, $\beta_{2}$-microglobulin $\left(\beta_{2} \mathrm{~m}\right)$. Two domains of the heavy chain form a groove in which small peptides can be presented to cytotoxic T lymphocytes (CTLs) (7). These peptides are either a product of degraded cellular proteins, or derived from viral proteins that are expressed within infected cells. Upon presentation of viral peptides, CTLs can distinguish uninfected from infected cells and subsequently kill infected cells (7). Nevertheless, many viruses have evolved ways to evade CTL-mediated killing. For example, several herpesvirus proteins were shown to induce downregulation of cellular MHC class I surface expression by interfering with either synthesis or maturation of class I molecules (for reviews see references 21, 22 and 46). As a consequence, these cells can not be recognized by CTLs as being infected. Cells expressing MHC class I molecules at a low level, however, are vulnerable to lysis mediated by natural killer (NK) cells. This threat was hypothesized to be overcome by both HCMV and MCMV by the expression of homologs of MHC class I proteins (encoded by UL18 and m144, respectively), which might serve as decoys to protect infected cells from killing by NK cells $(23,35)$. Indeed, an MCMV m144 null mutant strain was shown to be attenuated during the primary phase of virus infection in mice, whereas the virulence of this mutant strain was preserved in NK cell-depleted mice (23). Recent observations indicated, however, that the expression of the HCMV UL18-encoded protein enhanced rather than inhibited NK cell-mediated cytotoxicity (28). Furthermore, the UL18 gene product was found to interact with a receptor designated ILT2 (36) or LIR-1 (19), which was found to represent the predominant receptor for the UL18 protein on leukocytes (19). Strikingly, the ILT2/ LIR-1 receptor is expressed almost exclusively on monocytes and B cells (19). Since ILT2/LIR-1 is expressed on only a minor subset of NK cells (19), the significance of a direct interaction between the UL18-encoded protein and NK cells during HCMV infection is not yet clear (28).

In this report, we present the cloning and sequencing of a third herpesvirus gene putatively encoding an MHC class I homolog, the rat CMV (RCMV) r144 gene. We show that the predicted amino acid sequence derived from the r144 ORF bears signifi- 
cant similarity to the MCMV m144-encoded protein. Furthermore, we report the generation of an RCMV mutant strain (RCMV $\mathrm{r} 144$ ) in which the r144 gene has been deleted. The replication characteristics of this strain were found to be similar to those of wild-type (wt) RCMV, both in vitro and in vivo. Interestingly, in a rat footpad infection model, an increased influx of macrophages and CD8 ${ }^{+} \mathrm{T}$ cells was observed in tissue infected with wt RCMV as compared to tissue infected with RCMV $\Delta r 144$, suggesting a role for r144 in the interaction with these leukocytes.

\section{MATERIALS AND METHODS}

Cells and virus. Primary rat embryo fibroblasts (REF), rat fibroblast cell line Rat2 TK-(ATCC CRL 1764), rat heart endothelium cell line 116 (RHEC), and monocyte/macrophage cell line R2 $(R 2 M \Phi)$ were cultured as described previously $(13,20,45)$. RCMV (Maastricht strain) was propagated in REF (13). Virus titers were determined by plaque assay using standard procedures (12). RCMV DNA was isolated from culture medium as described by Vink et al. (43).

Identification, cloning and sequence analysis of the RCMV r144 gene. Cloning of the genomic RCMV fragments EcoRI O (3.1 kb) and XbaI H (6.0 kb) (Fig. 1) has been described previously (30). Both fragments were digested with various restriction endonucleases and the resulting fragments were cloned into vector pUC119. Both strands of each clone were sequenced using the Cy5 Autoread sequencing kit (Pharmacia Biotech, Roosendaal, The Netherlands) and an ALFexpress automated DNA sequencer (Pharmacia Biotech). Sequence analysis was done using the program PC/Gene (version 2.11; IntelliGenetics). A genomic fragment which overlaps the EcoRI $\mathrm{O}$ and $\mathrm{XbaI} \mathrm{H}$ fragments was obtained by PCR using primers $5^{\prime}$ AACCGGATCCGTATCTATCGTC-3' and 5'-CAAGGATCCACGTCTTAGATATC-3'. The sequences in italics replace the original genomic sequences AGATCC and GGATGA, respectively, to introduce $\mathrm{Bam} \mathrm{HI}$ recognition sites. The resulting 383 -bp PCR product was digested with $\mathrm{BamHI}$ and cloned into pUC119, generating plasmid p094 (Fig. 1). Both strands of p094 were sequenced as described above. The procedure of PCR, cloning, and sequencing was repeated to determine whether mutations had been introduced by Taq DNA polymerase during the initial PCR. The sequences of EcoRI O, XbaI H, and p094 were checked for having homology with sequences from the Genbank nucleic acid sequence database using the BLASTX search algorithm (24).

Construction of an $\mathrm{r} 144$ recombination plasmid. The genomic RCMV DNA fragments Xbal $\mathrm{H}$ as well as EcoRI O (Fig. 1) were cloned into pUC119 to generate plasmids pRXH and pREO, respectively. A 2.0-kb DNA fragment was deleted from pRXH by treatment with Asp $718 \mathrm{I}$. The remaining $7.1-\mathrm{kb}$ fragment was circularized by incubation with T4 DNA ligase (Pharmacia Biotech), resulting in plasmid pA. Subsequently, a 2.4-kb SphI/XbaI fragment derived from $\mathrm{pREO}$ was ligated into SphI/Xbal-digested plasmid $\mathrm{pA}$, thereby generating plasmid $\mathrm{pB}$. A $1.5-\mathrm{kb}$ $B a m \mathrm{HI}$ / EcoRI fragment from Rc/CMV (Invitrogen, Leek, The Netherlands), containing the neomycin resistance gene (neo), was treated with DNA polymerase I Klenow fragment (Pharmacia Biotech) and ligated into $\mathrm{XbaI}$-digested and Klenow-treated plasmid $\mathrm{pB}$. The resulting plasmid, p081 (Fig. 3A), was used to generate virus strain RCMV $\Delta r 144$.

Generation of an RCMV $\triangle \mathrm{r} 144$ deletion mutant. The construction of an RCMV r144 deletion mutant, RCMV $\Delta \mathrm{r} 144$, was done by transfection of Rat 2 cells with $10 \mu \mathrm{g}$ of linearized plas- 
mid p081, followed by RCMV infection and plaque purification, similarly as described earlier $(3,5)$.

Southern blot hybridization. DNA was isolated from wt RCMV and RCMV $\mathrm{r} 144$, and digested with various restriction endonucleases. Subsequently, the DNA was electrophoresed through $1 \%$ agarose gels and blotted onto Hybond $\mathrm{N}^{*}$ nylon membranes (Amersham, 'sHertogenbosch, The Netherlands), as described previously (10). Both a 3.1-kb insert from pREO, containing a large part of the r144 ORF (REO probe), and a 1.5-kb BamHI-EcoRI fragment containing the neo gene (neo probe) from Rc/CMV were used as probes (Fig. 3B). Hybridization and detection experiments were performed with digoxigenin DNA-labeling and chemoluminescence detection kits (Boehringer Mannheim, Almere, The Netherlands).

Replication of RCMV $\triangle \mathrm{r} 144$ in vitro. REF, RHEC, and R2MF were grown in 96-well microtiter plates and infected with either wt RCMV or RCMV $\Delta$ r144 at an MOI of either 0.01 or 1 . Culture medium samples (three per virus) were taken at day $1,3,5$ and 7 p.i., and subjected to plaque titer determination. The cells were fixed and stained with monoclonal antibodies (MAb) against an RCMV early gene product (RCMV 8 [14]). The degree of infection was determined by counting the number of antigen-positive cells relative to the total number of cells in three different wells (four microscopic fields per well at a magnification of $\times 400$ ).

Survival of immunocompromised rats infected with either wt RCMV or RCMV $\Delta r 144$. Male specific-pathogen-free Lewis/N RT1 rats (Central Animal Facility, University of Maastricht, Maastricht, The Netherlands) were used in all in vivo experiments. Rats were immunosuppressed 1 day before infection by $5 \mathrm{~Gy}$ of total-body Röntgen irradiation, as described by Stals et al. (39). All virus stocks that were used for inoculation in vivo were derived from tissue culture medium of virus-infected REF. Four-week-old rats (100 to $120 \mathrm{~g}$ ) were divided into two groups of five rats. Intraperitoneal infection was carried out with $1 \times 10^{6}$ plaque-forming units (PFU) of either wt RCMV or RCMV $\Delta$ r144. The number of surviving rats was recorded daily until day 28 p.i.

Dissemination of wt RCMV and RCMV $\triangle \mathrm{r} 144$ in vivo. Two groups of 10 rats ( 10 weeks old, 250 to $300 \mathrm{~g}$ ) were immunosuppressed, and infected with $5 \times 10^{6} \mathrm{PFU}$ of either RCMV or RCMV $\Delta r 144$, similarly as described above. On days 4 and 21 p.i., five rats from each group were sacrificed, and their internal organs were collected. These organs were subjected to both plaque assay and immunohistochemistry (12). Tissue sections $(4 \mu \mathrm{m})$ of the submaxillary salivary gland, spleen, kidney, liver, lung, heart, pancreas, thymus, aorta and servical lymph nodes were stained with MAb RCMV 8.

Additionally, two groups of five rats ( 6 weeks old, 160 to $200 \mathrm{~g}$ ) were immunosuppressed, and infected with $1 \times 10^{\circ} \mathrm{PFU}$ of either wt RCMV or RCMV $\Delta \mathrm{r} 144$, similarly as described above. The rats were sacrificed at day 330 p.i. and various tissues and organs (see below) were collected.

PCR. Total cellular DNA was extracted from various tissues and organs (salivary gland, spleen, kidney, liver, lung, heart, pancreas, thymus, aorta, servical lymph nodes, blood leukocytes and tibiairy bone marrow) of immunosuppressed, wt RCMV- or RCMVAr144-infected rats, at day 330 p.i.. DNA was purified using an XTRAX DNA extraction kit (Gull Laboratories, Salt Lake City, Utah). The DNA samples were subjected to a single-tube, nested PCR. The primers used in this PCR hybridized with the RCMV r122-123 major immediate early gene (4). The sequences of the primers are 5'-CCAGAGTGACGTTGCAGATGTTGGAAATCA-3' (primer 
RIE3F, representing nucleotides 3425 to 3454 of GenBank accession no. AF046125), 5'GGTCACGACCCTGCTGCCGTCTAGGT-3' (primer RIE3R2, representing a sequence complementary to nucleotides 3719 to 3744 of AF046125), 5'-ATGAAATGGTGATGAGAT-3' (primer RIE4F, representing nucleotides 3461 to 3478 of AF046125) and 5'-CTTCTAGTGATTTGGCAT-3' (primer RIE4R, representing a sequence complementary to nucleotides 3686 to 3707 of AF046125). The reaction mixtures $(50 \mu \mathrm{l})$ contained $1 \mu \mathrm{g}$ of target DNA, $0.05 \mu \mathrm{M}$ of both primer RIE3F and RIE3R2, $1 \mu \mathrm{M}$ of both primer RIE4F and RIE4R, $100 \mu \mathrm{M}$ of each dNTP, $1.25 \mathrm{U}$ of HotStarTaq DNA polymerase (QIAGEN, Leusden, The Netherlands), and HotStarTaq DNA polymerase buffer (QIAGEN). The reaction tubes were placed in a GeneAmp PCR System 9600 thermal cycler (Perkin-Elmer, Nieuwerkerk aan de IJssel, The Netherlands), which was programmed to incubate the samples for $15 \mathrm{~min}$ at $95^{\circ} \mathrm{C}$, followed by 30 cycles of $30 \mathrm{~s}$ at $95^{\circ} \mathrm{C}, 30 \mathrm{~s}$ at $70^{\circ} \mathrm{C}$, and $30 \mathrm{~s}$ at $72^{\circ} \mathrm{C}$, and $25 \mathrm{cycles}$ of $30 \mathrm{~s}$ at $95^{\circ} \mathrm{C}, 30 \mathrm{~s}$ at $55^{\circ} \mathrm{C}$, and $30 \mathrm{~s}$ at $72^{\circ} \mathrm{C}$. Finally, the tubes were incubated for $5 \mathrm{~min}$ at $72^{\circ} \mathrm{C}$. PCR products were analyzed by agarose gel electrophoresis and ethidium bromide staining.

Infection of rat footpads. To induce a local infection, 6-week-old, immunosuppressed rats (120 to $140 \mathrm{~g}$ ) were injected subcutaneously with $1 \times 10^{5} \mathrm{PFU}$ (in a volume of $0.2 \mathrm{ml}$ ) of either wt RCMV or RCMV $\triangle \mathrm{r} 144$ in the dorsum of the right hind paw, similarly as described previously (33). As a control, supernatant from mock-infected REF cultures was injected in the left hind paw of the rats. Each experimental group consisted of 5 animals. The thickness of the rat paws was measured daily, as described by Persoons et al. (33). Rats were sacrificed at either day 4,8 or 15 after infection. Sections $(4 \mu \mathrm{m})$ of the hind paws were investigated by indirect immunohistochemistry using the following monoclonals: RCMV 8 (see above)(14), Anti-rat LFA-1 L chain (clone WT.1; R\&D systems, Abongdon, UK), Anti-rat CD49d (VLA-4) (clone P12520; Pharmingen, San Diego), Anti-rat CD11b (a macrophage marker) (clone MRC OX-42; Serotec Ltd., Oxford, UK), Anti-rat CD8 (clone OX8; Harlan Sera-Lab Ltd., Sussex, UK), Anti-rat CD4 (clone W3/25; Harlan Sera-Lab Ltd.) and MoAb 323 (directed against NK cells) (15). The number of positively stained cells was determined by counting the number of positive cells per field of view (high power field [HPF]; magnification $\times 400$ ). Two representative fields were independently scored per section. Data are presented as mean \pm standard error of mean (SEM). The significance of the differences was determined by the Mann-Whitney U-Wilcoxon Rank Sum W test. P values < 0.05 were considered to indicate statistical significance.

Nucleotide sequence accession number. The sequence of the RCMV genome spanning from EcoRI O to XbaI H, which contains the r144 ORF (Fig. 1), and the predicted amino acid sequence derived from r144, have been deposited in the GenBank database under accession no. AF133339.

\section{RESULTS}

Identification, cloning, and sequence analysis of the RCMV $\Delta r 144$ gene. Previously, it was shown that the majority of RCMV genes is collinear with genes of both HCMV and MCMV $(3-6,43,44)$. However, the genes of HCMV and MCMV encoding MHC class I homologs are localized within dissimilar regions of their respective genomes $(17,34)$. Since previously described RCMV genes were found to share more sequence similarity with the corresponding genes of MCMV than of HCMV (3-6), we 
$50 \mathrm{~kb}$

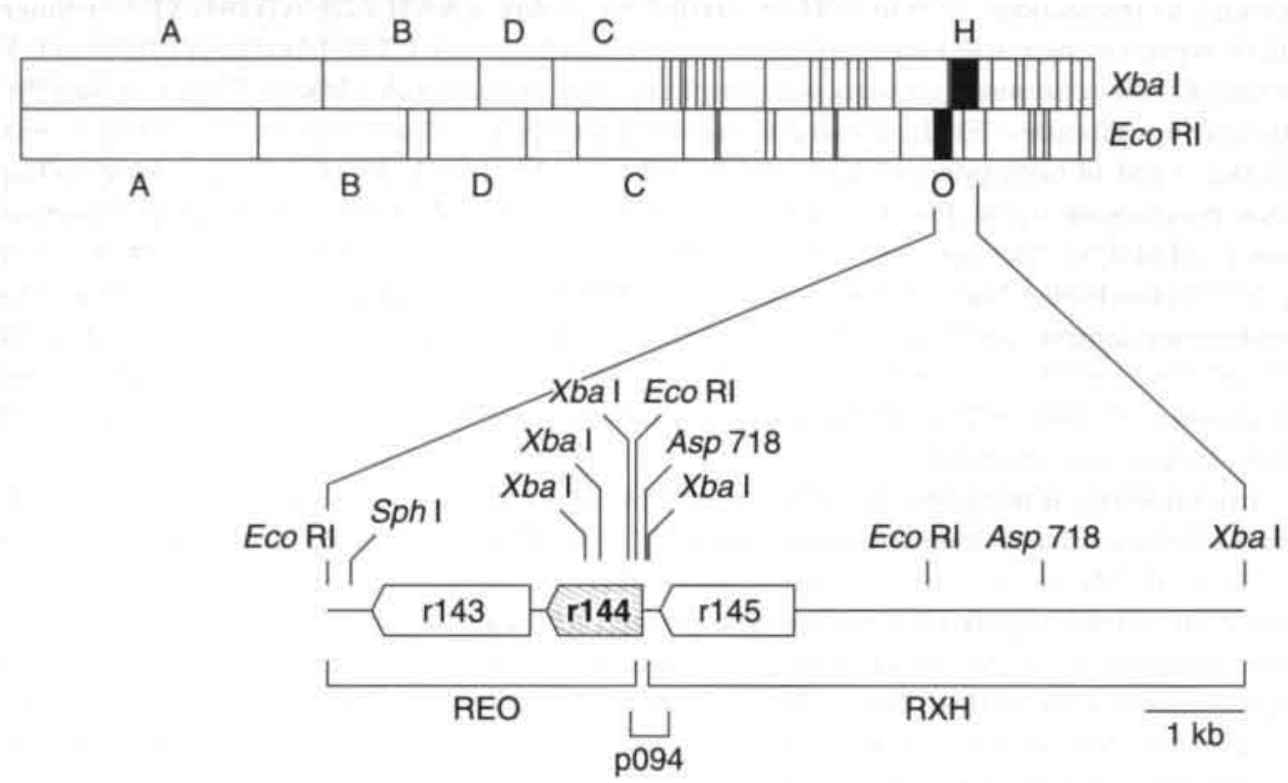

FIG. 1. Restriction map of the RCMV genome (30) and the relative position of the r144 gene, which putatively encodes an MHC class I homolog. A section of this map has been enlarged below the main map. White arrow boxes indicate the size and polarity of the RCMV ORFs surrounding the r144 ORF (hatched).

hypothesized that a putative RCMV gene homologous to MHC class I genes would be located in a genomic region similar to that of MCMV m144. Accordingly, we focused on a 20-kb region of the RCMV genome spanning from the EcoRI I fragment to the $\mathrm{Xbal} \mathrm{P}$ fragment (30) (Fig. 1). The sequence of each of the cloned fragments from this region was determined and screened for homology with sequences in the GenBank database. Thus, a 3.1-kb EcoRI fragment was identified, RCMV EcoRI O (REO), showing significant similarity with the MCMV m144 gene. Based on the similarity found between REO and the MCMV m144 gene, we hypothesized that REO only contained the 3'-terminal $90 \%$ of an RCMV ORF potentially encoding an MHC class I-like protein. Since the RCMV genomic DNA fragment adjacent to REO, XbaI H (RXH) (Fig. 1), was not found to have sequence similarity with class I genes, we anticipated that the region containing the 5'-terminal part of the MHC class I-like ORF might be located in a region between $\mathrm{REO}$ and $\mathrm{RXH}$, which was not yet cloned. To clone this region using PCR, two oligonucleotide primers were designed which would allow amplification of 
FIG. 2 - Next pages. Alignment of mammalian MHC class I proteins and virus-encoded class I homologs. (A) To compare the sequences of viral and mammalian MHC class I(-like) proteins, a CLUSTAL $W(41)$ multiple sequence alignment was generated. In the alignment, a PAM250 protein distance matrix was included. Pairwise alignment gap penalty $=3$. Multiple alignment gap penalty $=10$, gap extension penalty $=10$. Signal peptides, transmembrane domains, and potential glycosylation sequences (NXT/S) are enclosed in white boxes. Conserved cysteine residues, potentially engaged in disulphide bridge formation, are enclosed in black boxes. A schematic representation of the secondary peptide structure is shown below the sequences. $\alpha$-Helices are indicated as black arrows, $\beta$-sheets as white arrows. The positions of these structures were derived from an entry of the Brookhaven protein structure database (PDB) (31), containing the structure of recombinant HLA-A2 (8). (B) Three-dimensional orientation of both HLA$A 2 \alpha 1$ and $\alpha 2$ and the potential $\alpha 1$ and $\alpha 2$ domains of either HCMV gpUL18, MCMV gpm144, and RCMV gpr144. The gpr144 and gpm144 proteins were combined in a single drawing (gpr144/gpm144), since their predicted structures were highly similar. The predicted amino acid sequences of the proteins were modeled around the $\alpha$-carbon skeleton of HLA-A2 to indicate the gaps that were introduced by multiple sequence alignment. The images were generated by using Swiss-PdbViewer (40) and POV-Ray Tracer Version 3.1 (32). (C) A phylogenetic tree of all known virus-encoded class I MHC homologs and three mammalian MHC class I proteins. The tree was based on a multiple sequence alignment of the complete predicted amino acid sequences of gpr144, gpm144 (34), gpUL18 (1), molluscum contagiosum virus $(\mathrm{MCV})$ type 1 and $2 \mathrm{MCO} 0 \mathrm{R}(37,38)$, and three mammalian MHC class I proteins, rat RT1.Al (26), murine $H 2-K^{4}(27)$, and human $H L A-A 2$ (8). The alignment parameters were similar to the parameters described in $(A)$.

a region of the RCMV genome that links REO to RXH. By using these primers and RCMV DNA in PCR, a 383-kb product was generated. The sequence of this PCR fragment revealed that REO and RXH are separated by a 129-bp EcoRI-XbaI fragment. As expected, this fragment contains the 5'-terminal part of an ORF which putatively encodes an MHC class I-like protein. Thus, a 963-bp ORF of RCMV was identified (Fig. 1), which has the potential to encode a 321 -amino acid polypeptide with a predicted molecular mass of $36 \mathrm{kD}$. The sequence of this polypeptide shows $30 \%$ and $19 \%$ similarity with the amino acid sequences encoded by MCMV m144 and HCMV UL18, respectively. Analogous to the nomenclature of the corresponding MCMV gene, the 963-bp ORF was termed r144. We defined the putative gene products of r144, m144, and UL18 as gpr144, gpm144, and gpUL18, respectively. The prefix 'gp' (glycoprotein) was used to address the potential glycosylated state of these putative gene products.

Analysis of the predicted amino acid sequence of gpr144. The predicted amino acid sequence of the r144-derived protein was compared with sequences from a representative set of mammalian MHC class I polypeptides (rat strain Lewis RT1.AI [26], mouse strain BALB/c H2-Kd [27] and human HLA-A2 [25]) as well as the amino acid sequences derived from MCMV m144 (34) and HCMV UL18 (1). The sequences of these polypeptides were included in a CLUSTAL W multiple alignment. As shown in Fig. 2A, four cysteine residues are conserved between the gpr144, gpm144, gpUL18 


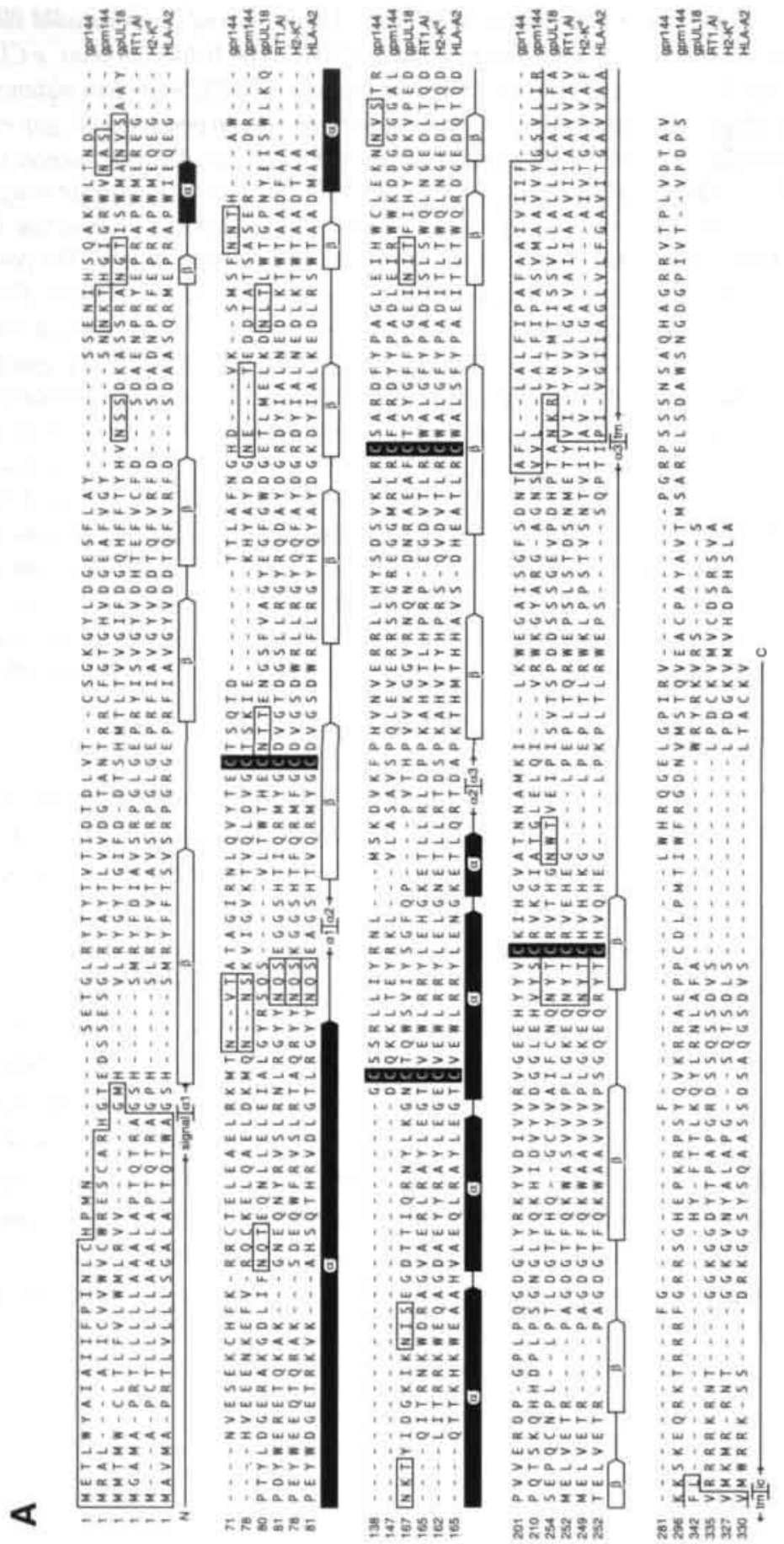




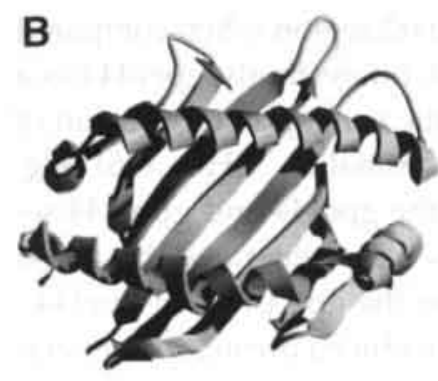

HLA-A2

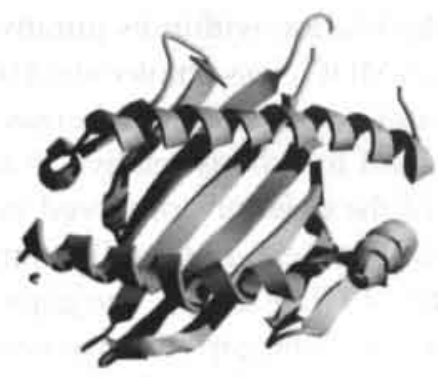

gpUL18

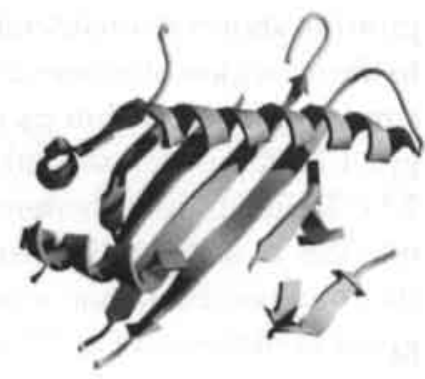

gpr144/gpm144

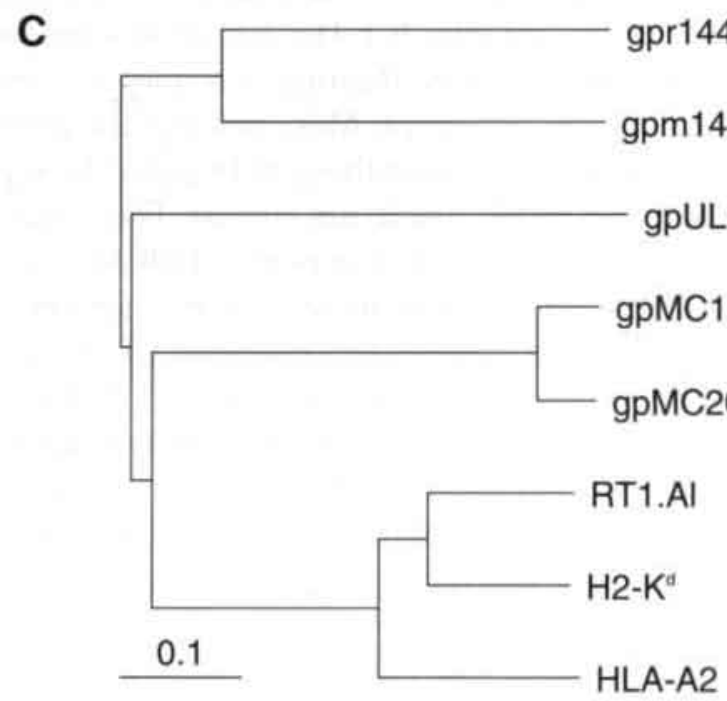

and mammalian MHC class I polypeptides. These conserved cysteines, which might play a role in disulphide bridge formation (8), are located at positions 111, 139, 176 and 235 of gpr144. Within the gpr144 sequence, three putative N-linked glycosylation sites are present. One of these sites, at position 95 to 97 , is positionally conserved between gpr144, gpm144 and mammalian class I proteins.

Based on the alignment in Fig. 2A, the putative r144 gene product, as well as the UL18- and m144-encoded proteins (21), can be assigned a similar domain structure as was previously determined for human HLA-A2. The HLA-A2 protein was found to consist of 6 domains: (i) a putative $\mathrm{N}$-terminal leader sequence, (ii) an $\alpha 1$ domain, (iii) an $\alpha 2$ domain, (iv) an immunoglobulin-like $\alpha 3$ domain, (v) a putative transmembrane $\alpha$-helix region, and (vi) a short intracellular region (8). It was previously shown that 
gpm144 shows a considerable deletion within its putative $\alpha 2$ region when compared to the $\alpha 2$ region of mammalian MHC class I molecules (16). Interestingly, gpr144 has a similar deletion within its putative $\alpha 2$ domain, whereas the corresponding region of gPUL18 comprises several small insertions relative to mammalian MHCs (16) (Fig. 2A). To illustrate the extent of the deletions observed in the gpr144 and gpm144 sequences in a three-dimensional context, ribbon diagrams were generated, based on the $\alpha$-carbon backbone model of HLA-A2 (8). The gaps in the gpUL18 and gpr144/ gpm144 ribbons in Fig. 2B represent the gaps that were introduced during the generation of the multiple alignment shown in Fig. 2A.

In order to show the relationship between the sequences of all known virus-encoded MHC class I homologs and those of several mammalian class I molecules, a phylogenetic tree was constructed (Fig. 2C). This tree shows that the mammalian class I molecules represent the most conserved group of sequences, whereas the virus-encoded homologs are relatively divergent. Most notably, the phylogenetic distances between the gPUL18 sequence and either the gpr144/gpm144 or poxvirus MHC-like sequences (gpMC1080R and gpMC2080R) are similar. This suggests that incorporation of a UL18-like gene into an ancestral genome of HCMV on the one hand, and incorporation of an r144/m144-like gene in an ancestral genome of both RCMV and MCMV on the other hand, were independent evolutionary events. This theory is underscored by the observation that the relative position of UL18 within the HCMV genome differs from that of both $\mathrm{r} 144$ and $\mathrm{m} 144$ within their respective genomes.

Generation of an RCMV r144 null mutant. To investigate the role of r144 in RCMV replication, we constructed a recombinant RCMV strain (RCMVAr144), in which the r144 gene was partially deleted and replaced by the neo gene (Fig. 3A). Subsequent to plaque purification, the purity and integrity of the recombinant strain were checked by Southern blot analysis. Virion DNA from both RCMV and RCMV $\Delta$ r144 was digested with various restriction endonucleases, electrophoresed, and transferred to a

FIG. 3 - Next page. Construction of an RCMV strain in which the r144 gene is disrupted. (A) The RCMV genome, of which the part containing the r144 ORF is shown at the top, was modified by homologous recombination with a recombination plasmid (bottom), resulting in RCMVAr144. ORFs are shown as arrow boxes. Wild-type and mutated r144 sequences are indicated with descending hatches. The neo gene that was inserted in the recombination plasmids is indicated with ascending hatches. (B) DNA from wt RCMV and RCMVAr144 was digested with NcoI and Scal, electrophoresed, blotted, and hybridized with probes derived from either the genomic REO fragment or the neo gene (both probes indicated as black boxes). ORFs are shown as arrow boxes. Wild-type and mutated r144 ORFs are indicated by descending hatches. The neo gene is indicated by ascending hatches. (C) An autoluminograph of a Southern blot containing wt RCMV (w) DNA, and RCMV $\triangle$ r144 () DNA. The estimated lengths of the detected NcolScal-digested DNA fragments are indicated at the sides. 

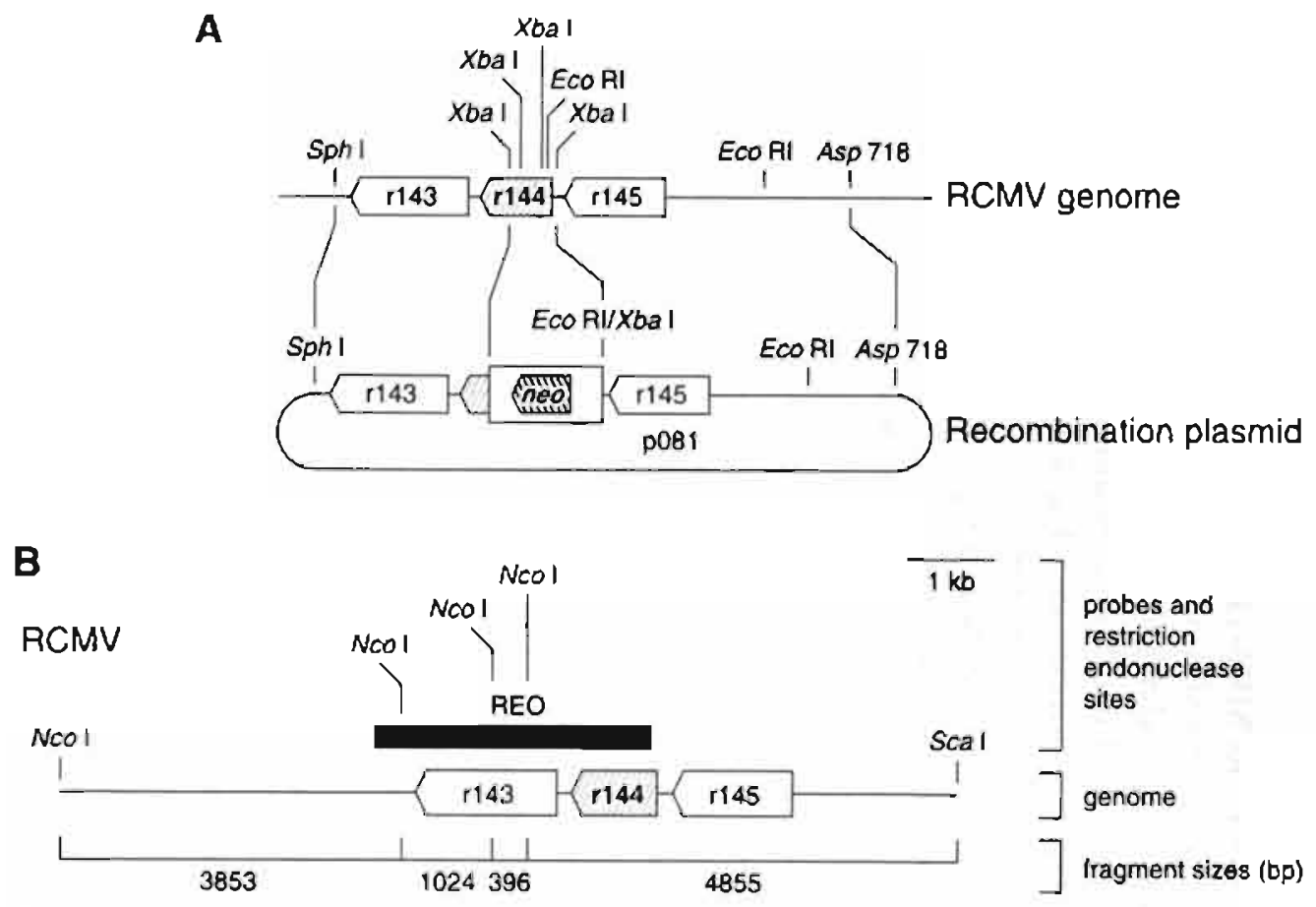

\section{probes ano}

restriction

endonuclease

siles

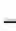

genome

Jragment sizes (bp)
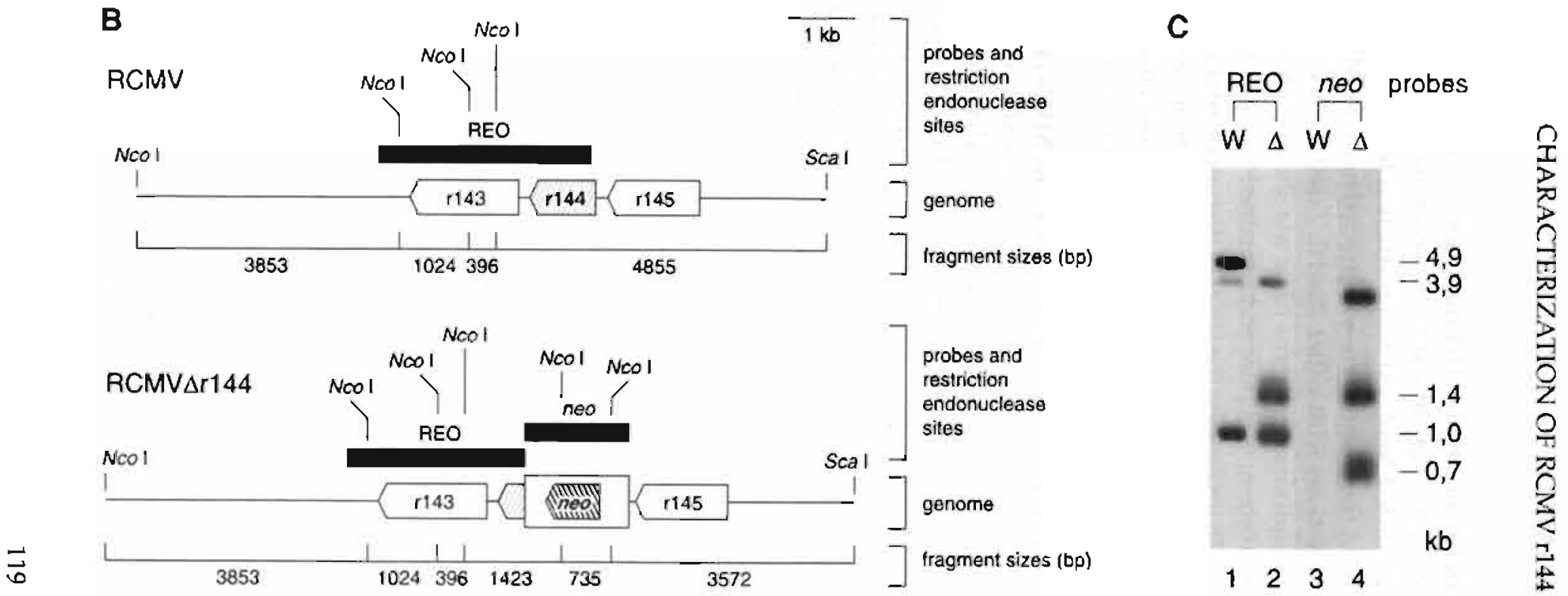
nylon membrane. Hybridization was done with either r144- or neo-specific probes. As shown in Fig. 3B and C, the observed hybridization signals correspond exactly to the predicted $\mathrm{NcoI}$ and ScaI restriction fragments. In addition, contaminating wt RCMV DNA fragments were not detected in the RCMV $\Delta$ r144 DNA (Fig. 3C, lane 2). Similarly, digestions with either BamHI, EcoRI, EcoRV, NcoI or PstI also yielded the expected hybridization patterns (data not shown). These findings indicated that the recombinant strain was pure and contained the appropriate mutation.

To investigate the effect of disruption of the r144 gene on transcription of its neighboring genes, poly (A)* RNA isolated from RCMV-, RCMV $\Delta \mathrm{r} 144$ - and mock-infected REF was subjected to Northern analysis. This indicated that there are no significant differences between RCMV $\mathrm{r} 144$ and wt virus in transcription of ORFs neighboring r144 (data not shown).

Replication characteristics of RCMV $\Delta \mathrm{r} 144$ in vitro. To compare the replication characteristics of RCMV $\Delta \mathrm{r} 144$ with those of wt RCMV in vitro, we infected three different cell types with these viruses, and determined the percentage of infected cells at various time-points after infection. In addition, the amount of infectious virus that was produced by each cell type was investigated. Fig. 4 (upper panel) shows that the percentage of infected cells did not differ significantly between wt RCMV- and RCMV $\Delta$ r144-infected cells, irrespective of the cell type. Moreover, no significant differences were seen between wt and recombinant virus in the virus titers produced by each cell type (Fig. 4, lower panel). These data indicate that r144 is not essential for RCMV replication in REF, RHEC, and R2M $\Phi$ in vitro. Similar results have previously been reported for both UL18-deleted HCMV (11) and m144-deleted MCMV (23).

In vivo RCMV $\Delta \mathrm{r} 144$ infection. As described previously, infection of immunocompetent rats with RCMV generally results in asymptomatic infections in which the virus can be detected almost exclusively in the salivary glands (12). By contrast, RCMV infection of immunocompromised animals usually leads to disease in which viral replication can be observed in many organs and tissues of the rats $(3,5,12,39)$. Consequently, in order to investigate the role of r144 in the pathogenesis of RCMV disease, we infected rats with either wt RCMV or RCMV $\Delta \mathrm{r} 144$ after the induction of immunosuppression by total body Röntgen irradiation. In an initial experiment, 4-week-old, immunosuppressed rats were inoculated with $1 \times 10^{6} \mathrm{PFU}$ of either wt RCMV or RCMV $\Delta \mathrm{r} 144$. The number of surviving rats in each group was monitored until day 28 p.i. (Fig. 5). Surprisingly, no significant difference was seen in the survival rate of groups of rats infected with either wt RCMV or recombinant virus.

In order to compare the dissemination of RCMV $\mathrm{r} 144$ with that of wt RCMV, we infected two groups of 10-week-old, immunosuppressed rats with $5 \times 10^{6} \mathrm{PFU}$ of either wt RCMV or RCMV $\Delta \mathrm{r} 144$. At days 4 and 21 p.i., the presence of virus in several internal organs was determined by both plaque assay and immunohistochemistry. As summarized in Table 1, no significant differences between wt RCMV and RCMVAr144 


\section{- RCMV}

- RCMV $\Delta$ r144
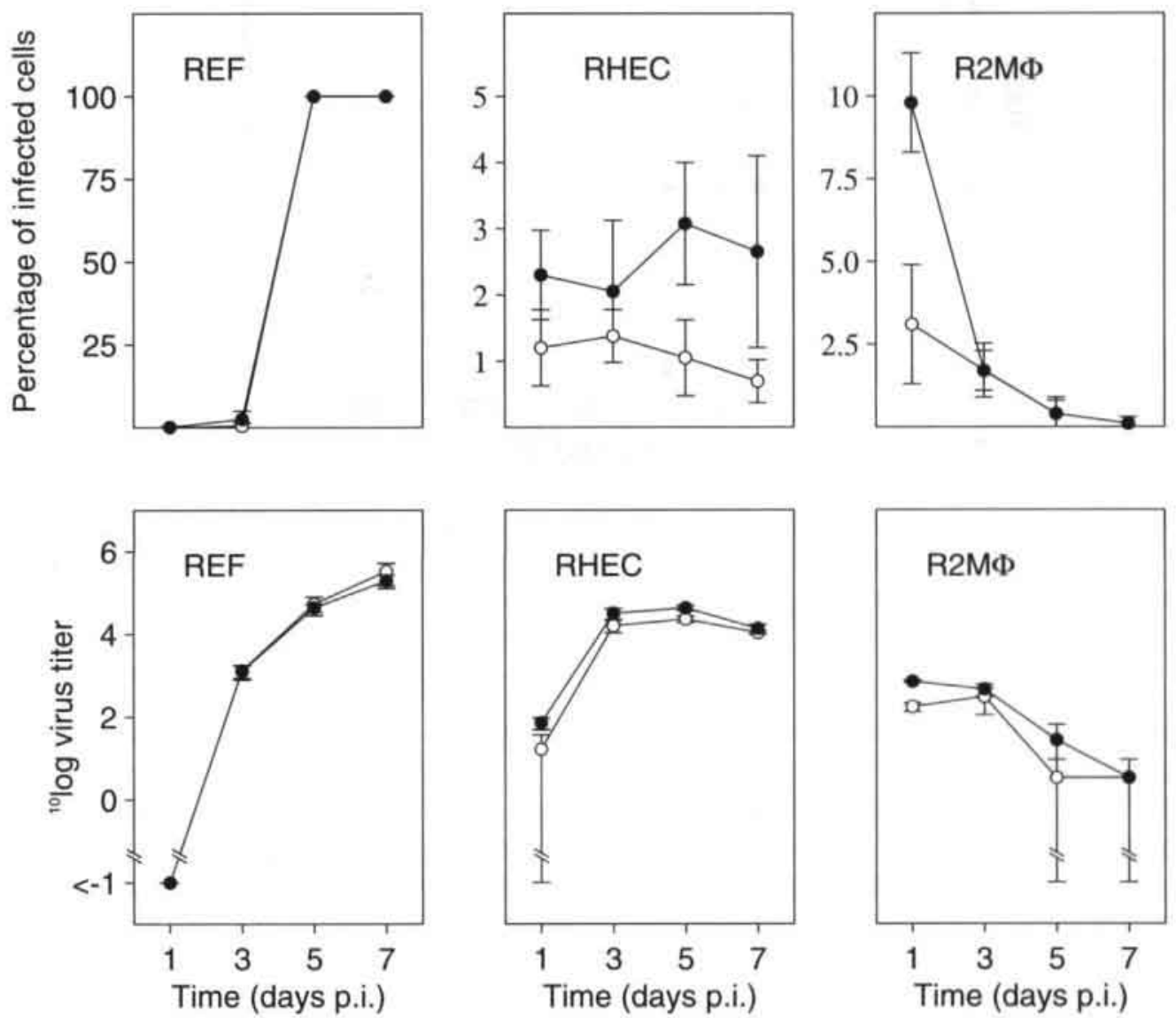

FIG. 4. The r144 gene is dispensable for RCMV replication in various cell lines in vitro. Rat embryo fibroblasts (REFs) were infected at an MOI of 0.01 with either wt RCMV or RCMVAr144. Rat heart

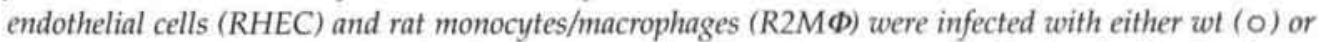
mutant virus (•) at an MOI of 1 . The upper graphs show the percentage of infected cells. The lower graphs show virus titers that were determined in culture medium up to 7 days p.i. Standard deviations are indicated by vertical bars. 
- RCMV

- RCMV $\Delta r 144$

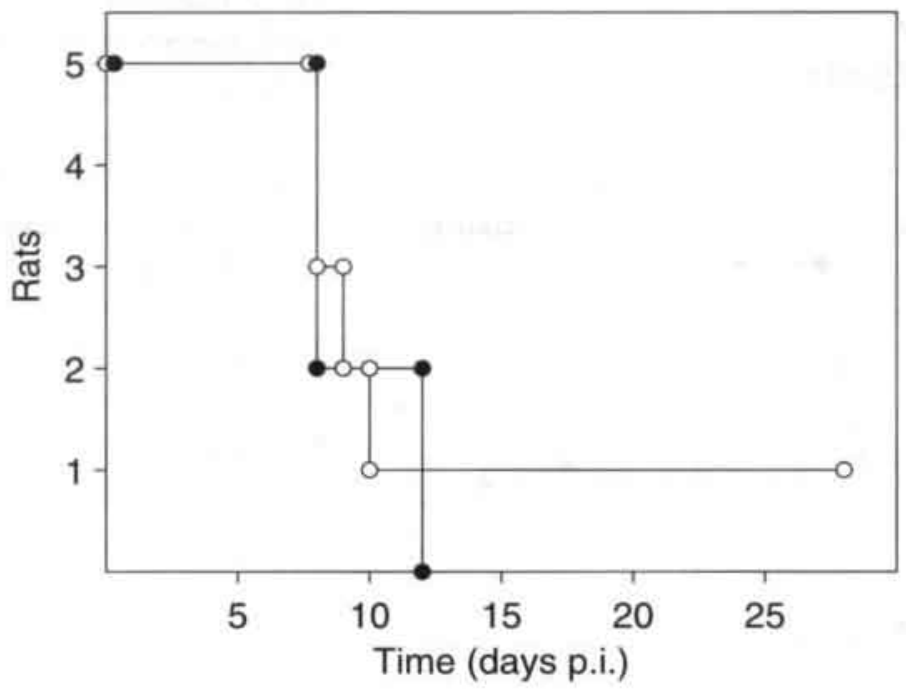

FIG. 5. The r144 gene is dispensable for primary RCMV infection in vivo. The graph indicates survival of two groups of immunosuppressed rats after intraperitoneal inoculation with $1 \times 10^{\circ}$ PFU of either wt RCMV (O) or RCMVAr144 (•). Survival was recorded up to day 28 p.i.

were observed in tissue distribution of virus at either day 4 or 21 p.i.. To exclude the possibility of RCMV $\Delta \mathrm{r} 144$ being overgrown by wt RCMV in vivo, due to either contamination or insufficient plaque purification, infectious virus was recovered from salivary glands of wt virus- and recombinant virus-infected rats at day 21 p.i. by cell culture. DNA was isolated from extracellular virions and subsequently analyzed by Southern blot hybridization. As expected, the results illustrated the integrity of the genomes of both wt and recombinant virus (data not shown).

Dissemination of RCMV $\Delta \mathrm{r} 144$ at day 330 p.i. Although differences between wt and recombinant virus were not seen during the acute phase of infection, we considered the possibility that disruption of the RCMV $\Delta \mathrm{r} 144$ gene might have an effect on long-term, persistent or latent infection of rats. To investigate dissemination of virus at a late stage of infection, our conventional tests to screen for either the presence of infectious virus (plaque test) or viral gene expression (immunohistochemistry) were not suitable for two main reasons. First, infectious RCMV is no longer produced after the establishment of latency, and second, the monoclonal that we use to detect viral gene expression (RCMV 8) is directed against a protein that is not expressed during 
TABLE 1. Dissemination of wt RCMV and RCMV $\mathrm{r} 144$ in various organs of infected rats.

\begin{tabular}{|c|c|c|c|c|c|c|c|c|c|c|}
\hline \multirow{3}{*}{ Organ } & \multicolumn{4}{|c|}{$\operatorname{IPOX}(\%)^{\circ}$} & \multicolumn{4}{|c|}{ Plaque assay $(\%)^{*}$} & \multirow{2}{*}{\multicolumn{2}{|c|}{$\begin{array}{c}\text { PCR }(\%)^{*} \\
\text { day } 330 \text { p.i. }\end{array}$}} \\
\hline & \multicolumn{2}{|c|}{ day 4 p.i. } & \multicolumn{2}{|c|}{ day 21 p.i. } & \multicolumn{2}{|c|}{ day 4 p.i. } & \multicolumn{2}{|c|}{ day 21 p.i. } & & \\
\hline & $W^{t}$ & $\Delta^{b}$ & $\mathrm{~W}^{b}$ & $\Delta^{b}$ & $\mathrm{~W}^{b}$ & $\Delta^{t}$ & $\mathrm{w}^{b}$ & $\Delta^{b}$ & $W^{t}$ & $\Delta^{\prime \prime}$ \\
\hline Salivary gland & $0 / 5$ & $0 / 5$ & $5 / 5$ & $5 / 5$ & $0 / 5$ & $0 / 5$ & $5 / 5$ & $5 / 5$ & $3 / 3$ & $4 / 5$ \\
\hline Spleen & $5 / 5$ & $2 / 5$ & $0 / 5$ & $0 / 5$ & $5 / 5$ & $4 / 5$ & $0 / 5$ & $0 / 5$ & $0 / 3$ & $4 / 5$ \\
\hline Kidney & $0 / 5$ & $0 / 5$ & $0 / 5$ & $0 / 5$ & $2 / 5$ & $1 / 5$ & $0 / 5$ & $1 / 5$ & $1 / 3$ & $2 / 5$ \\
\hline Liver & $0 / 5$ & $0 / 5$ & $0 / 5$ & $0 / 5$ & $0 / 5$ & $2 / 5$ & $0 / 5$ & $1 / 5$ & $3 / 3$ & $5 / 5$ \\
\hline Lung & $1 / 5$ & $0 / 5$ & $0 / 5$ & $0 / 5$ & $0 / 5$ & $0 / 5$ & $0 / 5$ & $1 / 5$ & $1 / 3$ & $1 / 5$ \\
\hline Heart & $3 / 5$ & $1 / 5$ & $0 / 5$ & $0 / 5$ & $0 / 5$ & $0 / 5$ & $0 / 5$ & $0 / 5$ & $0 / 3$ & $2 / 5$ \\
\hline Pancreas & $3 / 5$ & $1 / 5$ & $0 / 5$ & $0 / 5$ & $0 / 5$ & $1 / 5$ & $0 / 5$ & $0 / 5$ & $1 / 3$ & $2 / 5$ \\
\hline Thymus & $0 / 5$ & $1 / 5$ & $0 / 5$ & $0 / 5$ & $1 / 5$ & $3 / 5$ & $0 / 5$ & $1 / 5$ & $3 / 3$ & $0 / 5$ \\
\hline Lymphal tissue & $2 / 5$ & $1 / 5$ & $0 / 5$ & $0 / 4$ & $0 / 5$ & $0 / 5$ & $0 / 5$ & $2 / 4$ & $0 / 3$ & $0 / 5$ \\
\hline Aorta & $1 / 5$ & $0 / 5$ & $0 / 5$ & $0 / 5$ & $\mathrm{nd}^{\mathrm{b}}$ & $\mathrm{nd}^{\mathrm{b}}$ & $0 / 5$ & $0 / 5$ & $0 / 3$ & $2 / 5$ \\
\hline Leukocytes & $0 / 5$ & $0 / 5$ & $0 / 5$ & $0 / 5$ & $0 / 5$ & $1 / 5$ & $0 / 5$ & $0 / 5$ & $0 / 3$ & $0 / 5$ \\
\hline Bone marrow & nd $^{b}$ & nd $^{\prime}$ & $\mathrm{nd}^{\mathrm{b}}$ & nd" & nd' & nd' & nd" & nd' & $0 / 3$ & $0 / 5$ \\
\hline
\end{tabular}

"The ratios indicate the number of organs found positive for either wt RCMV or RCMV $\Delta \mathrm{r} 144$, relative to the total amount of organs tested (one organ per rat). IPOX, immune peroxidase assay.

"W, wt RCMV-infected; $\Delta, \mathrm{RCMV} \Delta \mathrm{r} 144$-infected; nd, not determined.

latency (data not shown). Therefore, to detect RCMV DNA at 330 days p.i., a sensitive, single-tube, nested PCR procedure was designed. This procedure enabled us to detect 1 to 10 copies of genomic RCMV DNA per $\mu \mathrm{g}$ of organ tissue ( 1 to 10 RCMV genome copies per $2.4 \times 10^{5}$ cells) (data not shown). Two groups of 6-week-old, immunosuppressed rats were infected with $1 \times 10^{6} \mathrm{PFU}$ of either wt RCMV or RCMV $\Delta \mathrm{r} 144$. Total DNA was purified from various organs of the rats at day 330 p.i., and subjected to PCR. Table 1 shows that DNA from both wt RCMV and RCMV $\Delta$ r144 was detected in a similar spectrum of organs of infected rats. Virus DNA was detected most consistently in the salivary glands and the liver (Table 1), irrespective of whether rats were infected with wt RCMV or RCMVAr144. Interestingly, virus DNA could be detected in the spleen of four out of five RCMV $\Delta$ r144-infected rats, whereas spleen tissue from three out of three wt RCMV-infected rats was PCR-negative. This difference is, given the variation in viral DNA load among infected rats (data not shown) and the limited number of animals tested (two out of five animals from the wt RCMV-infected group 
FIG. 6 - Next page. Infection of rat footpads with either RCMV or RCMVAr144. Six-week-old, inmunosuppressed rats were injected subcutaneously with $1 \times 10$ PFU of either wt RCMV (O) or RCMV $\Delta r 144$ (-) in the dorsum of the right hind paw, similarly as described previously (33). Rats were sacrificed at either day 4,8 or 15 after infection. Sections $(4 \mu \mathrm{m})$ of the hind paws were investigated by indirect immunohistochemistry using the following MAbs: (A) Anti-rat CD11b (directed against macrophages), (B) Anti-rat CD49d (directed against VLA-4), (C) Anti-rat CD4 W3/25 (directed against CD4), and (D) 323 (directed against NK cells). The number of positively stained cells was determined by counting the number of positive cells per field of view (high power field [HPF]; magnification $\times 400$ ). Time-points at which a significant difference between RCMV-and RCMV 1 r144-infected rat hind paws was found are indicated by an asterisk (*).

died during the course of the experiment), not significant. In a follow-up experiment, in which larger groups of animals are used, potential differences between wt RCMV and RCMV $\Delta$ r144 in the viral DNA load within organs of latently-infected rats will have to be investigated further.

Infection of rat footpads with RCMV and RCMV $\triangle$ r144. Previously, Persoons et al. (33) described a model for local RCMV infection in which virus is inoculated in the footpad of immunosuppressed rats. As a result of this infection, severe macro- and microscopic pathology can be seen, including paw thickening, ballooning of endothelial cells, adherence of polymorphonuclear and mononuclear cells to the endothelial surface, and infiltration of inflammatory cells into the perivascular area (33). We employed this model to compare wt RCMV and RCMVAr144 in the pathology induced by local infection with these viruses. At various time-points p.i., the thickening of the rat paws was measured. In addition, sections of virus- as well as mock-infected paws were investigated for the presence of infiltrating leukocytes, by using leukocyte subset-specific monoclonal antibodies (MAbs). As described previously (33), infection of rat footpads with RCMV resulted in thickening of the paws. Similar macroscopic alterations were observed after infection with RCMV $\Delta \mathrm{r} 144$, whereas changes in the mockinfected paws were not detected (data not shown). Interestingly, we found significant differences between wt RCMV and RCMV $\Delta \mathrm{r} 144$ in the number of infiltrating leukocytes in the infected paws. At day 15 p.i., a significantly lower number of macrophages was detected in RCMV $\Delta$ r144-infected paws than in RCMV-infected paws (Fig. $6 \mathrm{~A})$. In accordance with this, significantly lower numbers of cells expressing VLA-4 (Fig. 6B), LFA-1 (data not shown) and CD4 (Fig. 6C) were detected in RCMV $\Delta$ r144infected paws as compared to wt RCMV-infected paws at day 15 p.i.. VLA-4, LFA-1 and CD4 can be expressed on the surface of various subsets of leukocytes, including monocytes/macrophages. Also, a small, but significant difference between recombinant virus- and wt virus-infected paws was observed at day 15 p.i. in the number of CD8 ${ }^{+}$-cells ( $111 \pm 11$ and $152 \pm 9$, respectively). Although CD8 can be expressed on both 


\section{O WT RCMV}

- RCMV $\Delta r 144$
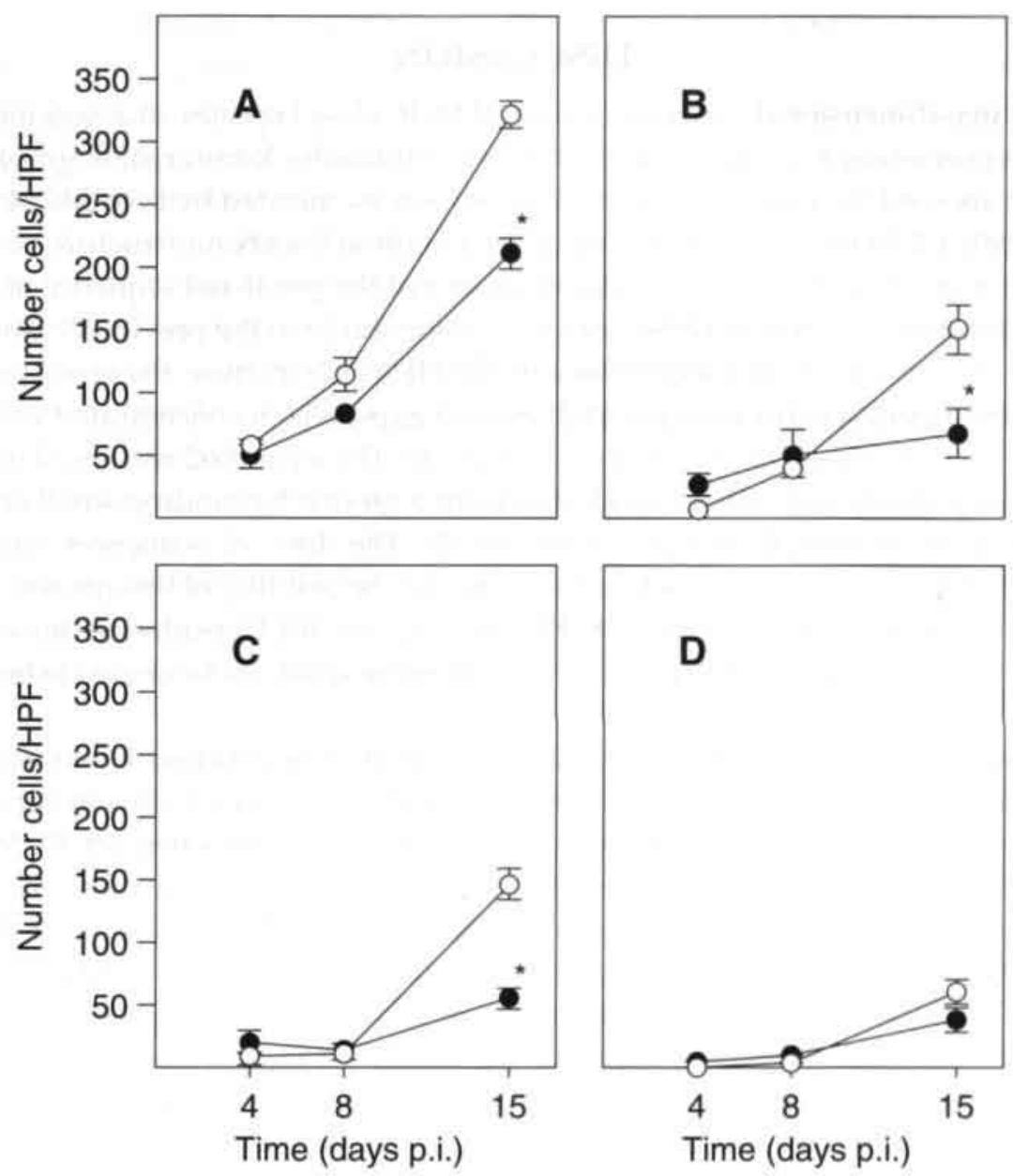

NK cells and a subset of T lymphocytes, it is likely that the CD8 $8^{-}$-cells do not represent NK cells, since the number of NK cells did not significantly differ between RCMV $\Delta \mathrm{r} 144$ and wt RCMV-infected paws (Fig. 6D). It is possible that the observed differences in leukocyte influx resulted from differences in replication between RCMV and RCMV $\Delta \mathrm{r} 144$. However, both viruses were found to have similar replication characteristics in the rat paws (data not shown). Taken together, our data indicate that a higher number of macrophages and CD8 ${ }^{+} \mathrm{T}$ cells infiltrate in wt virus- than in RCMVAr144- 
infected rat paws, indicating that the r144-encoded protein might play a role, either directly or indirectly, in the interaction with these leukocytes.

\section{DISCUSSION}

The three-dimensional structure of several MHC class I species, in association with $\beta 2 \mathrm{~m}$, has previously been determined at high resolution by X-ray cristallography $(7,8$, 31). This allowed the predicted amino acid sequences encoded by both MCMV m144 and HCMV UL18 to be modeled around the $\alpha$-carbon backbone structure of human class I protein HLA-A2 $(8,16)$. Similar modeling of the predicted sequence of RCMV gpr144 resulted in a protein ribbon diagram comparable to the previously published diagram of gpm144 (16). In comparison with the HLA-A2 structure, the predicted structures of both gpm144 (16) and gpr144 displayed gaps, which concentrated within the putative $\alpha 1$ and $\alpha 2$ regions of the proteins (Fig. 2B). The $\alpha 1$ and $\alpha 2$ regions of mammalian class I proteins were demonstrated to form a groove for binding small antigenic peptides to be presented on the cell surface (7). The 'loss' of sequences within the corresponding regions of gpm144 may account for the inability of this protein to form a complex with peptides, in contrast to HCMV gpUL18 (16). Considering the sequence similarity between gpr144 and gpm144, gpr144 might similarly be unable to bind peptides.

To study the function of the r144 gene, we generated an r144 knockout virus strain (RCMV $\Delta$ r144). This strain replicated with similar efficiency as wt virus in various cell lines in vitro. Moreover, we did not detect differences between wt RCMV and RCMV $\Delta$ r144 in their replication characteristics in vivo. First, the survival rate among groups of immunosuppressed rats infected with either RCMV $\Delta$ r144 or wt RCMV was similar. Second, the dissemination of virus did not differ between RCMVAr144- and wt RCMV-infected, immunosuppressed rats, in both the acute and latent phase of infection. We conclude from these data that the RCMV $\Delta r 144$ gene does not play an important role in virus replication in our in vitro and in vivo experimental systems.

Our results with the r144-deleted virus are in striking contrast to the data reported by Farrell and coworkers (23), who showed that an MCMV strain that was deleted of the m144 gene, which is the homolog of RCMV $\Delta \mathrm{r} 144$, was severely restricted in replication compared with wt MCMV during the acute phase of infection in mice. In addition, it was demonstrated by in vivo depletion studies that NK cells are responsible for the attenuated phenotype of the m144 knockout virus (23). Based on these findings, Farrell et al. proposed that MCMV employed the m144 gene product to mimic cellular class I molecules (of which the cell surface expression is downregulated upon infection) by inhibiting the NK cell response. Thus, the early clearance of MCMV-infected cells would be prevented (23). A function similar to that proposed for the m144-encoded protein was suggested for the HCMV UL18 gene product by Reyburn et al. (35). 
They showed that class I type HLA-A, -B and -C-deficient, 721.221 B lymphoblastoid cells were protected from NK-cell killing after transfection with an expression vector containing the HCMV UL18 gene (35). By contrast, Leong et al. reported that the expression of UL18 resulted in enhanced rather than reduced killing of target cells by NK cells (28). In the latter study, the role of UL18 in NK cell recognition was investigated using fibroblasts infected with either wt HCMV or UL18 knockout HCMV, and by using cell lines transfected with UL18. According to Leong and coworkers, the apparent discrepancies between their results and those of Reyburn et al. (35) could be due to the fact that in the latter study transfected cells were selected on the basis of surface expression of $\beta 2 \mathrm{~m}$ rather than gpUL18 (28). This selection could have resulted in enrichment of a population of transfected cells that express endogenous HLA-E, which was recently shown to protect 721.221 target cells from lysis by NK cells (9). Thus, the NK-protective effect that was described by Reyburn et al. could also be the result of the expression of HLA-E.

It is possible that potential differences between RCMV $\triangle \mathrm{r} 144$ and wt RCMV in replication in vivo might be concealed due to the irradiation-induced immunosuppression, which is generally applied in order to be able to study RCMV disease in rats $(3,5$, $12,39)$. If the r144 gene product was to serve as a decoy to evade immune surveillance, similarly as proposed for MCMV gpm144, an RCMV r144 knockout strain might be attenuated due to efficient clearance of this strain by the immune system of the rat. The induction of immunosuppression, however, might preserve the virulence of the r144 knockout strain. In contrast to the RCMV infection model in rats (and HCMV infection in humans), mice do not require immunosuppression prior to infection to establish MCMV disease. This difference could explain the apparent discrepancies between our findings with RCMV $\Delta \mathrm{r} 144$ and the results of Farrell et al. with the MCMV m144 knockout virus (23). Nevertheless, it is interesting to note that after total body irradiation and RCMV infection of rats, NK cells are regenerated efficiently between day 10 and 15 p.i., which is more rapidly than other types of leukocytes (42). Consequently, if RCMV gpr144 would function in the protection from lysis by NK cells, the regenerated NK cell population of irradiated rats should be capable of eliminating RCMV $\Delta$ r144 more efficiently than wt RCMV. We were, however, unable to detect differences in replication between wt and recombinant virus in vivo, either at day 4 or 21 after infection. It is of course possible that NK cells of immunosuppressed rats, despite being regenerated relatively rapidly and efficiently (42), are still impaired in function due to the irradiation.

It has previously been hypothesized by Leong et al. that viral MHC class I homologs may be more important in affecting monocyte and dendritic cell function than 
NK cell function (28). This hypothesis was supported by results of Cosman et al. (19), who found that the HCMV UL18 gene product can interact with a membrane receptor, designated ILT2 (36) or LIR-1 (19), which is predominantly expressed on monocytes and B lymphocytes. Since ILT2/LIR-1 is expressed on only a minor subset of NK cells (19), the physiological significance of the interaction of gpUL18 with this receptor on NK cells is unclear. Leong et al. hypothesized that the interaction of gpUL18 with ILT2/LIR-1 on monocytes or dendritic cells could suppress IL12-production, which would limit the secrection of IFN- $\gamma$ by NK cells, thereby altering the early immune response (28). Interestingly, such a mechanism could explain not only the severely restricted replication of the MCMV m144 knockout virus in vivo (23), but also the similarity between RCMV and RCMV $\mathrm{r} 144$ in their replication characteristics within immunosuppressed rats. In analogy to gpUL18, gpr144 could interact with a receptor expressed predominantly on monocytes or macrophages, which could lead to an immune evasive effect. Since monocytes are only regenerated at a relatively late stage after irradiation and RCMV infection of rats (between day 20 and 25 p.i.) (42), potential differences in clearance of either wt RCMV or RCMV $\Delta$ r144 at day 4 and 21 p.i. would remain unnoticed. Interestingly, in support of a putative interaction between gpr144 and leukocytes other than NK cells, we found an increased influx of macrophages and CD8 ${ }^{+} \mathrm{T}$ lymphocytes in wt RCMV-infected tissue as compared to RCMV $\Delta \mathrm{r} 144$-infected tissue in a local (rat footpad) infection model. Whether the increased influx of these leukocytes is the result of either a direct or indirect interaction with the r144-encoded protein will have to be investigated in future studies. The identification of a putative receptor for gpr144 on leukocytes might be crucial in the elucidation of the role of this protein during RCMV infection.

\section{ACKNOWLEDGEMENTS}

We thank Erik Beuken for DNA sequencing and generating plasmids p081 and p094, and Monique Coomans for assistance with PCR. We are grateful to Raisa Loginov for help with the rat paw infection model. We thank Wil Loenen for critically reading the manuscript.

\section{REFERENCES}

1. Beck, S., and B. G. Barrell. 1988. Human cytomegalovirus encodes a glycoprotein homologous to MHC class-I antigens. Nature 331:269-272.

2. Beck, S., and B. Barrell. 1991. An HCMV reading frame which has similarity with both the $V$ and $C$ regions of the TCR gamma chain. DNA Seq. 2:33-38.

3. Beisser, P. S., G. Grauls, C. A. Bruggeman, and C. Vink. 1999. Deletion of the R78 G protein-coupled receptor gene from rat cytomegalovirus results in an attenuated, syncytiuminducing mutant strain. J. Virol. 73:7218-7230. 
4. Beisser, P. S., S. J. F. Kaptein, E. Beuken, C. A. Bruggeman, and C. Vink. 1998. The Maastricht strain and England strain of rat cytomegalovirus represent different betaherpesvirus species rather than strains. Virology 245:341-351.

5. Beisser, P. S., C. Vink, J. G. van Dam, G. Grauls, S. J. Vanherle, and C. A. Bruggeman. 1998. The R33 G protein-coupled receptor gene of rat cytomegalovirus plays an essential role in the pathogenesis of viral infection. J. Virol. 72:2352-2363.

6. Beuken, E., R. Slobbe, C.A. Bruggeman, and C. Vink. 1996. Cloning and sequence analysis of the genes encoding DNA polymerase, glycoprotein B, ICP 18.5 and major DNA-binding protein of rat cytomegalovirus. J. Gen. Virol. 77:1559-1562.

7. Bjorkman, P. J. 1990. Structure, function, and diversity of class I major histocompatibility complex molecules. Annu. Rev. Biochem. 59:253-288.

8. Bjorkman, P.J., M. A. Saper, B. Samraoui, W. S. Bennett, J. L. Strominger, and D. C. Wiley. 1987. Structure of the human class I histocompatibility antigen, HLA-A2. Nature 329:506512.

9. Braud, V. M., D. S. Allan, C. A. O'Callaghan, K. Soderstrom, A. D'Andrea, G. S. Ogg, S. Lazetic, N. T. Young, J. I. Bell, J. H. Phillips, L. L. Lanier, and A. J. McMichael. 1998. HLAE binds to natural killer cell receptors CD94/NKG2A, B and C. Nature 391:795-799.

10. Brown, T. 1993. Analysis of DNA sequences by blotting and hybridization, p. 4.2.1-4.2.15. In F.M. Ausubel, R. Brent, R.E. Kingston, D.D. Moore, J.G. Seidman, J.A. Smith, \& K. Struhl (ed.), Current protocols in molecular biology, John Wiley \& Sons, Inc., New York, N.Y.

11. Browne, H., M. Churcher, and T. Minson. 1992. Construction and characterization of a human cytomegalovirus mtuant with the UL18 (class I homolog) gene deleted. J. Virol. 66:6784-6787.

12. Bruggeman, C. A., H. Meijer, F. Bosman, and C. P. A. van Boven. 1985. Biology of rat cytomegalovirus infection. Intervirology 24:1-9.

13. Bruggeman, C. A., H. Meijer, P. H. J. Dormans, W. H. M. Debie, G. E. L. M. Grauls, and C. P. A. van Boven. 1982. Isolation of a cytomegalovirus-like agent from wild rats. Arch. Virol. 73:231-241.

14. Bruning, J., W. H. M. Debie, P. H. J. Dormans, H. Meijer and C. A. Bruggeman. 1987. The development and characterization of monoclonal antibodies against rat cytomegalovirus induced agents. Arch. Virol. 94:55-70.

15. Chambers, W. H., N. L. Vujanovic, A. B. DeLeo, M. W. Olszowy, R. B. Herberman and J. C. Hiserodt. 1989. Monoclonal antibody to a triggering structure expressed on rat natural killer cells and adherent lymphokine-activated killer cells. J. Exp. Med. 169:1373-1389

16. Chapman, T. L., and P. J. Bjorkman. 1998. Characterization of a murine cytomegalovirus class I major histocompatibility complex (MHC) homolog: Comparison to MHC molecules and to the human cytomegalovirus MHC homolog. J. Virol. 72:460-466.

17. Chee, M. S., A.T. Bankier, S. Beck, R. Bohni, C. M. Brown, R. Cerny, T. Horsnell, C. A. Hutchison III, T. Kouzarides, J. A. Martignetti, E. Preddie, S. C. Satchwell, P. Tomlinson, K. M. Weston and B. G. Barrell. 1990. Analysis of the protein-coding content of the sequence of human cytomegalovirus strain AD169. Curr. Top. Microbiol. Immunol. 154:125169. 
18. Chee, M. S., Satchwell, S. C., Preddie, E., Weston, K. M. and Barrell, B. G. 1990. Human cytomegalovirus encodes three $\mathrm{G}$ protein-coupled receptor homologues. Nature 344:774777.

19. Cosman, D., N. Fanger, L. Borges, M. Kubin, W. Chin, L. Peterson, and M.-L. Hsu. 1997. A novel immunoglobulin superfamily receptor for cellular and viral MHC class I molecules. Immunity 7:273-282.

20. Damoiseaux, J. G. M. C., E. A. Döpp, W. Calame, D. Chao, G. G. MacPherson, and C. D. Dijkstra. 1994. Rat macrophage lysosomal membrane antigen recognized by monoclonal antibody ED1. Immunology 83:140-147.

21. Davis-Poynter, N. J., and H. E. Farrell. 1996. Masters of deception: A review of herpesvirus immune evation strategies. Immunol. Cell Biol. 74:513-522.

22. Farrell, H. E., M. A. Degli-Esposti and N. J. Davis-Poynter. 1999. Cytomegalovirus evasion of natural killer cell responses. Immunol. Rev., in press.

23. Farrell, H. E., H. Vally, D. M. Lynch, P. Fleming, G. R. Shellam, A. A. Scalzo, and N. J. Davis-Poynter. 1997. Inhibition of natural killer cells by a cytomegalovirus MHC class I homologue in vivo. Nature 386:510-514.

24. ISREC WU-BLAST server. [Online.] BLAST program, version 2.0. ISREC Bioinformatics group, Swiss Institute of Bioinformatics, Geneva, Switzerland. http://www.ch.embnet.org/ software/WUBLAST_form.html. [11 January 1999, last date accessed.]

25. Koller, B. H., and H. T. Orr. 1985. Cloning and complete sequence of an HLA-A2 gene: analysis of two HLA-A alleles at the nucleotide level. J. Immunol. 134:2727-2733.

26. Kraus, E., D. Lambracht, K. Wonigeit, and T. Hunig. 1996. Negative regulation of rat natural killer cell activity by major histocompatibility complex class I recognition. Eur. J. Immunol. 26:2582-2586.

27. Lalanne, J.-L., C. Delarbre, G. Gachelin, and P. Kourilsky. 1983. A cDNA clone containing the entire coding sequence of a mouse $\mathrm{H}-2 \mathrm{Kd}$ histocompatibility antigen. Nucleic Acids Res. 11:1567-1577.

28. Leong, C., T. L. Chapman, P. J. Bjorkman, D. Formankova, E. S. Mocarski, J. H. Philips, and L. L. Lanier. 1998. Modulation of natural killer cell cytotoxicity in human cytomegalovirus infection: The role of endogenous class I major histocompatibility complex and a viral class I homolog. J. Exp. Med. 187:1681-1687.

29. MacDonald, M. R., X.-Y. Li, and H. W. Virgin IV. 1997. Late expression of a $\beta$ chemokine homolog by murine cytomegalovirus. J. Virol. 71:1671-1678.

30. Meijer, H., J.C. Dreesen, and C. P. van Boven. 1986. Molecular cloning and restriction endonuclease mapping of the rat cytomegalovirus genome. J. Gen. Virol. 67:1327-1342.

31. NCBI Structure. [Online.] NCBI Structure Group. National Institutes of Health, Bethesda, Maryland. http://www.ncbi.nlm.nih.gov/Structure/index.html. [5 March 1999, last date accessed.]

32. Persistence of Vision. [Online.] Persistence of vision (tm) Ray Tracer Version 3.1. Hallam Oaks Pty. Ltd. Indianapolis, Indiana. http://www.povray.org/index.html. [5 March 1999, last date accessed.]

33. Persoons, M. C. J., F. S. Stals, M. C. van Dam Mieras, and C. A. Bruggeman. 1998. Multiple organ involvement during experimental cytomegalovirus infection is associated with disseminated vascular pathology. J. Pathol. 184:103-109. 
34. Rawlinson, W. D., H. E. Farrell, and B. G. Barrell. 1996. Analysis of the complete DNA sequence of murine cytomegalovirus. J. Virol. 70:8833-8849.

35. Reyburn, H. T., O. Mandelboim, M. Valés-Gómez, D. M. Davis, L. Pazmany, and J. L. Strominger. 1997. The class I MHC homologue of human cytomegalovirus inhibits attack by natural killer cells. Nature 386:514-517.

36. Samaridis, J., and M. Colonna. 1997. Cloning of novel immunoglobulin superfamily receptors expressed on human myeloid an lymphoid cells: structural evidence for new stimulatory and inhibitory pathways. Eur. J. Immunol. 27:660-665.

37. Senkevich, T. G., J. J. Bugert, J. R. Sisler, E. V. Koonin, G. Darai, and B. Moss. 1996. Genome sequence of a human tumorigenic poxvirus: prediction of specific host response-evasion genes. Science 273:813-816.

38. Senkevich, T. G., and B. Moss. 1998. Domain structure, intracellular trafficking, and $\beta 2-$ microglobulin binding of a major histocompatibility complex class I homolog encoded by Molluscum Contagiosum Virus. Virology 250:397-407.

39. Stals, F. S., F. Bosman, C. P. van Boven, and C. A. Bruggeman. 1990. An animal model for therapeutic intervention studies of CMV infection in the immunocompromised host. Arch. Virol. 114:91-107.

40. Swiss-PdbViewer. [Online] Glaxo Wellcome Experimental Research Swiss-PdbViewer v3.1. ExPASy Molecular Biology Server, Swiss Institute of Bioinformatics, Geneva, Switzerland. http://expasy.hcuge.ch/spdbv/mainpage.html. [5 March 1999, last date accessed.]

41. Thompson, J. D., D. G. Higgins, and T. J. Gibson. 1994. CLUSTAL W: improving the sensitivity of progressive multiple sequence alignment through sequence weighting, positionspecific gap penalties and weight matrix choice. Nucleic Acids Res. 22:4673-4680.

42. Van Dam, J. G., J. G. M. C. Damoiseaux, H. A. M. D. van der Heiden, G. Grauls, P. J. C. van Breda Vriesman, and C. A. Bruggeman. 1997. Infection with rat cytomegalovirus (CMV) in the immunocompromised host is associated with the appearance of a $\mathrm{T}$ cell population with reduced CD8 and T cell receptor (TCR) expression. Clin. Exp. Immunol. 110:349-357.

43. Vink, C., E. Beuken, and C. A. Bruggeman. 1996. Structure of the rat cytomegalovirus genome termini. J. Virol. 70:5221-5229.

44. Vink, C., E. Beuken, and C. A. Bruggeman. 1997. Cloning and functional characterization of the origin of lytic-phase DNA replication of rat cytomegalovirus. J. Gen. Virol. 78:29632973.

45. Vossen, R. C. R. M., J. G. Derhaag, M. E. P. Slobbe-van Drunen, A. M. Duijvestijn, M. C. E. van Dam-Mieras, and C. A. Bruggeman. 1996. A dual role for endothelial cells in cytomegalovirus infection? A study of cytomegalovirus infection in a series of rat endothelial cell lines. Virus Res. 46:65-74.

46. Wiertz, E. J. H. J., S. Mukherjee, and H. L. Ploegh. 1997. Viruses use stealth technology to escape from the host immune system. Mol. Med. Today 3:116-123. 
CHAPTER 5 


\section{CHAPTER 6}

\section{General Discussion}

This chapter will be published in a modified form in the 1999 edition of Intervirology. 
CHAPTER 6 


\section{ABSTRACT}

Cytomegaloviruses (CMVs) are well-known for their high prevalence rate within host populations as well as their ability to induce lifelong infections. To maintain a persistent and stable relationship with their host, CMVs have evolved various molecular mechanisms to both control host cell metabolism and evade immune surveillance. Among the viral gene products that are likely to be involved in these processes are homologs of cellular $\mathrm{G}$ protein-coupled receptors, MHC class I molecules, and chemokines. The viral genes encoding these homologs have probably been pirated by the viruses during a long pathogen/host co-evolution. In this report, the possible functions of these homologs in the pathogenesis of CMV infections are discussed. 


\section{INTRODUCTION}

Cytomegaloviruses are species-specific betaherpesviruses which cause acute, persisting, and latent infections in both humans and animals. Although human CMV (HCMV) infections of immunocompetent individuals usually run an asymptomatic course, infections of immunocompromised individuals (e.g., AIDS patients, organ transplant recipients, and neonates) can have life-threatening consequences.

A characteristic that is shared by all herpesviruses is the ability to induce a latent, lifelong infection. Obviously, such a lifelong interaction requires the virus to be highly adapted to its host and vice versa. Most importantly, the virus will have to employ strategies to remain hidden from the host's immune system. This can in principle be achieved by the virus by going into a dormant state in which only a subset of viral genes is expressed and targets for host immune responses are not displayed. Recent studies have indicated that herpesviruses use a variety of strategies to interfere with the immune system of the host (for reviews, see references 31, 36, 27 and 25). Most notably, several herpesvirus-encoded proteins have been identified that inhibit either synthesis, surface expression or peptide loading of cellular major histocompatibility (MHC) class I molecules. In addition, various herpesvirus genes were identified which encode homologs of immune effector molecules or regulatory proteins of the host. Table 1 summarizes the currently discovered betaherpesvirus gene homologs. This chapter focuses on CMV genes which have the potential to code for homologs of $\mathrm{G}$ protein-coupled receptors, MHC class I heavy chains and chemokines. The possible functions of these genes and their products will be discussed.

\section{HOMOLOGS OF G PROTEIN-COUPLED RECEPTORS}

Viral G protein-coupled receptors. G protein-coupled receptors (GCRs) are members of a large and diverse family of receptors that function in signal transduction through cell membranes (see reference (11) for a recent review). All GCRs are composed of a central core domain constituted of seven transmembrane (7-TM) helices (TM-I through -VII) connected by three intracellular (i1, i2, and i3) and three extracellular (e1, e2, and e3) loops (1). The majority of these receptors activate $\mathrm{G}$ proteins and are capable of transducing messages as different as photons, organic odorants, lipids, nucleotides, nucleosides, peptides, and proteins. Thousands of GCR variants are encoded by genes of eukaryotes as well as prokaryotes. In addition, some GCRs are encoded by genes of poxviruses and herpesviruses. It is likely that these genes have been hijacked by the viruses during co-evolution of pathogen and host.

The HCMV US27 and US28 genes. Within the genomes of human CMV (HCMV) $(19,20)$, murine CMV (MCMV) $(58)$ and rat CMV (RCMV) $(3,4)$ several genes were identified that are capable of encoding homologs of host cellular GCRs (Table 1). HCMV 
carries four of these genes: US27, US28, UL33, and UL78 $(19,20)$. Only two of these, UL33 and UL78, were found to have counterparts in RCMV (R33 and R78, respectively $(3,4)$ ) as well as MCMV (M33 and M78, respectively $(58))$. Of the predicted amino acid sequences derived from the CMV GCR-like genes, those encoded by HCMV US27 and US28 were found to have the highest similarity to sequences of cellular chemokine-binding GCRs (Fig. 1) (25). In addition, the US28 protein (pUS28) was reported to be capable of binding CC or ( $\alpha$-)chemokines, such as RANTES, MIP- $1 \alpha$ and MCP-1, hence triggering the mobilization of intracellular $\mathrm{Ca}^{2+}(50,33,40,62)$. The pUS28 protein was suggested to be responsible for $\beta$-chemokine sequestration in HCMV-infected cells (12). Interestingly, pUS28 was recently shown to selectively recognize fractalkine (or neurotactin), which is a membrane-associated CX3C chemokine (38). Since fractalkine is expressed on putative CMV target cells, like endothelial cells, it was hypothesized by Kledal et al. that the highly specialized pUS28-fractalkine interaction may be involved in the cell-to-cell transfer of HCMV (38).

The UL33 gene family. Due to the species specificity of HCMV, it is difficult to study the function of the HCMV US27 and US28 genes in vivo. Moreover, these genes do not have counterparts within the genomes of other (animal) cytomegaloviruses. In contrast, UL33- and UL78-like genes are conserved among all betaherpesviruses (Fig. 1 ), which illustrates their importance for the biological characteristics of these viruses. The functions of these genes can therefore also be studied in vivo, using animal models. Currently, the UL33 gene family consists of 5 members: HCMV UL33, MCMV M33, RCMV R33, and human herpesvirus 6 and 7 (HHV-6 and -7) U12 $(34,51)$. The predicted amino acid sequences of the proteins encoded by the UL33-like gene family were found to comprise several features characteristic of chemokine receptors $(3,26)$. In agreement with this, the HHV-6 U12-encoded protein (pU12) was reported to be a functional receptor for $\beta$-chemokines in vitro (37). Whether the other members of the pUL33-like family are similarly capable of binding chemokines and/or other ligands has not yet been described. Nevertheless, the UL33, M33 and R33 genes were found to be dispensable for in vitro replication of HCMV (46), MCMV (26) and RCMV (3), respectively. In contrast, both M33 and R33 were shown to be essential for virus replication in vivo. This was established by using recombinant viruses in which the M 33 and R33 genes were deleted from the MCMV and RCMV genomes, respectively. Unlike wild type (wt) RCMV, R33-deleted RCMV (RCMV $\triangle$ R33) did not efficiently replicate in salivary gland epithelial cells of immunocompromised rats, which indicated that the recombinant virus is not able to either enter or replicate in salivary gland epithelial cells (3). A similar observation was made in the murine model for M33-deleted MCMV (26). Also, a significantly lower mortality was seen among RCMV $\triangle R 33$-infected rats than among wt RCMV-infected rats (3). Although these data underline the importance of the UL33-like genes in the pathogenesis of CMV infection, the exact function of these genes is still unknown. 


\begin{tabular}{|c|c|c|c|c|}
\hline $\begin{array}{l}\text { Virus (Strain); } \\
\text { GenBank accession } \\
\text { nr(s).: (genome length) }\end{array}$ & ORF & Nucleotides & Gene product homologous to: & Refererices \\
\hline HCMV (AD169); & UL18 & $23637-24743$ & Class I MHC & $2,14,14,18,19,21,22,35,42,59,63$ \\
\hline \multirow[t]{5}{*}{$\mathrm{X} 17403 ;[229354 \mathrm{bp}]$} & UL20 & $25299-26321$ & T-cell receptor & 3,19 \\
\hline & UL33 & $43065-43087,43210-44423$ & Chemokine receptor & $12,19,20,46,52,64$ \\
\hline & UL78 & $112924-114219$ & Orphan G protein-coupled réceptor & 19,52 \\
\hline & US27 & $217904-218992$ & Chemokine receptor & $12,19,52,64$ \\
\hline & US28 & $219200-220263$ & CC chemokine receptor & $8,12,19,20,32,33,38,40,50,51,52,54,55,-$ \\
\hline HCMV (Toledo); & ULI44 & $8008-8538$ & TNF receptor & $\begin{array}{ll}17,7 & -62,64,67\end{array}$ \\
\hline \multirow[t]{2}{*}{ U33331 } & UL146 & $9450-9803$ & ELR' CXC chemokine & 17,53 \\
\hline & UL147 & $9868-10347$ & ELR- CXC chemokine & 17 \\
\hline RCMV (Maastricht), & R33 & $732-1895$ & Chemokine receptor & 4,52 \\
\hline U91788, AF077758; & $\mathrm{R} 78$ & $433-1857$ & Orphan G protein-coupled receplor & 5 \\
\hline AF133339 & $r 144$ & $2205-3170$ & Class I MHC & 6 \\
\hline MCMV (Smith); & M33 & $41486-41518,41630-42 \pi 7$ & Chemokine receptor & $26,52,58$ \\
\hline \multirow[t]{4}{*}{ U68299; |230278 bp| } & M78 & $110989 \cdot 112401$ & Orphan G protein-coupled receptor & 58,52 \\
\hline & $\mathrm{m} 131$ & cl88029-188271 & CC chemokine & $43,44,58$ \\
\hline & m131-129 & $c 187350-187947,188025-188271$ & CC chemokine & 44,58 \\
\hline & $\mathrm{ml} 44$ & c202745-203893 & Class I MHC & $18,21,22,23,29,30,58$ \\
\hline
\end{tabular}

"The 'c's preceding the nucleotide positions denote ORFs that are encoded by the complement of the indicated nucleotide sequences.

"The HCMV Toledo genes are additional to the HCMV AD169 genes in this table. 
TABLE 1. - Continued.

\begin{tabular}{|c|c|c|c|c|}
\hline $\begin{array}{l}\text { Virus (Strain): } \\
\text { GenBank accession } \\
\text { nr(s).; [genonie lenght] }\end{array}$ & ORF & Nucleotides & Gene product homologous to: & References \\
\hline HHV-6 (U1102); & $\mathrm{U} 12$ & $21680-21710,21800-22812$ & CC-Chenokine receptor & $34,37,52$ \\
\hline \multirow[t]{2}{*}{ X83413; [159321 bp] } & U5! & $82574-83479$ & Orphan G protein-coupled receptor & $34,47,52$ \\
\hline & U83 & $123528-123821$ & CC chemokine & 34,67 \\
\hline HHV-7 (II); & U12 & & Chemokine receptor & 51,52 \\
\hline \multirow[t]{2}{*}{ U434100; [144861 bp] } & U51 & $75304-76188$ & Orphan G protein-coupled receptor & 51 \\
\hline & U85 & c) $8071-118913$ & $O \times-2$ & 51 \\
\hline
\end{tabular}

"The 'c's preceding the nucleotide pasitions denote ORFs that are encoded by the complement of the indicated nucleotide sequences. 
Fig. 1 - Next page. Relationship between host-and CMV-encoded GPCR(-like) amino acid sequences and $\mathrm{MHC}$ class I heavy chain(-like) sequences. (A) A phylogenetic tree based on a multiple alignment of GPCR-like amino acid sequences encoded by HCMV US27 (pUS27), US28 (pUS28), UL33 (pUL33) and UL78 (pUL78) (19, 20), MCMV M33 (pM33) and M78 (pM78) (58), RCMV R33 (pR33) (3) and R78 (pR78) (4), HHV-6 and HHV-7 U12 (pU12) and U51 (pU51) (34, 51). In addition, the tree includes the amino acid sequences of human chemokine receptors CXCR4 (16) and CCR5 (48), and two nonchemokine receptors (Other GPCRs): $\beta 2$-adrenergic receptor (28) and rhodopsin (49). CLUSTAL W pairwise alignment (61) was set to BLOSUM30 protein weight matrix, gap open penalty $=10$, and gap extension penalty $=0.1$. Multiple alignment was set to BLOSUM series, gap open penalty $=10$, gap extension penalty $=0.05$, delay divergent sequences $=0.4$. $(B)$ A fylogenetic tree based on a CLUSTAL $W$ multiple sequence alignment of MHC class I-like amino acid sequences encoded by HCMV UL18 (gpUL18) (2), MCMV m144 (gpm144) (58), and RCMV r144 (gpr144) (5). Also included are the amino acid sequences of three mammalian MHC class I proteins, rat RT1.Al (39), murine H2- $K^{d}(41)$, and human HLA-A2 (9). In the alignment, a PAM250 protein distance matrix was included. Pairwise alignment gap penalty $=3$. Multiple alignment gap penalty $=10$, gap extension penalty $=10$.

The UL78 gene family. The UL78 gene family currently consists of 5 members: HCMV UL78 (19), RCMV R78 (4), MCMV M78 (58), and HHV-6 and -7 U51 (34, 51). Similar to the UL33-like genes, the positions of the UL78-like genes within the betaherpesvirus genomes are conserved. However, in contrast to the sequences of UL33like genes, the sequences of members of the UL78 family are rather divergent (Fig. 1). The predicted amino acid sequences derived from the UL78-like genes significantly resemble neither chemokine receptors nor any other of the thousands of GCRs currently known. The assumption that UL78-like genes have the potential to encode GCRs is based on three properties: (i) the presence of a 7-TM core domain within the predicted amino acid sequences derived from the UL78-like genes; (ii) the presence of 2 conserved cysteine residues within these sequences, which may play a role in correct folding of the putative GCRs; and (iii) a stretch of amino acids within these sequences which bears similarity to a domain known to be required for $G$ protein coupling (57). Only a few studies have hitherto reported on the characterization of members of the UL78 gene family. In a study by Menotti et al., the HHV-6 U51 gene product (pU51) was found to be expressed on the cell surface of infected cord blood mononuclear cells (47), in accordance with its putative function as a plasma membrane-associated protein. However, in cells transfected with a U51 expression construct, transport of pU51 to the cell surface was cell type-dependent: cell surface expression of pU51 was seen in activated T lymphocytes and $\mathrm{T}$ cell lines but not in other cell types (47). The relevance of these observations is yet unknown. In our laboratory, we have recently started to study the RCMV member of the UL78 gene family, R78. We have generated two different recombinant virus strains: an R78 null mutant (RCMV $\triangle R 78 \mathrm{a}$ ) and an RCMV mutant encoding a R78-derived GCR from which the putative intracellular C terminus 
A

0.1

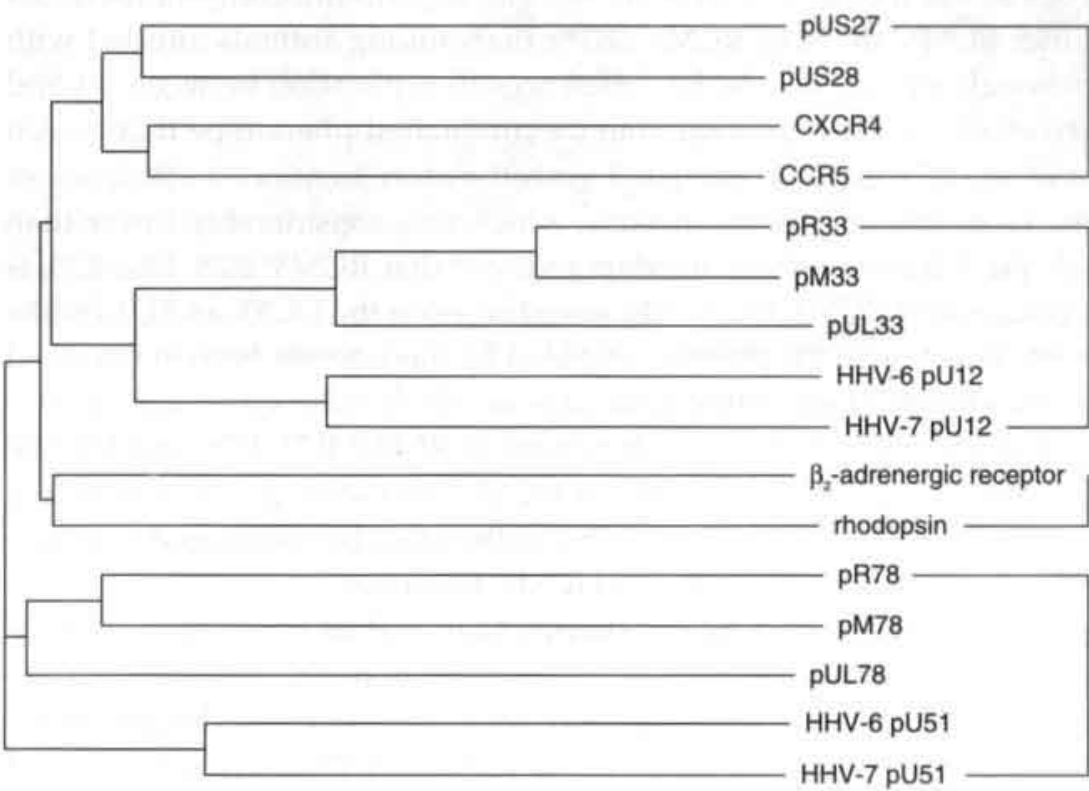

chemokine-

binding

receptors

UL33

family

UL78

family

\section{B}

\section{1}

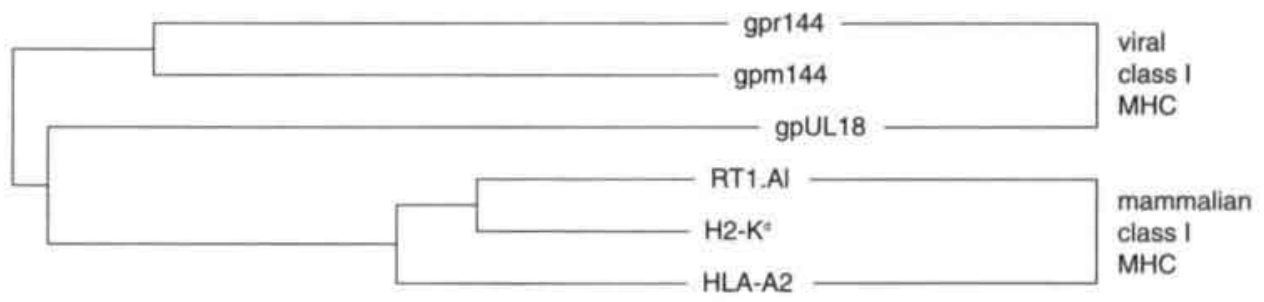

has been deleted (RCMV $\Delta \mathrm{R} 78 \mathrm{c})$. Interestingly, these recombinant viruses produced 10 - to 100 -fold lower virus titers than wt virus in vitro (4). Also, unlike wt RCMVinfected fibroblasts, fibroblasts infected with the recombinants developed a syncytium-like appearance (Fig. 2). Strains RCMV $\Delta$ R78a and RCMV $\Delta R 78 \mathrm{c}$ can therefore be considered as the first syncytium mutant (syn) CMV strains reported (4). We hypothesized that R78 plays a role, either directly or indirectly, in the stabilization of cell-tocell contacts (4). In fibroblasts infected with R78-deleted viruses, contacts between 
neighbouring cells may become instable, leading to plasma membrane fusion. The RCMV R78 gene was also found to play an important part in the pathogenesis of virus infection in vivo: a lower mortality was observed among immunocompromised rats infected with either RCMV $\triangle R 78 \mathrm{a}$ or RCMV $\triangle R 78 \mathrm{c}$ than among animals infected with $w t$ virus (4). Although we did not detect differences in replication between wt and recombinant viruses in vivo, it is possible that the attenuated phenotype that is seen after disruption of the R78 gene is correlated with the aforementioned efficiency of replication of the recombinant viruses in vitro, which was considerably lower than that of wt RCMV (4). Taken together, our data indicate that RCMV R78, like R33, is important for replication of RCMV in vivo. Future studies on the UL33- and UL78-like genes will focus on detection of the proteins encoded by these genes, both in vitro and in vivo, and the elucidation of signalling pathways in which these viral GCRs potentially function. Given the important in vivo functions of RCMV R33, R78, and MCMV $\mathrm{M} 33$, it is likely that the corresponding genes of HCMV also serve a vital function in vivo. The gene products of UL33 as well as UL78 can therefore be considered as attractive targets for the development of novel anti-HCMV therapies.

CMV homologs of MHC class I heavy chains. Mammalian major histocompatibility (MHC) class I proteins are members of the immunoglobulin superfamily. They are polymorphic, consisting of a membrane-bound, cell surface-expressed heavy chain, and an extracellular globulin-like light chain, $\beta_{2}$-microglobulin $\left(\beta_{2} \mathrm{~m}\right)$. Two domains of the heavy chain form a groove in which small peptides (antigens) can be presented to cytotoxic T lymphocytes (CTLs) (10). These peptides are generated by degradation of intracellular proteins, which can be encoded either by the genome of the cell or by genes of intracellular parasites, like viruses. Upon presentation of peptides by MHC class I molecules, CTLs can distinguish 'foreign' from 'self' peptides and thus discriminate between infected and uninfected cells. Subsequently, the infected cells are killed by the CTLs (10). Many viruses, however, have developed ways to evade CTLmediated killing. For instance, several herpesvirus proteins were found to downregulate antigen presentation of infected cells by interfering with either synthesis or maturation of cellular MHC class I molecules (for reviews see references 25, 30 and 65). As a consequence, these cells cannot be recognized by CTLs as being infected. Cells expressing class I molecules at a low level, however, are vulnerable to lysis mediated by natural killer (NK) cells. This threat was hypothesized to be overcome by both HCMV and MCMV by expressing homologs of MHC class I heavy chains (encoded by UL18 and $\mathrm{m} 144$, respectively), which might serve as decoys to protect infected cells from killing by NK cells $(29,24)$. Support for this hypothesis has come from a study by Farrell et al. on an m144-deleted MCMV strain ( $\Delta \mathrm{m} 144)(29)$. This recombinant strain was shown to be attenuated during the primary phase of virus infection in mice, whereas its virulence was comparable to that of wt MCMV in NK cell-depleted mice (29). To study the function of the RCMV homolog of the m144 gene, r144, we gener- 
A

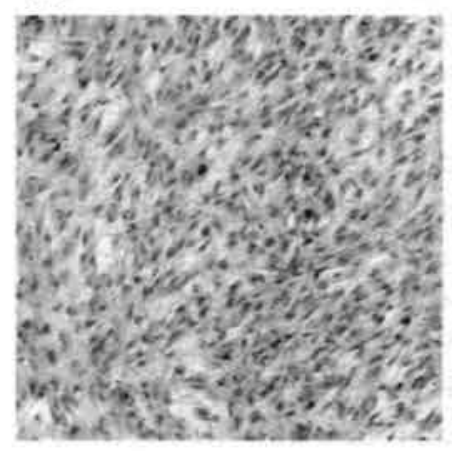

B

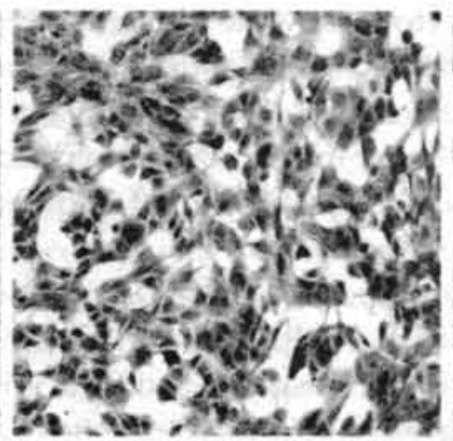

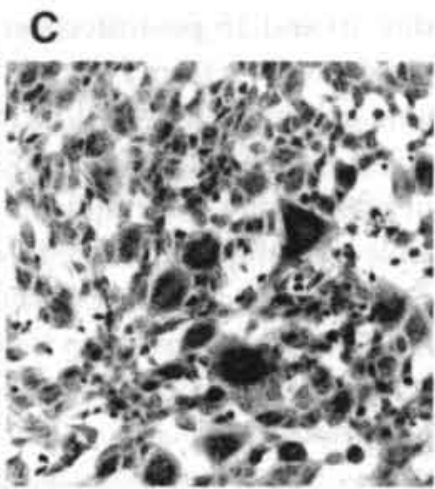

Fig. 2. Deletion of the R78 gene from the RCMV genome results in a syncytium-inducing (syn) recombinant strain. The micrographs (magnification $\times 400$ ) show uninfected rat embryo fibroblasts (REF) $(A)$, and REF infected with either wild type RCMV (B) or recombinant strain RCMV $A R 78 c(C)$ (4). The cells were stained with hematoxillin/eosin.

ated an r144 knockout virus strain (RCMVAr144). Like the m144-deleted MCMV strain (29), RCMV r144 replicated with similar efficiency as wt virus in various cell lines in vitro (5). However, in contrast to what was reported in the murine model (29), we did not detect differences between wt RCMV and RCMV $\triangle \mathrm{r} 144$ in their replication characteristics within infected rats. First, the survival rate among groups of immunosuppressed rats infected with either RCMV $\Delta \mathrm{r} 144$ or wt RCMV was similar. Second, the dissemination of virus did not differ between RCMVAr144- and wt RCMV-infected, immunosuppressed rats, both in the acute and latent phase of infection (unpublished results). We therefore concluded that the RCMV r144 gene does not play an important role in virus replication in our in vitro and in vivo experimental systems. It is possible that potential differences between RCMV $\Delta \mathrm{r} 144$ and wt RCMV in replication in vivo might be concealed due to the irradiation-induced immunosuppression, which is applied in order to be able to study RCMV disease $(3,4)$. If the r144 gene product (gpr144) was to serve as a decoy to evade immune surveillance, similarly as was proposed for the MCMV m144-encoded protein (gpm144), an RCMV r144 knockout strain might be attenuated due to efficient, early clearance of this strain by rat NK cells. As a result of immunosuppression, however, the virulence of the r144 knockout strain may be preserved. In contrast to the $\mathrm{RCMV} /$ rat model, immunosuppression is not required in the MCMV/murine model in order to establish virus-induced disease. This difference could explain the apparent discrepancies between our findings with RCMV r144 and the results of Farrell et al. with m144 (29). Nevertheless, after irradiation and RCMV infection of rats, NK cells are regenerated relatively efficiently and rapidly (between 
day 10 and 15 postinfection) (24). Consequently, if RCMV gpr144 would function in the protection from NK cell cytotoxicity, the regenerated NK cell population should be able to eliminate RCMV $\Delta r 144$ more efficiently than wt virus. We were, however, not able to detect differences between wt and recombinant virus in replication in vivo, neither at day 4 nor at day 21 after infection (unpublished results). It is of course possible that the regenerated NK cell population of immunosuppressed rats is still impaired in function due to the irradiation.

A function similar to that proposed for gpm144 (29) was attributed to the HCMV UL18 gene product (gpUL18) by Reyburn et al. (59). They showed that a B lymphoblastoid cell line (721.221) was protected from NK cytotoxicity after transfection with a vector expressing UL18. In contrast, Leong et al. found that the expression of UL18 resulted in enhanced rather than reduced killing of target cells by NK cells (42). According to Leong and coworkers, the apparent discrepancies between their results and those of Reyburn et al. (59) could be due to the fact that in the latter study transfected cells were selected on the basis of surface expression of $\beta_{2} \mathrm{~m}(42)$. This selection could have resulted in enrichment of a population of cells that express endogenous HLA-E, which was recently shown to protect 721.221 target cells from NK cell cytotoxicity (13). Consequently, the protection of UL18-transfected 721.221 cells from lysis by NK cells could be the result of the expression of HLA-E rather than UL18.

It was previously suggested by Leong et al. that viral MHC class I homologs may be more important in affecting the function of monocytes and dendritic cells than that of NK cells (42). This notion was supported by the finding that the HCMV UL18 gene product can interact with a membrane receptor, designated ILT2 (60) or LIR-1 (21), which is expressed predominantly on monocytes and B lymphocytes. Since ILT2/LIR1 is expressed on only a minor subset of NK cells (21), the physiological relevance of the interaction of gpUL18 with this receptor on NK cells is unclear. Leong et al. hypothesized that binding of gpUL18 to ILT2/LIR-1 on monocytes or dendritic cells could suppress IL12-production, which would limit the secrection of IFN- $\gamma$ by NK cells, thereby altering the early immune response (42). Interestingly, such a mechanism could explain not only the severely restricted replication of $\Delta \mathrm{m} 144$ in vivo (29), but also the similarity between RCMV and RCMV $\mathrm{r} 144$ in their replication characteristics within immunosuppressed rats. In analogy to gpUL18, gpr144 could interact with a receptor expressed predominantly on monocytes or macrophages, which could lead to an immune evasive effect. Interestingly, in support of a putative interaction between gpr144 and leukocytes other than NK cells, we found an increased influx of macrophages and CD8 ${ }^{+}$T lymphocytes in wt RCMV-infected tissue as compared to RCMVAr144-infected tissue in a local (rat footpad) infection model (5). Whether the increased influx of these leukocyte subtypes is the result of either a direct or indirect interaction with the gpr144 is currently under investigation. The identification of a putative receptor for either 
RCMV gpr144 or MCMV gpm144 on leukocytes might be crucial in the elucidation of the function of these proteins.

CMV homologs of chemokines. Chemokines belong to a family of chemoattractant cytokines that play a role in inflammatory responses against various pathogens. They promote the infiltration of leukocytes to the inflammatory site by both modulation of leukocyte chemotaxis and upregulation of the expression of leukocyte adhesion molecules (see reference 45 for a recent review). Chemokines bind to target cells via GCRs and can be classified according to the position of conserved cysteine residues within their predicted amino acid sequences. Currently, four groups of chemokines can be distinguished: (i) the CXC (or a) chemokines, which have an intervening non-conserved amino acid residue $(X)$ between the first and second conserved cysteine; (ii) the $\mathrm{CC}$ (or $\beta$ ) chemokines, in which the first two cysteines are adjacent; (iii) the C (or c) chemokines, which have only two of the four conserved cysteines; and (iv) the CX3C (or d) chemokines, which contain three irrelevant intervening amino acids between the first two conserved cysteines. To date, genes encoding homologs of chemokines have been identified in two CMV species only: HCMV (UL146, UL147 and UL152) (17) and MCMV (m131/129) $(30,43,44)$. Although we have recently determined the complete nucleotide sequence of the RCMV genome, we have as yet not been able to identify open reading frames (ORFs) that potentially encode chemokine-like polypeptides (unpublished results). The HCMV-encoded chemokine homologs show similarity to CXC chemokines, whereas the MCMV m131/129-encoded protein is more related to CC chemokines. Recent data indicate that the m131/129-encoded chemokine homolog is considerably larger than known cellular CC chemokines $(30,44)$. This protein, also designated MCK-2 (for MCMV-encoded chemokine 2) (44), is produced from a transcript in which the m131 ORF is spliced at its 3 ' end to the downstream m129 ORF $(30,44)$. To study the function of $\mathrm{m} 131 / 129$, a recombinant MCMV strain was generated in which the m131 ORF was disrupted (30). This strain $(\Delta \mathrm{m} 131)$ was reported to be cleared from the sites of in vivo infection more rapidly than wt virus. This effect was dependent on the function of both NK and CD4 ${ }^{*} / \mathrm{CD} 8+\mathrm{T}$ cells (30). Also, wt MCMV was found to elicit a stronger inflammatory response than $\triangle \mathrm{m} 131$ within spleen and liver tissue of infected mice (30). This suggests that m131 may function as a chemokine agonist by recruiting leukocytes to the sites of infection. The wt virus may profit from this if the cell types recruited are critical for virus replication and/or dissemination. The identification of a potential receptor for the m131/129-encoded polypeptide will be crucial in the understanding of the function of this protein in the pathogenesis of MCMV infection. 


\section{REFERENCES}

1. Baldwin, J. M. 1993 The probable arrangement of the helices in G protein-coupled receptors. EMBO J. 12:1993-1703.

2. Beck, S., B. G. Barrell. 1988. Human cytomegalovirus encodes a glycoprotein homologous to MHC class-I antigens. Nature 331:269-272.

3. Beck, S., and B. Barrell. 1991. An HCMV reading frame which has similarity with both the $\mathrm{V}$ and $\mathrm{C}$ regions of the TCR $\gamma$ chain. DNA Seq. 2:33-38.

4. Beisser, P. S., C. Vink, J. G. van Dam, G. Grauls, S. J. Vanherle, and C. A. Bruggeman. 1998. The R33 G protein-coupled receptor gene of rat cytomegalovirus plays an essential role in the pathogenesis of viral infection. J. Virol. 72:2352-2363.

5. Beisser, P. S., G. Grauls, C. A. Bruggeman, and C. Vink. 1999. Deletion of the R78 G protein-coupled receptor gene from rat cytomegalovirus results in an attenuated, syncytiuminducing mutant strain. J. Virol. 73:7218-7230.

6. Beisser, P. S., J. S. Kloover, G. Grauls, M. J. Blok, C. A. Bruggeman, and C. Vink. Unpublished results.

7. Benedict, C. A., K. D. Butrovich, N. S. Lurain, J. Corbeil, I. Rooney, P. Schneider, J. Tschopp, and C. F. Ware. 1999. Cutting edge: A novel viral TNF receptor superfamily member in virulent strains of human cytomegalovirus. J. Immunol. 162:6967-6970.

8. Billstrom, M. A., G. L. Johnson, N. J. Avdi, and G. S. Worthen. 1998. Intracellular signaling by the chemokine receptor US28 during human cytomegalovirus infection. J. Virol. 72:55355544.

9. Bjorkman, P. J., M. A. Saper, B. Samraoui, W. S. Bennett, J. L. Strominger, and D. C. Wiley. 1987. Structure of the human class I histocompatibility antigen, HLA-A2. Nature 329:506-512.

10. Bjorkman, P. J. 1990. Structure, function, and diversity of class I major histocompatibility complex molecules. Annu. Rev. Biochem. 59:253-288.

11. Bockaert, J., and J. P. Pin. 1999. Molecular tinkering of G protein-coupled receptors. EMBO J. 18:1723-1729.

12. Bodaghi, B., T. R. Jones, D. Zipeto, C. Vita, L. Sun, L. Laurent, F. Arenzana-Seisdedos, J. Virelizier, and S. Michelson. 1998. Chemokine sequenstration by viral chemoreceptors as a novel viral escape strategy: withdrawal of chemokines from the environment of cytomegalovirus-infected cells. J. Exp. Med. 188:855-866.

13. Braud, V. M., D. S. Allan, C. A. O'Callaghan, K. Soderstrom, A. D'Andrea, G. S. Ogg, S. Lazetic, N. T. Young, J. I. Bell, J. H. Phillips, L. L. Lanier, and A. J. McMichael. 1998. HLAE binds to natural killer cell receptors CD94/NKG2A, B and C. Nature 391:795-799.

14. Browne, H., G. Smith, S. Beck, and T. Minson. 1990. A complex between the MHC class 1 homologue encoded by human cytomegalovirus and $\beta_{2}$ microglobulin. Nature 347:770-772.

15. Browne, H., M. Churcher, and T. Minson. 1992. Construction and characterization of a human cytomegalovirus mtuant with the UL18 (class I homolog) gene deleted. J. Virol. 66:6784-6787.

16. Caruz, A., M. Samsom, J. M. Alonso, J. Alcami, F. Baleux, J.-L. Virelizier, M. Parmentier, and F. Arenzana-Seisdedos. 1998. Genomic organization and promoter characterization of human CXCR4 gene. FEBS Lett. 426:271-278. 
17. Cha, T.-A., T. Edward, G. W. Kemble, G. M. Duke, E. S. Mocarski, and R. R. Spaete. 1996. Human cytomegalovirus clinical isolates carry at least 19 genes not found in laboratory strains. J. Virol. 70:78-83.

18. Chapman, T. L., and P. J. Bjorkman. 1998. Characterization of a murine cytomegalovirus class I major histocompatibility complex ( $\mathrm{MHC}$ ) homolog: Comparison to $\mathrm{MHC}$ molecules and to the human cytomegalovirus MHC homolog. J. Virol. 72:460-466.

19. Chee, M. S., A.T. Bankier, S. Beck, R. Bohni, C. M. Brown, R. Cerny, T. Horsnell, C. A. Hutchison III, T. Kouzarides, J. A. Martignetti, E. Preddie, S. C. Satchwell, P. Tomlinson, K. M. Weston and B. G. Barrell. 1990. Analysis of the protein-coding content of the sequence of human cytomegalovirus strain AD169. Curr. Top. Microbiol. Immunol. 154:125169.

20. Chee, M. S., S. C. Satchwell, E. Preddie, K. M. Weston, and B. G. Barrell. 1990. Human cytomegalovirus encodes three $G$ protein-coupled receptor homologues. Nature 344:774777.

21. Cosman, D., N. Fanger, L. Borges, M. Kubin, W. Chin, L. Peterson, and M.-L. Hsu. 1997. A novel immunoglobulin superfamily receptor for cellular and viral MHC class I molecules. Immunity 7:273-282.

22. Cosman, D., N. Fanger, and L. Borges. 1999. Human cytomegalovirus, MHC class I and inhibitory signalling receptors: more questions than answers. Immunol. Rev. 168:177-185.

23. Cretney, E., M. A. Degli-Esposti, E. H. Densley, H. E. Farrell, N. J. Davis-Poynter, and M. J. Smyth. 1999. m144, a murine cytomegalovirus (MCMV)-encoded major histocompatibility complex class I homolog, confers tumor resistance to natural killer cell-mediated rejection. J. Exp. Med. 190:435-444.

24. Dam, J. G. van, J. G. M. C. Damoiseaux, H. A. M. D. van der Heiden, G. Grauls, P. J. C. van Breda Vriesman, and C. A. Bruggeman. 1997. Infection with rat cytomegalovirus (CMV) in the immunocompromised host is associated with the appearance of a $\mathrm{T}$ cell population with reduced CD8 and T cell receptor (TCR) expression. Clin. Exp. Immunol. 110:349-357.

25. Davis-Poynter, N. J., and H. E. Farrell. 1996. Masters of deception: A review of herpesvirus immune evasion strategies. Immunol. Cell. Biol. 74:513-522.

26. Davis-Poynter, N. J., D. M. Lynch, H. Vally, G. R. Shellam, W. D. Rawlinson, B. G. Barrell, and H. E. Farrell. 1997. Identification and characterization of a $\mathrm{G}$ protein-coupled receptor homolog encoded by murine cytomegalovirus. J. Virol. 71:1521-1529.

27. Davis-Poynter, N. J., and H. E. Farrell. 1998. Human and murine cytomegalovirus evasion of cytotoxic T lymphocyte and natural killer cell-mediated immune responses. Sem. Virol. 18:369-376.

28. Emorine, L. J., S. Marullo, C. Delavier-Klutchko, S. V. Kaveri, O. Durieu-Trautmann, and A. D. Strosberg. 1987. Structure of the gene for human $\beta_{2}$-adrenergic receptor: expression and promoter characterization. Proc. Natl. Acad. Sci. USA 84:6995-6999.

29. Farrell, H. E., H. Vally, D. M. Lynch, P. Fleming, G. R. Shellam, A. A. Scalzo, and N. J. Davis-Poynter. 1997. Inhibition of natural killer cells by a cytomegalovirus MHC class 1 homologue in vivo. Nature 386:510-514.

30. Farrell, H. E., M. A. Degli-Esposti, and N. J. Davis-Poynter. 1999. Cytomegalovirus evasion of natural killer cell responses. Immunol. Rev. 168:187-197. 
31. Früh, K., K. Ahn, and P. A. Peterson. 1997. Inhibition of MHC class I antigen presentation by viral proteins. J. Mol. Med. 75:18-27.

32. Gao, J. L., D. B. Kuhns, H. L. Tiffany, D. McDermott, X. Li, U. Franke, and P. M. Murphy. 1993. Structure and functional expression of the human macrophage imflammatory protein $1 \alpha /$ RANTES receptor. J. Exp. Med. 177:1421-1427.

33. Gao. J. L., and P. M. Murphy. 1994. Human cytomegalovirus open reading frame US28 encodes a functional $\beta$ chemokine receptor. J. Biol. Chem. 269:28539-28542.

34. Gompels, U. A., J. Nicholas, G. Lawrence, M. Jones, B. J. Thomson, M. E. Martin, S. Efstathiou, M. Craxton, and H. A. Macaulay. 1995. The DNA sequence of human herpesvirus-6: structure, coding content, and genome evolution. Virology 209:29-51.

35. Hassan-Walker, A. F., A. V. Cope, P. D. Griffiths, and V. C. Emery. 1998. Transcription of the human cytomegalovirus natural killer decoy gene, UL18, in vitro and in vivo. J. Gen. Virol. 79:2113-2116.

36. Hengel, H., W. Brune, and U. H. Koszinowski. 1998. Immune evasion by cytomegalovirus - survival strategies of a highly adapted opportunist. Trends Microbiol. 5:190-197.

37. Isegawa, Y., Z. Ping, K. Nakano, N. Sugimoto, and K. Yamanishi. 1998. Human herpesvirus 9 open reading frame U12 encodes a functional $\beta$-chemokine receptor. J. Virol. 72:61046112.

38. Kledal, T. N., M. M. Rosenkilde, and T. W. Schwartz. 1998. Selective recognition of the membrane-bound $\mathrm{CX} 3 \mathrm{C}$ chemokine, fractalkine, by the human cytomegalovirus-encoded broad spectrum receptor US28. FEBS Lett. 441:209-214.

39. Kraus, E., D. Lambracht, K. Wonigeit, and T. Hunig. 1996. Negative regulation of rat natural killer cell activity by major histocompatibility complex class I recognition. Eur. J. Immunol. 26:2582-2586.

40. Kuhn, D. E., C. J. Beall, and P. E. Kolattukudy. 1995. The cytomegalovirus US28 protein binds multiple CC chemokines with high affinity. Biochem. Biophys. Res. Commun. 211:325330.

41. Lalanne, J.-L., C. Delarbre, G. Gachelin, and P. Kourilsky. 1983. A cDNA clone containing the entire coding sequence of a mouse $\mathrm{H}-2 \mathrm{Kd}$ histocompatibility antigen. Nucleic Acids Res. 11:1567-1577.

42. Leong, C., T. L. Chapman, P. J. Bjorkman, D. Formankova, E. S. Mocarski, K. H. Philips, and L. L. Lanier. 1998. Modulation of natural killer cell cytotoxicity in human cytomegalovirus infection: The role of endogenous class I major histocompatibility complex and a viral class I homolog. J. Exp. Med. 187:1681-1687.

43. MacDonald, M. R., X.-Y. Li, and H. W. Virgin IV. 1997. Late expression of a beta chemokine homolog by murine cytomegalovirus. J. Virol. 71:1671-1678.

44. MacDonald, M. R., M. W. Burney, S. B. Resnick, H. W. Virgin IV. 1999. Spliced mRNA encoding the murine- cytomegalovirus chemokine predicts a $\beta$ chemokine of novel structure. J. Virol. 73:3682-3691.

45. Mantovani, A. 1999. The chemokine system: redundancy for robust outputs. Immunol. Today 20:254-257.

46. Margulies, B.J., H. Browne, and W. Gibson. 1996. Identification of the human cytomegalovirus G protein-coupled receptor homolog encoded by UL33 in infected cells and enveloped virus particles. Virology 225:111-125. 
47. Menotti, L., P. Mirandola, M. Locati, and G. Campadelli-Fiume. 1999. Trafficking to the plasma membrane of the seven-transmembrane protein encoded by human herpesvirus 6 U5l gene involves a cell-specific function present in T lymphocytes. J. Virol, 73:325-333.

48. Mummidi, S., S. S. Ahuja, B. L. McDaniel, and S. K. Ahuja. 1997. The human CC chemokine receptor 5 (CCR5) gene. Multiple transcripts with 5 -end heterogeneity, dual promoter usage, and evidence for polymorphisms within the regulatory regions and noncoding exons. J. Biol. Chem. 272:30662-30671.

49. Nathans, J., and D. S. Hogness. 1984. Isolation and nucleotide sequence of the gene encoding human rhodopsin. Proc. Natl. Acad. Sci. USA 81:4851-4855.

50. Neote, K., D. DiGregorio, J. K. Mak, R. Horuk, and T. J. Schall. 1993, Molecular cloning, functional expression, and signalling characteristics of a C-C chemokine receptor. Cell 72:415. 425.

51. Nicholas, J. 1996. Determination and analysis of the complete nucleotide sequence of human herpesvirus 7. J. Virol. 70:5975-5989.

52. Pelchen-Matthews, A., N. Signoret, P. J. Klasse, A. Fraile-Ramos, and M. Marsh. 1999. Chemokine receptor trafficking and viral replication. Immunol. Rev. 168:33-49.

53. Penfold, M. E., D. J. Dairaghi, G. M. Duke, N. Saederup, E. S. Mocarski, G. W. Kemble, and T. J. Schall. 1999. Cytomegalovirus encodes a potent alpha chemokine. Proc. Natl. Acad. Sci. USA 96:9839-9844.

54. Pleskoff, O., C. Treboute, A. Brelot, N. Heveker, M. Seman, and M. Alizon. 1997. Identification of a chemokine receptor encoded by human cytomegalovirus as a cofactor for HIV-1 entry. Science 276:1874-1878.

55. Pleskoff, O., C. Tréboute, and M. Alizon. 1998. The cytomegalovirus-encoded chemokine receptor US28 can enhance cell-cell fusion mediated by different viral proteins. J. Virol. 72:6389-6397.

56. Poland S. D., P. Costello, G. A. Dekaban, and G. P. Rice. 1990. Cytomegalovirus in the brain: in vitro infection of human brain-derived cells. J. Infect. Dis. 162:1252-1262.

57. Probst, W. C., L. A. Snyder, D. I. Schuster, J. Brosius, S. C. Sealfon. 1992. Sequence alignment of the G protein-coupled receptor superfamily. DNA Cell Biol. 11:1-20.

58. Rawlinson, W. D., H. E. Farrell, and B. G. Barrell. 1996. Analysis of the complete DNA sequence of murine cytomegalovirus, J. Virol. 70:8833-8849.

59. Reyburn, H. T., O. Mandelboim, M. Valès-Gûmez, D. M. Davis, L. Pazmany, and J. L. Strominger. 1997. The class I MHC homologue of human cytomegalovirus inhibits attack by natural killer cells. Nature 386:514-517.

60. Samaridis, J., and M. Colonna M. 1997. Cloning of novel immunoglobulin superfamily receptors expressed on human myeloid an lymphoid cells: structural evidence for new stimulatory and inhibitory pathways. Eur. J. Immunol. 27:660-665.

61. Thompson, J. D., D. G. Higgins, and T. J. Gibson. 1994. CLUSTAL W: improving the sensitivity of progressive multiple sequence alignment through sequence weighting, positionspecific gap penalties and weight matrix choice. Nucleic Acids Res. 22:4673-4680.

62. Vieira, J., T. J. Schall, L. Corey, and A. P. Geballe. 1998. Functional analysis of the human cytomegalovirus US28 gene by insertion mutagenesis with the green fluorescent protein gene. J. Virol. 72:8158-8165. 
63. Vitale M, R. Castriconi R, S. Parolini, D. Pende, M. L. Hsu, L. Moretta, D. Cosman, and A. Moretta. 1999. The leukocyte Ig-like receptor (LIR)-1 for the cytomegalovirus UL18 protein displays a broad specificity for different HLA class I alleles analysis of LIR-1* NK cell clones. Int. Immunol. 11:29-35.

64. Welch, A. R., L. M. McGregor, and W. Gibson. 1991. Cytomegalovirus homologs of cellular G protein-coupled receptor genes are transcribed. J. Virol. 65:3915-3918.

65. Wiertz, E. J. H. J., S. Mukherjee, and H. L. Ploegh. 1997. Viruses use stealth technology to escape from the host immune system. Mol. Med. Today 3:116-123.

66. Zipeto, D., B. Bodaghi, L. Laurent, J.-L. Virelizier, and S. Michelson. 1999. Kinetics of transcription of human cytomegalovirus chemokine receptor US28 in different cell types. J. Gen. Virol. 80:543-547.

67. Zou, P., Y. Isegawa, K. Nakano, M. Haque, Y. Horiguchi, and K. Yamanishi. 1999. Human herpesvirus 6 open reading frame U83 encodes a functional chemokine. J. Virol. 73:59265933. 


\section{SUMMARY}

Cytomegaloviruses (CMVs) are widespread species-specific betaherpesviruses that persist life-long in infected individuals. Although infection is predominantly asymptomatic in the immunocompetent host, in immunocompromised patients, such as transplant recipients and people suffering from AIDS, CMV can cause life-threatening disease. The effectiveness of existing CMV-specific antiviral agents and vaccines is limited, necessitating a continuing study of the molecular biology of CMV. The genome of human CMV (HCMV) consists of approximately $230 \mathrm{~kb}$ of doublestranded DNA and harbors at least 180 virus genes. The majority of these genes are yet uncharacterized. Some HCMV genes show significant sequence similarity with genes of the host organism. Among these are genes that show similarity with mammalian genes that encode chemokines, chemokine receptors, heavy chains of the class I major histocompatibility complex (MHC), tumor necrosis factor receptors and T-cell receptor $\gamma$ chains. The functions of these genes are not well understood. It is difficult to study their role in the pathogenesis of HCMV infection in vivo, due to the species-specificity of HCMV. The rat CMV (RCMV) genome is collinear with the genome of HCMV and the majority of the genes are conserved. Since RCMV infection can be studied in vivo, the rat/RCMV system can be used as a model to examine the in vivo function of the CMV genes that are homologous to host genes. This thesis reports the characterization of four RCMV genes: a major immediate early transactivator gene (R122-123), a putative chemokine receptor gene (R33), an orphan G protein-coupled receptor gene (R78) and a MHC class I heavy chain gene (r144). The role of R33, R78 and r144 were studied both in vitro and in vivo, by generating mutant RCMV strains in which either of these genes was disrupted. The efficiency of infection of these mutants was compared with that of wild-type (wt) RCMV in various cell types in vitro as well as in immunocompromised rats. The three strains that resulted from deleting either R33, R78 or r144 (mutant viruses RCMV $\Delta R 33, R C M V \Delta R 78$ and RCMV $\Delta$ r144, respectively), displayed a diversity of interesting phenotypes. RCMVD $\Delta 33$ was able to replicate in vitro with a similar efficiency as wt RCMV. However, this mutant was less pathogenic than wt virus in infected immunocompromised rats. Moreover, RCMV $\triangle R 33$ could not be detected in the rat salivary glands, the key organ for virus replication during primary RCMV infection. Therefore, we con- 
clude that the R33 gene is a determinant of the salivary gland tropism of RCMV. In contrast to RCMV $\triangle R 33$, the RCMV R78 null mutants were attenuated in vitro. They replicated less efficiently than wt RCMV in fibroblasts and smooth muscle cells in vitro. Furthermore, the R78-deleted viruses induced syncytia formation in infected fibroblasts in vitro. Hence, we hypothesize that the R78 gene is involved in the stabilization of protein complexes enabling either cell-to-cell spread of virus or viral egress from infected cells. In addition to the differences that we found in vitro, we observed that the R78 deletion mutant strains were also less pathogenic than wt RCMV in vivo. However, it is not known whether the observed syncytia formation in vitro can be related to the lower virulence of these mutants in vivo. Another RCMV gene that we studied is r144, which putatively encodes an MHC class I homolog. Deletion of the r144 gene from the RCMV genome generated a recombinant virus (RCMV $\Delta \mathrm{r} 144)$ that replicated with similar efficiency as wt RCMV in vitro. Unexpectedly, we were unable to detect differences in pathogenicity between wt and mutant virus after infection of immunocompromised rats. A difference between wt RCMV and RCMV $\triangle \mathrm{r} 144$ was seen, however, in a local, rat foot pad infection model. We found that the influx of macrophages and CD8 $8^{+} \mathrm{T}$-cells at the site of inoculation was significantly lower in RCMV $\triangle$ r144-infected rats than in wt RCMV-infected rats. This indicated that the r144 gene could play a role in the recruitment of a subset of leukocytes to the site of initial RCMV infection. 


\section{SAMENVATTING}

Cytomegalovirussen (CMV's) zijn veelvuldig voorkomende, gastheerspecifieke beta-herpesvirussen, die levenslang in geïnfecteerde individuen persisteren. Alhoewel infectie in immuncompetente personen voornamelijk asymptomatisch is, kan CMV een levensgevaarlijke bedreiging vormen in immuun-gecompromitteerden, zoals transplantatie- en AIDSpatiënten. De effectiviteit van bestaande, CMV-specifieke antivirale middelen en vaccins is beperkt, hetgeen de noodzaak van moleculair biologisch onderzoek van CMV rechtvaardigt. Het genoom van humaan CMV (HCMV) bestaat uit 229 kb dubbelstrengs-DNA en bevat tenminste 180 virus-genen. De meerderheid van deze genen is nog niet gekarakteriseerd. Sommige HCMV-genen vertonen significante overeenkomsten in sequentie met genen van de gastheer, waaronder genen die homologie vertonen met die van chemokinen, chemokine-receptoren, major histocompatibility complex (MHC's) klasse I zware ketens, tumor necrose factor-receptoren en T-cel-receptor $\gamma$-ketens. De functies van deze HCMV-genen zijn nog onduidelijk. De gastheerspecificiteit van HCMV bemoeilijkt de mogelijkheid om de rol van deze genen in de pathogenese van HCMV-infectie in vivo te bestuderen. Het rat-CMV (RCMV) -genoom is co-lineair met het HCMV-genoom en de meerderheid van de genen zijn geconserveerd. Omdat RCMV-infectie in vivo bestudeerd kan worden, kan het rat/RCMV-systeem als model worden gebruikt om de functie van de CMV-genen, die homoloog zijn aan gastheer-genen, in vivo te bestuderen. Dit proefschrift beschrijft de karakterisatie van vier RCMV-genen die coderen voor respectievelijk een major immediate early transactivator (R122123), een potentiële chemokine-receptor (R33), een orphan $G$ protein-coupled receptor (R78) en een zware-keten MHC-klasse-I-molecuul (r144). De rol van R33, R78 en r144 is zowel in vitro als in vivo bestudeerd met behulp van mutant-RCMV-stammen, waarbij telkens een van deze genen was uitgeschakeld. De infectie-efficiëntie van deze mutanten is vergeleken met die van wild-type (wt) - RCMV in zowel verschillende celtypen in vitro, als in immuun-gecompromitteerde ratten. Infectie met de drie virus-mutanten, die zijn ontstaan door de uitschakeling van R33, R78 en r144 (respectievelijk RCMV $\Delta R 33, R C M V \Delta R 78$ an RCMV $\Delta$ r144), vertoonden verscheidene interessante fenotypen. RCMV $\Delta R 33$ repliceerde in vitro even efficiënt als wt-RCMV. Echter, de mutant was minder pathogeen dan wt-RCMV in 
geïnfecteerde, immuungecompromitteerde ratten. Bovendien kon RCMV $\triangle R 33$ niet gedetecteerd worden in de speekselklieren van de rat - de belangrijkste organen voor virusreplicatie gedurende primaire RCMVinfectie. We concluderen dientengevolge dat het R33-gen een determinant is voor het speekselklier-tropisme van RCMV. De R78-deletiemutanten zijn, in tegenstelling tot RCMV $\triangle R 33$, ook in vitro verminderd in sterkte. Ze repliceerden minder efficiënt in fibroblasten en gladde spiercellen in vitro dan wt-RCMV. De R78-deletiemutanten induceerden bovendien syncytiumvorming in geïnfecteerde fibroblasten in vitro. Hypothetisch gezien kan het R78-gen daarom betrokken zijn bij de stabilisatie van eiwitcomplexen die de cel-cel-verspreiding of uitscheiding van virus bewerkstelligen. The R78deletiemutanten waren eveneens minder pathogeen dan wt-RCMV in vivo. Het is echter onduidelijk of de waargenomen syncytium-vorming in vitro kan worden gerelateerd aan de verminderde virulentie van deze mutanten in vivo. Een ander RCMV-gen dat bestudeerd is, r144, bevat MHC klasse Ihomoloog-coderende sequenties. Deletie van dit gen uit het RCMV-genoom resulteerde in een recombinant-virus (RCMV $\Delta$ r144) dat met overeenkomstige efficiëntie repliceerde als wt-RCMV in vitro. Tegen de verwachtingen in waren we niet in staat verschillen in pathogeniciteit aan te tonen tussen wten mutant-virus bij geïnfecteerde, immuungecompromitteerde ratten. Desalniettemin werden verschillen geobserveerd tussen wt RCMV en RCMV $\Delta$ r144 in een rattenpootjes-model voor lokale infectie. We toonden aan dat de influx van macrofagen en $\mathrm{CD}^{+}$-T-cellen op de plaats van inoculatie significant lager was in RCMV $\triangle$ r144-geïnfecteerde ratten, dan in wt-RCMVgeïnfecteerde ratten. Dit geeft aan dat het r144-gen een rol kan spelen in het recruteren van een subpopulatie van leukocyten naar de plaats van initiële RCMV-infectie. 


\section{DANKWOORD/ACKNOWLEDGEMENTS}

Aan alle collega's van de vakgroep Medische Microbiologie, dank jullie wel. Hier zou ik het bij kunnen laten en jullie aanmoedigen verder te lezen in hoofdstuk 1 . Echter, een mager dankwoord wil ik vooral Gert Grauls niet aandoen. Daarom allereerst een uitbundiger woord van dank voor al haar hulp met de dierproeven, maar ook voor die schijnbaar onuitputtelijke voorraad bindweefselcellen waar ik vaak uit geput heb. Eveneens mijn dank aan Gert's labgenoten, Joanne van Dam, Monique Coomans, Wil Loenen, Marjorie Nelissen, Harry van der Heijden en Jeroen Kloover, voor het rattenwerk, dat, zoals ik nu toch zelf gezien heb, in fijnbesnaardheid niet onderdoet voor het moleculair biologische onderzoek. Verder heeft mijn onderzoek veel profijt gehad van de hulp van drie Gezondheidsweten-schappen-studenten, Servi Steevens, Susan Swiggers en Suzanne Kaptein. Ik ben blij dat de stage bij Medische Microbiologie hen niet ontmoedigd heeft om verder te gaan in de wetenschap. Het doet me deugd dat Servi, die heel veel werk heeft verzet om recombinant-eiwitten en anti-sera te bereiden, nu goed boert in Amsterdam als promotie-onderzoeker. Susan, die heel veel kloon-werk en transfecties op haar naam heeft staan bij Microbiologie, is nu werkzaam als assistent-in-opleiding aan de Erasmus-universiteit in Rotterdam. Suzanne heeft een enorm karwei geleverd bij de karakterisatie van de 'immediate early'-genen, en zet nu als assistent-in-opleiding het R33-en R78-werk voort aan de vakgroep Medische Microbiologie. Het celcultuur-werk is bijzonder veraangenaamd door de ter beschikkingstelling van kweekmedia, sera, zoutoplossingen en additieven, in hoeveelheden die genoeg zijn om een bad in te nemen. Vooral dankzij beide Anita's, Jozien, Martine en Henk van de diagnostiek-afdeling Virologie, die mij af en toe een flesje hebben geleend. Viroloog dr. Frans Stals spoorde me aan mij te verdiepen in het moleculaire mimicri-aspect van het cytomegalovirus-onderzoek. Dankzij hem ben ik, onder begeleiding van dr. Rob Slobbe op zoek gegaan naar een klasse I MHC-homoloog op het rat-cytomegalovirus. Die speurtocht heeft uiteindelijk geleid tot de vonst van meerdere interessante virus-genen die uiteindelijk aan studie zijn onderworpen. Veel dank aan Arjen Bakker van de vakgroep Humane Biologie, wiens computer ik vele malen op de meest ongunstige tijdstippen heb benut in ruil voor slechts een zakje drop. Waar andere computers faalden, zijn via zijn computer vele figuren voor de artikelen in dit proefschrift uitgeprint. Ik heb heel veel te danken aan prof. dr. Cathrien Bruggeman, die mij zes jaar geleden met mijn AIO-aanstelling een breed palet aan mogelijkheden aanbood waauit ik uiteindelijk vier rat-cytomegalovirusgenen heb mogen kiezen die vervolgens aan onderzoek zijn onderworpen en waarvan het resultaat hier nu voor jullie ligt. My gratitude also to Dr. Susan Michelson and Dr. Jean-Louis 
Virelizier who gave me the opportunity to continue the cytomegalovirus research as an EMBO research fellow at the Pasteur Institute in Paris, thus, strongly motivating me to complete this thesis quickly. Natuurlijk heel veel dank aan Rien Blok en Erik Beuken, met wie het heel prettig samenwerken was op dat verre, hermetisch afgesloten C/C1 laboratorium - Erik voor zijn nuchtere beheer van het "HIV-lab", dat zonder zijn aanwezigheid zou verwilderen tot een woest oerwoud. Ik dank hem heel veel voor zijn hulp, instructies en adviezen. Ben ik iemand vergeten te bedanken? Natuurlijk, co-promotor dr. Kees Vink, die mij vanaf 1 maart 1994 tot heden intensief heeft begeleid tijdens mijn AIO-opleiding, die mij jarenlang in goede banen heeft geleid omdat ik anders in slechte zou kunnen zijn geëindigd, voor zijn goedbedoelde pogingen de laboratoriumsfeer (en onbedoeld ook andere delen van de afdeling Medische Microbiologie in een straal van dertig meter rondom die beruchte ruimte H5.H1001) op te luisteren met zijn gezang, geklap en soms zelfs gedans, maar vooral voor het kritische en strenge, maar rechtvaardige kommentaar dat hij heeft geleverd jegens mijn doen en laten tijdens mijn opleiding en voor wie ik vooral een heel aardig dankwoordje moet schrijven omdat hij anders, tenoverstaande van al mijn vrienden en familie, een vernietigende laudatio zal uitspreken.

Patrick Beisser

Parijs, november 1999 


\section{CURRICULUM VITAE}

Patrick Beisser werd op 1 oktober 1969 geboren te Dordrecht. In 1982 begon zijn middelbare school-opleiding aan het Grotius College in Heerlen. Zijn atheneum beindexamen werd afgesloten in 1988, waarna hij zich inschreef aan de Faculteit der Gezondheidswetenschappen van de Universiteit Maastricht. In 1989 koos hij voor de afstudeerrichting Biologische Gezondheidskunde. Het onderzoek voor zijn afstudeerscriptie, de ontwikkeling van een hoge-resolutie-banderingstechniek voor karyotypering, werd begeleid door Dr. J. Engelen in het laboratorium Cytogenetica van de vakgroep Moleculaire Celbiologie en Genetica, in de periode 1991 tot 1992. In 1992 behaalde hij de graad Doctorandus in de Gezondheidswetenschappen. Hierna volgde hij nog een jaar stage bij de vakgroep Medische Microbiologie, waar hij, begeleid door Dr. F. Stals, cytomegalovirus-infectie in neonaten bestudeerde. In 1993 vervolgde hij zijn werk als Assistent in Opleiding aan dezelfde vakgroep, onder supervisie van Prof. Dr. C. Bruggeman en Dr. C. Vink. In 1999 werd een aanvraag voor een long-term fellowship van de European Molecular Biology Organization gehonoreerd met een Post-Doc-toelage voor de voortzetting van het cytomegalovirus-onderzoek in het laboratorium van Dr. J.-L. Virelizier en Dr. S. Michelson van de afdelingVirale Immunologie aan het Pasteur-Instituut te Parijs. 


\section{PUBLICATIONS}

Beisser, P. S., S. J. F. Kaptein, E. Beuken, C. A. Bruggeman, and C. Vink. 1998. The Maastricht strain and England strain of rat cytomegalovirus represent different betaherpesvirus species rather than strains. Virology 245:341-351.

Beisser, P. S., C. Vink, J. G. van Dam, G. Grauls, S. J. Vanherle, and C. A. Bruggeman. 1998. The R33 G protein-coupled receptor gene of rat cytomegalovirus plays an essential role in the pathogenesis of viral infection. J. Virol. 72:2352-2363.

Beisser, P. S., G. Grauls, C. A. Bruggeman, and C. Vink. 1999. Deletion of the R78 G protein-coupled receptor gene from rat cytomegalovirus results in an attenuated, syncytium-inducing mutant strain. J. Virol.73:7218-7230.

Beisser, P. S., J. S. Kloover, G. Grauls, M. J. Blok, C. A. Bruggeman, and C. Vink. 1999. The r144 MHC Class I-Like Gene of Rat Cytomegalovirus is Dispensable for both Acute and Long-Term Infection in the Immunocompromised Host. J. Virol. In press.

Vink, C., P. S. Beisser, and C. A. Bruggeman. 1999. Molecular Mimicry by Cytomegaloviruses (CMVs): the Function of CMV-Encoded Homologues of G Protein-Coupled Receptors, MHC Class I Heavy Chains and Chemokines. Intervirology. In press. 
